\title{
APPENDIX H
}

\section{FIELD VERIFICATION REPORT \\ IDAHO NATIONAL ENGINEERING LABORATORY \\ MAY 2 - 10, 1994}

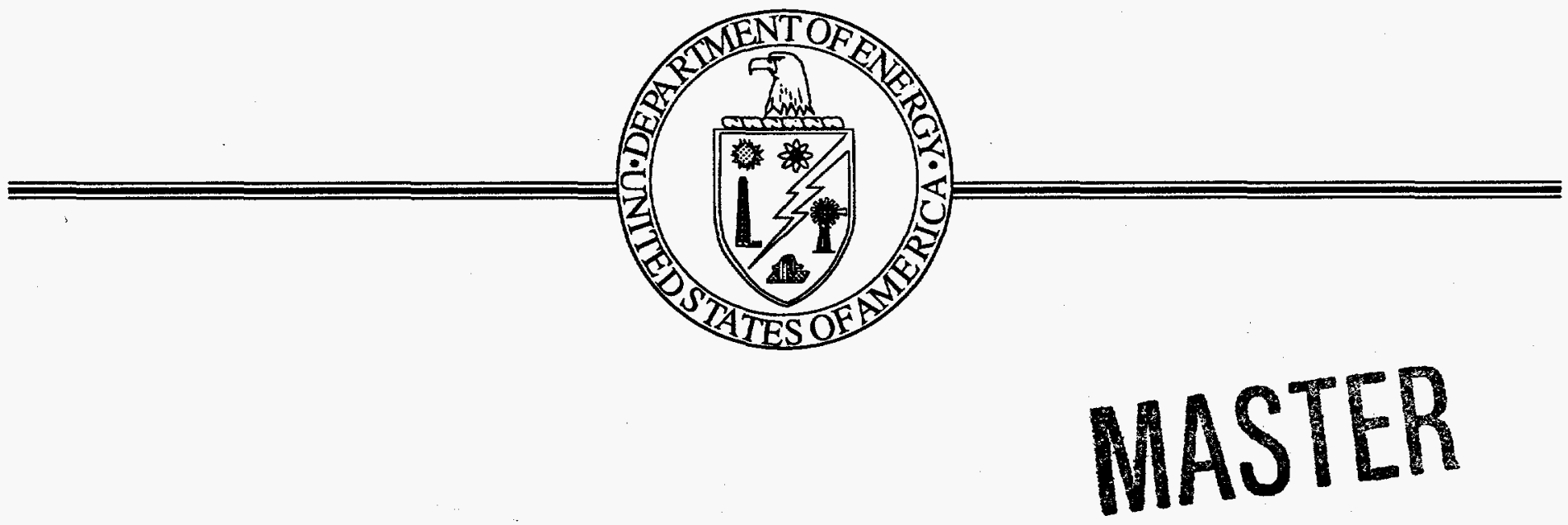




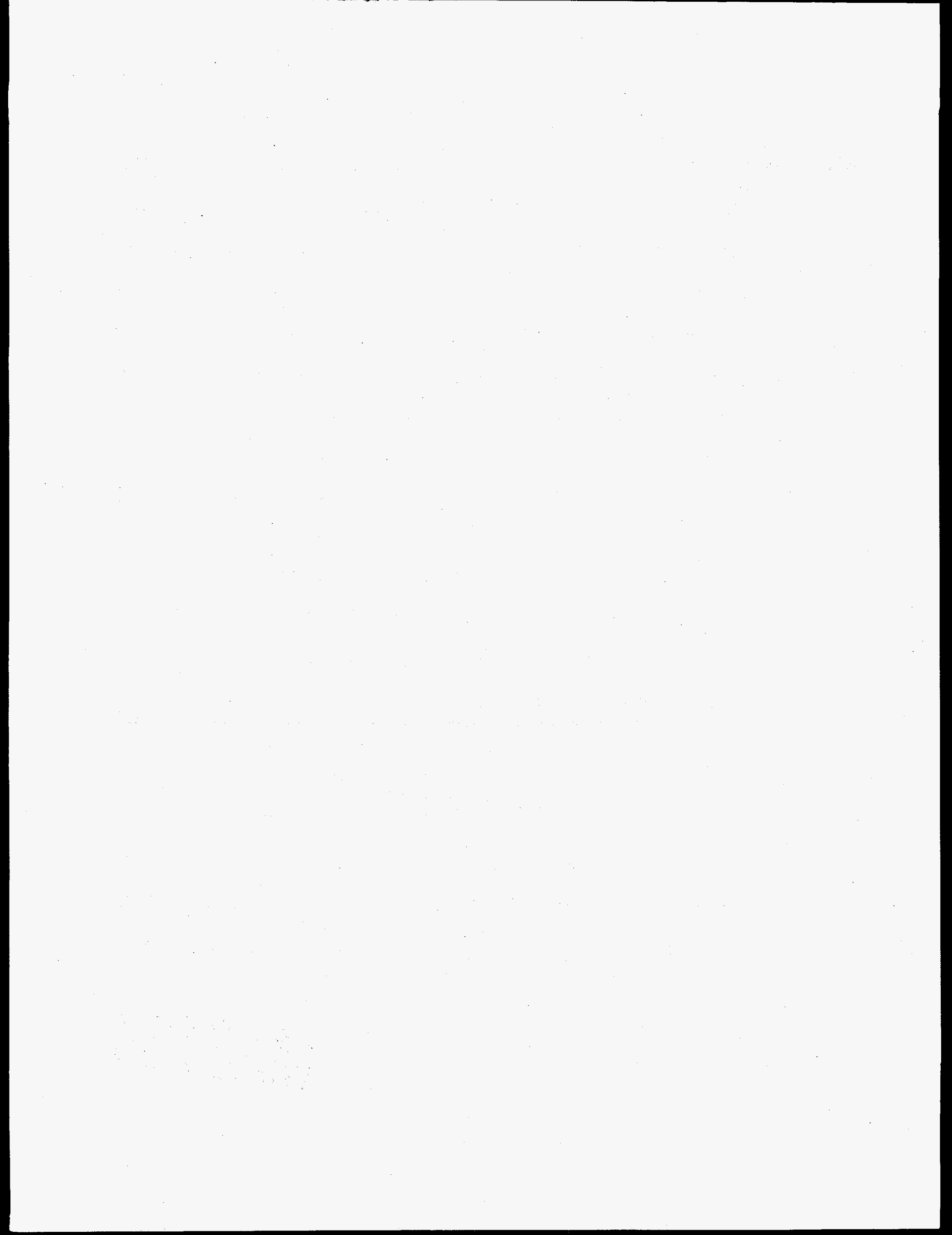




\section{DISCLAMmERR}

Portions of this document may be illegible in electronic image products. Images are produced from the best available original docoment. 


\title{
DOE/EH--0396P-Vol.3
}

\section{CONTENTS}

\author{
VOLUME 1
}

FOREWORD $\ldots \ldots \ldots \ldots \ldots \ldots \ldots \ldots \ldots \ldots \ldots \ldots \ldots \ldots \ldots \ldots \ldots$ i

EXECUTIVE SUMMARY $\ldots \ldots \ldots \ldots \ldots \ldots \ldots \ldots \ldots \ldots \ldots \ldots \ldots \ldots \ldots \ldots$ iii

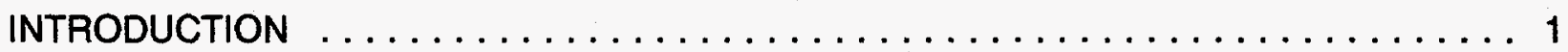

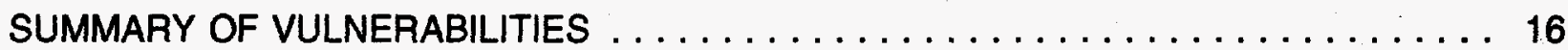

MANAGEMENT SYSTEM WEAKNESSES $\ldots \ldots \ldots \ldots \ldots \ldots \ldots \ldots \ldots \ldots \ldots$

COMMENDABLE PRACTICES $\ldots \ldots \ldots \ldots \ldots \ldots \ldots \ldots \ldots \ldots \ldots \ldots \ldots \ldots \ldots$

SUMMARY OF MANAGEMENT RESPONSE PLAN $\ldots \ldots \ldots \ldots \ldots \ldots \ldots \ldots$

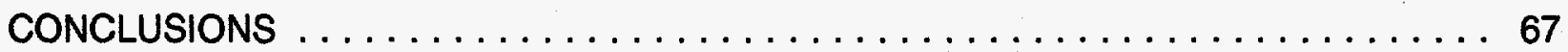

GLOSSARY OF CHEMICAL TERMS $\ldots \ldots \ldots \ldots \ldots \ldots \ldots \ldots \ldots \ldots$

VOLUME 2

APPENDIX A: Tasking Memorandums $\ldots \ldots \ldots \ldots \ldots \ldots \ldots \ldots \ldots \ldots \ldots \ldots \ldots \ldots \ldots \ldots$

APPENDIX B: Project Plan for the Chemical Safety Vulnerability Review ......... B-1

APPENDIX C: Field Verification Guide for the Chemical Safety Vulnerability Review . . . C-1

APPENDIX D: Field Verification Report, Lawrence Livermore National Laboratory . . . . D-1

APPENDIX E: Field Verification Report, Oak Ridge Reservation $\ldots \ldots \ldots \ldots \ldots \ldots$ E-1

APPENDIX F: Field Verification Report, Savannah River Site $\ldots \ldots \ldots \ldots \ldots \ldots$ F-1

APPENDIX G: Field Verification Report, Hanford Site $\ldots \ldots \ldots \ldots \ldots \ldots$ G-1

iii

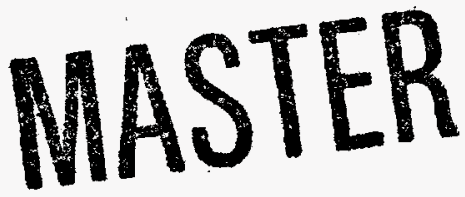




\section{VOLUME 3}

APPENDIX H: Field Verification Report, Idaho National Engineering Laboratory . . . . . . H-1 APPENDIX I: Field Verification Report, Rocky Flats Plant $\ldots \ldots \ldots \ldots \ldots \ldots$ APPENDIX J: Field Verification Report, Brookhaven National Laboratory $\ldots \ldots \ldots \ldots$. . J-1 APPENDIX K: Field Verification Report, Los Alamos National Laboratory . . . . . . . . . K-1 APPENDIX L: Field Verification Report, Sandia National Laboratories, New Mexico . . . L-1 APPENDIX M: Mini-Visits to Small DOE Sites $\ldots \ldots \ldots \ldots \ldots \ldots \ldots \ldots$ APPENDIX N: Working Group Meeting, June 7-8, $1994 \ldots \ldots \ldots \ldots \ldots \ldots$. . . . . . . N-1 APPENDIX 0: Commendable Practices $\ldots \ldots \ldots \ldots \ldots \ldots \ldots \ldots \ldots \ldots \ldots$ APPENDIX P: Related Chemical Safety Initiatives at DOE $\ldots \ldots \ldots \ldots \ldots \ldots \ldots$ APPENDIX Q: Regulatory Framework and Industry Initiatives Related to Chemical Safety

APPENDIX R: Chemical Inventory Data from Field Self-Evaluation Reports . . . . . . R-1 


\section{CONTENTS}

EXECUTIVE SUMMARY $\ldots \ldots \ldots \ldots \ldots \ldots \ldots \ldots \ldots \ldots \ldots \ldots \ldots$

1.0 INTRODUCTION $\ldots \ldots \ldots \ldots \ldots \ldots \ldots \ldots \ldots \ldots \ldots \ldots \ldots \ldots$

1.1 Purpose and Scope $\ldots \ldots \ldots \ldots \ldots \ldots \ldots \ldots \ldots \ldots \ldots$

1.2 Site Description $\ldots \ldots \ldots \ldots \ldots \ldots \ldots \ldots \ldots \ldots \ldots \ldots$

1.3 Facilities Visited $\ldots \ldots \ldots \ldots \ldots \ldots \ldots \ldots \ldots \ldots \ldots \ldots \ldots \ldots$

2.0 SUMMARY OF RESULTS $\ldots \ldots \ldots \ldots \ldots \ldots \ldots \ldots \ldots \ldots \ldots \ldots$

2.1 Identification of Chemical Holdings $\ldots \ldots \ldots \ldots \ldots \ldots \ldots \ldots \ldots$

2.2 Facility Physical Condition $\ldots \ldots \ldots \ldots \ldots \ldots \ldots \ldots \ldots \ldots \ldots \ldots$

2.3 Operational Control and Management Systems $\ldots \ldots \ldots \ldots \ldots \ldots \ldots \ldots \mathrm{H}-21$

2.4 Human Resource Programs $\ldots \ldots \ldots \ldots \ldots \ldots \ldots \ldots \ldots \ldots$ H-24

2.5 Emergency Management Programs . . . . . . . . . . . . . . . H-25

3.0 CATEGORIZATION AND PRIORITIZATION OF VULNERABILITIES . . . . . . . H-28

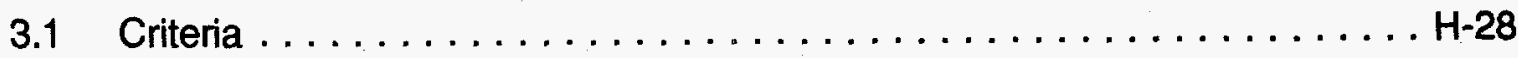

3.2 Chemical Safety Vulnerabilities at Idaho National Engineering Laboratory H-29

\section{ATTACHMENTS}

ATTACHMENT 1. Team Composition $\ldots \ldots \ldots \ldots \ldots \ldots \ldots \ldots \ldots \ldots \ldots \ldots$

ATTACHMENT 2. Vulnerability Forms $\ldots \ldots \ldots \ldots \ldots \ldots \ldots \ldots \ldots \ldots \ldots$

ATTACHMENT 3. Selected Acronyms $\ldots \ldots \ldots \ldots \ldots \ldots \ldots \ldots \ldots \ldots \ldots$. . . . . . . 
$H-4$ 


\section{EXECUTIVE SUMMARY}

This report presents the results of a review of chemical safety vulnerabilities associated with facilities owned or operated by the Department of Energy (DOE) at the Idaho National Engineering Laboratory (INEL) from May 2 to May 10, 1994. The INEL review was part of the Chemical Safety Vulnerability Review being conducted by the Office of Environment, Safety and Health at the direction of the Secretary of Energy. The purpose of the review is to identify and characterize conditions or circumstances involving potentially hazardous chemicals at DOE facilities. Specifically, the review is designed to identify, characterize, and prioritize chemical safety vulnerabilities that might result in (1) fires or explosions from uncontrolled chemical reactions, (2) exposure of workers or the public to chemicals, or (3) releases of chemicals to the environment.

Ongoing activities involving hazardous chemicals at the INEL include the varied use, handling, transportation, retention, and disposal of hazardous chemicals primarily related to storage, conditioning for final disposition, and processing of spent fuel and other radioactive materials; reactor research and development functions; environmental restoration and waste management; maintenance functions; and analytical laboratory activities. During the field verification review, team members reviewed those facilities included in the INEL self-evaluation effort (i.e., CPP-601/602/621 Fuel Processing Facility, Idaho Chemical Processing Plant [ICPP] Tank Farm, Pad A at the Radioactive Waste Management Complex, Pit 9 at the Radioactive Waste Management Complex, Army Reentry Vehicle Facility Site Sodium-Potassium Waste Storage Unit, Power Burst Facility Reactor Area Evaporation Pond, and Argonne National Laboratory-West [ANL-W] Analytical Laboratory). In addition, the Fluorinel Dissolution Process and Fuel Storage (FAST) Facility, the Waste Calcining Facility, and the Rover Headend Processing Plant at the ICPP; the Radioactive Sodium Storage Facility and Radioactive Scrap and Waste Facility at ANL-W; and selected emergency response facilities were examined by the review team. Although the field verification review involved examination of the ANL-W site, it did not specifically address the recent chlorine leak at ANL-W. Examination and evaluation of the circumstances surrounding that incident are the subject of an ongoing Type A Accident Investigation.

The INEL continues to face significant chemical hazards associated with its continuing operations, transition activities, and waste management and remediation activities. However, based on the facilities reviewed in this field verification, those hazards are generally well understood. Strong management systems and programs are in place to minimize or mitigate those hazards, and many commendable practices were documented. However, some weaknesses remain. Three vulnerabilities were identified as a result of the INEL field verification review. None of the identified vulnerabilities represent a condition or circumstance with the potential for severe near-term consequences.

- Spills and releases to the soil from past operations at the ICPP pose a hazard to workers involved in future activities that may disturb soils at the site (e.g., from construction or decontamination and decommissioning);

- Hazardous chemicals and wastes have been stored on site for excessive periods without a clear disposition plan; and 
- Weaknesses in emergency management program documentation could influence the effectiveness of responses to hazardous material and releases.

Commendable practices related to chemical safety at the INEL include the following:

- The establishment of a sitewide chemical exchange system for excess chemicals;

- Successful efforts at the ICPP to eliminate inventory of bulk hazardous chemicals at facilities in transition;

- The planning, execution, and documentation for flushing chemical storage and processing systems at the FAST Facility and the Fuel Processing Facility;

- Maintenance and work control related to chemical systems at the ICPP;

- The replacement of aging safety systems at the ANL-W Analytical Laboratory;

- Use of the Waste Management Authority (committee) at the ICPP to review waste implications prior to changes in process or chemical use/purchase;

- A model chemical hygiene program for laboratory operations at the ANL-W Analytical Laboratory;

- The use of the Idaho Training Advisory Council to facilitate the exchange of information and improve consistency of training related to chemical safety across site contractors; and

- The development of a nomograph for use in planning response to chemical incidents at the ICPP.

The vulnerabilities identified at the INEL; along with those identified at other DOE sites during the field verification phase of the Chemical Safety Vulnerability Review, will be evaluated to determine DOE-wide generic vulnerabilities. Facility-specific and site-specific vulnerabilities are made available to the sites for use in developing management response plans which, in turn, will provide input to the DOE-wide management response plan. 


\subsection{INTRODUCTION}

\subsection{Purpose and Scope}

Based on direction from the Secretary of Energy, the Assistant Secretary for Environment, Safety and Health established the Chemical Safety Vulnerability Working Group to review and identify chemical safety vulnerabilities within the Department of Energy (DOE). The Office of Environment, Safety and Health was designated to lead the review, with full participation from DOE line organizations having operational responsibilities. The information obtained from the review will provide the Working Group with valuable input for determining generic chemical safety vulnerabilities that face the DOE complex. Identifying and prioritizing generic chemical safety vulnerabilities will enhance the Department's focus on programs, funding, and policy decisions related to chemical safety.

The Chemical Safety Vulnerability Review was designed and undertaken to identify and characterize adverse conditions and circumstances involving potentially hazardous chemicals at facilities owned or operated by the Department. Specifically, the review was designed to identify, characterize, and prioritize chemical safety vulnerabilities associated with conditions or circumstances that might result in (1) fires or explosions from uncontrolled chemical reactions, (2) exposure of workers or the public to hazardous chemicals, or (3) release of hazardous chemicals to the environment. A project plan ${ }^{1}$ was developed, using information from line organizations with operational responsibilities, to guide the review.

This report documents activities related to the field verification phase of the Chemical Safety Vulnerability Review. The field verification process was designed to use independent teams of technical professionals with experience in a variety of environment, safety, and health disciplines to verify the accuracy and completeness of the data compiled during the field self-evaluation phase of the review. This phase used a standardized question set developed and distributed by the Working Group to collect data related to chemical safety from 84 facilities located at 29 sites. Based on review of this input, nine sites, including the ldaho National Engineering Laboratory (INEL), were chosen to participate in the field verification phase of this review.

The review considered a broad range of facilities at the INEL (based on facility type and operational status), with special attention given to those facilities being transferred to, awaiting, or undergoing decontamination and decommissioning (D\&D). Different types of chemical- and waste-handling facilities (i.e., laboratories; process facilities; and waste treatment, storage, and disposal facilities) were examined during the review to permit identification of vulnerabilities arising from hazardous chemicals and wastes at the INEL. Although this review involved examination of the Argonne National Laboratory-West (ANL-W) site, it did not specifically address the recent chlorine leak at ANL-W. Examination and evaluation of the circumstances surrounding that incident are the subject of an ongoing Type A Accident Investigation.

1 "Project Plan for the Chemical Safety Vulnerability Review," dated March 14, 1994. 
The INEL field verification team, under the direction of a DOE team leader, was composed of DOE and contractor personnel with technical expertise in various aspects of chemical safety, including management, operations, training, chemical process safety, industrial hygiene, maintenance, environmental protection, and emergency management. A team composition list is provided in Attachment 1 of this appendix.

The team met with management or technical representatives from each of the facilities reviewed. Individual and small group meetings were also held, and team members conducted facility walkthroughs, document reviews, and personnel interviews to gather information related to potential chemical safety vulnerabilities at the INEL. The team leader met regularly with management to discuss the team's activities and any issues that may have surfaced during the previous day. Before the field verification team left the INEL site, management from local DOE and contractor organizations conducted a factual accuracy review of the draft document. An outbriefing was conducted for DOE and contractor management on Tuesday, May 10,1994. A draft copy of this report was provided to DOE and contractor management.

\subsection{Site Description}

The INEL site consists of 890 square miles of desert in southeastern Idaho. Its borders are 32 miles west of Idaho Falls and 80 miles southwest of Yellowstone National Park (see Figure 1). The INEL site is 39 miles long from north to south and 36 miles wide at its broadest point (see Figure 2). It has an average elevation of 4,865 feet, underlaid with beds of basalt rock. The climate is semiarid, with an average precipitation level of 8.5 inches. The average temperature at the site is $42^{\circ} \mathrm{F}$, with extremes ranging from $103^{\circ} \mathrm{F}$ to $-49^{\circ} \mathrm{F}$. The entire INEL site is designated as a National Environmental Research Park. All lands within the site boundaries constitute a protected outdoor laboratory where scientists from DOE, other Federal and State agencies, universities, and private research foundations conduct ecological studies.

The INEL was established in 1949 as the National Reactor Testing Station and contains the largest concentration of nuclear reactors in the world. There are 53 research reactors at the INEL, of which 2 or 3 are typically in operation and roughly 15 more are operable at any point in time. Some landmark achievements of those test reactors are that they include the first nuclear reactor to generate a usable amount of electrical power, the world's first materials testing reactor, and the first experimental breeder reactor.

Contractor activities at the INEL are managed by the DOE Idaho Operations Office (ID), with the exception of ANL-W, which is managed by the DOE Chicago Operations Office through the Argonne Area Office-West (AAO-W). Four primary contractors conduct specific operations at areas around the site: University of Chicago; EG\&G Idaho; Westinghouse Idaho Nuclear Company, Incorporated (WINCO); and Babcock \& Wilcox (B\&W). Two other contractors provide specific services: Protection Technology ldaho (PTI) is in charge of site security, and Morrison Knudsen-Ferguson of Idaho Company (MK-FIC) manages most construction at INEL. These contractors, plus DOE and other Federal agencies, employ more than 12,500 personnel at the INEL. 


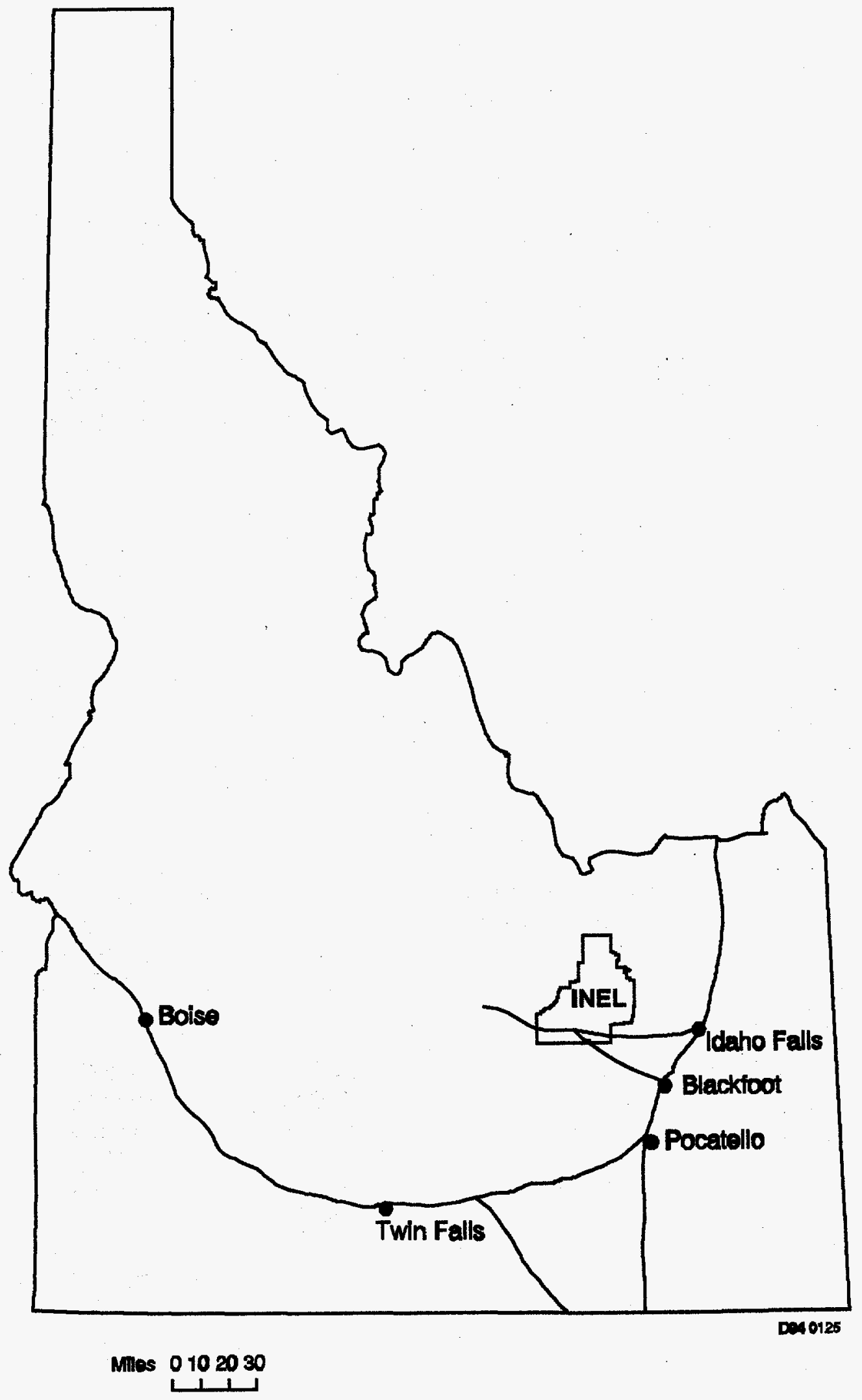

Figure 1. INEL Location.

$\mathrm{H}-9$ 


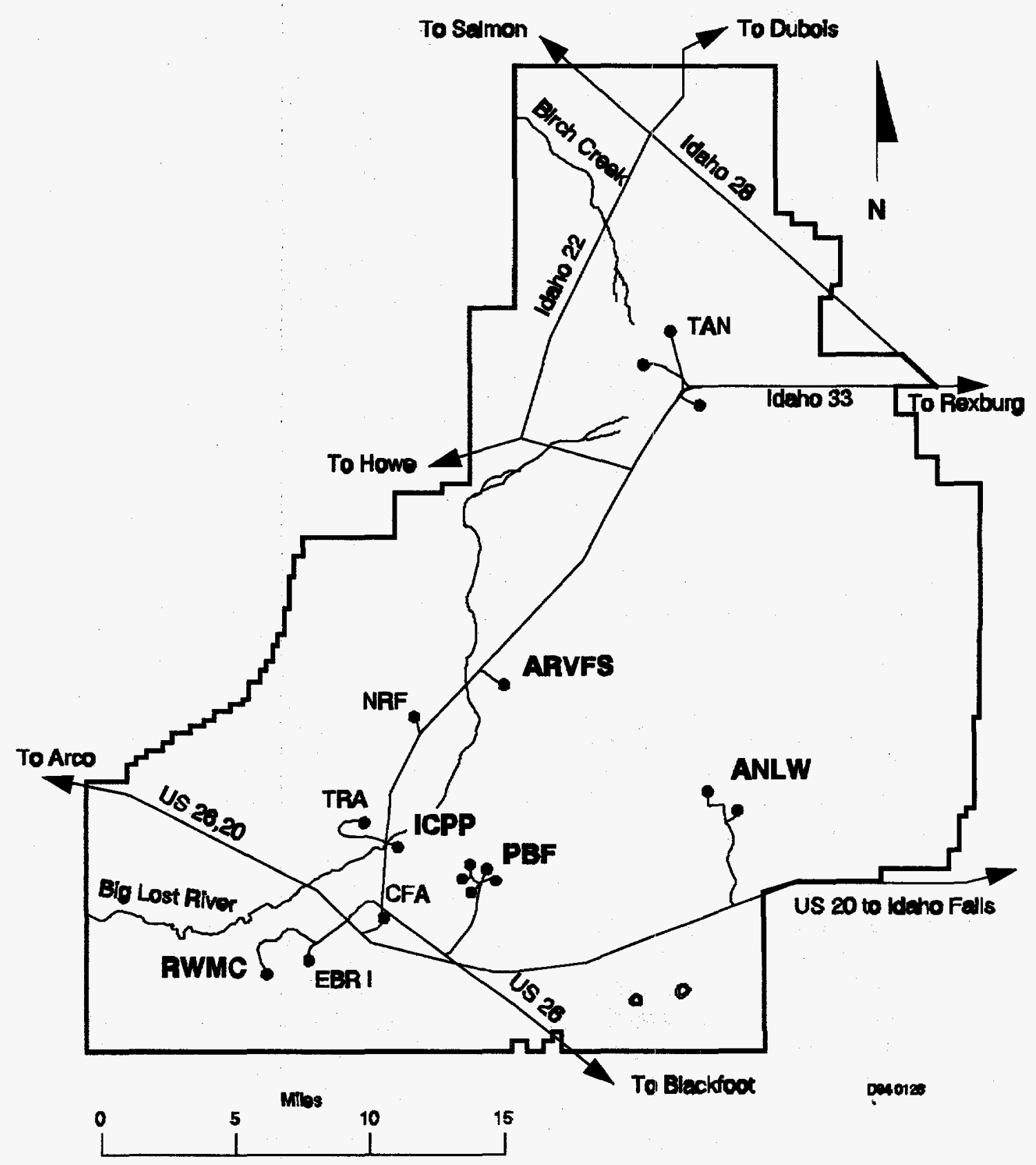

Figure 2. INEL Site. 
ANL-W is located in the southeast comer of the site. The University of Chicago is the operating contractor at ANL-W. ANL-W is the nation's testing ground for liquid metal reactor technology. The complex includes the Experimental Breeder Reactor II (EBR-II), the first pool-type, liquid-metal-cooled reactor. In addition to demonstrating the feasibility of operating this kind of reactor, research has helped improve fuel and materials performance for future liquid metal reactors. EBR-II research has contributed to an innovative design for an advanced nuclear power plant, called the Integral Fast Reactor.

ANL-W has four other reactors and two fuel examination facilities. The Zero Power Physics Reactor provides reactor physics data for any type of fast neutron spectrum reactor. The Argonne Fast Source Reactor is used to calibrate instruments and to study fast reactor physics. The Transient Reactor Test Facility produces short, controlled bursts of nuclear energy to simulate accident conditions leading to fuel damage. The Neutron Radiography Facility is a nondestructive examination tool and a neutron source for isotope production, performing activation analysis and studying radiation effects on materials.

The Radioactive Waste Management Complex (RWMC), operated by EG\&G Idaho, is located in the southwest corner of the site. Solid radioactive waste generated in national defense and research programs is stored or buried at the 144-acre RWMC site. Major activities at the RWMC include receipt and disposal of low-level radioactive waste; receipt, nondestructive examination, and interim storage of transuranic waste; support to environmental restoration program activities; and various engineering evaluations and demonstration projects.

Transuranic wastes, primarily produced at other DOE facilities, are temporarily stored above ground for monitoring and eventual shipment to a Federal repository. The RWMC will be the site of several waste remediation technology applications to retrieve and process transuranic, mixed, and hazardous wastes that were buried in pits and trenches at the complex prior to 1970.

Located in the south-central INEL are four operation areas managed by two different contractors: the Central Facilities Area (CFA), the Power Burst Facility (PBF), and the Test Reactor Area (TRA) are operated by EG\&G Idaho, and the Idaho Chemical Processing Plant (ICPP) is operated by WINCO.

The CFA serves as headquarters for many services for the entire INEL, including security, fire protection, medical facilities, communications systems, warehouses, a cafeteria, vehicle and equipment pools, and a bus system. The Radiological and Environmental Sciences Laboratory (RESL) operated by DOE is also at the CFA. RESL scientists monitor water, air, soil, and area farm produce to substantiate that the INEL operations are safe for site employees and the public. Monitoring results are reported quarterly to the U.S. Environmental Protection Agency, the State of Idaho, and site contractors.

For years, the PBF was a testing facility for nuclear fuels for commercial nuclear reactors. Because of its unique capabilities, the PBF is being considered for use in brain cancer treatment for a program called Boron Neutron Capture Therapy. The reactor is currently on standby.

The TRA, the world's most sophisticated materials testing complex, houses extensive facilities for studying the effects of radiation on materials, fuels, and equipment. The Advanced Test 
Reactor (ATR) produces a neutron flux that allows simulation of long-duration radiation effects on materials and fuels. ATR also is used for production of important isotopes used in medicine, research, and industry. TRA has other smaller reactors, a hot-cell facility, and radiation measurements and radiochemistry laboratories. The ATR Critical Facility provides physics data in support of the ATR program. The Advanced Reactivity Measurement Facility and the Coupled Fast Reactivity Measurement Facility are small pool reactors that are operated at a maximum level of 100 kilowatts. These facilities provide irradiation services for research and materials testing.

The ICPP was constructed in the 1950s to reprocess spent Government-owned fuel from nuclear reactors. The facility is composed of multiple structures used to store irradiated fuels, dissolve spent fuels, extract recoverable uranium, and disposition residual acidic highly radioactive waste as calcine. During the 1980s, many ICPP facilities were replaced or upgraded. In April 1992, DOE decided to terminate fuel reprocessing at the ICPP and revised the mission to provide for (1) storing, conditioning for final disposal, and processing of spent fuel and other radioactive materials and (2) conducting research and development activities. Phaseout and deactivation of the facilities involved in fuel reprocessing are currently in progress. Spent fuel and radioactive waste are being managed on a long-term basis with daily monitoring of important system functions. The New Waste Calcining Facility, completed in 1982, is used to convert liquid radioactive waste to a granular solid form, achieving an eight-to-one volume reduction and producing a safe temporary storage form. Also at ICPP is the Remote Analytical Laboratory, one of the most sophisticated analytical laboratories in the world. This laboratory provides analytical support to ICPP functions.

At the northern end of the INEL is Test Area North (TAN), which consists of facilities for handling, storing, examining, and performing research and development work on spent nuclear fuel. This work is done in the TAN Hot Shop (operated by EG\&G Idaho), the largest hot shop in the world, and in adjacent smaller hot cells. Manufacturing activities at TAN are conducted by B\&W.

\subsection{Facilities Visited}

Visiting every DOE facility at INEL was not possible under the time constraints of this review. As a result, the field verification team focused its efforts to achieve the maximum results possible in the time available. Operations selected for field review focused on facilities examined in the INEL self-evaluation. These included the CPP-601/602/621 Fuel Processing Facility, the ICPP Tank Farm, Pad A at the RWMC, Pit 9 at the RWMC, the Army Reentry Vehicle Facility Site (ARVFS) Sodium-Potassium Storage Unit, the PBF Reactor Area Evaporation Pond, and the ANL-W Analytical Laboratory. In addition, other facilities were reviewed by the field verification team, including the Fluorinel Dissolution Process and Fuel Storage (FAST) Facility, the Waste Calcining Facility, and the Rover Headend Processing Plant at the ICPP; the Radioactive Sodium Storage Facility (RSSF) and the Radioactive Scrap and Waste Facility (RSWF) at ANL-W; and selected emergency response facilities. MK-FIC training activities were examined as part of the Human Resources Program functional area review; no B\&W facilities or activities conducted by PTI were examined during this review.

The CPP-601/602 Fuel Processing Facility includes the CPP-601 Building, the CPP-602 Building, and the CPP-621 Area. The CPP-601 Building is the main ICPP 
processing complex and is a rectangular structure about 240 feet long, 100 feet wide, and 90 feet high from lower subgrade level (60 feet below ground) to the rooftop. Principal process operations include nuclear fuel dissolution and liquid-to-liquid extraction purification. These operations are conducted in shielded cells within the CPP-601 Building. The process makeup area (i.e., upper level of the CPP-601 Building) supports in-cell operations. Due to the ICPP mission change, operations are being discontinued and systems are being flushed of residual material as part of the facility transition.

The CPP-602 Building is connected to the CPP-601 facility. The lower level of the CPP-602 Building houses the denitration process. The denitrator room measures about 12 feet long, 10 feet wide, and 14 feet high. The CPP-602 Building also contains the LC-106 storage vault, which is used for storage of special nuclear materials and measures 10 feet wide, 44 feet long, and 14 feet high, and Z-Cell, which is used for storage of uranium solution awaiting feed to the denitrator and measures 6 feet wide, 24 feet long, and 21 feet high. Also located in this building are various chemical laboratories and associated support areas, including offices.

CPP-621 is the Chemical Storage Area and contains a pumphouse, two bulk nitric acid vessels with capacities of 30,000 gallons and 18,400 gallons, and two bulk aluminum nitrate vessels with capacities of 16,000 gallons and 6,200 gallons. The pumphouse measures 27 feet long, 25 feet wide, and 20 feet high.

The ICPP Tank Farm provides interim storage of acidic highly radioactive liquid waste before calcination. The tank farm consists of 18 tanks: two 320,000-gallon tanks, nine 300,000 -gallon tanks, four 30,000-gallon tanks, and three 8,500-gallon tanks. Ten of the nominal 300,000 -gallon tanks provide interim storage of highly radioactive liquid waste that is transferred to the tank farm from other facilities at ICPP. The eleventh 300,000-gallon tank is a spare. The three 18,500-gallon tanks are interim storage tanks for second-and third-cycle raffinates from the CPP-601 Building extraction operations. The four 30,000-gallon tanks are out-of-service because they do not meet Resource Conservation and Recovery Act (RCRA) secondary containment requirements.

Pad A at the RWMC was constructed in 1972 for disposal of solid mixed waste (i.e., hazardous waste contaminated with radioactive material) primarily from the Rocky Flats Plant in Colorado. Wastes were placed at Pad A from September 1972 until August 1978. There are 18,232 drums and 2,020 boxes containing contaminated sodium and nitrate salts, depleted uranium, beryllium, and low-activity waste. Pad A has not been used for any other function since 1978.

Pit 9 at the RWMC is an inactive waste disposal site that measures 379 feet long, 127 feet wide, and 17 feet deep. Pit 9 was open from November 1967 to June 1969 and contains 150,000 cubic feet of packaged waste; 350,000 cubic feet of interstitial soil; and 250,000 cubic feet of overburden. Remediation technologies are currently being evaluated to determine the most effective solution for retrieval, treatment, and final disposal of the wastes in Pit 9 .

The ARVFS Sodium-Potassium Waste Storage Unit consists of a multiplate arch building that measures 9 feet, 3 inches high at the center; 16 feet wide; and 18 feet long. Soil has been placed over the top of the building to form a mound about 3 feet higher than the surrounding 
terrain. The entrance to the bunker is sealed by a semicircular steel plate that is tack-welded in place. Stored in the bunker are four containers totaling 180 gallons of primary sodiumpotassium coolant contaminated primarily with cesium, strontium, and other mixed fission products.

The PBF Reactor Area Evaporation Pond operated from 1972 to 1985 to support the Thermal Behavioral Program's testing of pressurized water reactor fuel rods under hypothetical accident conditions. Demineralized and secondary coolant was discharged to the pond between 1978 and 1984.

The ANL-W Analytical Laboratory performs chemical, radiochemical, and physical measurements in support of ANL-W nuclear activities. The Laboratory measures 11,000 square feet and houses six interconnected hot cells for remote analytical chemistry applications for irradiated and spent fuel, eight general-purpose laboratories for low-level and nonradioactive applications, one advanced analytical instrumentation laboratory for application to remote radioactive sample analysis, two laboratories for radiochemical counting, one glovebox laboratory, and two mass spectrometer laboratories.

In terms of facilities examined beyond those addressed in the INEL self-evaluation, the field verification team also reviewed the FAST Facility, the Waste Calcining Facility, and the Rover Headend Processing Plant at ICPP; the RSSF and the RSWF at ANL-W; and selected emergency response facilities. The FAST Facility was used for dissolution of spent naval nuclear fuel. This facility is 10,080 square feet and occupies five levels. The Waste Calcining Facility operated from 1963 to 1981, and was used to convert liquid radioactive waste to granular form. The New Waste Calcining Facility has served that function since 1982. The Rover Headend Processing Plant was used to recover enriched uranium from fuel used in the Rover project. The RSSF is used to store radioactive and mixed waste and consists of five weather-proof shipping containers holding radioactive sodium, sodium-potassium alloy, sodium-contaminated asbestos, and lead. The RSSF is located in the northeast corner of the ANL-W site. The RSWF is an interim storage area for radioactive scrap, radioactive waste, and mixed waste. The RSWF covers 4 acres north of the ANL-W site and consists of about 1,200 metal liners, 16-24 inches in diameter and about 13 feet long, buried vertically in the ground. Each of the liners is capped by a seal-welded cover.

\subsection{SUMMARY OF RESULTS}

The field verification process was designed to verify the accuracy and completeness of the data provided to the Chemical Safety Vulnerability Working Group by the INEL facilities selected to participate in the field self-evaluation process. The verification process offered an opportunity to examine site-specific chemical safety vulnerabilities and to make informed judgments about the seriousness of these conditions.

The goal of the field verification visit was to develop a prioritized list of chemical safety vulnerabilities at INEL. Before arriving on site, team members reviewed the self-evaluation data and other documents to allow team members to develop a list of observations related to potential vulnerabilities for their functional areas. During the onsite portion of the review, team members visited facilities selected for self-evaluation to verify reported observations and to look for other conditions or circumstances that might result in chemical safety vulnerabilities. 
Facilities that were not included in the original self-evaluation were also reviewed (i.e., the FAST Facility, the Waste Calcining Facility, and the Rover Headend Processing Plant at the ICPP; the RSSF and the RSWF at ANL-W; and selected emergency response facilities).

To facilitate effective team management and to expedite the identification of vulnerabilities across a wide range of disciplines associated with chemical safety, the field verification review was organized to include five functional areas:

- Identification of chemical holdings, including the properties of chemicals located at the facility, the characterization of those chemicals, and an analysis of the inventory.

- Facility physical condition, including engineered barriers, maintenance conditions, chemical systems, safety systems, storage, monitoring systems, and hazards identification.

- Operational control and management systems, including organizational structure; requirements identification; hazard analysis; procedural adherence; maintenance control; engineering and design reviews; configuration control; safe shutdown plans; and site programs for quality assurance, chemical safety, inventory control, access control, disposal, transportation and packaging, and corrective actions.

- Human resource programs, including technical competence, staffing, training and qualifications, employee involvement, employee concerns, personnel performance requirements, and visitor and subcontractor control.

- Emergency management programs, including the emergency response plan, inplant consequences, environmental issues, coordination with the community, and community right-to-know issues.

These functional areas were evaluated on the basis of lines of inquiry provided in Attachment 1 of the "Field Verification Guide for the Chemical Safety Vulnerability Review," dated April 8, 1994. Verification of the self-evaluation data was accomplished by walkthrough of facilities, conduct of interviews with management and technical personnel, examination of facility and site documentation, and review of incident reports and other documents.

The INEL continues to face significant chemical hazards associated with its continuing operations, transition activities, and waste management and remediation activities. However, based on the facilities reviewed in this field verification, those hazards are generally well understood. Strong management systems and programs are in place to minimize or mitigate those hazards, and many commendable practices were documented. However, some weaknesses remain, and three vulnerabilities were identified.

Commendable practices identified related to chemical safety at the INEL include (1) the establishment of a sitewide chemical exchange system for excess chemicals; (2) successful efforts at the ICPP to eliminate inventory of bulk hazardous chemicals at facilities in transition; (3) the planning, execution, and documentation for the flushing of chemical storage and processing systems at the FAST Facility and the Fuel Processing Facility; (4) maintenance and work control related to chemical systems at the ICPP; $(5)$ the replacement of aging safety 
systems at the ANL-W Analytical Laboratory; (6) use of the Waste Management Authority (committee) at the ICPP to review waste implications prior to changes in process or chemical use/purchase; (7) a model chemical hygiene program for laboratory operations at the ANL-W Analytical Laboratory; (8) the use of the Idaho Training Advisory Council to facilitate the exchange of information and improve consistency of chemical-related training among site contractors; and (9) the development of a nomograph for use in planning response to chemical incidents at the ICPP. The results of the field verification review at INEL are summarized below.

\subsection{Identification of Chemical Holdings}

Verification activities for the chemical holdings functional area of the Chemical Safety Vulnerability Review for WINCO, EG\&G Idaho, and ANL-W facilities at INEL included all applicable elements of the lines of inquiry. Special attention was given to the characterization, control, and documentation of chemical inventory and chemical wastes at INEL, and adequacy of storage and containment of those materials. All facilities included in the sites'

self-evaluation were reviewed, as were the additional facilities described in Section 1.3.

A wide variety of hazardous materials are used at the INE:L facilities reviewed, with WINCO being the largest user of process, cleanout, and analytical chemicals. The ANL-W chemical laboratory uses small quantities of more than 600 different chemicals; EG\&G Idaho uses chemicals primarily in maintenance, analytical, and water treatment activities. Only very small quantities of highly hazardous materials, such as carcinoglens, are used. Comprehensive inventories of all chemicals used are maintained for each facility. The WINCO electronic data base system (i.e., Haz-Trac) provides online tracking. The ANL-W electronic data base system (i.e., SARA Inventory) is updated quarterly for the site and monthly for the Laboratory. The EG\&G Idaho electronic data base (i.e., SYSTEM 80) maintains its inventory by material name only and is used for procurement control, for meeting the Occupational Safety and Health Act (OSHA) Hazard Communication (HAZCOM) Standard, and for reporting required by Title III of the Superfund Amendments and Reauthorization Act. A physical inventory is taken annually to provide quantitative information. An effort to develop a unified chemical inventory tracking system for the entire INEL is being led by WINCO. An INEL sitewide electronic data base of available excess materials is maintained by EG\&G Idaho, and is considered a commendable practice. When no onsite need materializes for excess chemicals, an effort is made to sell them back to suppliers or other users; failing this, the materials are designated as waste and disposed of properly.

Controls are exercised over procurement to ensure that quality, industrial hygiene, and waste minimization requirements are met. Workers are trained in the use of hazardous materials, are provided with material safety data sheets (MSDSs), and are informed about health hazards associated with hazardous materials in their workplace. Hazardous materials are appropriately labeled, and facilities in which these materials are used are posted as required by regulations. Storage of chemicals is governed by facility procedures, which require segregation according to compatibility classes. Storage cabinets, rooms, and areas observed by the verification team demonstrated good management practices. Bulk chemical storage areas in Building CPP-621 and chemical makeup areas in Buildings CPP-601, CPP-602, and CPP-666 are appropriately segregated and contained. Since the decision to discontinue spent fuel processing in 1992, excess chemicals from these facilities are being made available to

$$
\mathrm{H}-16
$$


other users at INEL or are being sold to suppliers or other users; the resale of surplus chemicals is also considered a commendable practice.

Chemical heels and residues exist in some process equipment in WINCO facilities. The fluorinel dissolver equipment has been flushed and placed in standby; the condition of the facility is well documented. Cleanout of the chemical processing facilities in Buildings CPP-601 and CPP-602 is in progress. When the Waste Calcining Facility (Building CPP-633) was shut down in 1981, the process inventory was removed but the equipment was not cleaned and flushed. Thus, process residues remain in the calciner, and the silica gel columns used to trap ruthenium are still in place. The Rover Headend Processing Plant (Building CPP-640) was shut down in 1984. The aqueous process inventory was removed at the time and the aqueous processing equipment was flushed, but the inventory in the dry processing equipment was left in place. This inventory includes about 93 kilograms of enriched uranium. Plans for cleanout of these facilities are described in WINCO-1193, Nuclear Fuel Reprocessing Phaseout for the Idaho Chemical Reprocessing Plant (draft) (Rev.1), dated February 1994. The currently active high-level liquid waste tanks contain solids of unknown composition. A project is planned to retrieve and analyze sludge from one tank. All high-level waste tanks currently in service will be emptied and retired from service within $15-21$ years.

The future disposition of some chemicals in process or in storage is uncertain. About 10,000 gallons of cooling water containing dichromate is stored in tanks, pipes, and coils in the tank farm. Current plans are to leave this material in place until the tank farm is retired in 15-21 years. About 1,000 gallons of hexone solvent extractant is being held in Building CPP-601 until the purity of the uranium products is confirmed to be acceptable and until there is no further use for the solvent extractant. When removed, it is likely that the hexone will be slightly contaminated with radionuclides and will thus be classified as mixed waste. Alternatives considered for disposal include burning in the Waste Experimental Reduction Facility (WERF) incinerator or in a licensed commercial incinerator. Other chemicals in a similar status include radioactively contaminated sodium and sodium-potassium being stored by ANL-W and EG\&G Idaho. An alternative being considered is to deactivate these highly reactive materials in ANL-W facilities. Further evaluation of these alternatives is in progress.

About 400 spills, leaks, and discharges of hazardous materials to the soil have been identified for INEL, with 83 of these being at ICPP. The WINCO Environmental Restoration Program is intended to identify, characterize, and remediate (if required) such occurrences consistent with applicable regulatory requirements. Administrative and engineered controls are in place to minimize risks to workers.

Large quantities of hazardous and radioactive wastes have been placed in the RWMC, including Pit 9 and Pad A. These areas will be controlled and/or remediated under the Comprehensive Environmental Response, Compensation, and Liability Act (CERCLA) and RCRA.

Strong RCRA waste management programs have been developed, and practices that conform to requirements have been implemented. Wastes are characterized before disposition, usually through sampling and analysis, although historical values are used in repetitive situations. 
Qualified personnel review planned generation of wastes for control, minimization, and compliance with applicable laws, rules, and regulations governing the generation, handling, storage, treatment, and final disposition of waste streams. WINCO established the Waste Management Authority to ensure that these goals are accomplished. The field verification team regards this effort as a commendable practice. All RCRA hazardous and mixed waste drum storage areas reviewed demonstrated compliance with regulations and site requirements.

Both air and water discharges are controlled. Comprehensive surveys of air emission points have been or will be completed, primarily in response to forthcoming permit requirements specified by Title $V$ of the Clean Air Act Amendments. Analyses have been conducted for criteria pollutants and substances on the toxics list. Similar surveys of process and sanitary water have been or will be completed (1) to ensure proper routing of process and sanitary wastes, (2) to reduce point source discharges, and (3) to evaluate opportunities for source reduction. Aqueous discharges are permitted under the National Pollutant Discharge Elimination System and the State of Idaho Wastewater Land Application Permitting System. At ANL-W, all wastewater from sinks in laboratories and janitors' closets is collected and characterized to determine the appropriate disposition. This practice is considered a commendable practice.

Two vulnerabilities were identified related to chemical holdings. First, numerous spills, leaks, and discharges of hazardous materials to soil have occurred at INEL. Known release sites have been cataloged and investigated and are being remediated, as appropriate. Additional release sites may be discovered when soil is disturbed and, if not properly controlled, could pose hazards to workers. Second, hazardous materials have been stored for extended periods at the INEL without provision for their final disposition. These materials include sodium and sodium-potassium, cooling water containing dichromate, and hexone. A more detailed discussion of these vulnerabilities is provided in Section 3.2 and in Attachment 2 of this appendix.

\subsection{Facility Physical Condition}

Verification activities for the facility physical condition functional area of the Chemical Safety Vulnerability Review included review of the overall condition of facilities and the effectiveness of maintenance activities as they relate to chemical safety. Facilities, maintenance programs, and work activities of three site contractors-ANL-W, EG\&G Idaho, and WINCO-were examined. Areas evaluated included (1) engineering design control and configuration management; (2) work control and conduct of maintenance activities, including pre-work safety evaluation; (3) corrective and preventive maintenance (PM) programs; (4) implementation of administrative controls to protect workers, including the use of lockout/tagout, special work permits, and the use of personal protective equipment (PPE); (5) the condition of chemical primary and secondary containments; (6) identification of chemical hazards, including proper labeling of chemical containments and piping; and (7) the proper control and use of hazardous chemicals, such as solvents and paints, during maintenance of facilities and equipment. In addition to the typical evaluation methods used, regularly scheduled maintenance and planning meetings were attended. 
Evaluation of engineering control programs focused on procedures, quality assurance, and configuration management. ANL-W requires only a limited amount of nonreactor design support and, therefore, prefers to rely on Plant Services or offsite contractors for this work. ANL-W procedures for nonreactor engineering control and acceptance exist. However, in one instance observed, these procedures failed to prevent a subcontractor working on the hot cell modification project from supplying equipment that was not suited for the intended application. The deficiency was discovered by facility management as the equipment was being readied for installation. In this case, project quality ultimately depended on the owner and not necessarily on how well the quality assurance program for engineering functioned. ANL-W is currently reworking all aging critical and safety-related systems in Building 752 (e.g., electrical, ventilation, steam, waste lines, chemical drains) and is maintaining up-to-date as-built drawings and equipment files for this work.

EG\&G Idaho and WINCO have well-developed engineering procedures and standards that are based on adherence to relevant national consensus documents and require appropriate levels of verification and approval commensurate with the risk and consequence of equipment or system failure. The design of chemical systems and the selection and acceptance of related equipment are adequately addressed in these programs. Thus, all design engineering work, whether performed by onsite staff or by offsite contractors, is being adequately controlled and integrated into the maintenance work control system. All new maintenance tasks performed at EG\&G Idaho and WINCO facilities are being documented individually, and projects are systematically completed and closed. To date, all facility safety system documentation has been updated. Both contractors are actively pursuing reduction of their backlogs for nonsafety-system as-built drawings, and adequate progress is being reported.

The evaluation of maintenance programs focused on work control and preventive maintenance activities, emphasizing the integration of engineering support into work packages, the reduction of risk to maintenance workers through work control and pre-job safety analysis, the avoidance of catastrophic equipment failure through effective prevention programs, and the safe control and use of hazardous chemicals in maintenance activities.

The three site contractors' maintenance work control programs are functioning effectively. At a minimum, each work control program requires that a pre-work safety evaluation be performed and that the necessary safety controls (e.g., PPE, lockout/tagout, process or pressure isolation) and administrative controls (e.g., quality levels, special work permits, and radiation work permits) are identified. Under these programs, work orders are reviewed and approved by representatives from the quality assurance, environment, safety, and health physics organizations before work is initiated, and work orders are closed only after the necessary postmaintenance testing has been completed and verified. The Total Quality Management (TQM) Core Team's approach to work control was developed by WINCO and has been identified by the field verification team as a commendable practice. It was noted that WINCO also requires that drawings and equipment files be updated (i.e., as-built) before approving closure of maintenance work orders.

Each site contractor has implemented a preventive maintenance program. Neither ANL-W nor EG\&G Idaho reports a backlog of preventive maintenance, but both allow a 25-percent grace period before a task is reported as overdue (e.g., annual preventive maintenance is afforded a 3-month grace period). WINCO reports no backlog of preventive maintenance tasks and 
allows no grace period. WINCO Plant Services reports a preventive maintenance delinquency rate average for the last 12 months of less than 0.5 percent. Both EG\&G Idaho and WINCO have also adopted predictive maintenance techniques to warn about pending equipment failure. Such techniques include vibration analysis, thermography, and analysis of used lubricating oil.

All three contractors demonstrated a proactive attitude toward identifying and mitigating chemical hazards in their facilities. Chemical piping, tankage, pressure vessels, and primary and secondary chemical containers were found to be appropriately labeled and in generally good mechanical condition. One aluminum nitrate tank in Building CPP-621 was removed from service when cracks were observed in its shell. Subsequent evaluation determined that this tank was not fit for further service, and it was flushed and retired. Secondary containments, including berms, dikes, and engineered containments, were found to be in good condition. The removal of all underground fuel tanks at the INEL is scheduled for completion within the next 2 years.

In addition to reducing process chemical inventories, each contractor has effectively minimized inventories of maintenance solvents and has replaced hazardous solvents with nonhazardous substitutes. MSDSs are available near chemical storage and use areas, and maintenance workers are qualified in their use and interpretation.

The physical condition of the facilities and waste sites was found to be as reported in the contractors' self-evaluations. ANL-W is currently refurbishing and modifying the 30 -year-old hot cells and ventilation systems in Building 752. Because of this ongoing project, housekeeping in active work areas was not impressive, but it was evident that contamination was being well controlled. Significant progress in sampling, characterizing, emptying, and flushing unused, obsolete chemical systems has been made in Building 752 . However, except for the removal of a contaminated perchloric acid fume hood without incident, there has been insufficient funding available to complete the removal of these systems and to make better use of the building space.

The EG\&G Idaho waste storage and disposal sites selected for evaluation have no associated physical facilities other than inflatable buildings, burial pads, and underground bunkers. A limited review of these sites revealed no physical deficiencies. Air-monitoring instruments were reported to be operating properly, and the access control fencing and other personnel entry barriers appeared to be in good condition.

The WINCO facilities evaluated included the ICPP Fuel Processing Buildings CPP-601/602, the modern FAST Facility, and the Chemical Storage Area (Building CPP-621). Each of these facilities was found to be in good condition and demonstrated exemplary housekeeping. During previous fuel-processing campaigns in the older buildings, noncorrosion-resistant transfer piping developed an undetected leak, releasing hazardous chemicals to the soil column. In this case, the leak was directly beneath the facility and has yet to be characterized or remediated. When this leak was discovered, accurate flow-metering instrumentation and new encased transfer piping were installed in several ICPP applications to detect and contain future leakage. Because of the decision to discontinue the processing of spent fuel at the INEL, chemicals are being removed from each of the WINCO facilities noted above. Most process piping and vessels are being emptied and flushed. Noncontaminated bulk chemicals 
are either being sold to offsite commercial chemical operations or are being used in other operations at INEL.

No chemical vulnerabilities related to the facility physical condition functional area were identified for the three site contractors reviewed.

\subsection{Operational Control and Management Systems}

Verification activities for the operational control and management systems functional area of the Chemical Safety Vulnerability Review included examination of selected systems used by INEL site contractor management to improve chemical safety and to limit vulnerability in chemical and waste-handling operations. The management systems of the three management and operating (M\&O) contractors-WINCO, EG\&G Idaho, and ANL-W-were reviewed, and this review was augmented by interviewing the ID facility managers assigned to oversee the ICPP and the RWMC and by interviewing the President of the local chapter of the Oil, Chemical, and Atomic Workers (OCAW) Union, which represents organized employees of these three contractors.

Management at WINCO and EG\&G Idaho has established systems that are judged to provide an acceptable degree of chemical safety in the conduct of activities, programs, and operations. The review of management systems in ANL-W facilities did not indicate any chemical safety vulnerabilities; however, as stated in Section 1.1, this review did not address management systems operative in the part of ANL-W that experienced a chlorine gas release on April 15, 1994. A Type A Accident Investigation Team is investigating those issues concurrent with this review.

All three M\&O contractors have implemented management systems designed to ensure adequate safety review prior to procurement of hazardous chemicals. Although the systems differ in operational detail, they all rely on industrial hygiene specialists to judge (1) whether the requester is properly trained to handle the chemical safely, (2) whether the requester's facility is adequately equipped for use of the chemical, and (3) whether a less hazardous chemical might fulfill the objectives of the experiment. In addition, WINCO established the Waste Management Authority, which is charged with ensuring that all mixed, hazardous, radioactive, and liquid industrial waste streams are identified, minimized, and controlled to meet best waste management practices and to conform to applicable regulations and agreements.

Systems of management review and authorization of operations involving the use of chemicals are in place for all three contractors:

- WINCO has a well-developed safety analysis system that requires hazard and accident analyses for new or modified operations that exceed prior experience at the ICPP. WINCO has also implemented a formal system of scrutinizing all proposals for new or modified operations for unreviewed safety questions and for performing unreviewed safety question determinations where indicated. Moreover, WINCO is in the process of upgrading its current safety analyses to conform to the requirements of the recently issued DOE 5480.23. 
- EG\&G Idaho management requires a preliminary hazards screening to determine whether a proposed or modified operation transcends safety considerations previously experienced and analyzed and, if so, requires that a formal safety analysis be prepared, reviewed, and approved before initiating the operation. Environmental checklists document the elements and actions that must be completed in fulfilling the requirements of a hazards analysis. EG\&G Idaho has issued a preliminary hazards analysis for the remediation project at RWMC Pit 9 . This project is designed to remove from the Pit 9 burial site the actinide and mixed waste containers with actinide contents that exceed 10 nanocuries per gram. The hazards analysis for the project is being prepared in phases. Phase 1 (i.e., the preliminary hazards analysis) was completed in 1992; Phase 2 will be completed by a selected contractor in late 1994; and the Final Safety Analysis Report is expected to be completed in 1996, before the initiation of full-scale remediation.

- $\quad$ ANL-W management mandates the preparation of hazards assessments for new or modified operations that do not fall within previously analyzed Laboratory experience. The ANL-W Environment, Safety and Health Manual, Section II-Chapter 15, dated

February 1, 1986, defines the protocol for preparing hazards assessments.

Each of the three M\&O contractors has a well-developed and functioning system for reporting and investigating abnormal events, including provisions to address "near misses" and to emphasize "lessons learned." The ANL-W system is described in the ANL-W Procedures Manual and includes a well-structured critique procedure. Formal safety committee meetings are used to publicize "lessons learned."

Based on the observations noted in the facilities visited during the review, all three M\&O contractors have implemented comprehensive industrial hygiene programs to address facility-specific health hazards. All have work control systems, incorporating such elements as work permits, hazard analyses, health and safety plans, and procedure reviews. These systems were designed to ensure that health hazards are identified and that proper protective measures, such as PPE and engineering controls, are used to mitigate hazard consequences and to protect worker health. In addition, INEL instituted the Industrial Hygiene Steering Committee to facilitate consistency within the different contractor industrial hygiene programs.

The type of maintenance work control program selected and the style of program management adopted by each of the three M\&O contractors depend on the magnitude of the contract, on the complexity of the present and past operations to be maintained, and on the distribution of the work force at INEL. ANL-W has been involved in liquid metal reactor research and development with all operations located at one site. WINCO was primarily a chemical processor but is now a manager of fuel and waste, with all operations also at a single site. EG\&G Idaho is a reactor operator, waste manager, and site support contractor, with its operations work force split among 10 individual sites.

In those facilities examined in this review, ANL-W depends less on formal, complex, computer-based work control programs and more on the professionalism and diligence of its facility management staff in planning and scheduling maintenance, procuring and accepting materials, preparing and approving work package documents, providing specific technical direction, establishing and maintaining the appropriate levels of quality, and overseeing the safety of maintenance work. Because ANL-W maintenance operations are of a relatively 
smaller scale and may be less schedule driven than those of other INEL contractors, this approach is entirely appropriate.

WINCO has adopted the principles of TQM in its maintenance program. Maintenance work control has been decentralized by establishing core teams of qualified employees, with each team member being equally empowered to strategize, evaluate, approve, and implement work orders within the bounds of individual responsibility and expertise. Each team includes

(1) permanently assigned specialists in integrated scheduling and facility engineering;

(2) multicraft maintenance foremen; and (3) specialists in planning, administration, environment, safety, health physics or industrial hygiene, quality, and materials procurement. Senior management is apprised of work progress by the daily reporting of exceptions, allowing them to focus more clearly on problem areas. This work control system has been functioning successfully for 1 year.

EG\&G Idaho, with its diverse mission and widely distributed work force, has elected to institutionalize the control of maintenance work by publishing an administrative policy that defines the minimum programmatic requirements for maintenance and allows each of the 10 operating areas to develop and implement its own program. However, through a series of self-assessments, EG\&G Idaho has determined that a significant diversity exists among the 10 areas with respect to their interpretation and degree of implementation of the policy. To address this problem, a revision to the policy is planned and the EG\&G Idaho Conduct of Maintenance Manual was issued on July 1, 1993. A revised work control process has been developed and is scheduled for full implementation by late October 1994.

Also, EG\&G Idaho is piloting an innovative, computer-based maintenance work control program based on a comprehensive master equipment list. This program links specific pieces of equipment and systems to service hazards, quality assurance levels, and safety and health requirements. As currently envisioned, the equipment number and specific maintenance task will be entered, and the computer, in turn, will be used to define the necessary administrative requirements and controls for performing the task safely and then to print the work order. The schedule for full implementation of this program has not yet been developed.

The DOE decision in 1992 to cease spent reactor fuel reprocessing at the ICPP has required the WINCO organization to develop a shutdown plan for most of its chemical operations. In response to this need, WINCO issued WINCO-1193, Nuclear Fuel Reprocessing Phaseout Plan for the Idaho Chemical Processing Plant (draft) (Rev. 1), dated February 1994, and WINCO-1174, Idaho Chemical Processing Plant Transition Plan, dated March 1994. These documents clearly articulate the steps required to complete the chemical process mission and to secure selected facilities either for total closure or for future operations with a different mission.

Recent steps have been taken to improve the effectiveness of the ID oversight system at INEL. ID facility managers are now located at the site and are provided (through a modified matrix management system) with technical managers and "facility representatives" to maintain near-continuous oversight of field operations. The new system is designed to reduce paperwork and to rely on direct personal communications to enhance the benefits of DOE oversight. One of these benefits is improved chemical safety. Thus far, the revised oversight system is judged by ID management to have worked well in achieving its objectives. The 
facility managers have been given considerable latitude in allocating their resources to meet oversight needs for their specific facilities.

The effectiveness of the union-management relationship at INEL was examined during discussions with the President of the local chapter of the OCAW, which represents 1,169 employees of WINCO, EG\&G Idaho, and ANL-W at INEL. Union membership has raised no issues in recent years related to chemical safety problems at INEL. The current safety program atmosphere is judged to be conducive to promoting cooperation and collaboration between the local union and M\&O contractors in maintaining safety performance (including chemical safety performance) at a high level. The effectiveness of the joint union/management councils in addressing safety issues appears to be a major factor in contributing to high safety morale at INEL.

No chemical safety vulnerabilities related to the operational control and management systems functional area were identified for the three site contractors reviewed.

\subsection{Human Resource Programs}

Verification activities for the human resources programs functional area of the Chemical Safety Vulnerability Review at the INEL included all elements of the lines of inquiry, with particular emphasis on issues related to training, staffing, employee involvement, and visitor and subcontractor control. The programs of four site contractors, EG\&G Idaho, WINCO, ANL-W, and MK-FIC (the site construction manager), as they are implemented in the facilities for which self-evaluations were performed, were examined during the site visit. The review addressed staffing, training content, management commitment, and employee involvement, including "stop-work" authority.

Staffing levels at all four contractor organizations were judged to be appropriate to ensure that chemical safety and training issues in the facilities were adequately addressed. Based on the findings of INEL Environment, Safety, and Health Progress Assessment, there is an open position for an industrial hygienist at AAO-W and an open action item to create such a position at ID. Filling these positions will enhance oversight of the contractor's chemical safety related programs.

Each of the site contractors at INEL provides training organizations. Mandatory 24- or 40-hour hazardous waste operations training, as well as DOE Radiological Control (RADCON) Manual Radiological Worker Training, is provided either by the site contractor or by Eastern Idaho Technical College through a contract arrangement, depencling on demand. The training provided meets OSHA requirements stipulated in 29 CFR 1910.120, "Hazardous Waste Operations and Emergency Response," as well as the DOE RADCON Manual.

Training provided to site personnel on the requirements of 29 CFR 1910.1200, "Hazard Communication," and 29 CFR 1910.1450, "Occupational Exposure to Hazardous Chemicals in Laboratories," was also examined. All INEL and subcontractor personnel receive basic hazard communication and facility-specific training as part of General Employee Training. The purpose of this training is to acquaint all personnel with the pertinent statutory requirements for hazard communications, as well as to familiarize them with warning labels, signs, "stopwork" authority, and MSDSs. Other specialized training (e.g., for carcinogen control, toxic 
Substance Control Act overview, nitric acid safety) is provided as job requirements dictate. All the training modules examined were performance based, with a minimum passing score of 80 percent required. Retraining is facilitated through the use of computerized tracking systems. In all cases observed, training required by site personnel was current and appropriate for access to the facility in question. Proof of training was required before facility access was allowed. Each of the site contractors performs audits and self-assessments of their training programs, including reviews of subcontractor training records.

Two of the site training programs or initiatives reviewed deserve particular mention. The ANL-W Analytical Laboratory has a model chemical hygiene training program that exceeds the requirements of the OSHA Laboratory Standard, the OSHA HAZCOM Standard, and DOE 5480.10. The assigned Chemical Hygiene Officer has implemented this standard proactively. The storage, labeling, and administrative controls for the purchase, handling, and disposition of chemicals are excellent. The Chemical Hygiene Officer has made a concerted effort to find substitutes for high-risk chemicals such as ethers and benzene. The training program provided to the Analytical Laboratory staff is current, succinct, and performance based. The observed condition of the chemical laboratories in this aging facility indicates the excellence of the chemical safety training provided, and serves as a model program for other organizational elements to follow. The second training initiative of note was the establishment of the Idaho Training Advisory Council. The purpose of this council, which has representatives from all the site contractors and ID, is to act as a forum for discussing INEL training issues and making recommendations to management. The council is also working on standardizing safety training throughout the INEL, as well as coordinating training efforts and sharing resources. The council's structure and its products will be particularly useful during the upcoming transition to a new site contractor team.

The INEL site contractors are promoting a high level of worker awareness on all safety issues, including the handling and use of chemicals. In addition to formal training, HAZCOM materials (including MSDSs) were prominently displayed in all facilities visited. Promotional materials emphasizing chemical safety, as well as the fact that all employees have the right and responsibility to stop unsafe work practices, were also much in evidence. These issues are discussed periodically in safety committee meetings. Lessons learned from the site and other DOE facilities are also reviewed. There is a strong commitment on the part of all site contractors about the importance of safety training and worker involvement in making the workplace safer. This translates to a maturing safety culture at the INEL site. INEL has the necessary human resource systems in place to meet both DOE and OSHA requirements in the area of chemical safety. Personnel observed were well trained, motivated, and cognizant of the chemical hazards in their facilities.

No explicit chemical vulnerability issues related to the human resource programs were identified for the four site contractors reviewed.

\subsection{Emergency Management Programs}

Verification activities for emergency management programs functional area of the Chemical Safety Vulnerability Review included evaluation of the effectiveness of emergency management activities, plans, and programs in the context of chemical safety vulnerabilities associated with INEL facilities. All facilities examined in the sites' self-evaluations were 
reviewed; in some emergency management areas, the review was necessarily expanded to include INEL sitewide emergency operations.

The INEL Emergency Management System comprises several comprehensive emergency management program elements, including emergency plans and procedures, coordination between the INEL and the community, emergency response training and drills or exercises, emergency supplies and equipment, and supporting emergency facilities. The top-level document that establishes and describes the INEL's overall emergency management program is the Idaho National Engineering Laboratory/West Valley Demonstration Project Emergency Plan 1993. Subordinate to this document are a series of facility-specific emergency plans, building-specific emergency plans, and associated emergency plan implementing procedures that have been developed at the INEL. All facility-specific emergency plans reviewed addressed emergency response to nonradioactive hazardous chemical accidents. The quality of the planning documents reviewed varied among the site contractors, but a series of improvements are being implemented. The INEL has appointed an offsite emergency planning coordinator to represent ID and all INEL contractors and to coordinate all offsite emergency planning activities for offsite agencies. This person is also a member of the Local Emergency Planning Committee. This appointment has improved the offsite participation and coordination associated with INEL emergency management programs.

The INEL maintains several types of emergency response facilities to support INEL emergency management programs. The INEL Emergency Operations Center (EOC), the INEL Warning Communications Center (WCC), the ICPP Emergency Control Center (ECC), and the ANL-W ECC were reviewed. No concerns were identified in these facilities. The INEL EOC and the INEL WCC are relatively new and are very impressive facilities. Weather updates are automatically provided to the INEL EOC every 6 minutes by the National Oceanic and Atmospheric Administration. The INEL EOC also maintains the capability to conduct hazardous chemical plume dispersion calculations by various approved computer models.

In the event of a hazardous chemical emergency at an INEL facility, a sitewide " 777 " emergency telephone number is available (except at ANL-W) for rapid reporting of the occurrence to the INEL WCC. The INEL WCC will initiate off-facility emergency response actions. The first responder on the scene at the originating facility will be in charge at the scene until properly relieved. First responders are concerned only with protecting people and assessing emergency conditions. The incident command system methodology has recently been implemented at the INEL. Incident command will be established on scene by the incident response team leader. If available, the facility incident response team will provide the initial hazardous material (HAZMAT) response. The INEL Fire Department will also respond to provide additional HAZMAT or other support and/or mitigation. If necessary, an emergency command center and the INEL EOC will be activated to provide additional support in the event of an emergency involving hazardous chemicals. During cliscussions with WINCO ICPP emergency preparedness and hazard analysis personnel, it was learned that a nomograph is being developed that will provide for a rapid determination of the impacted distance of a hazardous chemical release and is expected to improve the emergency response on backshifts without reliance on a sophisticated computer model. The development of this tool is considered to be a commendable practice. 
Members of the ANL-W facility Incident Response Team (IRT) and INEL Fire Department firefighters ( 3 firestations on site with a total onshift complement of about 16 responders) are trained by the State of Idaho in HAZMAT response to the HAZMAT "technician" level. The ICPP IRT is trained to the same levels by the ICPP Training section; EG\&G Idaho personnel train members of their IRT.

The number of drills and exercises emphasizing hazardous chemical accident scenarios both within INEL facilities and off site is increasing. A closer working relationship is being established among site contractors, the INEL Fire Department, and the fire departments of surrounding communities. The extent of coordination and cooperation is exemplified by joint participation in training and drills and periodic meetings with community officials. The INEL dedicated HAZMAT vehicle provides backup support for offsite emergencies.

The INEL facilities reviewed that contain significant quantities of hazardous chemicals maintain adequate types and quantities of HAZMAT response equipment and supplies, including Level A suits. The INEL Fire Department maintains a dedicated HAZMAT response vehicle and additional supplies. A new sophisticated HAZMAT truck is on order and is expected to arrive soon. The CFA ECC provides logistical support for all types of emergency responses. If additional fire, hazardous materials, and/or emergency medical response resources are needed, firefighters and vehicles from surrounding communities can be provided through implementation of memorandums of understanding. Backup HAZMAT support personnel, dedicated vehicles, and supplies are available from Idaho Falls, Blackfoot, and Pocatello, Idaho.

One vulnerability was identified in the functional area of emergency management programs. The vulnerability arises from the fact that some emergency management program documentation is missing, inadequate, in error, or out-of-date. Implementation of the Idaho National Engineering Laboratory/West Valley Demonstration Project Emergency Plan 1993 in the event of a sitewide hazardous materials emergency is not certain because the formal procedures to implement the Idaho National Engineering Laboratory/West Valley Demonstration Project Plan 1993 and the emergency action levels (EALs) have yet to be developed. These sitewide procedures (i.e., emergency plan implementing procedures [EPIPS]) are to identify the detailed actions necessary to achieve an integrated, sitewide emergency response as set forth in DOE 5500.3A. Supporting emergency plan information and procedures for implementing the incident command system at ANL-W are missing but are under development and are nearing completion; some plan information is outdated. EALs are not consistent across the site and in some cases are missing, inadequate, in error, or incomplete. The absence or inconsistency of this documentation represents an INEL sitewide emergency management program vulnerability. A more detailed discussion of this vulnerability is provided in Section 3.2 and in Attachment 2 of this appendix. 


\subsection{CATEGORIZATION AND PRIORITIZATION OF VULNERABILITIES}

\subsection{Criteria}

A vulnerability is a weakness or potential weakness involving hazardous chemicals that could result in a threat to the environment, the public, or worker health and safety. Vulnerabilities can be characterized by physical or programmatic conditions associated with uncertainties, acknowledged weaknesses, and/or unacknowledged weaknesses in the area of chemical safety. Conditions required to create the vulnerability should either currently exist or be reasonably expected to exist in the future, based on degradation of systems and chemicals or through expected actions (e.g., D\&D of facilities).

A vulnerability will be determined to exist if current or expected future conditions or weaknesses could result in the following:

- The death of or serious physical harm ${ }^{2}$ to a worker or a member of the public, or the continuous exposure of a worker or member of the public to levels of hazardous chemicals above hazardous limits; or

- Environmental impacts resulting from the release of hazardous chemicals above established limits.

The prioritization of the chemical safety vulnerabilities is based on the professional judgment of team members concerning the immediacy of the potential consequences posed by each vulnerability and on the potential severity of those consequences. The first step in the prioritization process was to group vulnerabilities according to the timeframe in which they are expected to produce consequences. The following categories are defined for the timeframe within which the consequences are expected to occur:

- Immediate-Any chemical safety vulnerability that could result in immediate consequences.

- Short-Term-Any chemical safety vulnerability at a facility in which there is a significant chance of a consequence occurring within a 3-year timeframe, as a result of chemical degradation, change in mission for the facility, degradation of the containment systems, change in personnel at the facility, or other factors affecting the facility.

- Medium-Term-Any chemical safety vulnerability at a facility in which there is a significant chance of a consequence occurring within a 3-10-year timeframe, as a result of chemical degradation, change in mission for the facility, degradation of the containment systems, change in personnel at the facility, or other factors affecting the facility.

- Long-Term-Any chemical safety vulnerability at a facility in which there is a significant chance of a consequence occurring in the timeframe greater than 10 years as a result of

2 Serious physical harm is defined as impairment of the body, leaving part of the body functionally useless or substantially reducing efficiency on or off the job. 
chemical degradation, change in mission for the facility, degradation of the containment systems, change in personnel at the facility, or other factors affecting the facility.

Vulnerabilities within each category are further prioritized, based on the severity of the potential consequences, as "high," "medium," or "low" priority. Consequences of high priority would cause death or irreversible injury or illness to workers or the public, or would cause environmental damage that is irreversible or very costly to remediate. Low-priority consequences would be reversible injuries, iliness, or environmental damage.

\subsection{Chemical Safety Vulnerabilities at Idaho National Engineering Laboratory}

Three vulnerabilities were identified by the verification review at the INEL. Each is summarized below and presented in more detail in Attachment 2 of this appendix.

\section{CSVR-INEL-CH-01: Contamination of Soil by Discharges of Large Quantities of Hazardous Material.}

Four hundred spills, leaks, and discharges of hazardous materials to the soil have been identified for INEL, 83 of which were found at ICPP. Spills of hazardous materials have occurred from process lines and from bulk storage areas at the ICPP. In the past, there have also been intentional discharges of hazardous materials to soils. Known releases have occurred from pipes in the vent tunnel at CPP-601, from bulk chemical storage facilities at CPP-621, and leaks of high-level waste and dichromate at the tank farm. Other releases to soil have occurred through discharge of cleaning agents to french drains, tank overflows, punctured drums, and discarded paints and paint solvents.

These leaks, spills, and discharges create the potential for the future exposure of workers and release to the environment during construction, D\&D, and other activities that disturb the soil. WINCO has taken several important steps to mitigate those hazards. Efforts have been made to identify, investigate, and in some cases remediate historical leak sites, and procedures are in place specifying required actions in the event that additional spill locations are discovered. Known locations have been designated as Environmentally Controlled Areas and are posted to protect the health and safety of workers. These conditions and circumstances represent a low-priority vulnerability with a potential for short-term consequences.

\section{CSVR-INEL-CH-02: Delays in Disposition of Hazardous Materials and Waste.}

For some facilities, the INEL has made substantial progress in arranging for final disposition of surplus hazardous chemicals and improperly stored hazardous wastes. However, there are several examples where planning and arrangement for final disposition have not been provided. About 10,000 gallons of cooling water containing dichromate are stored in two tanks without secondary containment in the ICPP tank farm area. The cooling system has not been used since 1988 and will not be needed again for at least 5-10 years.

In addition, about 1,000 gallons of reclaimed hexone solvent extractant is being held in cell tankage in CPP-601. The material is contaminated with fission products, and its future use and disposition are uncertain. The ARVFS bunker managed by EG\&G Idaho contains four containers of sodium-potassium mixed waste that have been stored there since 1974. The 
bunker is an interim-status storage facility, and the containers were last inspected in 1979. The condition of the containers is unknown. Treatment options are currently being considered for both of the latter examples; however, each represents a continuing risk to workers and the environment that could be eliminated by their removal for treatment or disposal. These conditions and circumstances represent a medium-priority vulnerability with a potential for medium-term consequences.

\section{CSVR-INEL-EMP-01: Weaknesses in the INEL Emergency Management Programs Documentation.}

The Idaho National Engineering Laboratory/West Valley Demonstration Project Emergency Plan 1993 was developed to ensure consistent and controlled emergency response actions for any operational emergency, including those associated with chemical incidents. However, the plan is not supported by EPIPs and does not include EALs. In addition, EALs for hazardous chemical events are inconsistent among INEL contractors and within the INEL Emergency Plan. Some hazardous material EALs are inconsistent between a contractor's plan and their own EPIPS.

The EPIPs and the EALs play a fundamental role in ensuring proper response to a chemical emergency. EALs are the specific indicators used to determine occurrence category and emergency class. The category of emergency (based on severity) drives the level of activation, the level of initial resources, and protective measures taken on or off site. If the level of initial response is incorrect, an incident could escalate. These conditions and circumstances represent a medium-priority vulnerability with a potential for immediate consequences. 


\section{ATTACHMENT 1}

\section{TEAM COMPOSITION}

\section{Area of Responsibility}

Team Leader

Management/Operations

Human Resource Programs

Chemical Process Safety

Industrial Hygiene

Environmental Protection

Maintenance

Emergency Management

Site Liaison

Coordinator

Technical Editor

\section{Name/Organization}

Michael A. Kilpatrick

Office of Environment, Safety and Health U.S. Department of Energy

Leon H. Meyer

The LHM Corporation

John A. Leonowich

Battelle, Pacific Northwest Laboratory

John A. Porter

JP Techservices, Inc.

Kim L. Delman

Albuquerque Operations Office

U.S. Department of Energy

Raymond F. Machacek

Arthur D. Little, Inc.

John S. Stone

ICF Kaiser Hanford

Robert D. Mogle

Battelle, Pacific Northwest Laboratory

Don S. Michaelson

Idaho Operations Office

U.S. Department of Energy

Rita A. Bieri

Los Alamos National Laboratory

Robert F. McCallum

McCallum-Turner, Inc. 


\section{ATTACHMENT 2}

CHEMICAL SAFETY VULNERABILITY REVIEW

VULNERABILITY FORM

DATE: May 10, 1994

Site/Facility: Idaho National Engineering Laboratory

Vulnerability Number: CSVR-INEL-CH-01

Functional Area(s): Identification of Chemical Holdings

1. Brief Description of Vulnerability.

Contamination of soil by discharge of large quantities of hazardous materials.

2. Summary of Vulnerability.

Four hundred spills, leaks, and discharges of hazardous materials have been identified for the INEL, 83 of which were found at the Idaho Chemical Processing Plant (ICPP). Spills of hazardous materials to soil have occurred from process lines and from bulk storage areas at ICPP. In the past, there have also been intentional discharges of hazardous materials. Known occurrences have been characterized and remediated, where appropriate. In the absence of good records of the early history of the INEL, additional spill/discharge areas may be discovered in the future and could pose a hazard to workers.

3. Basis.

a. Requirements:

- DOE 5400.1 requires that the environment be protected.

- DOE 5480.10 requires that the health of workers be protected.

- IDAPA 16.01.05 specifies Idaho Rules, Regulations, and Standards for identification of and treatment, storage, and disposal of hazardous waste.

- 40 CFR 300, "Comprehensive Environmental Response, Compensation, and Liability Act," specifies regulations for investigation and cleanup of waste sites.

b. Chemicals Involved: Various process solutions and bulk chemicals, including acids, bases, inorganics, and organics.

c. Relevant Self-Evaluation Data: The self-evaluations acknowledged that spills and discharges of hazardous materials have occurred.

d. Contributing Causes: Lack of definitive requirements and informal conduct of operations in the early history of the INEL.

e. Potential Consequences: Potential for exposure of employees to hazardous materials in future activities that disturb the soil (e.g., construction, decontamination and decommissioning). These conditions and circumstances represent a low-priority vulnerability with a potential for short-term consequences. 
Site/Facility:

Idaho National Engineering Laboratory

Vulnerability Number:

CSVR-INEL-CH-01

Functional Area(s): Identification of Chemical Holdings

4. Supporting Observations.

- Building CPP-601 - A leak of condensate from the vent tunnel occurred when a pipe corroded. Other uncontained lines have been removed from service and replaced with contained ones. Examination of the old lines showed no evidence of other leaks, but the lines could not be examined in their entirety. Thus, other leaks under this or other structures are possible.

- Building CPP-621 - Leaks and spills of chemicals (i.e., nitric acid, sulfuric acid, hydrofluoric acid, and aluminum nitrate) occurred in the bulk chemical storage area, mainly in the early history of the INEL (i.e., 1950s-1980s) but are not well documented. French drains were at one time used for disposal of acid leaks and spills. Leaks have occurred in the earthen pipe trench leading from the storage area to the chemical processing building. This trench was previously uncontained but now has a plastic liner at the bottom.

- Tank Farm - There were two known leaks of high-level liquid waste (containing hazardous chemicals as well as radionuclides) to soil and at least one known leak of cooling water containing dichromate. Pipes used in the transfer of wastes to the tank farm have also leaked.

- Chlorinated hydrocarbon cleaning agents used in maintenance activities were disposed of by discharge to french drains. Grease pits were used for the discharge of oils and greases.

- Leaks of hexone and hydrocarbons have occurred due to puncturing of drums by forklifts or from overflow of tanks.

- Paint solvents and paints containing lead, mercury, and chromium have been discarded to soil.

- Condensate and cooling water that contained chemical and radionuclide contaminants were discharged to injection wells.

- Structures have been erected over several known waste sites. Although the hazardous material is still in place at these locations, there is no evidence of any resultant hazard.

- Because these leaks, spills, and discharges create the potential for future exposure to workers during construction, decontamination and decommissioning, and other activities that disturb the soil, WINCO has taken several important steps to mitigate that hazard. An attempt was made in 1985 to catalog all known sites where hazardous materials may have leaked to soil. Historical records were searched, and older employees were asked to recall leak events from memory. Procedures are now in effect that specify required actions in the event of a spill or the discovery of an old leak site. 
Site/Facility:

Idaho National Engineering Laboratory

Vulnerability Number: CSVR-INEL-CH-01

Functional Area(s): Identification of Chemical Holdings

4. Supporting Observations. (Continued)

- All accessible leak sites have been investigated to some degree. Some of the known waste sites have been characterized by digging and sampling, and a network of wells has been installed to monitor for hazardous and radioactive materials.

- Some leak sites have been remediated or have been determined to require no action under applicable regulations. Regulatory agencies have been involved as appropriate.

- There are 83 units (locations) listed in the WINCO Environmental Restoration Project. Many of these units received discharges other than hazardous materials. The units are grouped geographically into Environmentally Controlled Areas that are posted to protect the health and safety of workers. 


\section{H-36}


Site/Facility: Idaho National Engineering Laboratory/Sitewide

Vulnerability Number: CSVR-INEL-CH-02

Functional Area(s): Identification of Chemical Holdings, Operational Control and Management Systems

1. Brief Description of Vulnerability.

Delays in disposition of hazardous materials and wastes.

2. Summary of Vulnerability.

Hazardous materials and wastes have been stored for extended periods of time at the INEL without provision for their final disposition. Two examples of materials needing disposition are the primary coolant fluid in the tank farm at the Idaho Chemical Processing Plant (ICPP) that contains dichromate and the hexone solvent extractant contaminated with fission products in Building CPP-601. An example of a characteristic hazardous waste needing disposition is the sodium-potassium mixed waste stored at the Army Reentry Vehicle Facility Site (ARVFS).

3. Basis.

a. Requirements: IDAPA 16.01.05 specifies Idaho Rules, Regulations, and Standards for identification of and treatment, storage, and disposal of hazardous waste.

b. Chemicals Involved:

- Hexone solvent extractant (contaminated with fission products)

- Potassium dichromate

- Sodium-potassium alloy (contaminated with fission products)

c. Relevant Self-Evaluation Data: In the self-evaluation, the site discusses the personnel protection provided by the closed system in which the dichromate solution is used. The site further states that efforts are being made to remove and treat the sodium-potassium.

d. Contributing Causes:

- Formal policies for the use or disposal of excess chemicals have not been developed.

- Adequate resources not provided.

- No facility in the country currently has the capability to treat the sodium-potassium.

e. Potential Consequences: The most likely environmental impacts would be localized spills or fission products release that could involve reportable quantities, although offsite migration could also occur. Residual environmental risks or liabilities could result. Injuries and other impacts to worker safety and health would likely be localized. These conditions and circumstances represent a medium-priority vulnerability with a potential for medium-term consequences. 
Site/Facility:

Vulnerability Number:

Functional Area(s):
Idaho National Engineering Laboratory/Sitewide

CSVR-INEL-CH-02

Identification of Chemical Holdings, Operational Control and Management Systems

4. Supporting Observations.

- About 10,000 gallons of cooling water containing about 500 parts per million of dichromate is being stored in two above-ground tanks and in piping and cooling coils in the radioactive waste tanks in the tank farm. There is currently no strategy to dispose of this nonradioactive material other than to leave it in place until the tank farm is retired in 10-20 years. Cooling has not been needed since 1988, and cooling will not be required until possibly during removal of heels from the tanks beginning in 5-10 years. Since the nonradioactive material is not needed for such a long period, it should be removed from the surge tanks and treated. It may be necessary, however, to keep a solution inside the cooling coils to maintain a higher hydraulic pressure on the nonradioactive side of the coil as long as there is waste in the tanks.

In addition, the filled surge tanks do not have any secondary containment and have a design that would not meet good management practices today. The floor drains under the surge tanks were plugged 3 years ago, but any large spills would flow out the doors of Building CPP-628. There are also thermometers penetrating the tank walls near the bottom of the tanks, and there are sample and drain lines that could not be isolated if the small-diameter lines leaked or ruptured.

- Reclaimed hexone solvent extractant (about 1,000 gallons) is being held in cell tankage in Building CPP-601. The material is contaminated with fission products. It is still classified as a process material but may eventually be declared a radioactive waste. WINCO has tentative plans to transport this material to a commercial incinerator licensed to bum combustible materials with fission products.

- The ARVFS bunker contains four containers of sodium-potassium mixed waste that have been stored since 1974. Two of the containers are 55-gallon stainless-steel drums, and two carbon-steel containers are 60-gallon and 10-gallon drums. All containers are stored in a metal bin with vermiculite. During the last visual inspection of the four containers in 1979, the two carbon steel containers showed external corrosion. Another 15 years has passed since this last inspection, and the condition of the carbon steel containers is unknown. If the containers are leaking or allowing air to contact the sodium-potassium mixed waste, a potentially unstable mixture could result.

The INEL has attempted to have the wastes removed and treated with little success. First, the site attempted to develop a process to react the sodium-potassium with chlorine gas to form sodium chloride and potassium chloride. However, this effort was abandoned because of feasibility problems. The site then issued a Request for Proposal soliciting private-sector packaging, transportation, and treatment, but this effort also failed because of a lack of responsive proposals. Within the past week, DOE Chicago Operations Office and the DOE Idaho Operations Office have met with the Idaho Department of Environmental Quality to pursue treatment of the sodium-potassium waste from ARVFS in the Sodium Components Maintenance Shop at ANL-W. The plan is to treat the waste to produce a sodium carbonate/potassium carbonate radioactive waste that can be transported to the Radioactive Waste Management Complex.

The ARVFS is only an interim status storage facility for hazardous waste, and the condition of the waste containers and waste will not improve with passing time. 
Site/Facility: $\quad$ Idaho National Engineering Laboratory/Sitewide

Vulnerability Number: CSVR-INEL-EMP-01

Functional Area(s): Emergency Management Programs

1. Brief Description of Vulnerability.

Weaknesses in the INEL emergency management programs documentation.

2. Summary of Vulnerability.

Although the Idaho National Engineering Laboratory/West Valley Demonstration Project Emergency Plan's stated purpose is to ensure consistent, integrated, and controlled emergency response actions for any operational emergency (this includes a hazardous materials event), it is not currently supported by emergency plan implementing procedures (EPIPs) as required by DOE 5500.3A. Emergency action levels (EALs) for hazardous chemical events are inconsistent among contractors, are missing in the INEL Emergency Plan, and some hazardous material (HAZMAT) EALs are inconsistent between a contractor's plan and the contractor's own EPIPs. Because of these inadequacies in program documentation, an emergency response to a hazardous material incident could be less than optimum.

3. Basis.

a. Requirements:

- DOE 5500.3A, Sections $9 e$ and 11d(2), requires EPIPs to implement emergency plans.

- DOE 5500.3A, Section 11c(3), requires that EALs be developed for recognizing and classifying emergency events and form the basis for notification and determination of what protective actions will be implemented and when.

- DOE 5500.1B defines emergency response planning guides (ERPGs).

- DOE 5500.2B, Section 5b, requires the use of ERPGs where developed and applicable. (Note: ERPGs are defined as three different levels, ERPG-1, ERPG-2, ERPG-3.)

b. Chemicals Involved: All hazardous chemicals at the INEL.

c. Relevant Self-Evaluation Data: The INEL self-evaluation did not identify the need to update out-of-date and inconsistent documentation as an environment, safety, and health concern requiring immediate attention; and the ANL-W self-evaluation did not identify the need to support the current incident command system with appropriate documentation and procedures.

d. Contributing Causes:

- Incomplete implementation of identified requirements.

- Sufficient attention and resources have not been applied to development of plans and procedures.

- Inconsistent examples of definitions of "emergency" in DOE 5500.1B and DOE 5000.3B, Section 7.1(1). 
Site/Facility:

Idaho National Engineering Laboratory/Sitewide

Vulnerability Number: CSVR-INEL-EMP-01

Functional Area(s): Emergency Management Programs

3. Basis. (Continued)

- Incomplete guidance on EAL criteria from DOE Headquarters.

- Lack of formal policy on INEL sitewide emergency management issues from the Idaho Operations Office.

e. Potential Consequences: Adequate implementation of the sitewide emergency plan for response to an actual emergency is not ensured without procedures. INEL Emergency Plan response would likely be accomplished on an ad hoc basis. Adequate implementation of the incident command system is not ensured without procedures. Adequate classification of an emergency and implementation of correct protective actions is not ensured without consistent and correct EALs and emergency classification categories. The above four potential consequences have the potential to increase the risk to workers and responders in a HAZMAT event. These conditions and circumstances represent a medium-priority vulnerability with a potential for immediate consequences.

4. Supporting Observations.

- Review of available INEL documentation identified facility-specific and responder-specific emergency response plans and procedures, but no sitewide EPIPs. Discussions with EG\&G Idaho indicated that EPIPs do not exist for the Idaho National Engineering Laboratory/West Valley Demonstration Project Emergency Plan and EALs are not included in the plan.

EALs are the specific indicators used to determine occurrence category and emergency classes. The category of emergency (based on severity) drives the level of activation and most likely indicates that some form of protective action may need to be taken onsite or offsite. The level of activation often drives the level of initial resources to respond to and mitigate an event. If the level of initial response is incorrect, an event could escalate.

- The Idaho Chemical Processing Plant Emergency Plan establishes release of nonradiological hazardous material EALs to be greater than ERPG-2 values at locations within the ICPP, outside the ICPP, and beyond the INEL boundary to establish Alert, Site Area Emergency, and General Emergency classifications, respectfully. This approach appears to be logical.

- At least one ICPP facility reviewed appears to contain a chemical source term sufficient to result in an emergency with impact beyond the respective ICPP boundary.

- The Waste Reduction Operations ComplexWaste Experimental Reduction Facilly/Power Burst Facility Emergency Plan Implementing Procedures Manual and Radioactive Waste Management Complex Emergency Plan Implementing Procedures Manual use greater than ERPG values or greater than protective action guides generically at the same locations as WINCO, but they do not specify which level of ERPG must be exceeded to classify. Conversely, the Environmental Restoration and Waste Management Emergency Plan/Resource Conservation and Recovery Act Contingency Plan for the Power Burst Facility provides only an interim descriptive occurrence EAL to classify an event and does not address a parametric ERPG level. The document states that hazards assessments, including EALs, are under development. 
Site/Facility:

Idaho National Engineering Laboratory/Sitewide

Vulnerability Number: CSVR-INEL-EMP-01

Functional Area(s): Emergency Management Programs

4. Supporting Observations. (Continued)

- Section II of ANL-W's Guidelines Appendices for ANL-W Site and Facility Emergency Plans and Procedures provides the following:

- For a toxic/flammable radioactive release onsite, the size/type of spill requires implementation of the Department of Transportation Emergency Response Guidebook protective actions; and

- The detection of aibome flammable material requires an EAL greater than ERPG-3 (or 10 percent of the lower explosive limit (LEL), or 10 percent of the immediately Dangerous to Life or Health Limit), with an "Alert" classification.

- Conversely, the ANL-W Emergency Handbook, Volume II, which includes the "Laboratory and Office Buildings (752) Emergency Plan and Procedures," Table III, provides the following:

- For a toxic or flammable gas release within the Analytical Laboratory, the EAL is defined for an uncontrolled release of an inert gas, with an "Unusual Event" (UE) classification; and

- The EAL is also defined for an uncontrolled release of a flammable gas (e.g., $H_{2}$, propane, methane) within the Analytical Laboratory with an "Alert" classification.

Besides being contradictory, these EALs do not address a toxic gas release and the UE classification is no longer a valid emergency classification level.

- ANL-W has implemented the incident command system methodology, but has not completed development of plan and supporting EPIPs. To ANL-W's credit, procedures are in the developmental stage and are nearing completion.

- It was reported and documented that a joint contractor Technical Support, Integration, and Assessment Subcommittee was established by the INEL Emergency Planning Coordinating Committee to facilitate sharing technical information relative to emergency planning issues. The EG\&G Idaho Emergency Management Unit has also generated and distributed ERPG guidance on developing EALs to the INEL contractors. 


\section{ATTACHMENT 3}

\section{SELECTED ACRONYMS}

\begin{tabular}{|c|c|}
\hline $\begin{array}{l}\text { AAO-W } \\
\text { AL } \\
\text { ANL-W } \\
\text { ARVFS } \\
\text { ATR }\end{array}$ & $\begin{array}{l}\text { Argonne Area Office-West } \\
\text { DOE Albuquerque Operations Office } \\
\text { Argonne National Laboratory-West } \\
\text { Army Reentry Vehicle Facility Site } \\
\text { Advanced Test Reactor }\end{array}$ \\
\hline B\&W & Babcock \& Wilcox \\
\hline $\begin{array}{l}\text { CERCLA } \\
\text { CFA }\end{array}$ & $\begin{array}{l}\text { Comprehensive Environmental Response, Compensation, and Liability Act } \\
\text { Central Facilities Area }\end{array}$ \\
\hline $\begin{array}{l}\text { D\&D } \\
\text { DOE }\end{array}$ & $\begin{array}{l}\text { Decontamination and Decommissioning } \\
\text { U.S. Department of Energy }\end{array}$ \\
\hline $\begin{array}{l}\text { EAL } \\
\text { EBR-II } \\
\text { ECC } \\
\text { EOC } \\
\text { EPIP } \\
\text { ERPG }\end{array}$ & $\begin{array}{l}\text { Emergency Action Level } \\
\text { Experimental Breeder Reactor ॥ } \\
\text { Emergency Control Center } \\
\text { Emergency Operations Center } \\
\text { Emergency Plan Implementing Procedure } \\
\text { Emergency Response Planning Guide }\end{array}$ \\
\hline FAST & Fluorinel Dissolution Process and Fuel Storage (Facility) \\
\hline $\begin{array}{l}\text { HAZCOM } \\
\text { HAZMAT }\end{array}$ & $\begin{array}{l}\text { Hazard Communication } \\
\text { Hazardous Material }\end{array}$ \\
\hline $\begin{array}{l}\text { ICPP } \\
\text { ID } \\
\text { INEL } \\
\text { IRT }\end{array}$ & $\begin{array}{l}\text { Idaho Chemical Processing Plant } \\
\text { DOE Idaho Operations Office } \\
\text { Idaho National Engineering Laboratory } \\
\text { Incident Response Team }\end{array}$ \\
\hline $\begin{array}{l}\text { MK-FIC } \\
\text { MSDS } \\
\text { M\&O }\end{array}$ & $\begin{array}{l}\text { Morrison Knudsen-Ferguson of Idaho Company } \\
\text { Material Safety Data Sheet } \\
\text { Management and Operating }\end{array}$ \\
\hline $\begin{array}{l}\text { OCAW } \\
\text { OSHA }\end{array}$ & $\begin{array}{l}\text { Oil, Chemical, and Atomic Workers } \\
\text { Occupational Safety and Health Administration/Act }\end{array}$ \\
\hline $\begin{array}{l}\text { PBF } \\
\text { PPE } \\
\text { PTI }\end{array}$ & $\begin{array}{l}\text { Power Burst Facility } \\
\text { Personal Protective Equipment } \\
\text { Protection Technology Idaho }\end{array}$ \\
\hline
\end{tabular}




\section{SELECTED ACRONYMS (Continued)}

$\begin{array}{ll}\text { RADCON } & \text { Radiological Control } \\ \text { RCRA } & \text { Resource Conservation and Recovery Act } \\ \text { RESL } & \text { Radiological and Environmental Sciences Laboratory } \\ \text { RSSF } & \text { Radioactive Sodium Storage Facility } \\ \text { RSWF } & \text { Radioactive Scrap and Waste Facility } \\ \text { RWMC } & \text { Radioactive Waste Management Complex } \\ & \\ \text { TAN } & \text { Test Area North } \\ \text { TRA } & \text { Test Reactor Area } \\ \text { TQM } & \text { Totally Quality Management } \\ \text { UE } & \text { Unusual Event } \\ \text { WCC } & \text { Warning Communications Center } \\ \text { WERF } & \text { Waste Experimental Reduction Facility } \\ \text { WINCO } & \text { Westinghouse Idaho Nuclear Company, Incorporated }\end{array}$




\section{APPENDIX I}

FIELD VERIFICATION REPORT

ROCKY FLATS PLANT

MAY 2 - 11, 1994

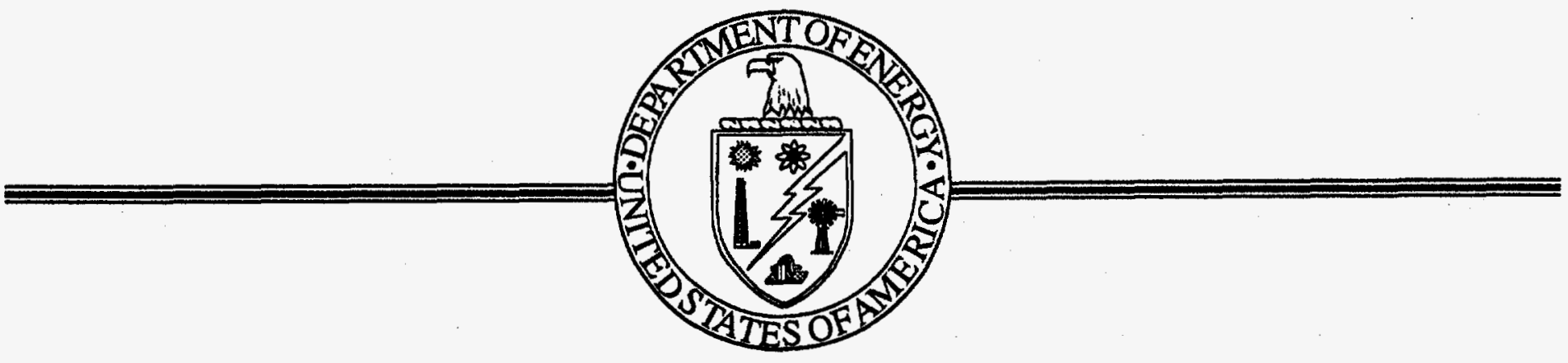





\section{CONTENTS}

EXECUTIVE SUMMARY $\ldots \ldots \ldots \ldots \ldots \ldots \ldots \ldots \ldots \ldots \ldots \ldots \ldots$

1.0 INTRODUCTION $\ldots \ldots \ldots \ldots \ldots \ldots \ldots \ldots \ldots \ldots \ldots \ldots \ldots \ldots \ldots \ldots$

1.1 Purpose and Scope $\ldots \ldots \ldots \ldots \ldots \ldots \ldots \ldots \ldots \ldots \ldots \ldots$

1.2 Site Description $\ldots \ldots \ldots \ldots \ldots \ldots \ldots \ldots \ldots \ldots \ldots \ldots \ldots \ldots$

1.3 Facilities Visited $\ldots \ldots \ldots \ldots \ldots \ldots \ldots \ldots \ldots \ldots \ldots \ldots \ldots$

2.0 SUMMARY OF RESULTS $\ldots \ldots \ldots \ldots \ldots \ldots \ldots \ldots \ldots \ldots \ldots \ldots$

2.1 Identification of Chemical Holdings $\ldots \ldots \ldots \ldots \ldots \ldots \ldots \ldots \ldots \ldots$

2.2 Facility Physical Condition $\ldots \ldots \ldots \ldots \ldots \ldots \ldots \ldots \ldots \ldots \ldots$

2.3 Operational Control and Management Systems $\ldots \ldots \ldots \ldots \ldots \ldots \ldots$

2.4 Human Resource Programs $\ldots \ldots \ldots \ldots \ldots \ldots \ldots \ldots \ldots \ldots \ldots$

2.5 Emergency Management Program . . . . . . . . . . . . . . . I I-21

3.0 CATEGORIZATION AND PRIORITIZATION OF VULNERABILITIES $\ldots \ldots \ldots \ldots$. . . I-23

3.1 Criteria $\ldots \ldots \ldots \ldots \ldots \ldots \ldots \ldots \ldots \ldots \ldots \ldots \ldots \ldots \ldots \ldots \ldots$

3.2 Chemical Safety Vulnerabilities at Rocky Flats Plant . . . . . . . . . . . . I I-24

\section{ATTACHMENTS}

ATTACHMENT 1. Team Composition $\ldots \ldots \ldots \ldots \ldots \ldots \ldots \ldots \ldots \ldots \ldots$

ATTACHMENT 2. Vulnerability Forms $\ldots \ldots \ldots \ldots \ldots \ldots \ldots \ldots \ldots \ldots \ldots$

ATTACHMENT 3. Selected Acronyms . . . . . . . . . . . . . . . . I-41 


\section{EXECUTIVE SUMMARY}

This report presents the results of a review of chemical safety vulnerabilities associated with facilities owned or operated by the Department of Energy (DOE) at the Rocky Flats Plant (RFP). The field verification review was conducted from May 2 to May 11, 1994, and was part of the Chemical Safety Vulnerability Review being conducted by the Office of Environment, Safety and Health at the direction of the Secretary of Energy. The overall study is intended to use personnel representing line organizations having operational responsibilities. The Office of Environment, Safety and Health is coordinating the effort.

The purpose of the review is to identify and characterize conditions or circumstances involving potentially hazardous chemicals at DOE sites and facilities, with emphasis on facilities being transitioned to, awaiting, or undergoing decontamination and decommissioning. Specifically, the review is designed to identify, characterize, and prioritize chemical safety vulnerabilities associated with conditions or circumstances that may result in (1) fires or explosions from uncontrolled chemical reactions, (2) exposure of workers or the public to chemicals, or (3) release of chemicals to the environment.

Earlier in 1994, an extensive self-evaluation of potential chemical safety vulnerabilities at RFP was performed. The self-evaluation included a review of a range of facilities, in addition to consideration of sitewide programs, such as the Integrated Work Control Program. The facilities reviewed included laboratories, process facilities, receiving and storage warehouses, and waste treatment facilities. Field verification activities at RFP began with an analysis of the self-evaluation and visits to all the facilities specifically examined in the self-evaluation. The review efforts were extended to additional interviews and facilities that were considered to be an integral part of the identified operation (e.g., the chemical preparation and storage rooms directly adjacent to Building 371 ) or where further information seemed to be important to be able to provide context for an observation.

In all cases, the field verification was conducted with a view toward identifying possible DOE-wide chemical safety vulnerabilities. The effort identified five issues that should be considered as part of the subsequent effort to identify DOE-wide chemical safety vulnerabilities. None of the conditions or circumstances identified requires immediate action to prevent severe consequences:

- Lack of accurate and complete chemical inventories impedes the effective analysis of hazards posed to workers.

- Chemical hazards are provided disproportionately less management support than are radiation hazards; as a result, the range of controls over chemical safety vulnerabilities may be incomplete.

- Resource Conservation and Recovery Act (RCRA) requirements are given precedence over chemical safety, such that operations not yet regulated by RCRA are not likely to be candidates for pilot programs to introduce new or improved controls over hazardous chemicals.

- Deterioration of physical conditions has the potential to create chemical hazards. 
- Decisions on budget content and priorities delay correction of known chemical safety issues.

These vulnerabilities, along with those identified during field verification efforts at other DOE sites, will be evaluated to identify DOE-wide generic vulnerabilities. In addition, information from the Office of Environmental Management's Surplus Facilities Inventory Assessment and the extended review of facilities in which there may be potential nitrate-organic vulnerabilities (similar to those at Tomsk-7) will be considered for any additional insights into potential chemical safety vulnerabilities. 


\subsection{INTRODUCTION}

\subsection{Purpose and Scope}

Based on direction from the Secretary of Energy, the Assistant Secretary for Environment, Safety and Health established the Chemical Safety Vulnerability Working Group to review and identify chemical safety vulnerabilities at facilities operated by the Department of Energy (DOE). The information obtained from the review will provide the Working Group with valuable input for identifying generic chemical safety vulnerabilities that confront the DOE complex. Prioritizing the generic chemical safety vulnerabilities that are identified will establish the proper basis for departmental focus on programs, funding, and policy decisions related to chemical safety. The Secretary directed the Office of Environment, Safety and Health (EH) to lead this review, with full participation from DOE line organizations having operational responsibilities.

The Chemical Safety Vulnerability Review was designed and undertaken to identify and characterize adverse conditions and circumstances involving potentially hazardous chemicals at facilities owned or operated by the Department. Specifically, the review was intended to identify, characterize, and prioritize chemical safety vulnerabilities associated with conditions or circumstances that might result in (1) fires or explosions from uncontrolled chemical reactions, (2) exposure of workers or the public to hazardous chemicals, or (3) release of hazardous chemicals to the environment. Using input provided by line organizations with operational responsibilities, the Working Group developed the "Project Plan for the Chemical Safety Vulnerability Review," dated March 14, 1994, to guide the review.

The field self-evaluation phase of the review used a standardized question set developed and distributed by the Working Group to collect data related to chemical safety from 84 facilities located at 29 sites. Based on analysis of self-evaluation data, nine large sites, including the Rocky Flats Plant (RFP), and four small sites were selected to participate in the field verification phase of the review. The field verification process was designed to use independent teams of technical professionals with experience in a variety of technical disciplines to confirm the accuracy and completeness of the data compiled during the field self-evaluation phase of the review. This report documents activities related to the field verification phase of the Chemical Safety Vulnerability Review.

The field verification team visiting RFP examined a broad range of facilities (based on facility type and operational status), with special attention given to those facilities being transitioned to, awaiting, or undergoing decontamination and decommissioning (D\&D). Different types of chemical- and waste-handling facilities were examined to permit identification of vulnerabilities arising from hazardous chemicals and wastes at the site. Facilities selected for review at RFP included Building 551, General Warehouse; Building 559, Plutonium Analytical Laboratory; Building 371, Plutonium Recovery; Building 374, Waste Treatment; Building 881, General Laboratory and Central Computing; and Building 207, Industrial Waste Holding Tank. Specific facilities were selected for review at RFP based on (1) the types of chemical hazards known to exist at given facilities; (2) the need to review a cross-section of laboratory, process, pilot plant, chemical storage, and utility facilities; and (3) the need to examine chemical hazards associated with facilities at different points in their life cycle (i.e., operating, standby, shutdown, abandoned, etc.) or under changing mission. 
The field verification team, under the direction of a DOE team leader, was composed of DOE and contractor personnel with technical expertise in various aspects of chemical safety, including management and operations, training, chemical process safety, industrial hygiene, maintenance, environmental protection, and emergency management. The team included a Working Group member and an EH Site Representative who served as site liaisons. A team composition list is provided in Attachment 1 of this appendix.

The team began its review by visiting each of the facilities selected for self-evaluation. The team met with management or technical representatives from each of the facilities reviewed. Individual and small group meetings were also held, and team members conducted walkthroughs, document reviews and personnel interviews to gather information related to potential chemical safety vulnerabilities at RFP. The team leader met daily with management personnel to discuss the team's activities and issues that may have surfaced during the previous day. Before the field verification team left RFP, management from local DOE and contractor organizations conducted a factual accuracy review of the draft report. An outbriefing was conducted on Wednesday, May 11, 1994, and a draft copy of this report was left with DOE and contractor management.

\subsection{Site Description}

The Rocky Flats Plant is located in northern Jefferson County, Colorado, about 16 miles northwest of downtown Denver and 7-10 miles from the communities of Boulder, Broomfield, Westminster, Arvada, and Golden. The closest community, Leyden, is located about 3 miles to the south. The 384-acre plant site is situated within a 6,550-acre restricted preserve, which serves as a buffer zone between the plant itself and the surrounding communities. (See Figures 1 and 2.)

Construction of the Rocky Flats Plant began in 1951, and initial operations occurred the following year. The plant was operated at that time by Dow Chemical U.S.A., a unit of the Dow Chemical Company. EG\&G Rocky Flats, Inc., took over the operating contract on January 1, 1990.

For nearly 40 years, the Rocky Flats Plant was a key facility in the Federal Government's nationwide complex for nuclear weapons research, development, and production. RFP supported the nuclear weapons program and other work related to national defense, providing unique processing capabilities for the fabrication of weapons components from plutonium, uranium, beryllium, and stainless steel. The plant also played a key role in the decommissioning and maintenance of nuclear weapons. In response to the breakup of the Soviet Union and the end of the Cold War, RFP's nuclear production mission was curtailed. The new mission is one of site environmental restoration, waste management, decontamination, and economic development.

\subsection{Facilities Visited}

Because visiting every DOE facility at the site was not possible under the time constraints of this review, the Working Group focused its efforts to achieve the maximum results possible in the time available. Five facilities at RFP were selected to participate in the self-evaluation phase of the Chemical Safety Vulnerability Review. Based on analysis of the self-evaluation 


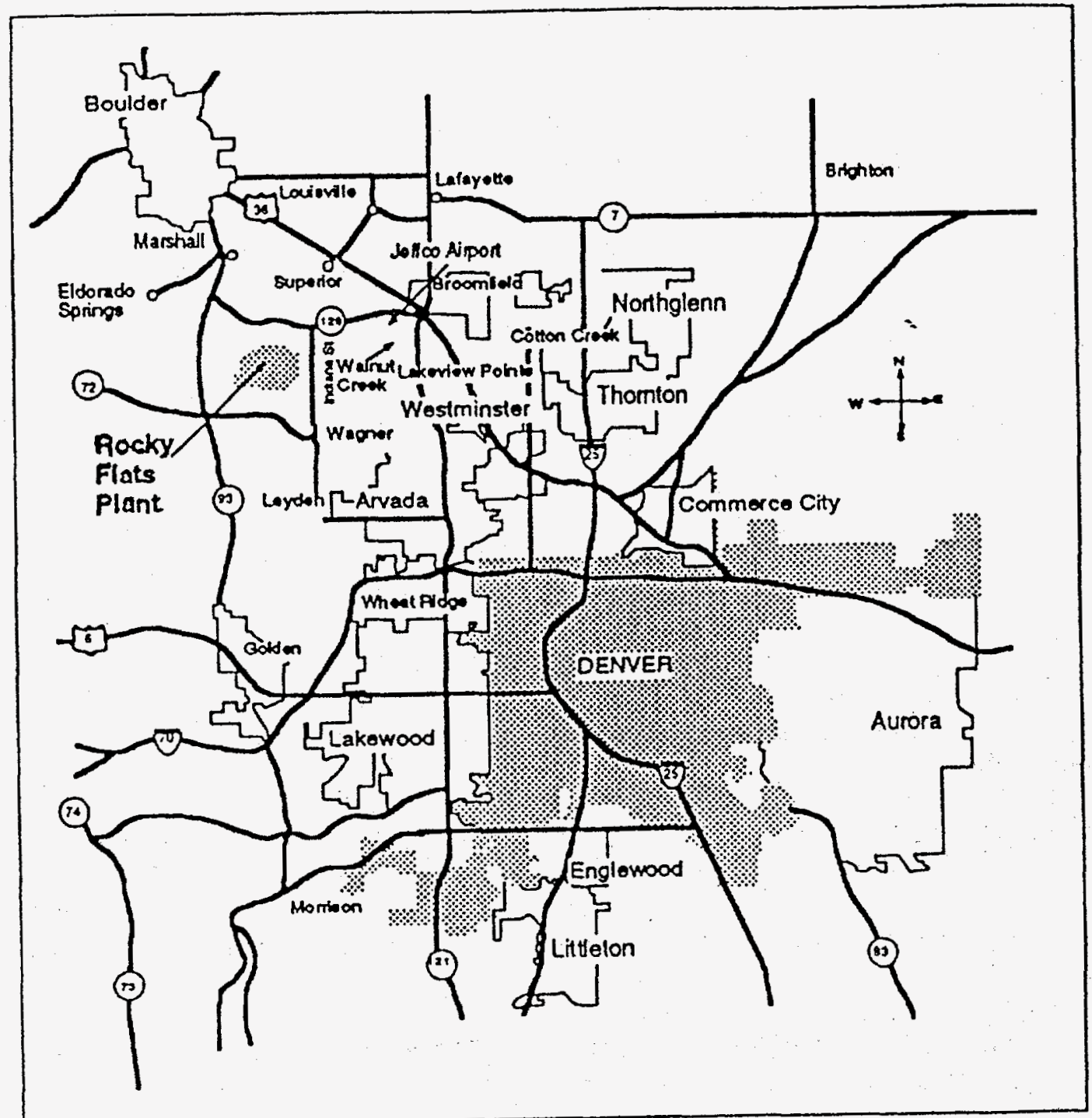

Figure 1. Rocky Flats Plant and Surrounding Communities 


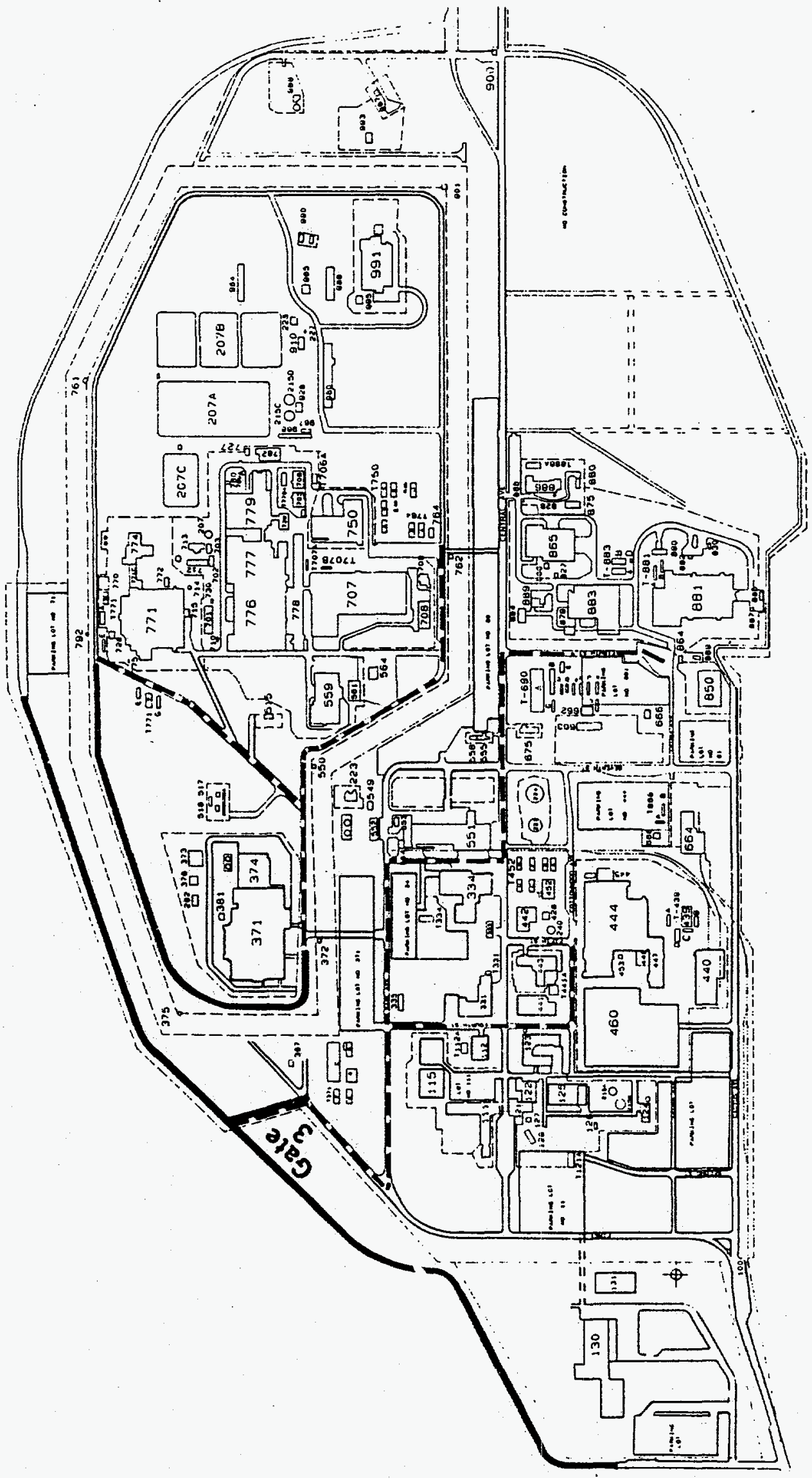


data, the facilities identified for self-evaluation were determined to be appropriate for the verification visit. In addition, review efforts were extended to additional facilities that are considered paired building combinations (e.g., Buildings 371/374). Operations activities involving hazardous chemicals at RFP selected for field review include laboratories, process facilities, warehouses, waste treatment facilities, and waste holding tanks. The following facilities were reviewed by the field verification team.

Building 551, General Warehouse: Building 551 is a general-use warehouse facility built about 35 years ago. The facility was constructed for supplying, storing, and shipping supplies and equipment. The facility stores materials and supplies in their original containers. The building contains a paint locker for storage of paint and solvents. Building 551 contains general stores such as rubber gloves, maintenance materials, spare parts, and bulk chemicals used throughout RFP.

Building 559, Plutonium Analytical Laboratory: Building 559 was built in 1967 as a plutonium analytical laboratory to support plutonium processing operations at RFP. Its principal mission was analyzing gaseous, liquid, and solid samples to quantify their major components, including isotopes, alloying agents, and impurities. This facility has an underground waste-holding pit that is no longer in service; the drains leading to the pit are administratively controlled and, in some cases, are engineered to prevent the introduction of process waste. At present, Building 559 is a fully operational, analytical laboratory charged with the mission to provide identification, characterization, and analysis of process-related waste forms generated at RFP. In addition, it provides analytical support to all special nuclear materials projects.

Building 371, Plutonium Recovery: Building 371 is a four-level, partially underground structure of reinforced concrete that was constructed for the recovery and refining of plutonium and is a plutonium storage facility for the plant site. Recovery and refining processes are shut down with no immediate plans for restart. At present, analytical and standards laboratories are operating in the facility. Operation of the process scrubber system continues. Various chemicals are stored throughout the facility with acids and caustic for the treatment of processes constituting the majority of the chemicals present. Building 371 contains two 90-day waste storage areas, four satellite waste storage areas, and 39 active residue storage areas regulated under the Resource Conservation and Recovery Act (RCRA).

Building 374, Waste Treatment: The waste treatment facility treats liquid process wastes for the entire Rocky Flats Plant. The facility, which consists of a main floor, a basement, and mezzanines, contains the waste treatment processing area; tanks for receiving and storing liquid process wastes containing chemical contaminants and low concentrations of radioactive materials; a drum-handling and storage area; and support, mechanical equipment, and utilities areas. Liquid process wastes from plutonium recovery and other process buildings on the plant are transferred to waste treatment after any significant quantities of radioactive materials have been removed by normal recovery operations. Two types of liquids are sent for waste treatment: (1) process wastes, such as nitric acid and sodium hydroxide solutions (which contain large quantities of chemicals and a low concentration of radioactive materials) and (2) liquids such as laundry water, process cooling water, and steam condensate (which contain lesser quantities of chemicals and could contain residual amounts of radioactive materials). Ultimately, the final products are dry sludge, salt, and distilled water. 
Building 881, General Laboratory and Central Computing: The original purpose of Building 881, constructed in 1953, was the processing and machining of stainless steel and enriched uranium. Residual enriched uranium remains in some areas of the building, primarily in ventilation ducts and electrical conduits. An ion exchange process, located near Room 114, extends vertically through four levels and was used to process uranium nitrates. Hydrofluoric acid and other reactive chemicals were used in the ion exchange process but are no longer in use. All production of uranium components has been transferred to other manufacturing buildings. At present, laboratory, development support, and administrative operations are performed in Building 881. The laboratories provide general analytical and standards calibration services, development operations provide waste technology development, as well as some development and/or testing of mechanical systems for weapons systems. Administrative operations provide computer support.

Building 207, Industrial Waste Holding Tank: Building 207 is an aboveground, industrialwaste holding tank. It was used as a laundry water feed tank for the Building 774 Evaporator and later as a temporary storage facility for low-level wastewater before the wastewater was moved to the Building 207 A, B, and C Solar Ponds. The tank has been taken out-of-service and has remained inactive or shut down for the past 9 years. Review of this facility was limited to a walkaround. Documentation concerning the contents of the tank was requested but could not be located.

In addition, two facilities that use chlorine, Buildings 124 and 995, were included in the field review as an issue of special concern. 


\subsection{SUMMARY OF RESULTS}

Field verification is one phase in the process being used to arrive at conclusions regarding the existence and significance of chemical safety vulnerabilities across the DOE complex. The field verification process was designed to use independent teams of safety professionals to confirm the accuracy and completeness of the data provided to the Chemical Safety Vulnerability Working Group by RFP facilities selected to participate in the field self-evaluation process. The verification process offered an opportunity to examine site-specific chemical safety vulnerabilities and to make informed judgments about the relevance of these conditions as they relate to determinations of generic chemical safety vulnerabilities.

The goal of the field verification team was to identify and prioritize chemical safety vulnerabilities at RFP. Before arriving on site, the team reviewed the self-evaluation data and other documents to allow team members to develop a list of observations related to potential vulnerabilities for their functional areas. During the onsite portion of the review, team members visited the facilities selected for self-evaluation to confirm reported observations and to look for other conditions and circumstances could result in chemical safety vulnerabilities. In some instances, facilities or areas that were not involved in the original self-evaluation were reviewed and have provided valuable information for the review.

To support effective team management and to expedite the identification of vulnerabilities across a wide range of technical disciplines associated with chemical safety, each field verification review has been organized to include five functional areas:

- Identification of chemical holdings, including the properties of chemicals located at the facility, the characterization of those chemicals, and an analysis of the inventory.

- Facility physical condition, including engineered barriers, maintenance conditions, chemical systems, safety systems, storage, monitoring systems, and hazards identification.

- Operational control and management systems, including organizational structure; requirements identification; hazard analysis; procedural adherence; maintenance control; engineering and design reviews; configuration control; safe shutdown plans; and site programs for quality assurance, chemical safety, inventory control, access control, disposal, transportation and packaging, and corrective actions.

- Human resource programs, including technical competence, staffing, training and qualifications, employee involvement, employee concerns, personnel performance requirements, and visitor and subcontractor control.

- Emergency management program, including the emergency plan, in-plant consequences, environmental issues, coordination with the community, and community right-to-know issues.

These functional areas were evaluated on the basis of lines of inquiry provided in Attachment 1 of the "Field Verification Guide for the Chemical Safety Vulnerability Review," dated April 8, 1994. Verification of the self-evaluation data was accomplished by walkthroughs of facilities, conduct of interviews with management and technical personnel, 
examination of facility and site documentation, and review of incident reports and other documents.

The self-evaluation report for RFP was substantial. It identified current weaknesses and plans for improvement. To a large extent, the field verification team confirmed the vulnerabilities identified in the self-evaluation. The team's identification of generic chemical safety vulnerabilities drew on those identified in the self-evaluation but attempted to emphasize those matters that appeared to have DOE-wide implications.

Summaries of the functional areas are provided in the sections below. Completed chemical safety vulnerability forms resulting from the field verification activities at RFP are provided in Attachment 2 of this appendix.

\subsection{Identification of Chemical Holdings}

In the four buildings reviewed, hazardous chemical inventories total less than 25 percent of the threshold quantities identified in 29 CFR 1910.119 and 40 CFR 68. Although a range of potentially hazardous chemicals, including carcinogens, are routinely used in the different buildings, control measures have been implemented to mitigate personal exposures and generation of significant quantities of hazardous wastes.

Overall, plant-wide progress has been made toward enhancing hazardous chemical control programs through the improvement of existing programs: the Chemical Hygiene Program (CHP), the Environmental Planning and Community Right-to-Know (EPCRA), Chemical Control System (ECCS), the Excess Chemical Program, and the Waste and Environmental Management System (WEMS).

The preliminary design for the ECCS was completed in fiscal year (FY) 91 and has not been implemented sitewide. It was designed to provide compliance with regulatory requirements, including 40 CFR 370, "Emergency Planning and Community Right-To-Know," and Executive Order 12856, "Toxic Material Release Inventory Reporting Program." It was not intended to, nor does it, track all hazardous chemicals on the site. In the ECCS, each chemical is identified by a unique bar-code. As discussed in the self-evaluation, up to 40 percent of hazardous chemicals arrive at their locations without initially entering the ECCS. Only new chemical purchases are entered in the bar-coded system. Because individual building managers determine their own needs and order chemicals directly, the ECCS competes with facility-specific tracking systems that may provide more accurate, real-time information regarding chemical quantities, conditions, and specific locations. (In general, inventory activities performed under the ECCS indicate only that a chemical is located in a given building. The facility-specific inventory data base may identify the cabinet and room number where the hazardous chemical or waste material is located.) Facility-specific data bases, coupled with facility-designated Chemical Control Officers (CCOs), such as those being implemented in Building 559, provide more complete inventory information.

In February 1993, the Excess Chemical Program was established to identify, characterize, and dispose of excess chemicals throughout the site. However, a statement made in the selfevaluation report indicates that "actual movement and disposition of excess chemicals from existing locations has been slow to develop." Furthermore, activities resulting from this 
program highlight unique safety issues, in that potentially significant numbers of out-of-date chemicals or reactive chemicals may be identified and consolidated before ultimate disposal. At present, some reactive chemicals housed in Buildings 881 and 551 are being stored inappropriately under potentially unsafe conditions. RFP is currently using outside contractors to dispose of reactive chemicals. In addition, as facility excess chemical inventories were being performed, a number of chemicals were found that had not been bar-coded while they were being used in the facility.

Procedures in 1-1000-HWB, Hazardous Waste Requirements Manual, have been implemented across the facility to assist in proper labeling and container management and to ensure that all wastes are characterized and sent to the correct permitted storage area within the allowable accumulation time. The hazardous and mixed waste components of the chemical holdings are tracked under WEMS.

Due to the historical operating conditions and the extended shutdown of some facilities with materials in line, residual chemicals remain in some pipes, drains, and structures. The degree of characterization and quantification for these residuals vary widely within a facility and from facility to facility. For example, detailed studies have been performed in Building 371 to determine "low points," or areas where materials may be located. Efforts to drain these structures are expected to be long term, and detailed schedules and plans for these activities do not yet exist.

Mixed residues (also referred to as "recoverable products") in tanks and piping at Building 371 were declared by a court order (Sierra Club v. DOE, 89-B-181, dated April 12, 1990) to be RCRA-regulated waste. Discussions are in progress to determine the best method for managing this waste. Management of this waste poses a vulnerability in that RCRA requirements appear to conflict with those for worker safety (see Vulnerability CSVR-RFP-000-03). All other inventories of hazardous and mixed waste in the buildings reviewed are managed in accordance with State of Colorado waste management regulations under delegated authority from the U.S. Environmental Protection Agency. Containers of hazardous, mixed, and radioactive wastes are stored in a manner that prevents or minimizes the potential for inadvertent releases of contained materials. Waste generators initiate waste collection in Satellite Accumulation Areas (SAAs) and are responsible for proper waste characterization. Personnel known as "RCRA custodians" manage the SAAs, the 90-day accumulation areas, and the "to-be-permitted" areas in their buildings in accordance with the requirements established in the Hazardous Waste Requirements Manual. Waste generators and RCRA custodians receive both initial and annual refresher training in hazardous waste management.

Specific information concerning chemical holdings components can be obtained from the programs described above. Individually, these programs provide key information regarding sitewide chemical inventories, but no one program provides accurate and complete sitespecific information on chemical inventories. Toward this end, RFP has initiated development of the Chemical Program to provide a more integrated approach to the management of all aspects of hazardous chemicals. The program includes computerized tracking of the chemicals from prepurchase approval through storage, use, and final disposition and is expected to provide the framework for a systematic and comprehensive approach to accurate and real-time information on chemical holdings at RFP. Because of the loss of existing 
expertise, the schedule for implementing the integrated Chemical Program, and the limitations of key components of this program, RFP still does not have the ability to manage the hazardous chemical inventory fully at both the facility and site levels. When existing programs are integrated, some expertise from the individual programs will be lost. The group of skilled chemical packers, developed and trained under the current Excess Chemical Program, will not be involved in the newly integrated Chemical Program. Use of the ECCS in conjunction with designated CCOs (i.e., to provide more facility ownership) will not be implemented sitewide for some time. The Chemical Program will be piloted in Building 881 in late FY 94 and FY 95. On the other hand, in Building 559 a CCO currently manages day-to-day operations (e.g., purchasing, receiving, use, disposal, building-specific locations) involving all hazardous chemicals, including hazardous waste. The Building 559 facility data base provides a current, accurate, and complete facility inventory.

As it functions today, ECCS does not provide a comprehensive data base for the management of all hazardous chemical holdings, hazardous chemicals, and hazardous and mixed waste. Facility inventory data generated and maintained for sitewide ECCS use must (1) have facility ownership, (2) be available on a real-time basis (current and accurate), (3) include facilityspecific information (location, container type, and condition), and (4) be accepted and consistently used at the facility level. The ECCS must be used in conjunction with other systems that may be incompatible with ECCS (e.g., WEMS, facility-specific data bases) to determine a total facility or total sitewide inventory of hazardous chemicals. This poses a vulnerability (see Vulnerability CSVR-RFP-000-01) in that facility workers do not have realtime, current, and accurate inventories of the chemicals in their workplace. This affects all continued and mission-change operations, including transition to and conduct of D\&D, because all hazards analyses associated with hazardous chemicals in the facility and on site are dependent on accurate chemical inventory information. These needs become increasingly important as specific areas of a building are expected to be under continued change, including the number, type, condition, and location of chemical holdings. The inability to provide accurate, current inventory information regarding "areas within a facility" increases the risk of exposure of workers to hazardous chemicals for a selected task.

\subsection{Facility Physical Condition}

The EG\&G Rocky Flats, Inc., self-evaluation presents a factual review of the status of preventive maintenance and engineering configuration change control at RFP. The selfevaluation recognized that preventive maintenance activities have been given a lower priority because of the emphasis placed on reducing the corrective maintenance backlog. The selfevaluation also recognizes that very little predictive maintenance is performed at RFP. It fails, however, to consider the adverse effect on timely completion of corrective and preventive maintenance activities and on morale that results from the complexity of the Integrated Work Control Program (IWCP). Further, the report did not consider the long-term effects of continued reduction in maintenance budget and staff on the physical condition of RFP facilities.

For the facilities reviewed at RFP, the mechanical integrity of the primary and secondary containment systems and equipment is generally satisfactory, but the level to which specific facilities are maintained varies according to the mission status. The corrective maintenance program is reactive. For example, two of three major ventilation fan motors in Building $\mathbf{3 7 1}$ 
failed within the last several months. Replacement motors have been ordered and will be installed when received. The preventive maintenance program is mission driven.

RCRA-regulated facilities and activities (such as stabilization and consolidation) receive attention, whereas standby facilities receive minimal preventive maintenance because of staff and budget limitations. Because of existing plant priorities, completion of preventive maintenance activities has fallen behind and has become secondary to achieving a reduction in the growing corrective maintenance backlog. A preventive maintenance program manager was hired within the past month to focus on this activity. A sitewide predictive maintenance. program that indicates the need for preventive maintenance before equipment fails should be considered. With one exception (thermal tomography of high-voltage electric power lines), the predictive maintenance program at RFP is very weak and, where applied, is piecemeal.

Mechanical integrity of pressure vessels, boilers, and process piping is closely monitored by operations and maintenance personnel, with support provided as needed from the Systems Engineering and Design Engineering organizations. However, no formal sitewide pressure vessel or piping inspection program (ultrasonic or radiographic) exists to monitor system deterioration with time. When containment systems must be breached, formal written procedures must be approved by the appropriate engineering, maintenance, and operations personnel. A safety review and a quality assurance review of all procedures are required.

Maintenance management systems are in place to govern corrective and preventive maintenance activities. The EG\&G Rocky Flats, Inc., Maintenance Implementation Plan provides a graded approach to comply with the provisions of DOE $4330.4 \mathrm{~A}$. The IWCP, a complex and time-consuming work control program, clearly defines all preventive and mitigative measures for nonroutine work activities. It significantly extends the time required to complete routine preventive and corrective maintenance activities and is a factor in the low morale of maintenance crafts personnel. The IWCP permit authorizes personnel to begin work once signatures on the permit indicate all work groups are satisfied that the equipment and the area have been prepared for the assigned work, necessary safety precautions have been taken, and regulatory permits have been received. The IWCP encompasses all preventive and corrective maintenance activities for vital safety systems. About 10 percent of sitewide preventive maintenance activities are undertaken using the IWCP, yet the administrative burden imposed by this program has significantly contributed to the overall time for completing routine maintenance activities and has increased the maintenance backlog. For example, the corrective maintenance work order backlog for Building 371 increased from 1,200 to 1,400 items during the past 11 months (see Vulnerability CSVR-RFP-000-04).

Engineered design safeguards to protect worker safety are included in the facility design or modification package. The Configuration Change Control Program provides control of the technical baseline (1) to ensure continued safe operation by maintaining the existing approved configuration of all elements; (2) to identify breaches in the technical baseline; (3) to provide effective and timely action to restore the technical baseline; and (4) to provide a process for determining that any changes to the baseline are necessary and safe, have been properly reviewed, and have been approved prior to installation. A core group of health and safety personnel interface with engineering design personnel during the project review and approval process. The extent to which the Industrial Hygiene organization participates in the engineering design review is determined by the health and safety core groups. The selfevaluation report concludes that the Configuration Change Control Program needs 
improvement. The verification team supports this conclusion, since decisions on implementation of the program rest largely with individual building managers.

At RFP, raw water and wastewater are chlorinated at Building 124 and Building 995, respectively. Both chlorinator facilities are housed in sealed cabinets located outdoors. Each sealed cabinet, and the point at which the chlorine is introduced into the water system, is equipped with continuous chlorine monitors having both audible and visual alarms. Formal, approved, written procedures govern both the changeout of chlorine cylinders and responses to off-normal alarms. Cylinder exchange requires two workers in protective clothing and equipped with full self-contained breathing apparatus.

The reduction in maintenance staff through budget reduction, personnel transfer, retirement, and facility shutdown will continue to result in loss of craftspeople who have intimate knowledge of unrecorded aspects of both operating and shutdown facilities. This loss of craft expertise and undocumented facility-specific information has the potential to affect adversely the safe operation of chemical-handling facilities at RFP.

\subsection{Operational Control and Management Systems}

Although EG\&G Rocky Flats, Inc., has put in place an array of policies and procedures, many of which are related to safe management of hazardous materials, the field self-evaluation identified some chemical safety vulnerabilities. Management has generally recognized those areas where improvements are needed. The configuration change control system at RFP is one important system needing improvement. Complete and accurate drawings for all chemical-related systems are needed to ensure maximum operational safety now and for future activities. The overall chemical safety program will be greatly enhanced if these improvements are completely and correctly implemented.

The self-evaluation document was relatively thorough and provided a direct tie-in between the specific interests of the field verification team and important operational control and management systems at the site. The information contained in the self-evaluation will be valuable as the site addresses the potential chemical safety vulnerabilities identified.

The field verification team had the opportunity to review numerous documents regarding sitewide operational control and management systems, to discuss practices with site staff, and to observe conditions at the facilities selected for review. RFP does not have a centrally organized and integrated system for managing hazardous chemicals. The EG\&G Rocky Flats, Inc., policy manual, maintained by the Standards, Audits and Assurance organization, does not provide for such a system, nor does the manual explicitly include safe management of hazardous chemicals as a key activity or priority in the many policy documents contained in the manual. In the fall of 1993, however, an experience at Building 865 gave rise to a lessons-learned evaluation (see memorandum from G.P. Fraser to Distribution, "Lessons Learned Document Corrections - Excess Chemicals in Building 865," dated October 8, 1993) that, in part, has led to the designation of a specific individual mandated to develop an integrated management plan for chemicals at RFP. This activity is just beginning and is being funded out of monies from work packages supporting overhead activities for health and safety. In a related effort, differences between existing programs and those required for inclusion in the Occupational Safety and Health Administration's (OSHA) Voluntary Protection Program 
have recently been analyzed. If a commitment is made to move in such a direction, a number of changes will be required to place stronger operational controls on hazardous chemicals.

In some cases, chemical hazards are viewed as being less significant than radiation hazards. Examples include the following:

- The routine monitoring program for ionizing radiation is extensive, whereas the monitoring program for chemical hazards is not fully implemented.

- Although technology limits the amount and type of information that can be collected, meaningful personnel air-sampling data for potential chemical hazards are not readily available.

- The occupational medical program has a considerable amount of radiation exposure data available for use in medical evaluation, although chemical exposure data for use in medical evaluation are minimal.

Clearly, providing employees with enhanced information concerning possible hazards encountered when working with chemicals will improve the occupational health program. This disparity in management support and emphasis is considered a vulnerability (see Vulnerability CSRV-RFP-000-02).

The current hazard analysis methodology with regard to chemical hazards is evolving at RFP. Lessons learned from each activity are being used to modify and improve future activities so that task control is better defined and the safety of workers, the public, and the environment is enhanced. However, the accuracy and usefulness of the hazard analysis process are strongly dependent on the accuracy and specifics of the chemical hazards analyzed (e.g., in room locations, types and conditions of chemicals in each process and room). The hazard analysis methodology employed in Building 771 is fairly comprehensive and may serve as a model for other buildings. The self-evaluation deals extensively with this area and notes the vulnerabilities created by a less-than-adequate characterization of processes involving hazardous chemicals.

As discussed in Sections 2.1 and 3.2 (see Vulnerability CVSR-RFP-000-01), the success and use of hazard analyses are directly related to the accuracy and completeness of chemical inventory information.

Under basic systems that control work involving hazardous chemicals at the site, fundamental decisions are made by the various line management organizations. Work packages are intended to identify needed support services from subject matter experts (e.g., reactive chemical management), with sitewide service programs funded under a separate group of (overhead) work packages. The effectiveness of this system depends on (1) the ability of the line to identify and secure support for its changing resource needs and (2) the willingness of senior management to fund sitewide programs fully enabling progress in the safe management of hazardous chemicals. The self-evaluation report provided information suggesting that this approach is not fully effective, and the field verification team was able to confirm the pertinent information in the self-evaluation report. 
Packaging and transportation procedures and requirements appear adequate. Training in this area is standardized and continues to be refined. Department of Transportation regulations provide the basis for this training. The decision to use a single sitewide repackaging procedure will enhance consistency and minimize handling.

\subsection{Human Resource Programs}

Programs at RFP were reviewed to determine how chemical safety is integrated by EG\&G Rocky Flats, Inc., into areas of personnel training and qualification, staffing levels, employee concerns, personnel performance, and communications. The field verification team found that, due to attrition, the level of corporate knowledge of the processes that have not been operated in recent years has reached a low level. The self-evaluation report did not address this issue. This is significant because some facilities were shut down without fully draining the contents from the process equipment. This equipment will have to be operated in some modified form to recover and dispose of these solutions. In the area of hazard communication, the file of material safety data sheets (MSDSs) was not complete, as was recognized in the self-evaluation report. Labels for some equipment that contained chemicals were not current; some low-level waste drums were reported as being improperly labeled in the self-evaluation report.

Although the number of personnel in the various facilities is adequate to perform the current work, the minimal experience level of these personnel may impede their performance where detailed knowledge of equipment and processes is needed. Note the following:

- The six plutonium processing buildings at RFP have not operated since 1989. Operations were suspended with process materials in place in anticipation a of quick resumption of work, and these materials remain in the equipment. In the interim, personnel who were knowledgeable about these processes have been lost through retirement, transfer, reassignment, or other staff actions.

- Personnel currently assigned to these buildings have little experience predating 1989, and their subsequent experience has not been from operation of equipment that will be used to remove residual process solutions. The Transition Management organization is planning to dispose of equipment from these buildings after removal of the process materials.

Transition Management is attempting to document everything needed for this work using subject matter experts. In addition, process descriptions are being prepared by the Site Planning and Integration Team.

General training at RFP is provided by the Performance Based Training (PBT) organization. PBT provides General Employee Training to all employees, visitors, and contractors. In addition, PBT provides 8-hour refresher and 24-hour and 40-hour basic training to selected employees to meet OSHA requirements specified in 29 CFR 1910.120, "Hazardous Waste Operations and Emergency Response." PBT also provides training to operating personnel on specialty topics (e.g., hazard communication), which in turn allows trained operators to use PBT guides, lesson plans, and reference material to instruct technicians. Workers also receive job-specific and on-the-job safety training for those chemicals to which they are likely to be exposed. Examinations (oral, written, or both) are administered and graded, and the results are documented. In addition, operating procedures contain "notes" that call attention to 
hazards associated with chemicals used to perform specific operations. These notes, which help maintain continuing safety alertness, are placed in procedures at steps where these chemicals are used.

The training program meets the requirements of 29 CFR 1910.1200," Hazard Communication"; however, its implementation is weak in that the MSDS files, although extensive, are not current or complete. In addition, labels identifying the chemical contents of some containers are not current. For example, the tanks in Building $\mathbf{3 7 4}$ were labeled for conditions that existed when operations were modified; these labels have not been updated to reflect current conditions.

\subsection{Emergency Management Program}

The emergency management program at RFP includes provisions that address planning, preparedness, and response for emergencies involving chemicals. The RFP Emergency Plan is the central document that establishes and describes the overall emergency management program. The associated implementing procedures (i.e., the Emergency Plan Implementing Procedures) identify the detailed actions necessary to implement sitewide emergency responses set forth in the plan. Documented responder-specific procedures (e.g., fire department hazardous materials response and RFP shift superintendent response) are currently in place. Facility-specific emergency plans and associated implementing instructions are in place for those facilities that have resumed operational activities (i.e., Buildings 559 and 707). The facilities for which operational activities are planned in the near term (e.g., Buildings 371 and 374) have drafts of emergency plans and procedures in various stages of preparation, and the remaining RFP facilities have no emergency plans or procedures.

Emergency response facilities include a well-equipped, central Emergency Operations Center and satellite functional work centers for use by the RFP emergency response organization. In the event of an emergency, a mobile incident command post, staffed by the RFP shift superintendent, fire and security officers, and technical personnel are established near the scene. Fire response vehicles and equipment, two emergency medical vehicles, a dedicated hazardous-materials-response vehicle, and an equipment trailer are maintained at the RFP fire station. A variety of emergency equipment is maintained in lockers within each facility.

RFP has established a 24-hour-per-day sitewide emergency "2911" telephone call system that contacts the RFP shift superintendent, fire department, and RFP security simultaneously. At the facility level, the shift manager is initially in charge of response and is supported by the Building Emergency Support Team. Facility evacuation is initiated by an appropriate announcement on the Life Safety/Disaster Warning public address system, and facility occupants evacuate to a predesignated assembly point for accountability. Accountability for persons evacuated from most facilities within the protected area is accomplished by means of a personal accountability tag system. In addition, since the system does not provide for positive accountability of facility occupants, search and rescue teams are used to ensure complete facility evacuation.

The RFP fire department provides primary emergency response functions for fire, emergency medical, and hazardous materials events. Fire department staffing includes two onshift 
companies (minimum of 12 persons) with all firefighters trained in hazardous materials response (i.e., to the "specialist" or "technician" level to meet the OSHA requirements codified in 29 CFR 1910.120, "Hazardous Waste Operations and Emergency Response") and as emergency medical technicians. The onshift chief and captains are trained as Incident Commanders. The captain at the event scene assumes the role of Incident Commander until relieved by the chief officer or RFP shift superintendent. The RFP shift superintendent typically relocates from his central office and establishes the incident command post. Technical support is provided to the Incident Commander by the facility shift manager and by oncall staff from the Industrial Hygiene and Safety Department.

Additional fire, hazardous materials, and/or emergency medical response resources are available from local community response organizations. Formal agreements are in place for emergency medical transportation and hospital care. Informal agreements (a formal mutual aid agreement is pending) are in place for support by the Jefferson County's hazardous materials response organization and community fire districts.

As identified in the RFP self-evaluation, assessment of facility-specific hazards at numerous RFP facilities is evolving. Assessments of facility industrial hygiene and occupational safety hazards are in progress (refer to Section 2.1). Preliminary Hazards Assessments, which incorporate the methodology of DOE 5500.3A, "Planning and Preparedness for Operational Emergencies," but use inaccurate and incomplete chemical inventory information, are in progress for 14 facilities. An integrated approach for conducting hazards assessments, the Integrated Safety Assessment process, has been initiated as a pilot effort for Building 771 . This process, intended to satisfy various requirements pertaining to hazards assessment, is designed to be performed by a multidisciplinary team and will establish a baseline of facilityspecific hazards. In concert with the State of Colorado, a concurrent effort is in progress to establish emergency planning zones applicable to release of hazardous materials from an RFP facility. 


\subsection{CATEGORIZATION AND PRIORITIZATION OF VULNERABILITIES}

\subsection{Criteria}

A vulnerability is a weakness or potential weakness involving hazardous chemicals that could result in a threat to the environment, the public, or worker health and safety. Vulnerabilities can be characterized by physical or programmatic conditions associated with uncertainties, acknowledged deficiencies, and/or unacknowledged deficiencies in the area of chemical safety. Conditions required to create the vulnerability should either currently exist or be reasonably expected to exist in the future, based on degradation of systems and chemicals or through expected actions (e.g., D\&D of facility).

A vulnerability will be determined to exist if current or expected future conditions or weaknesses could result in the following:

- The death of or serious physical harm ${ }^{1}$ to a worker or a member of the public or continuous exposure of a worker or member of the public to levels of hazardous chemicals above hazardous limits; or

- Environmental impacts resulting from the release of hazardous chemicals above established limits.

The prioritization of the chemical safety vulnerabilities is based on the professional judgment of team members concerning the immediacy of the potential consequences posed by each vulnerability and on the potential severity of those consequences. The first step in the prioritization process was to group vulnerabilities according to the timeframe in which they are expected to produce consequences. The following categories have been established for the timeframe within which the consequences are expected to occur:

- Immediate - Any chemical safety vulnerability that could result in immediate consequences.

- $\quad$ Short-Term - Any chemical safety vulnerability at a facility in which there is a significant chance of a consequence occurring within a 3-year timeframe as a result of chemical degradation, change in mission for the facility, degradation of the containment systems, change in personnel at the facility, or other factors affecting the facility.

- Medium-Term - Any chemical safety vulnerability at a facility in which there is a significant chance of a consequence occurring within a 3-10-year timeframe as a result of chemical degradation, change in mission for the facility, degradation of the containment systems, change in personnel at the facility, or other factors affecting the facility.

1 Serious physical harm is defined as impairment of the body, leaving part of the body functionally useless or substantially reducing efficiency on or off the job. 
- Long-Term - Any chemical safety vulnerability at a facility in which there is a significant chance of a consequence occurring within a timeframe of more than 10 years as a result of chemical degradation, change in mission for the facility, degradation of the containment systems, change in personnel at the facility, or other factors affecting the facility.

Vulnerabilities within each category should be further prioritized to specify "high," "medium," or "low" priority based on the severity of the potential consequences. Examples of the second level of prioritization include the following:

- Prioritize potential harm to workers or the public according to the possible level of injury and/or health effect, ranging from transient reversible illness or injury to death.

- Prioritize environmental impacts based on the level of irreversible damage and/or restoration costs.

\subsection{Chemical Safety Vulnerabilities at Rocky Flats Plant}

Five vulnerabilities were identified during the conduct of this review. These conditions and circumstances are largely consistent with those already identified by personnel at the Rocky Flats Plant, but they have been recast to a form similar to that already developed for the DOEwide effort.

\section{CSVR-RFP-000-01: Lack of accurate and complete chemical inventories impedes the effective analysis of hazards posed to workers.}

The recognition and control of hazardous chemicals are directly proportional to the accuracy and completeness of chemical inventories. Facility hazardous chemical inventories are generally reported using the Emergency Planning and Community Right-to-Know Act (EPCRA) Chemical Control System (ECCS), a sitewide tracking tool. The ECCS has limitations as both a stand-alone sitewide and facility tracking tool. It is inadequate for uses such as worker hazards assessment, emergency planning, and operating procedures, including D\&D. ECCS was designed to track chemicals subject to Title III of the Superfund Amendments and Reauthorization Act and was not intended, nor does it have the capability, to provide current and accurate facility inventories. Hazardous and mixed-waste chemical holdings are tracked separately under the Waste and Environmental Management System (WEMS). There is no systematic approach to the management of chemical holdings at the Rocky Flats Plant in that requirements and practices for purchasing, receiving, handling, storing, and disposing of chemicals vary greatly from facility to facility. Management of chemical holdings in Buildings 371,551 , and 881 is inadequate in that current and accurate "total facility chemical holdings," including location, quantities, and chemical condition, are not available to plant personnel. The ongoing inability to provide total facility inventories places workers at increased risk of exposure to hazardous chemicals in virtually every aspect of their work. This is especially true with pending mission changes and transition activities, where specific areas of a building are expected to be in a continued state of change, including the chemical holdings in those areas. These conditions and circumstances represent a medium- to highpriority vulnerability with a potential for short-term consequences. 
CSVR-RFP-000-02: Chemical hazards are provided disproportionately less management support than are radiation hazards.

Potential chemical hazards are not given the same degree of attention as potential ionizing radiation hazards. The need for comprehensive routine monitoring programs for potential chemical exposures comparable to programs required for radiation is not generally recognized. Less than complete personal monitoring creates a void in the data used by industrial hygiene and occupational medicine in evaluating potential chemical hazards. Placing less emphasis on chemical safety than on radiation safety may lead employees to believe that nuclear considerations take precedence over chemical safety. This may result in otherwise avoidable worker exposures to hazardous chemicals. These conditions and circumstances represent a medium-priority vulnerability with a potential for short-term consequences.

\section{CSRV-RFP-000-03: RCRA requirements are given precedence over chemical safety.}

Regulatory requirements with clearly established penalties for nonresponse receive management's prompt attention. Attempts to fulfill RCRA inspection requirements may require that employees work in areas where hazardous materials are present. For example, plutonium aqueous recovery system operations in Building 371 ceased in 1984 and the solution remaining in process piping and tanks (containing primarily plutonium nitrate and nitric acid) was never removed. A 1990 U.S. District Court order requires that this material be managed as hazardous waste, subject to regulation under RCRA and Colorado Code of Regulations 6CCR 1007-3, Part 264. These regulations require frequent and total inspections of systems containing this waste. The piping in Building 371 is deteriorating; as this condition continues, the potential for leakage or rupture increases and any entry into the area to perform the inspections can expose employees to hazardous and toxic chemicals.

Management's focus has been on regulatory requirements associated with RCRA, which have penalties for noncompliance, rather than on mitigating risks associated with worker activities not yet regulated by RCRA. To date, no strategy has been devised that simultaneously addresses both worker chemical safety and environmental compliance. These conditions and circumstances represent a medium-priority vulnerability with a potential for short-term consequences.

\section{CSVR-RFP-000-04: Deterioration of facility physical conditions has the potential to create chemical safety hazards.}

The mechanical integrity of the primary and secondary containment systems and equipment at RFP is generally satisfactory, but the level to which specific facilities are maintained depends on the mission status. The preventive maintenance program is mission driven, with RCRAregulated facilities and activities such as stabilization and consolidation receiving priority for staffing and budget. Corrective maintenance for all RFP facilities is reactive. With the exception of the thermal tomography of high-voltage power lines, a sitewide predictive maintenance program does not exist at RFP. The Integrated Work Control Program (IWCP) is a complex and time-consuming work control program that clearly defines all preventive and mitigative measures for nonroutine work activities. The IWCP also significantly extends the time necessary to complete routine preventive and corrective maintenance activities contributing to maintenance backlog, and it is a factor in the low morale of maintenance crafts 
personnel. The reduction in staff through budget reduction and personnel departure has resulted in the loss of craft expertise and undocumented facility-specific information and has the potential to affect adversely the safe operation of chemical-handling facilities at RFP. These conditions and circumstances represent a low-priority vulnerability with a potential for short-term consequences.

\section{CSVR-RFP-000-05: Decisions on budget content and priorities delay correction of known chemical safety vulnerabilities.}

A review of the RFP self-evaluation indicated a number of instances in which the implementation of corrective actions had been delayed because of budget constraints or because relatively low priority had been assigned to chemical safety vulnerabilities. For example, the self-evaluation report notes that "actual movement and disposition of excess chemicals from existing storage locations has been slow to develop" (see page 9). Most work at RFP is accomplished under work packages, which are developed under a formal procedure and management process. The content of these work packages is generally assigned to line managers, who have latitude in determining the need for or actual use of experts in industrial safety, industrial hygiene, emergency management, or hazards assessment. The team verified the self-evaluation report's analysis that the continued existence of some chemical vulnerabilities could be directly traced to relatively low priority assigned to chemical hazards, and to the ability of line managers to unilaterally decide to downscope efforts related to safe management of chemicals. These conditions and circumstances represent a medium-priority vulnerability with a potential for medium-term consequences. 
Area of Responsibility

Team Leader

Special Assistant to Team Leader

Management/Operations

Management/Training

Chemical Process Safety

Industrial Hygiene

Environmental Protection

Maintenance

Emergency Management

Site Liaison

Coordinator

Technical Editor

\section{Name/Organization}

Rebecca F. Hansen Operations Management Division U.S. Department of Energy

Joseph J. Krupar, Jr. Office of Safety and Quality Assurance U.S. Department of Energy

Del Bunch

Management Strategies, Inc.

Woodson B. Daspit

Technical and Professional Services

Patricia R. Worthington

Office of Risk and Policy Analysis

U.S. Department of Energy

Todd F. Lewis

Babcock \& Wilcox Idaho, Inc.

Clifford H. Summers

Arthur D. Little, Inc.

F. Richard Myal

Compa Industries, Inc.

Thomas A. Kevern

Program Management, Inc.

Laura E. Cindel

Rocky Flats Field Office

U.S. Department of Energy

Mary E. Meadows

Environmental Management Associates

Larry D. Warren

Evergreen Innovations, Inc. 


\section{ATTACHMENT 2}

CHEMICAL SAFETY VULNERABILITY REVIEW

VULNERABILITY FORM

DATE: May 9,1994

Site/Facility: Rocky Flats Plant

Vulnerability Number: CSVR-RFP-000-01

Functional Area(s): Chemical Process Safety

1. Brief Description of Vulnerability.

Lack of accurate and complete chemical inventories impedes the effective analysis of hazards posed to workers.

2. Summary of Vulnerability.

The recognition and control of hazardous chemicals are directly proportional to the accuracy and completeness of chemical inventories. Facility hazardous chemical inventories are generally reported using a sitewide tool, the Emergency Planning and Right-to-Know Act (EPCRA) Chemical Control System (ECCS), which is inadequate for most uses (e.g., worker hazards assessments, emergency planning, operating procedures, decontamination and decommissioning [D\&D]) in that it can not provide current and accurate facility inventories on a real-time basis. The ECCS was designed to track only those chemicals regulated under Superfund Amendments and Reauthorization Act (SARA) Title III.

3. Basis.

a. Requirements:

- 29 CFR 1910.1200

- 29 CFR 1910.106

- 29 CFR 1910.119

- 29 CFR 1910.1450

- 40 CFR 350

- 40 CFR 355

- 40 CFR 370

- 40 CFR 262

- DOE 5480.10

- DOE 5700.6C

b. Chemicals Involved: The range of hazardous materials in various types of buildings includes organic solvents, organic and inorganic acids and bases, lead base paint, carcinogens, products/chemicals, heavy metals, and hazardous and mixed wastes located throughout the site.

c. Relevant Self-Evaluation Data: EG\&G Rocky Flats, Inc., "Chemical Safety Vulnerability Field SelfEvaluation," March 29, 1994. Section 2.9 discusses surveillance findings and corrective actions, and Section 2.0 discusses ECCS, the Excess Chemical Program, and the Waste and Environmental Management System (WEMS). 


\author{
Site/Facility: Rocky Flats Plant \\ Vulnerability Number: CSVR-RFP-000-01 \\ Functional Area(s): Chemical Process Safety
}

3. Basis. (Continued)

d. Contributing Causes:

- Facility inventory data are based on the ECCS, which has limitations both as a facility inventory tool and as a sitewide inventory tool.

- As a facility inventory tool, ECCS has limitations because facility-specific inventory data bases have different needs and may be incompatible with ECCS.

- As a sitewide inventory tool, ECCS provides information only on EPCRA (SARA Title III) reportables; it has not been fully implemented sitewide; up to 40 percent of chemicals do not pass through the central warehouse where bar-codes are assigned and arrive at designated facilities without ECCS bar-codes in place; and ECCS does not include all chemicals already on site, in process lines, or in tanks not yet characterized.

- Total facility inventories are performed, at best, on an annual basis.

- Requirements and practices for purchasing, receiving, haridling, storing, and disposing of chemicals vary greatly from building to building.

e. Potential Consequences:

- Inability to quantify and characterize hazardous chemical inventories fully (e.g., type, quantity, location, and condition of the chemicals) in the conduct of facility hazard assessments places workers at increased risk of exposure to hazardous chemicals. As facilities at RFP experience mission change or undergo transition to D\&D, specific areas of the building (including chemical holdings in those areas) are expected to be in continued change. Adequate material characterization needs to be conducted before any procedures for removal of material or equipment are undertaken. Accurate, real-time inventories are needed to enhance worker protection and to minimize exposure to hazardous chemicals. These conditions and circumstances represent a medium- to high-priority vulnerability with a potential for short-term consequences.

4. Supporting Observations.

RFP is not currently able to provide accurate, complete, and totall facility inventories. This inability affects the safety management of hazardous chemicals in the areas summarized below:

Accountability - Use of ECCS as a sitewide tool to provide total facility inventories has resulted in lack of "facility ownership" for inventories. In addition, inventories are generally conducted by ECCS staff, although some facilities have developed their own data bases to get local control of accurate and current data. Building 559 has developed a system for total facility inveritory to track all chemicals, including those used in waste management. Only a limited number of facilities have designated Chemical Control Officers (CCOs). These are Building 559, Building 881 (a pilot project for fiscal year 95) and Building 371 (shared CCO with Building 374 on interim basis, effective the week of May 9, 1994). 
Site/Facility: Rocky Flats Plant

Vulnerability Number: CSVR-RFP-000-01

Functional Area(s): Chemical Process Safety

4. Supporting Observations. (Continued) Management of Change

- As areas within a building undergo changes to support new missions or transition to D\&D, the key to managing these changes is to know what the current inventories are for that area.

- The Excess Chemicals Program identifies and consolidates (for interim storage) potentially reactive and incompatible chemicals awaiting ultimate disposal.

- In Building 881 , some potentially shock-sensitive chemicals are stored in metal office cabinets that had been designed by RFP for interim storage of reactive chemicals. The metal cabinet containing the shock-sensitive chemical was labeled using temporary tape and a marker. This label was subsequently replaced with a proper sign by the area manager. The location of these metal cabinets (Room 127 hallway) is easily accessible to personnel moving throughout the first floor corridors and could result in the contents of the cabinets being disturbed.

- Materials identified as reactive are being stored temporarily in the flammable storage area in Building 551. Warehouse personnel have been instructed not to move or disturb these chemicals before removal by designated experts. These chemicals are located on a shelf containing other chemicals and are identified and isolated from the other chemicals by only two strips of yellow tape. Once stabilized, these chemicals will be removed.

- For Building 371, consolidation of reactive chemicals, including special nuclear materials, in the Central Storage Vault is being considered.

- As more buildings at the Rocky Flats Plant (RFP) are transitioned to the D\&D Program and as chemicals in these buildings continue to age prior to initiation and before completion of the excess chemical identification, the number of reactive chemicals is expected to increase. 
Site/Facility: Rocky Flats Plant

Vulnerability Number: CSVR-RFP-000-01

Functional Area(s): Chemical Process Safety

4. Supporting Observations. (Continued)

Process Knowledge

- Process knowledge of hazardous chemical inventory is inadequate for some buildings.

- Process piping and tanks in Building 371 contain "mixed residues" or recoverable products, although an accurate accounting of the quantity of these materials present is not available. Stabilization and removal of some hazardous materials are expected to be long-term efforts, but these programs are not currently active. Before any work commences on these systems (e.g., leaking pipes), personnel should be thoroughly trained on the associated hazards. The longer the delay before action is taken, the less knowledgeable personnel will be and the more difficult it will be to develop new protocols to deal with unknown scenarios.

- Room 4101 in Building 374 contains a number of large tanks with contents that have not been fully documented. Labels on the tanks state that the contents are concentrated acids, but based on historical process knowledge, some also contain dilute acid solutions or water and some are empty.

- Residuals in the piping and drains in Building 881 have not been fully characterized and quantified. The initial baseline study from Building 881 was terminated before completion.

\section{Audits and Corrective Actions}

- Corrective actions associated with surveillance findings on the chemical tracking systems are related to full implementation of the ECCS. ECCS was not designed for sitewide inventories for both EPCRA and non-EPCRA chemicals. In addition, facility ownership of inventory tracking is lacking. Any sitewide system used must be accurate, current, and flexible enough to meet individual facility needs. (Individual data bases exist for some buildings but have different formats with different levels of specificity and complexity.)

Process and Equipment Integrity

- Some piping was not designed for its current use (extended shutdown with concentrated nitric acid solutions).

- Chemical holdings currently located in piping and structures adversely affect safe performance of maintenance and inspection activities.

\section{Training and Performance}

- To support job-specific training, there is a need to know the current hazardous chemical inventory so that workers are aware of and understand the hazards associated with their assigned tasks. 
Site/Facility: Rocky Flats Plant

Vulnerability Number: CSVR-RFP-000-02

Functional Area(s): Operations Control and Management Systems

1. Brief Description of Vulnerability.

Chemical hazards are provided disproportionately less management support than are radiation hazards.

2. Summary of Vulnerability.

Potential chemical hazards are not given the same degree of management attention as potential ionizing radiation hazards. Programs for monitoring, evaluating, and characterizing chemical hazards are not as mature as those aimed at radiation hazards. Weaknesses in the hazard communication program limit the information available to employees and occupational health professionals.

3. Basis.

a. Requirements:

- 29 CFR 1910.1200, "Hazard Communication"

- DOE 5480.10, "Contractor Industrial Hygiene Program"

- DOE 5483.1A, "Occupational Safety and Health Program for DOE Contractor Employees at Government-Owned Contractor-Operated Facilities"

b. Chemicals Involved: All potentially hazardous chemicals

c. Relevant Self-Evaluation Data: EG\&G Rocky Flats, Inc., "Chemical Safety Vulnerability Field SelfEvaluation," dated March 30, 1994, states in Section 10.7, "Building 371 Occurrence Reporting and Processing Systems (ORPS) data indicated that chemical incidents are not given the same attention as nuclear incidents in the facility." This report also stated that many nuclear considerations apparently take precedence over chemical safety in the ORPS report. Paragraph 1.1 of the field self-evaluation states that the MSDS program is less than adequate.

d. Contributing Causes:

- Historical perception that chemicals present an acceptable risk and that ionizing radiation is more hazardous than most chemicals drives emphasis to health physics concerns.

- The number of MSDSs makes it hard to maintain all sheets current.

- Some process system components were labeled for a mode of operation that is no longer in use.

- Work that has been completed has not been documented so that current status is known.

- Lack of technology that quantifies potential employee exposure to hazardous chemicals. 
Site/Facility: Rocky Flats Plant

Vulnerability Number: CSVR-RFP-000-02

Functional Area(s): Operations Control and Management Systems

3. Basis. (Continued)

e. Potential Consequences:

- Employees are led to believe that nuclear considerations take precedence over chemical safety

- Personnel injury due to exposure to hazardous chemicals

- Release of chemicals to the environment

- Damage to facilities

- These conditions and circumstances represent a medium-priority vulnerability with a potential for short-term consequences.

4. Supporting Observations.

- A comprehensive routine monitoring program for potential chemical exposure is not as fully implemented as the radiation monitoring program.

- Considerable data for occupational medical surveillance evaluation are available concerning ionizing radiation; personal air sampling data for work with potentially hazardous chemicals are not as readily available.

- Chemical inventory requirements and specifications are not as well defined as those dealing with nuclear materials.

- Weaknesses in the Hazard Communication Program result in employees having less information regarding chemical hazards than ionizing radiation hazards. Weaknesses include the following:

- MSDSs are not always available.

- In Building 374, tanks and associated piping were labeled for the existing operation, but when operations were modified, the labels were not changed to reflect their current status. In the Building 374 separation area and in Room 4041, equipment is labeled as containing concentrated nitric acid, hydrochloric acid, sulfuric acid, and hydrogen peroxide. Some equipment is reported by facility personnel as containing less hazardous substances or to be empty.

- In Building 551, material identified as reactive is temporarily stored on a shelf with other chemicals. They only identification consists of two yellow strips of tape, which also serve as isolation. Once stabilized, these chemicals will be removed.

- Chemical inventories are not always complete.

- Interviews (e.g., Performance Assurance) clearly identified nuclear issues as a separate and higher priority than chemical issues.

- Historically, safety analyses for operations at the site emphasized accidents involving potential releases of radioactivity.

- The radiation protection staff is at least 20 times larger than the industrial hygiene staff. 
Site/Facility: Rocky Flats Plant

Vulnerability Number: CSVR-RFP-000-03

Functional Area(s): Identification of Chemical Holdings

1. Brief Description of Vulnerability.

Resource Conservation and Recovery Act (RCRA) requirements are given precedence over chemical safety.

2. Summary of Vulnerability.

Regulatory requirements with clearly established financial penalties for nonresponse receive management's prompt attention. Attempts to fulfill RCRA inspection requirements may place employees at risk.

3. Basis.

a. Requirements:

- 6 CCR 1007-3, Part 264, Subpart J, "Tank Systems"

- 40 CFR 264, Subpart J, "Tank Systems"

- Rocky Flats Plant (RFP) Operational Safety Analysis Program

- Letter from the Colorado Department of Health (CDH) to DOE, "Conditional Approval of Mixed Residues Tank Systems Management Plan," dated April 13, 1994

b. Chemicals Involved: The range of hazardous materials in various types of buildings includes organic solvents, organic and inorganic acids and bases, lead base paint, carcinogens, products/chemicals, heavy metals, and hazardous and mixed waste located throughout the site.

c. Relevant Self-Evaluation Data: Discussions with plant personnel and comments included in the facility self-evaluation. The self-evaluation states that "there is a potential that regulatory guidelines for fineable milestones such as RCRA will often get attention over worker health and safety that does not carry immediate fines and adverse publicity." It further states that "conflicts between nuclear safety and worker safety are not uncommon, but a relatively new phenomenon is the potential for the compromising of worker safety in order to meet environmental requirements such as RCRA milestones and inspections." (Part II, Section 10.7 of EG\&G Rocky Flats, Inc., "Chemical Safety Vulnerability Field Self-Evaluation," dated March 30, 1994).

d. Contributing Causes: The court has determined that recoverable product remaining in piping, drums, and tanks, after the cessation of operations of the aqueous recovery system in Building $\mathbf{3 7 1}$ in April 1984, is to be managed as mixed waste (subject to RCRA requirements), not as recoverable product. Cessation of other operations at RFP, also subject to RCRA requirements, occurred in December 1989. Noncompliance with RCRA regulations can result in fines. 
Site/Facility: $\quad$ Rocky Flats Plant

Vulnerability Number: CSVR-RFP-000-03

Functional Area(s): Identification of Chemical Holdings

3. Basis. (Continued)

e. Potential Consequences: Should a leak occur during an inspection of the piping in Building 371, there is risk of serious injury to workers from exposure to toxic and radiologic materials. The statement is made (EG\&G Rocky Flats, Inc., "Chemical Safety Vulnerability Field Self-Evaluation," March 30, 1994) that "the failure of system components containing chemical solutions continues to provide a great potential for release to the environment or personal injury." There is also risk to workers in other RFP areas (such as the warehouse) in which current practices, non-RCRA regulated, can lead to hazardous and toxic chemical exposure. These conditions and circumstances represent a medium-priority vulnerability with a potential for short-term consequences.

4. Supporting Observations.

- The plutonium aqueous recovery system located in Building 371 was shut down in 1984, with recoverable plutonium (as plutonium nitrate) remaining in tanks and ancillary piping. Inventory in tanks, other containers, and ancillary piping was not removed. Some of the piping is not secondarily contained, and its construction is not chemically suitable for long-term storage of corrosives such as nitric acid. A percentage of the piping to be inspected is above floor level, as well as in spaces that are difficult to access and/or view. In addition, viewing the entire circumference of the piping containing the waste may not be possible due to obstructions. Inspection of the entire circumference of the piping is a RCRA requirement.

- Additional observed examples of practices and procedures currently accepted at RFP, and that do not receive management attention because they are not RCRA-regulated, include the following:

- Containers of acid loosely stored on the floor in Room 4101 of Building 374.

- Tanks in Room 4101 of Building 374, incorrectly identified as containing concentrated acids but are stated to be empty.

- Three-high stacking of drums of hazardous materials in Building 551 (warehouse).

- Lack of a procedure to obtain and use the most recent MSDSs in Building 551.

- Lack of a procedural counterpart to manual 1-10000-HWR for nonhazardous wastes.

- RCRA requires daily inspections of tanks and ancillary piping that contain hazardous wastes and are not secondarily contained. The CDH letter to DOE has reinforced this requirement and notes that RFP has not addressed issues regarding tank system integrity assessments in the Mixed Residues Tank Systems Management Plan. The letter includes tank systems inspection requirements. The plant Operational Safety Program requires an Operational Safety Analysis for all work activities in which a potential exists for exposure to toxic materials. These requirements are, at times, at odds with one another. Preparation and implementation of a strategy that meets both RCRA requirements and minimizes worker exposures to toxic and radiological risks are lacking. 
Site/Facility: Rocky Flats Plant

Vulnerability Number: CSVR-RFP-000-04

Functional Area(s): Facility Physical Condition

1. Brief Description of Vulnerability:

Deterioration of facility physical conditions has the potential to create chemical safety hazards.

2. Summary of Vulnerability:

The cumulative effect of declining maintenance budgets and reduced staffing results in the continued deterioration of an aging physical facility. This deterioration has the potential to adversely impact chemical safety of the Rocky Flats Plant (RFP).

3. Basis.

a. Requirements: DOE 4330.4A, "Maintenance Management Program"

b. Chemicals Involved: Various

c. Relevant Self-Evaluation Data: Based on existing plant priorities, completion of preventive maintenance activities has fallen behind and has become secondary to achieving a reduction in the existing backlog of corrective maintenance activities. More than 2,400 preventive maintenance activities are delinquent by more than 1 month, many of which involve important safety systems-including exhaust fans; pressure relief devices; filter systems; chemical containment systems; and various analyzers, detectors, and alarm systems. (See Section 6.2 of EG\&G Rocky Flats, Inc., "Chemical Safety Vulnerability Field Self-Evaluation," dated March 30, 1994.)

d. Contributing Causes:

- The preventive maintenance program at RFP is mission driven.

- Facilities resuming operations or Resource Conservation and Recovery Act (RCRA) regulated facilities receive attention while standby facilities receive minimal preventive maintenance due to staffing and budgetary limitations.

- The predictive maintenance program at RFP is very weak and, where applied, is piecemeal. No formal sitewide predictive maintenance program exists at RFP.

- The Integrated Work Control Program (IWCP) as it currently exists is complex, time consuming, and expensive for accomplishing maintenance activities. The IWCP is a contributing cause for unnecessary schedule delays and has adversely affected worker morale.

- The change in mission from production to environmental restoration, with the declining maintenance budget and resulting staff reassignment and reduction, has adversely affected worker morale. 
Site/Facility: Rocky Flats Plant

Vulnerability Number: CSVR-000-04

Functional Area(s): Facility Physical Condition

3. Basis. (Continued)

e. Potential Consequences:

- Exposure to hazardous chemicals

- Personal injury or contamination

- Release of chemicals to the environment

- Damage to facilities

- These conditions and circumstances represent a low-priority vulnerability with a potential for shortterm consequences.

4. Supporting Observations.

- Maintenance crafts and supervisory personnel and preventive maintenance funds were stripped from Buildings 371 and 374 , which were in standby, and used for resumption of Buildings 559 and 707 . The preventive maintenance budget and maintenance personnel were never replaced, resulting in deterioration of the physical condition of Buildings 371 and 374 .

- Preventive maintenance in Building 371, which houses the Cientral Storage Vault (CSV), has been minimal. This is evidenced by the deterioration of certain ventilation, cooling, control, and monitoring systems.

- Electric motors serving two of the three major ventilation fans have failed within the past 3 months. These two ventilation fans remain out-of-service, leaving one ventilation fan to serve the building.

- Cooling tower feedwater pump capacity has dropped from $10,000 \mathrm{gpm}$ to $5,000 \mathrm{gpm}$ and can no longer provide sufficient cooling to maintain the CSV temperature at an optimum $70^{\circ} \mathrm{F}$ to $80^{\circ} \mathrm{F}$.

- Electrical discontinuities exist in the standby Vestiune cable for the stacker-retriever vehicle in the csV.

- The moisture content analyzer at the CSV is inoperable.

- Corrective maintenance backlog in Building 371 has increased from 1,200 to 1,400 items over the past 11 months.

- Because of lack of funding, a formal predictive maintenance program has not been established at RFP.

- The change of maintenance crafts and supervisory personnel through promotion, transfer, voluntary severance, retirement, and a declining maintenance budget has resulted in a loss of expertise. New maintenance personnel do not have extensive experience with specific facilities and, consequently, are less efficient in conducting routine, facility-specific maintenance activities. 
Site/Facility: $\quad$ Rocky Flats Plant

Vulnerability Number: CSVR-RFP-000-05

Functional Area(s): Operational Control and Management Systems

1. Brief Description of Vulnerability.

Decisions on budget content and priorities delay correction of known chemical safety issues.

2. Summary of Vulnerability.

Funding for the systematic removal of hazardous chemicals from the Rocky Flats Plant (RFP) buildings and the areas surrounding them depends on (1) the allocation of resources to individual work packages and (2) the existence of sitewide policies and programs focused on such activities. Plans for removal of residues in ducts, stabilization and consolidation of special nuclear material, and liquid stabilization appear to have been developed at the expense of funding needed for chemical hazards abatement programs, except where specific constraints were imposed to meet requirements related to the Resource Conservation and Recovery Act (RCRA). As a consequence, staff expertise, staffing levels, and specific remedial actions have lagged behind needs.

3. Basis.

a. Requirements: Section 161 of the Atomic Energy Act requires DOE to ensure that management and operating contractors "protect health and minimize danger to life or property." DOE implements this requirement through the nuclear safety clause in contracts and through DOE 5483.1A, "Occupational Safety and Health Program for DOE Contractor Employees at Government-Owned Contractor-Operated Facilities," which mandates application of standards comparable to those promulgated by the Occupational Safety and Health Administration (OSHA). Good practices are defined as those identified for OSHA's Voluntary Protection Program (VPP) and contained in 29 CFR 1910.119, "Process Safety Management," even where chemical quantities are below the requirements level.

b. Chemicals Involved: Bulk quantities of carbon tetrachloride, nitric acid, and hydrogen fluoride and small quantities of many other chemicals in bottles, pipes, and tanks.

c. Relevant Self-Evaluation Data: Sections 1.3, 2.7, 4.1, and 10.7, of EG\&G Rocky Flats, Inc., "Chemical Safety Vulnerability Field Self-Evaluation," dated March 30, 1994. Section 1.3 identifies the limited scope of hazards assessments and notes that only 10 assessments have been completed or are under way. Section 2.7 notes the dependency of the chemical tracking program on operations practice in priority quality input data. Section 4.1 notes the current limitations of the Operational Safety Analysis Program. Section 10.7 provides conclusions regarding Building 371 and the difference in treatment accorded to chemical incidents versus nuclear incidents.

d. Contributing Causes: Lack of resources applied to the problem, failure to put in place explicit support requirements for management of chemical safety issues, and a Plant Action Tracking System, which does not now collect or aggregate the many issues related to management of hazardous chemicals are all contributing causes. 
Site/Facility: Rocky Flats Plant

Vulnerability Number: CSVR-RFP-000-05

Functional Area(s): Operational Control and Management Systems;

3. Basis. (Continued)

e. Potential Consequences: Possible injuries or accidents during cleanout operations due to shortcomings in preplanning and mitigation efforts; lack of expert staff to cope efficiently with more severe, but lowprobability accidents, should one occur. Continued deficiency findings by auditors and inspectors. These conditions and circumstances represent a medium-priority vulnerability with a potential for medium-term consequences.

4. Supporting Observations.

- An integrated program is generally regarded as the preferred (i.e., most cost-effective) means of satisfying requirements for safe management of hazardous chemicals. Such a program is not now mandated by any policy, nor does the RFP policy manual explicitly embed safe management of hazardous chemicals as a key activity or priority in the many policy documents contained in the manual.

- A memorandum from G.P. Fraser to Distribution, titled "Lessons Leamed Document Corrections Excessing Chemicals in Building 865," dated October 8, 1993, distributed a lessons-leamed evaluation regarding chemical cleanout at Building 865 . Sitewide followup has not occurred, other than designation of a new individual with the mandate to develop an integrated management plan for chemicals at RFP. This latter activity is just getting under way and, at present, is being funded out of overhead work packages.

- An analysis was presented (see "Comprehensive Safety and Health Program," R. Cordova presentation, dated January 18,1994 ) on the difference between existing programs and those required for VPP status; no decision has been made to undertake those programs neecled to move to VPP status.

- Most sites fund industrial safety and industrial hygiene support out of overhead or as a direct charge for performing an activity. In such cases, the adequacy of prograrns relating to chemical safety can be managed by directing efforts at either the overhead account or the relevant direct account. A hybrid program is used at RFP. Moreover, building managers can unilaterally decide to issue "stop charging" orders without the involvement or concurrence of health and safety.

- Health and safety approval is required in "work in known areas of hazardous material contamination, but not otherwise explicitly required for handling or movement of hazardous chemical, or modification of existing systems/structures" (see "Maintenance Work Package Planning Process," Appendix 1, page 1). This limited scope of health and safety approvals can lead to actions that fail to meet requirements for safe handling of hazardous chemicals.

- More than 8 months have elapsed since a generic issue was identified as a result of Building 865 cleanout. Lack of treatment of chemical hazards and workers in the RFP Safety Analysis Reports has been a longstanding issue. 
ATTACHMENT 3

\section{SELECTED ACRONYMS}

CFR Code of Federal Regulations

DOE Department of Energy

D\&D Decontamination and Decommissioning

EH DOE Office of Environment, Safety and Health

OSHA Occupational Safety and Health Act (or Administration)

RCRA Resource Conservation and Recovery Act

RFP Rocky Flats Plant 


\title{
APPENDIX $\mathbf{J}$
}

\author{
FIELD VERIFICATION REPORT \\ BROOKHAVEN NATIONAL LABORATORY \\ MAY 16 - 23, 1994
}

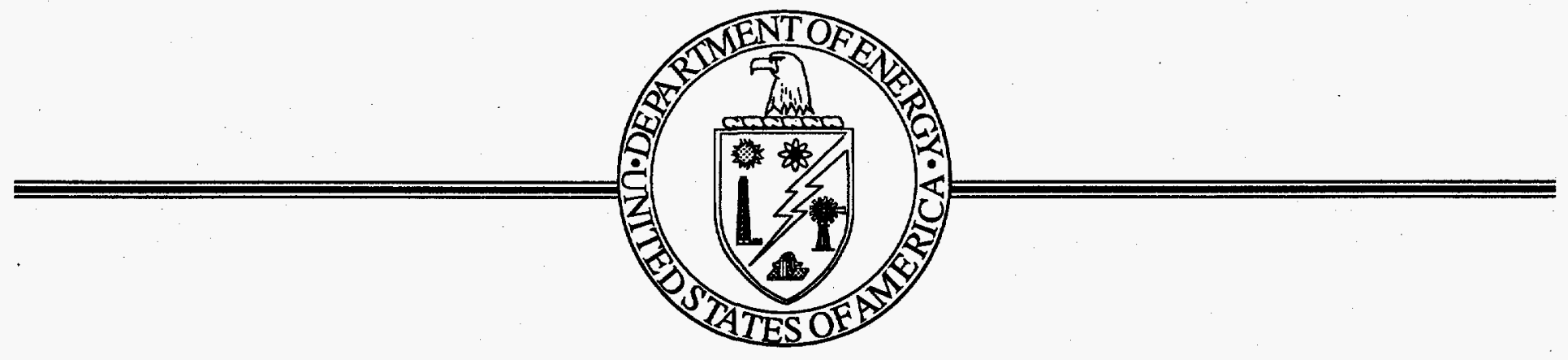





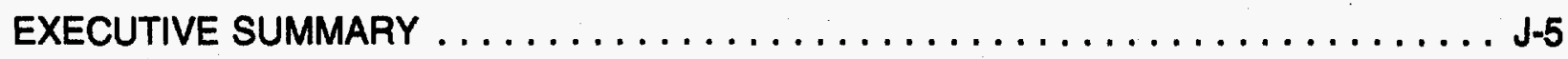

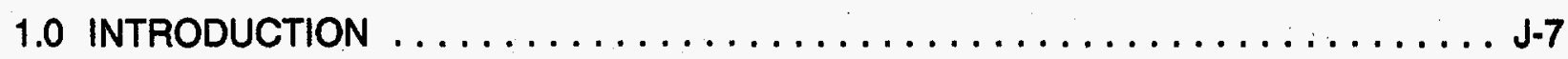

1.1 Purpose and Scope $\ldots \ldots \ldots \ldots \ldots \ldots \ldots \ldots \ldots \ldots \ldots \ldots \ldots .7$

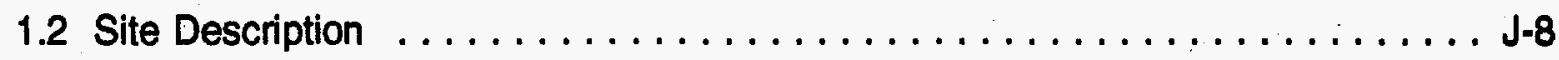

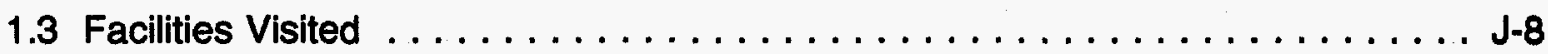

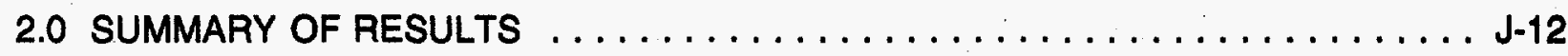

2.1 Identification of Chemical Holdings $\ldots \ldots \ldots \ldots \ldots \ldots \ldots \ldots \ldots . . \ldots \ldots$

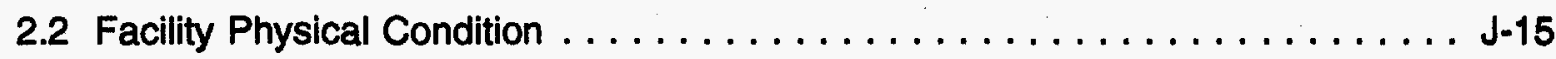

2.3 Operational Control and Management Systems $\ldots \ldots \ldots \ldots \ldots \ldots \ldots$ J-17

2.4 Human Resource Programs $\ldots \ldots \ldots \ldots \ldots \ldots \ldots \ldots \ldots \ldots \ldots . \ldots \ldots .18$

2.5 Emergency Management Program $\ldots \ldots \ldots \ldots \ldots \ldots \ldots \ldots \ldots \ldots$ J-20

3.0 CATEGORIZATION AND PRIORITIZATION OF VULNERABILITIES $\ldots \ldots \ldots \ldots$ J-23

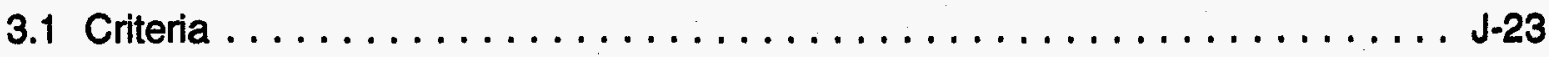

3.2 Chemical Safety Vulnerabilities at Brookhaven National Laboratory . . . . . . . J-24

\section{ATTACHMENTS}

ATTACHMENT 1. Team Composition $\ldots \ldots \ldots \ldots \ldots \ldots \ldots \ldots \ldots \ldots \ldots \ldots$ J-27

ATTACHMENT 2. Vulnerability Forms $\ldots \ldots \ldots \ldots \ldots \ldots \ldots \ldots \ldots \ldots \ldots$ J-29

ATTACHMENT 3. Selected Acronyms $\ldots \ldots \ldots \ldots \ldots \ldots \ldots \ldots \ldots \ldots \ldots$ J-43 


$$
\text { J-4 }
$$




\section{EXECUTIVE SUMMARY}

This report presents the results of a review of chemical safety vulnerabilities associated with facilities owned or operated by the Department of Energy (DOE) at the Brookhaven National Laboratory (BNL). The field verification review took place on May 16-23, 1994, and was part of the Chemical Safety Vulnerability Review being conducted by the Office of Environment, Safety and Health at the direction of the Secretary of Energy. The purpose of the review is to identify and characterize conditions or circumstances involving potentially hazardous chemicals at DOE sites and facilities-with emphasis on facilities being transitioned to, awaiting, or undergoing decontamination and decommissioning. Specifically, the review is designed to identify, characterize, and prioritize chemical safety vulnerabilities associated with conditions or circumstances that might result in (1) fires or explosions from uncontrolled chemical reactions, (2) exposure of workers or the public to chemicals, or (3) releases of chemicals to the environment. Activities involving hazardous chemicals at BNL are conducted in laboratories, process facilities, utilities, decontamination facilities, and waste treatment and storage facilities.

Field verification activities began with an analysis of the self-evaluation and visits to each facility examined in the self-evaluation. The self-evaluation included a review of a range of facilities, in addition to consideration of sitewide programs. The review was extended to additional facilities and interviews where further information was needed.

In all cases, the field verification review at BNL was conducted with a view toward identifying possible DOE-wide chemical safety vulnerabilities. Observations specific to individual operations or facilities were conveyed during the course of the site visit but were not considered further unless they appeared to be related to an issue that could be significant to a number of DOE sites. The effort did identify four issues that should be considered as part of the subsequent effort to identify DOE-wide chemical safety vulnerabilities. None of the conditions or circumstances identified requires immediate action to prevent severe consequences:

- Weaknesses in planning impede the effective elimination of hazards posed to workers and members of the public.

- Protracted implementation of core safety programs increases the potential for chemical safety vulnerabilities.

- Shortfalls in resources could lead to new chemical safety vulnerabilities and could impede the ability to resolve identified issues in a timely manner.

- Formal control measures have not been implemented to ensure that personnel who do not read or speak English understand the safety requirements and potential hazards associated with work in hazardous environments.

These vulnerabilities, along with those identified during field verifications at other DOE sites, will be evaluated to identify DOE-wide generic vulnerabilities. In addition, information from the Office of Environmental Management's Surplus Facilities Inventory Assessment and the extended review of facilities where there may be potential organic-nitrate vulnerabilities 
(similar to those at Tomsk-7) will also be considered for any additional insights into potential chemical safety vulnerabilities.

Commendable practices observed by the field verification team included an effective and simple system for controlling plant maintenance work, an individual initiative to include a nonEnglish speaking/reading clause in contracts, and the specific inclusion of chemicals in the safety analysis for the new Hazardous Waste Management Facility. These commendable practices, along with those observed at other sites, will be considered in developing the final report of the review of DOE operations. 


\subsection{INTRODUCTION}

\subsection{Purpose and Scope}

Based on direction from the Secretary of Energy, the Assistant Secretary for Environment, Safety and Health established the Chemical Safety Vulnerability Working Group to review and identify chemical safety vulnerabilities at facilities operated by the Department of Energy (DOE). The information obtained from the review will provide the Working Group with valuable input for identifying generic chemical safety vulnerabilities that confront the DOE complex. Prioritizing the chemical safety vulnerabilities that are identified will establish the proper basis for departmental focus on programs, funding, and policy decisions related to chemical safety. The Secretary directed the Office of Environment, Safety and Health to lead this review, with full participation from DOE line organizations having operational responsibilities.

The Chemical Safety Vulnerability Review was designed and undertaken to identify and characterize adverse conditions and circumstances involving potentially hazardous chemicals at facilities owned or operated by the Department. Specifically, the review was intended to identify, characterize, and prioritize chemical safety vulnerabilities associated with conditions or circumstances that might result in (1) fires or explosions from uncontrolled chemical reactions, (2) exposure of workers or the public to hazardous chemicals, or (3) release of hazardous chemicals to the environment. Using input provided by line organizations having operational responsibilities, the Working Group developed the "Project Plan for the Chemical Safety Vulnerability Review," dated March 14, 1994, to guide the review.

This report documents activities related to the field verification phase of the Chemical Safety Vulnerability Review. The field self-evaluation process used a standardized question set developed and distributed by the Working Group to collect data related to chemical safety from 84 facilities located at 29 sites. Based on analysis of self-evaluation data, nine large sites, including Brookhaven National Laboratory (BNL), and four small sites were selected to participate in the field verification phase of the review. The field verification process was designed to use independent teams of technical professionals with experience in a variety of technical disciplines to confirm the accuracy and completeness of the data compiled during the field self-evaluation phase of the review.

The field verification team visiting BNL examined a broad range of facilities (based on facility type and operational status), with special attention given to those facilities being transitioned to, awaiting, or undergoing decontamination and decommissioning. Different types of chemical- and waste-handling facilities were examined to permit identification of vulnerabilities arising from hazardous chemicals and wastes at the site. Facilities selected for review at BNL included the Hazardous Waste Management Facility (HWMF), the Wastewater Treatment Plant, the Personnel Decontamination Facility Hold-Up Tank, the Tandem Van de Graaff Accelerator, and the Central Water Treatment Plant. Facilities were selected for review based on (1) the types of chemical hazards known to exist at given facilities; (2) the need to review a cross-section of laboratory, process, chemical storage, waste handling, and utility facilities; and (3) the need to examine chemical hazards associated with facilities at different points in their life cycle (such as operating, on standby, shutdown, or abandoned) or under changing mission. 
The field verification team, under the direction of a DOE team leader, was composed of DOE and contractor personnel with technical expertise in various aspects of chemical safety, including management, operations, training, chemical process safety, industrial hygiene, maintenance, environmental protection, and emergency management. A team composition list is provided in Attachment 1 of this appendix.

The team began its review by visiting each of the facilities selected for self-evaluation. The team met with management or technical representatives from each of the facilities reviewed. Individual and small group meetings were also held, and team members conducted walkthroughs, document reviews, and personnel interviews to gather information related to potential chemical safety vulnerabilities at BNL. The team leader met daily with management personnel to discuss the team's activities and issues that may have surfaced during the previous day. Before the field verification team left BNL, management from local DOE and contractor organizations conducted a factual accuracy review of the draft report. An outbriefing was conducted on Monday, May 23, 1994. A draft copy of this report was left with DOE and contractor management.

\subsection{Site Description}

BNL is a multidisciplinary scientific research center located close to the geographical center of Suffolk County, New York, about 60 miles east of New York City (see Figure 1). The 5,620 -acre site is mostly wooded, except for a developed area (see Figure 2) of about 1,600 acres. BNL was established by the Manhattan Engineer District of the U.S. Army Corps of Engineers, with its primary purpose being to advance scientific research in areas of interest to universities, industry, and government.

The Laboratory carries out basic and applied research in high-energy nuclear and solid-state physics, fundamental material and structural properties and interactions of matter, nuclear medicine, biomedical and environmental sciences, and selected energy technologies.

\subsection{Facilities Visited}

Facilities reviewed at BNL included the three facilities that participated in the self-evaluation phase of the Chemical Safety Vulnerability Review. In addition, the Tandem Van de Graaff Accelerator was reviewed by the team to evaluate potential issues and for comparison of similar issues found at other sites. Since chlorine use is being reviewed as an issue of special concern, review efforts were extended to the water treatment facilities. The field verification team reviewed activities involving hazardous chemicals in the following facilities at BNL.

Hazardous Waste Management Facility: The HWMF supports operations of the Laboratory through the removal of wastes generated at the site. This complex is the principal area for handling, packaging, and storing Resource Conservation and Recovery Act hazardous waste and DOE radioactive waste material generated at BNL. Activities are located within a fenced area of about 12 acres in the southeastern corner of the site. Two buildings are used for storage of hazardous wastes (Buildings 444 and 446), with another designed specifically for the storage of wastes packaged in drums (Building 483). Flammable and reactive wastes are 


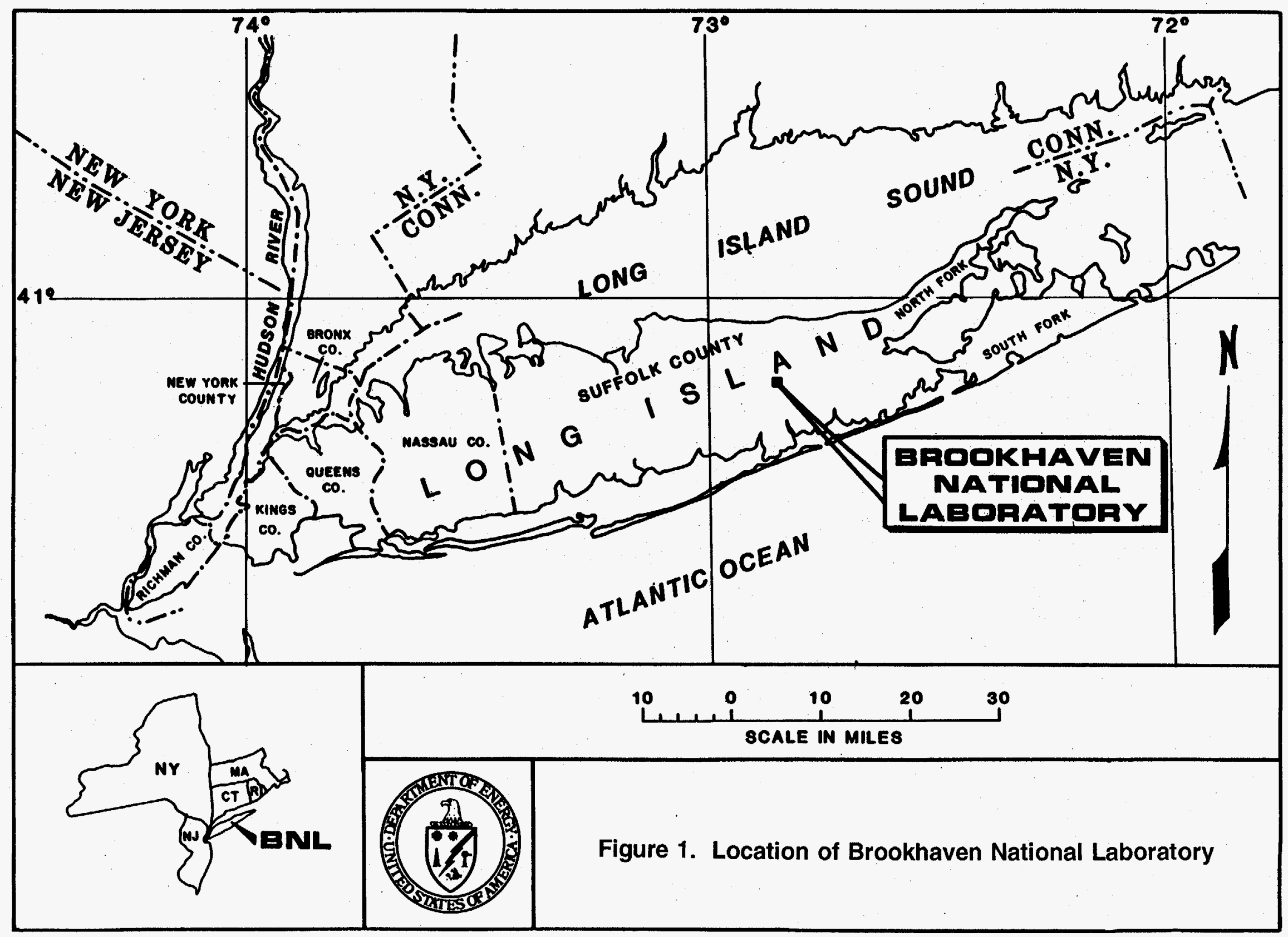




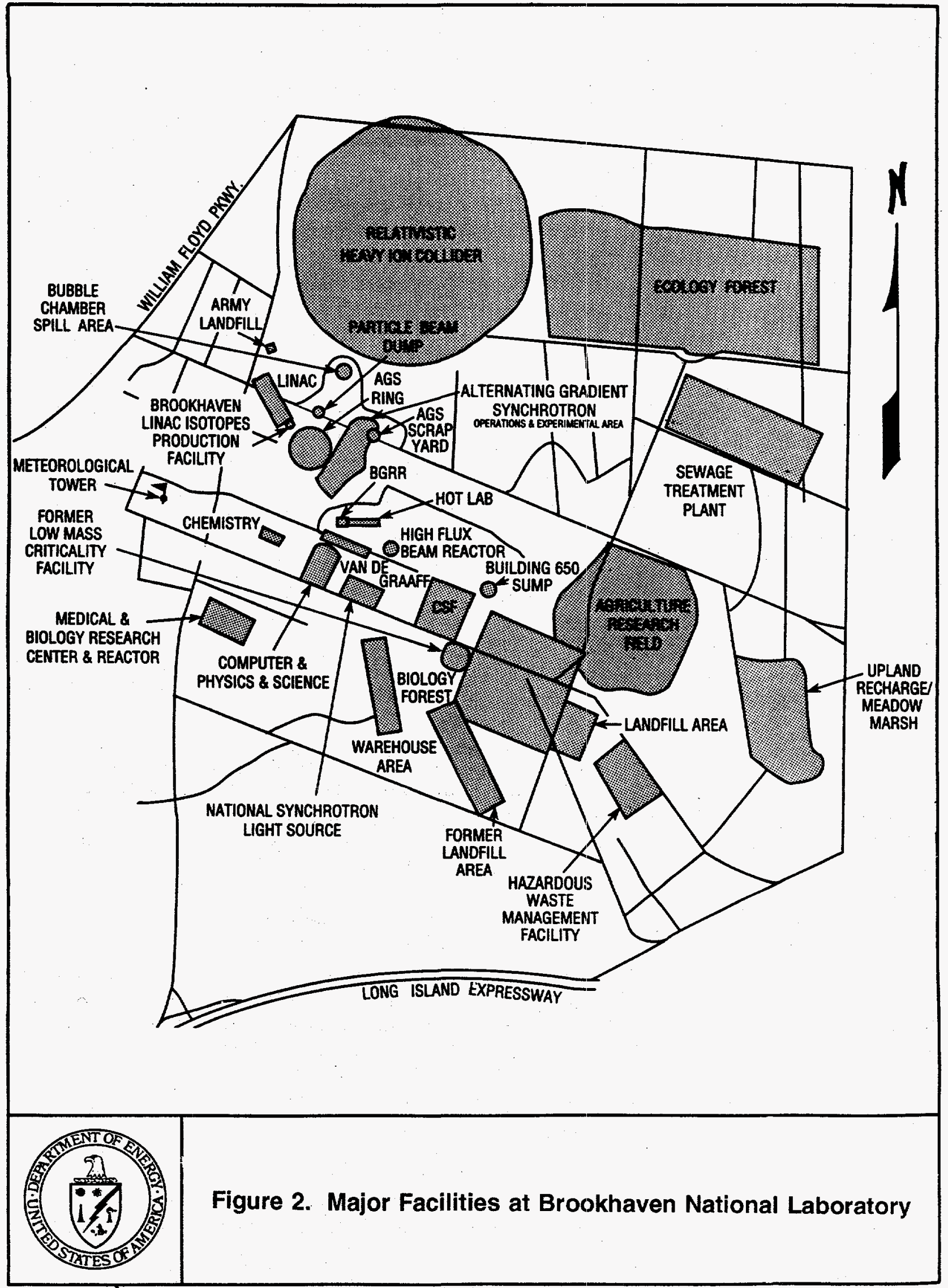


stored in three stand-alone "Haz-Stor" buildings (Buildings 360,361 , and 386). All HWMF buildings are used for the interim storage of hazardous wastes before packaging for offsite shipment.

With the exception of Building 483, most existing buildings were constructed between 1956 and 1966. Construction of a new HWMF is expected to begin in the near future. On completion of the new HWMF, the existing facility will be decommissioned. Initial characterization and remedial actions are being addressed by the BNL Office of Environmental Restoration.

Wastewater Treatment Facility: The sewage treatment facility is located northeast of the developed portion of the site. The purpose of this facility is to provide treatment of sanitary wastewater for protection of the environment and to meet regulatory discharge requirements.

Most of the sewage collection system was built by the U.S. Army in 1942. Treatment units at the facility include barminutors and grit chambers, prechlorination with sodium hypochlorite, a 250,000-gallon clarifier for primary clarification, and sand filtration by two of six sand filter beds with underlaid effluent collection. Subsequent discharge is to the headwaters of the Peconic River. Adjustment of $\mathrm{pH}$ is conducted by addition of lime to the sand filter beds. Average monthly sewage flow rates vary from 0.5 to 0.8 million gallons per day. Improved sewage collection and treatment is planned, funded, and initiated.

Inactive treatment equipment at the facility includes an Imhoff Tank, sludge-drying beds, and World War l-era sand filter beds. The Imhoff Tank was used for both wastewater clarification and sludge digestion. Sludge in slurry form was dried in the sludge-drying bed located near the Imhoff Tank. The old sand filter beds are overgrown with vegetation. Characterization of the entire wastewater treatment facility is being addressed by the BNL Office of Environmental Restoration.

Personnel Decontamination Facility Hold-Up Tank: The Personnel Decontamination Facility Hold-Up Tank (Tank 490-07) is a 550-gallon water collection tank, located below grade at the BNL Medical Research Center, Building 490. The purpose of this tank is to collect rinsewater generated as a result of emergency decontamination of patients. The tank has never been used, and plans are in place for its removal.

Tandem Van de Graaff Accelerator: The Tandem Van de Graaff Accelerator, operated by the Physics Department, has been in use since July 1970 and includes two Tandem Van de Graaff machines that can be used independently or in a coupled mode. The two machines are housed in a long building with a control room at its center, a mechanical equipment room containing water pumps and high-speed gas-handling equipment for pressurizing the accelerators with insulating gas, and various experimental stations in target rooms with a series of beam lines directed into them. Office and laboratory areas are adjacent to the experimental areas. Each accelerator has a capacity of 11,000 cubic feet of a mixture of nitrogen, carbon dioxide, and sulfur hexafluoride insulating gas at a pressure of 12-15 atmospheres.

Central Water Treatment Plant: The Central Water Treatment Plant was built in March 1964 to reduce the high natural concentration of carbon dioxide, iron, and low $\mathrm{pH}$ of groundwater in 
this area. The plant was designed to provide up to 4,500 gallons per minute of treated water. This plant is located on the western side of the developed site. Treatment consists of aeration, lime neutralization, coagulation, and filtration. Ten 150-pound cylinders contain the chlorine gas used for water disinfection. The original plant was renovated in 1986 and new filters were installed; however, the chlorine addition system was not renovated.

\subsection{SUMMARY OF RESULTS}

Field verification is one phase in the process of arriving at a conclusion regarding the existence and significance of chemical safety vulnerabilities across the DOE complex. The field verification process was designed to use independent teams of safety professionals to confirm the accuracy and completeness of the data provided to the Chemical Safety Vulnerability Working Group by BNL for facilities selected to participate in the field selfevaluation process. The verification process offered an opportunity to examine site-specific chemical safety vulnerabilities and to make informed judgments about the relevance of these conditions as they relate to determinations of generic chemical safety vulnerabilities.

The goal of the field verification team was to identify and prioritize chemical safety vulnerabilities at BNL. Before arriving on site, the team reviewed the self-evaluation data and other documents to allow team members to develop a list of observations related to potential vulnerabilities for their functional area. During the onsite portion of the review, team members visited the facilities that participated in the self-evaluation to confirm reported observations and to look for other conditions and circumstances that could result in chemical safety vulnerabilities. In some instances, facilities or areas that were not involved in the original selfevaluation (i.e., Tandem Van de Graaff Accelerator and Central Water Treatment Plant) were reviewed and have provided valuable additional information.

To support effective team management and to expedite the identification of vulnerabilities across a wide range of technical disciplines associated with chemical safety, each field verification review has been organized to include five functional areas:

- Identification of chemical holdings, including the properties of chemicals located at the facility, the characterization of those chemicals, and an analysis of the inventory.

- Facility physical condition, including engineered barriers, maintenance conditions, chemical systems, safety systems, storage, monitoring systems, and hazards identification.

- Operational control and management systems, including organizational structure; requirements identification; hazard analysis; procedural adherence; maintenance control; engineering and design reviews; configuration control; safe shutdown plans; and site programs for quality assurance, chemical safety, inventory control, access control, disposal, transportation and packaging, and corrective actions.

- Human resource programs, including technical competence, staffing, training and qualifications, employee involvement, employee concerns, personnel performance requirements, and visitor and subcontractor control. 
- Emergency management program, including the emergency plan, inplant consequences, environmental issues, coordination with the community, and community right-to-know issues.

These functional areas were evaluated on the basis of lines of inquiry provided in Attachment 1 of the "Field Verification Guide for the Chemical Safety Vulnerability Review," dated April 8, 1994. Verification of the self-evaluation data was accomplished by walkthrough of facilities, conduct of interviews with management and technical personnel, examination of facility and site documentation, and review of incident reports and other documents.

The self-evaluation report for BNL appeared to paint too optimistic a picture of the status of programs used to control hazardous chemicals. It did not identify existing weaknesses and only provided a hint of plans for improvement. To a large extent, the field verification team confirmed the existence of vulnerabilities at BNL that had been identified at other sites, even where those vulnerabilities had not been identified in the BNL self-evaluation. The team's identification of generic chemical safety vulnerabilities attempted to emphasize those issues that appeared to have DOE-wide implications.

Summaries of the functional areas are provided in the sections below. Completed chemical safety vulnerability forms resulting from the field verification activities at BNL are provided in Attachment 2 of this appendix.

\subsection{Identification of Chemical Holdings}

Three facilities were reviewed at BNL from a chemical inventory standpoint: the Tandem Van de Graaff Accelerator (Building 901A), the Central Water Treatment Plant (Building 624), and HWMF (primarily Buildings 444 and 446 ). Information relevant to chemical process safety was obtained through facility inspections; interviews with operating staff; reviews of facility safety and operating policies, procedures, and logs; and drawing and independent review documents relating to the facilities.

The Tandem Van de Graaff Accelerator facility has the proper safety systems in place to ensure that the insulating gas ( 41,000 pounds as of May 1994, composed of 45 percent sulfur hexafluoride, 45 percent nitrogen, 5 percent carbon dioxide, and 5 percent oxygen) does not present an asphyxiation risk to the operators. The pure sulfur hexafluoride $(28,000$ pounds as of May 1994), which is used on an as-needed replenishment basis, is contained in an underground bank of 39 "excessed" helium storage cylinders. The manifold system for distributing this gas is in a remotely located building. The insulating gas system pressure is monitored continuously and the system will lose 2-3 percent of the active inventory annually during normal operations. This release is readily accommodated by the building ventilation system; most of the loss goes into the central vacuum system (beam area) and is exhausted directly outside. Examination of the internal components of the accelerator shows that the primary containment barrier has incurred no physical degradation. Alarms are installed to ensure sufficient levels of oxygen are present and to detect the presence of sulfur hexafluoride in the operating areas. Three storage cabinets contain solid compounds of 58 elements (mainly metal salts). The content in any one container is below the Laboratory-wide reporting system threshold, but these materials were included on a list provided by the facility staff. This facility has its own configuration management system, an effective computerized 
preventive maintenance control scheme for experimental equipment and safety-related systems, and a captive operating staff. The safety analysis document used as a basis for interim operation addresses the requirements in DOE 5480.25, "Safety of Accelerator Facilities," and has been submitted to the Brookhaven Area Office for approval. The equipment has been maintained in good operating condition (the facility has been in operation for almost 25 years), procedures are in place, operating logs are kept, and it is apparent that the management and operating personnel in this area take pride in the safety and quality record that they have achieved. There were no conditions identified in this facility that would lead to a chemical safety vulnerability.

The Central Water Treatment Plant has an isolated room, with its own outside entrance, which contains up to 10 chlorine cylinders (up to 1,500 pounds total chlorine is permitted and this limit is administratively controlled). The quantity of chlorine in the active cylinder bank is recorded each workday and is based on weight differentials. The high-chlorine alarm signal is fed into the control room and was demonstrated to be operational. The potential exists for exposure of employees to chlorine because procedures for handling chlorine were not available in the room where the active cylinder bank is installed. The team noted a distinct chlorine odor during the initial visit, but the odor was not noticeable during return visits (see Vulnerability CSVR-BNL-000-03). The development of the draft Chlorine Handling Procedure indicates that BNL is taking steps to alleviate problems associated with the lack of procedures. Some operating procedures were on file in the operating room, but most of the actual job performance is based on operator proficiency. This facility does not differ from ordinary municipal water treatment installations, so it is exempt from requirements in DOE 5481.1B. No hazardous wastes are generated by this facility.

The accumulation, storage, packaging, and eventual offsite shipment of Laboratory-generated hazardous wastes are performed at the HWMF. At the time of the Chemical Safety Vulnerability Review, approximately 215,000 pounds of hazardous chemicals and wastes were stored in this facility. This varied from 114,000 pounds of "evaporator bottoms" (less than 3 percent is actual radioactive contaminated residues; the rest is concrete/vermiculite encasement) to gram quantities of "acutely hazardous" (such as cyanide) materials. The hazardous materials are logged in on BNL Form 2568, "Hazardous Materials Waste Control Form (Nonradioactive)," and assigned a serial number by HWMF personnel. The inventory is controlled (the team was provided with specific as well as overall inventory data on request) while the material is within the facility fence. A sitewide program for handling or recycling unused chemicals does not exist. Storage conditions range from unprotected to sheltered with heat, depending on waste sensitivity to environmental conditions. Material degradation was evident, especially on cylinders that contain unknown gases and are stored outside. The facilities are old, and construction of a new facility is scheduled to begin in August 1994, with completion projected for calendar year 1996 or later. A preliminary hazard assessment was conducted for this facility in January 1994. The Implementation Plan for the Basis for Interim Operation document was rejected by the Brookhaven Area Office; a second version is scheduled to be submitted in May 1994. BNL workers are unnecessarily exposed to hazardous chemicals because such materials are treated as waste instead of being recycled; the requirement that some packages be opened and repackaged based on after-the-fact changes in shipping criteria; and the potential for repackaging due to repository or governmental policy shifts at other DOE facilities. (See Vulnerability CSVR-BNL-000-01.) 
In summary, potential chemical safety vulnerabilities related to chlorine handling in various water treatment processes (see Vulnerability CSVR-BNL-000-01) and in processing hazardous wastes (see Vulnerability CSVR-BNL-000-01) exist at BNL. This chlorine-handling vulnerability could also affect the public.

\subsection{Facility Physical Condition}

The field verification review included a detailed walkdown of the Tandem Van de Graaff Accelerator (Building 901A), Central Water Treatment Plant (Building 624), Wastewater Treatment Facility (Buildings 575 and 579), and HWMF (Buildings 444 and 446) to gain an understanding of the physical condition of the structures, process equipment, utilities, and primary and secondary containment systems and to confirm data contained in the self-evaluation report. First-line maintenance supervisors, design engineering personnel, and maintenance management personnel were interviewed to determine the overall physical condition of the facilities and the quality of BNL maintenance programs.

At present, the mechanical integrity of the primary and secondary containment systems and equipment appears to be generally satisfactory for the facilities included in the field verification at BNL. However, maintenance and manpower budgets have remained essentially constant for the past 4 years in spite of a deteriorating physical infrastructure and new environment, safety, and health (ES\&H) needs. There is no direct relationship between the physical condition of a facility and the preventive maintenance budget for that facility. Examples include the HWMF (Building 483), where the safety shower was inoperable; the waste incinerator (Building 444), where electrical repairs are incomplete; and the diesel fuel tank (Building 446), which is not equipped with secondary containment. There is no formal preventive maintenance budget for the HWMF. Sitewide, the preventive maintenance program has about 2,730 open work orders from the average 8,400 done each year. In addition, the corrective maintenance program is by its very nature reactive and, at present, has about 1,970 open work orders from the average 10,500 done each year. Enhancement of the existing sitewide predictive maintenance program using techniques to indicate the need for preventive maintenance before equipment fails would provide additional protection against failures that could lead to incidents involving hazardous chemicals. There is no formal sitewide pressure vessel or piping inspection program using ultrasonic or radiographic test methods to monitor system deterioration. With the exceptions of thermography of high-voltage electrical power lines, transformer oil testing, and vibration analysis at the Central Steam Plant and Central Chilled Water Plant, the predictive maintenance program at BNL is not consistent with generally accepted industrial practices.

The BNL Operations and Maintenance Manual provides a standard for developing and implementing maintenance management programs using a graded approach as provided for in DOE 4330.4A. However, under the terms of the BNL standards, many provisions of DOE 4330.4A have been identified as not applicable for BNL facilities. BNL did not prepare an annual site maintenance plan, as defined in DOE $4330.4 \mathrm{~A}$, in fiscal year (FY) 93 (nor was one requested by the Chicago Operations Office). In FY 92, the annual work plan document was used as the site maintenance plan per instructions from the Chicago Operations Office. Maintenance implementation plans, as defined in DOE $4330.4 \mathrm{~A}$, have been prepared for the two BNL reactors. The two recently identified nonreactor nuclear facilities, which include the HWMF, have not yet prepared maintenance implementation plans but have committed to do 
so in FY 94. Annual budget preparation for routine preventive and corrective maintenance is based largely on the previous year's budget, adjusted for inflation and for new, known, recurring maintenance requirements. Major maintenance projects are identified and performed on a priority basis. The annual work plan, an outline document requested by the Chicago Operations Office, governs the preventive and corrective maintenance budget for FY 92 through FY 98 . No annual update has been requested or furnished since FY 92 . A less-than-adequate maintenance planning and budgeting process, in conjunction with a fixed maintenance staff level and an expanding inventory of facilities, has resulted in a deteriorating facility physical condition. Innovative approaches to conducting routine maintenance have permitted maintenance personnel to work smarter and have forestalled more rapid facility deterioration.

A computer-based program, the Maintenance Control Reporting System, is used to develop comprehensive work packages for routine corrective and preventive maintenance. This system provides computer-generated work procedures, maintenance work orders, replacement-part serial numbers, warehouse inventory information for over 10,000 consumable replacement parts, and cost-accounting information relating to the specific work orders. The creation and use of this program for routine maintenance work control by Plant Engineering Division is considered a commendable practice.

To promote the safety of maintenance and engineering personnel while work is performed, engineered design safeguards are included in facility design, modification, and maintenance packages. The Plant Engineering Division has developed the computer-based Key Plan to provide a visual display of each structure at BNL and to indicate where safety instructions are mandatory when preparing corrective or preventive maintenance packages. To provide further assistance, Plant Engineering Division personnel have also developed and maintain a computer-based visual display that generates detailed illustrations of site physical structures, utilities (electrical, water, steam, and sewers), environmentally sensitive areas, and topographic features. Routine inspections of selected facilities are conducted, backflow controllers and pressure-relief devices are tested, and piping identification is verified. For example, mechanical equipment rooms are inspected at 6-month intervals for various items, including pipe labels; the 500 backflow control devices on site are formally tested every year and rebuilt or replaced every 5 years; pressure-relief valves at the steam plant are rebuilt, calibrated, and tested on a formal schedule every 3 years; and air compressor pressure-relief valves are maintained on a yearly schedule. Health and safety personnel interface with engineering design personnel during the project review and approval process.

Chlorine gas is used at the Central Water Treatment Plant (Building 624) and at six potable water supply wells for iron content reduction and for biological control. Ten 150-pound cylinders are manifolded to a pressurized chlorine gas header operating at 80 pounds per square inch upstream of the pressure regulator. Brass fittings on the chlorine gas manifold at Building 624 were corroded; indications of a leak were observed immediately downstream of the pressure regulator; and a distinct odor of chlorine was detected in the chlorinator room during the familiarization tour (see Vulnerability CVSR-BNL-000-01). 


\subsection{Operational Control and Management Systems}

The facilities selected for this review pose low hazards relative to other industrial and research operations at BNL and elsewhere. The operational control and management systems applied to the selected facilities are not inconsistent with the present operations.

BNL has recently put in place an array of policies and procedures, many of which are related to safe management of hazardous materials. The ES\&H Management Plan has set forth a blueprint for the kind of programs that should be put in place at the site and includes a variety of activity data sheets summarizing possible areas of improvement. The overall chemical safety program will be greatly enhanced if these improvements are completely and correctly implemented.

The self-evaluation document provided a summary of important operational control and management systems at the site. The field verification team had the opportunity to review numerous documents regarding sitewide operational control and management systems, to discuss actual practices with site staff, and to observe conditions at the facilities selected for review.

As clearly set forth in the ES\&H standards and other key site documents, most safety-related work at BNL is organized according to a graded approach to safety. Numerous documents require that the level of quality and formality for safety analysis and equipment be determined through an analysis of the risks posed by prospective operations. The standards and manuals go further and provide helpful details on how to actually implement a graded approach. BNL-O\&M-I-010, Operations and Maintenance Manual delegates responsibility "for establishing the Laboratory's conduct of operations, and maintenance management, and for the administration of these programs" to the Associate Director for Management and Physical Plant. Associate and Assistant Directors are responsible "for ensuring that the conduct of operations policies are supported and implemented in the programs under their jurisdiction. Cognizant Associate and Assistant Directors shall approve Conduct of Operations Conformance Matrices prepared by departments and divisions with their line of authority." Finally, "Department Chairpersons and Division Heads are directly responsible for implementing conduct of operations programs. They shall ensure that departmental and division facilities and activities comply with the conduct of operations requirements based on a graded approach that considers the risks involved with the activity." Note that supervisors are responsible only for acting in accordance with the "general conduct of operations principles."

Under the basic systems that control work involving hazardous chemicals at the site, the fundamental decisions on the level of operational controls to be applied to each operation are made by various line management organizations. As noted in Section 2.2, sitewide maintenance programs are carried out under overhead work orders. Work orders properly identify the basic safety precautions for work by crafts personnel in possibly hazardous areas (e.g., reactive chemical management). The effectiveness of this system depends on (1) the ability of the line to identify and secure support for its changing resource needs and (2) the willingness of senior management to fund sitewide and overhead programs necessary for progress in safe management of hazardous chemicals. 
BNL policies do not appear to provide for a separate vision regarding the need for engineered barriers in the management of hazardous chemicals, nor do the various manuals and standards explicitly embed strong administrative controls over hazardous chemicals as a key activity or priority. Resources allocated to date have not resulted in consistent or fully implemented controls over hazardous chemicals at all facilities. Clearly, providing employees with stronger controls over possible hazards encountered when working with chemicals will improve the occupational health program. Weaknesses involving management support and emphasis have been considered as vulnerabilities at other sites.

As a related matter, BNL has initiated an evaluation of the difference between existing programs and those required for the Occupational Safety and Health Administration Voluntary Protection Program status. If a commitment is made to move to such a program, a number of changes will have to be made to provide stronger operational controls over hazardous chemicals.

The current hazard analysis methodology is evolving with regard to chemical hazards. However, the accuracy and usefulness of the hazard analysis process is strongly dependent on the accuracy and thoroughness in identifying potential hazards in the workplace (e.g., in room locations, types, and conditions of chemical in each process and room). The selfevaluation did not identify any weaknesses in this area.

The hazard analysis methodology employed in the existing HWMF appears to be fairly superficial, and a decision has been made (reflected in a formal "basis for interim operation") to forgo further analysis pending shutdown of the facility in 1996. A more complete document, a preliminary safety analysis report, is being prepared for replacing the HWMF and contains an analysis of hazards posed by chemical operations in the new facility. The team noted that vulnerabilities are created by a less-than-adequate characterization of processes involving hazardous chemicals (see Vulnerability CSVR-BNL-001-01). As discussed in Section 2.1, the successful use of hazard analysis is directly related to the accuracy and completeness of the chemical inventory.

Each of these observations is traceable, in part, to the difficult circumstances that arise when new requirements and directions are issued during a period of limited and possibly declining budgets. The fundamental structure of placing most of the Safety and Environmental Protection Division costs in an overhead account, together with a well-publicized effort to constrain growth in the overhead account, appears to create a potential for built-in conflict between research mission and excellence in ES\&H.

The team's review of existing and planned ES\&H programs and budgets resulted in a general conclusion that weaknesses, if left unchecked, will turn into new or more severe chemical safety vulnerabilities. This was identified as a vulnerability for further consideration as a DOE-wide concern. Vulnerability CVSR-BNL-000-03 was identified as a medium-priority vulnerability that could result in short-term consequences.

\subsection{Human Resource Programs}

Verification activities associated with the human resource programs functional area focused on training and qualifications, technical competence, employee involvement, staffing, employee 
concerns, and visitor and subcontractor control. Discussions related to human resource programs were held with BNL management, training, and operations personnel. BNL policy documents related to chemical safety programs were also reviewed. Procedures and documents were examined to review the strategy used to implement policies. During the course of these activities, one chemical safety vulnerability was identified concerning the protracted period over which core safety programs are implemented (see Vulnerability CSVR-BNL-000-02).

The Tandem Van de Graaff Accelerator (Building 901A), the Central Water Treatment Plant (Building 624), and the HWMF (primarily Buildings 444 and 446) were visited. Personnel assigned to these facilities were interviewed to determine the effectiveness of the implementation of human resources programs relative to chemical safety in the workplace.

BNL promotes worker awareness of safety issues related to chemicals. Chemical hazard information is communicated to employees in many ways. In addition to formal training, facility-specific safety briefings are provided for all personnel entering certain facilities. The BNL Training Policy has been approved; however, the lower tier program-implementing documents are incomplete and lack the rigor associated with a formal training program. A training manual addressing this issue is in the early stages of development.

With three exceptions, staff levels in areas related to chemical safety were found to be sufficient to ensure that personnel are not working excessive hours and have sufficient time to address chemical safety issues. At HWMF, operations personnel have been working an average of 46 hours per week for the past 6 weeks. This fact has been noted by BNL management, and several additional HWMF operations positions are in the process of being approved. In the Occupational Safety and Health Training Department, personnel have been working an average of 55 hours per week for the past 6 months. Action has not been taken by BNL management to address this resource variance. The ratio of full-time equivalent training personnel to total staff at BNL is much less than that of many other DOE facilities.

In addition, although a variety of health and safety professionals are available to support operating facilities (with sufficient resources generally available to oversee routine chemical activities and provide technical assistance), adequate industrial hygiene and occupational safety resources are not available to provide infrastructure and programmatic support (see Vulnerability CSVR-BNL-000-03).

The team found that BNL first-level management has been addressing employee concerns effectively. BNL has implemented a formal program to address these concerns. The program is independent of the line organization. Employees regard the program as effective and useful, although it is more appropriate for personnel-oriented issues than safety-related issues. The formal BNL program is administered by the Employee Relations Committee, which ensures confidentiality of the program and provides activity reports to the director. This program is supplemented by the DOE Occupational Safety and Health (OS\&H) Protection Program.

The BNL Self-Assessment Program has been established to determine the adequacy of efforts in achieving ES\&H goals. The program uses multitiered approach involving appraisals and multiple levels of self-assessment. The Office of Planning and Program Review coordinates 
self-assessments of the adherence to BNL policies, procedures, and requirements. The Laboratory ES\&H Management Advisory Committee oversees the process and provides an annual report to the director. Implementation of the program is lagging; the results of selfassessments are not shared with affected personnel; the 1992-93 Tier II Self-Assessment Report and the 1993 Annual Self-Assessment Report have not been published (draft reports have been shared with management); and personnel have not received training prior to performing self-assessments.

The prescription of training for an individual is the responsibility of the individual, his or her immediate supervisor, and management of the facility or program in which the individual is employed. Each supervisor is responsible to ensure that the individual receives the requisite training of his or her respective organization. Safety training requirements, the emphasis placed on the completion of training, and the accuracy and retention of records vary greatly between organizations. BNL is working to implement a centralized training data base, which should improve recordkeeping.

The communication required to establish and maintain a cohesive and effective safety training function in the BNL organization is extensive. At some facilities, communications regarding work assignments, job location, and required safety training do not ensure that all BNL personnel and visitors are receiving proper safety training before being granted unescorted access.

A fence does not surround the entire BNL perimeter, nor is there a perimeter patrol road. General access to the BNL site is through monitored entry points. Perimeter access control is consistent with the level of chemical hazards and other potential threats. Once an individual is inside the perimeter, entry into some facilities is uncontrolled. Personnel assigned to BNL facilities are encouraged to supplement access control by challenging all unknown personnel in the facility.

The effort of one construction safety engineer to address the issue of safety and hazard awareness for subcontractor personnel who do not read or speak English was recognized as a commendable practice. Contract specifications to address this issue have not been institutionalized and no formal control measures (such as testing) have been established to verify comprehension of chemical safety requirements and hazards by non-English speakers. This is considered to be a chemical safety vulnerability (see Vulnerability CSVR-BNL-000-04).

A potential exists for a chemical safety vulnerability at BNL due to the protracted period over which core safety programs are implemented. These programs include mandated ES\&H training programs, hazards analysis programs, emergency preparedness, and a complete integrated sitewide chemical inventory system (see Vulnerabilities CSVR-BNL-000-01 and CSVR-BNL-000-02).

\subsection{Emergency Management Program}

The emergency management program for BNL has been in place for many years and continues to evolve as new needs are identified and new requirements are imposed. The sitewide and facility-specific emergency plans were not originally developed with a view toward mitigating potential releases of hazardous chemicals but focused predominantly on 
radiological and nuclear criticality issues, with hazardous chemical issues receiving less emphasis. This review evaluated the existing documentation and capabilities with a specific focus on chemical safety vulnerabilities. This approach included review of emergency plans and procedures, review of other related documents and inspection records, conduct of walkthroughs of various facilities, review of emergency response facilities and equipment, and conduct of interviews with numerous individuals representing all facets of the emergency preparedness program.

BNL has developed a sitewide emergency plan, augmented by individual facility-specific local emergency plans for significant site facilities. The sitewide emergency plan addresses multiple types of events, including chemical hazards events, radiological and criticality events, natural phenomena, severe-weather events, and security events. These plans do consider a range of real and potential hazards, including chemical hazards; however, they were not developed using the results of a mature hazards identification and analysis program because that program is not complete. Completion of the hazards identification and analysis program is planned for December 1994, if adequately funded. In addition to the broad-based plans, topic-specific plans have been developed where necessary (e.g., for oil spills and hazardous materials).

Coordination with offsite authorities and organizations is implemented primarily through interaction with, and participation on, the Suffolk County Local Emergency Planning Committee. BNL has the only fire department in Suffolk County composed entirely of full-time, paid personnel. The fire department participates in the county-wide mutual-aid agreement, which includes over 100 other fire and emergency services organizations. Members of the BNL fire/rescue department are highly trained and appear fully qualified to perform the full range of emergency response duties they may be called upon to perform. In fact, BNL provides fire/rescue personnel and equipment as a significant resource for assistance throughout Suffolk County, including response to offsite hazardous materials incidents.

BNL does not have a formal program for performance-based, position-specific training for other members of its emergency response organization. Instead, BNL relies on individual employees to read those emergency response procedures for which they are responsible; to attend procedure briefings when new procedures are issued; and to participate in drills and exercises. This approach has been identified as a weakness on a number of occasions, most recently during a January 1994 appraisal by the Chicago Operations Office; however, as of this time BNL has not changed its training process.

The BNL Emergency Plan does not appear to recognize "sheltering in place" as an effective protective action, especially for hazardous-chemical events. Evacuation of personnel is the only protective action discussed. Hazardous-chemical events are characterized by little or no warning before the actual release, and by the fact that physical contact with the released material is the only means of receiving a dose. Therefore, evacuation could actually expose site personnel to the hazard. On the other hand, sheltering is very effective for short periods of time to prevent or significantly reduce exposures to hazards not involving direct radiation.

Another weakness of the BNL Emergency Plan is the implicit assumption that there are no events with consequences that would involve the offsite public. Although the notification of offsite authorities is addressed in the sitewide emergency plan, the supporting safety 
assessments do not address potential public impacts, which necessitate special planning. For example, the BNL document providing a basis for interim operations of the HWMF concludes that "no significant off-site release or consequences would result from a postulated major chemical spill." Even if this were true, a more proactive treatment of this issue, including explicit provisions to cope with possible offsite impacts, would demonstrate the Department's full commitment to protection of the public and the environment.

Facilities and equipment necessary for response to hazardous-materials incidents were generally available but varied from facility to facility. During facility walkdowns, the team noted the general availability of eyewash stations, emergency showers, and personnel protective equipment in most locations where such equipment may be needed. Within the last few months, BNL has received two new fire trucks with 1,500 gallon-per-minute pumpers, the specifications and equipment loadings of which were developed by BNL firefighters. In addition, BNL has an initial response hazardous-materials vehicle that is equipped to support initial response operations up through and including Class A chemical suits. A more extensively equipped trailer for hazardous-material incident response is also available and would be brought to the scene of the incident by the BNL Utilities organization.

BNL is in the process of moving the Emergency Operations Facility (EOF) from a nondedicated facility on the second story of the Police Group Headquarters, Building 50, to a dedicated bunker-type facility, Building 754. For hazardous-materials emergency consequence assessment, BNL uses EPIcodeß, Version 4.1. BNL has an upgraded meteorological tower and other provisions for acquiring real-time meteorological data, including the colocation onsite of the Next Generation Radar (NEXRAD) Facility of the National Weather Service/National Oceanographic and Atrnospheric Administration.

Exercises and drills are part of the emergency preparedness program and were addressed in the sitewide emergency plan. Some offsite authorities and response organizations are afforded the opportunity to participate in drills and exercises.

In summary, the overall state of emergency preparedness at BNL has not resulted in identification of a significant chemical safety vulnerability from the limited standpoint of this review. However, the thoroughness and rigor applied to emergency planning and the level of maturity of the emergency preparedness program vary considerably from facility to facility, with the overall program considered marginal. The BNL emergency preparedness program was the subject of a detailed review by the Chicago Operations Office during January 18-28, 1994. The basic findings of that review were confirmed by the field verification team, and additional weaknesses were identified for consideration by BNL. It should be noted that a significant number of new and/or revised standard operating procedures for the emergency plan have been implemented over the past few years and that a number of necessary (significant) improvements in the overall emergency preparedness program are scheduled for completion by the end of December 1994. 


\subsection{CATEGORIZATION AND PRIORITIZATION OF VULNERABILITIES}

\subsection{Criteria}

A vulnerability is a weakness or potential weakness involving hazardous chemicals that could result in a threat to the environment, the public, or worker health and safety. Vulnerabilities can be characterized by physical or programmatic conditions associated with uncertainties, acknowledged deficiencies, and/or unacknowledged deficiencies in the area of chemical safety. Conditions required to create the vulnerability should either currently exist or be reasonably expected to exist in the future, based on degradation of systems and chemicals or through expected actions (e.g., D\&D of facility).

A vulnerability will be determined to exist if current or expected future conditions or weaknesses could result in either of the following:

- The death of or serious physical harm ${ }^{1}$ to a worker or a member of the public or continuous exposure of a worker or member of the public to levels of hazardous chemicals above hazardous limits; or

- Environmental impacts resulting from the release of hazardous chemical above established limits.

The prioritization of the chemical safety vulnerabilities is based on professional judgment of team members concerning the immediacy of the potential consequences posed by each vulnerability and on the potential severity of those consequences. The first step in the prioritization process was to group vulnerabilities according to the timeframe in which they are expected to produce consequences. The following categories are defined for the timeframe within which the consequences are expected to occur:

- Immediate - Any chemical safety vulnerability that could result in immediate consequences.

- Short-Term - Any chemical safety vulnerability at a facility in which there is a significant chance of a consequence occurring within a 3-year timeframe as a result of chemical degradation, change in mission for the facility, degradation of the containment systems, change in personnel at the facility, or other factors affecting the facility.

- Medium-Term - Any chemical safety vulnerability at a facility in which there is a significant chance of a consequence occurring within a 3-10-year timeframe as a result of chemical degradation, change in mission for the facility, degradation of the containment systems, change in personnel at the facility, or other factors affecting the facility.

\footnotetext{
${ }^{1}$ Serious physical harm is defined as impairment of the body, leaving part of the body functionally useless or substantially reducing efficiency on or off the job.
} 
- Long-Term - Any chemical safety vulnerability at a facility in which there is a significant chance of a consequence occurring within a timeframe of more than 10 years as a result of chemical degradation, change in mission for the facility, degradation of the containment systems, change in personnel at the facility, or other factors affecting the facility.

Vulnerabilities within each category should be further prioritized to specify "high," "medium," or "low" priority based on the severity of the potential consequences. Examples of the second level of prioritization include the following:

- Prioritize potential harm to workers or the public according to the possible level of injury and/or health effect, ranging from transient reversible illness or injury to death.

- Prioritize environmental impacts based on the level of irreversible damage and/or restoration costs.

\subsection{Chemical Safety Vulnerabilities at Brookhaven National Laboratory}

Four vulnerabilities were identified during the conduct of this review. Each is related to vulnerabilities identified in other reviews and is identified here to focus on vulnerabilities evident at BNL and to provide a more complete set of vulnerabilities with potential DOE-wide implications. Each of the four vulnerabilities is summarized below and is presented in detail in Attachment 2 of this appendix.

\section{CSVR-BNL-000-01: Weaknesses in planning impede the effective elimination of hazards posed to workers and members of the public.}

Weaknesses in planning are evident in the site maintenance program, facility and/or process construction and design, management of chemicals, and packaging of waste materials.

Maintenance programs are not effective in preventing facility deterioration to minimize the loss of chemicals from facility systems. Relatively new system designs have not incorporated engineered controls to prevent chemical exposures. Several older facilities are used to store hazardous materials. These facilities do not include all safety systems that are common to general industry. Site chemical inventories are incomplete and do not provide the detail needed to plan appropriately for procurement, use, storage, and disposal of hazardous chemicals. Immature and incomplete programs fail to mitigate chemical release incidents to workers or the environment. These conditions and circumstances represent a medium- to high-priority vulnerability with a potential for short-term consequences.

\section{CSVR-BNL-000-02: Protracted implementation of core safety programs increases the potential for chemical safety vulnerabilities.}

The three means for managing hazardous chemicals are (1) a knowledgeable and well-directed operating organization, (2) technically capable advocates for ES\&H who can provide specialized assistance to line organizations, and (3) an array of core or model safety programs to guide both groups. The core safety programs at the BNL have not been fully implemented, and completion of such programs, including training, is not scheduled for several years. Protracted implementation of core safety program elements could lead to chemical safety vulnerabilities in several areas, including (1) hazards assessment to support 
emergency management, (2) ES\&H training, and (3) guidance associated with chemical inventory in the ES\&H Standards for Hazard Communication and the Laboratory Chemical Hygiene Plan. These conditions and circumstances represent a medium-priority vulnerability with a potential for short-term consequences.

CSVR-BNL-000-03: Shortfalls in resources could lead to new chemical safety vulnerabilities and could impede the ability to resolve identified issues in a timely manner.

The BNL Safety and Environmental Protection Division provides technical expertise to line programs and supports independent reviews of self-assessments by various operating organizations. A declining Laboratory budget, combined with a fairly rigid control over general and administrative expenses (which is where most costs for the Safety and Environmental Division are funded), means that BNL is entering a period in which there could be real decreases in resources applied to ES\&H. Budget constraints will lead to a deterioration in the capabilities to provide the technical support necessary to carry out mandated ES\&H programs. The relatively small number of personnel at BNL who are well qualified to recognize and provide solutions to chemical safety vulnerabilities can be expected to decrease with time. These conditions and circumstances represent a medium- to high-priority vulnerability with a potential for short-term consequences.

CSVR-BNL-000-04: Formal control measures have not been implemented to ensure that personnel who do not read or speak English understand the safety requirements and potential hazards associated with work in hazardous environments.

The requirement for contract specifications to provide positive assurance that subcontractor personnel who do not read or speak English understand workplace safety requirements and hazards has not been institutionalized. On an individual basis, specifications for subcontracts have, at the request of a safety engineer, included a clause stating, "Workers shall be able to comprehend work and safety instructions in English or a supervisor who can translate shall be provided and be present at all times." On several occasions, a safety engineer has suspended work by invoking the contract clause that requires a bilingual person to be present at all times. These conditions and circumstances represent a high-priority vulnerability with a potential for short-term consequences. 


\section{ATTACHMENT 1}

\section{TEAM COMPOSITION}

\section{Area of Responsibility}

Team Leader

Management/Operations

Management/Training

Chemical Process Safety

Industrial Hygiene

Environmental Protection

Maintenance

Emergency Management

Site Liaison

Coordinator

Technical Editor

\section{Name/Organization}

Victor I. Crawford

Office of Environmental Audit

U.S. Department of Energy

Del Bunch

Management Strategies, Inc.

Thomas L. Van Witbeck

Toma Enterprises

Ernest W. Johnson

Oak Ridge Associated Universities

J. Michael Brooks

EG\&G Rocky Flats, Inc.

Raymond F. Machacek

Arthur D. Little, Inc.

F. Richard Myal

Compa Industries, Inc.

David M. Rohrer

Office of Health

U.S. Department of Energy

Gerald A. Granzen

Brookhaven Area Office

U.S. Department of Energy

Rita A. Bieri

Los Alamos National Laboratory

Larry D. Warren

Evergreen Innovations, Inc. 


\section{ATTACHMENT 2}

CHEMICAL SAFETY VULNERABILITY REVIEW VULNERABILITY FORM

DATE: May 20, 1994

Site/Facility: Brookhaven National Laboratory

Vulnerability Number: CSVR-BNL-000-01

Functional Area(s): Identification of Chemical Holdings, Facility Physical Condition, Operational Control and Management Systems

1. Brief Description of Vulnerability.

Weaknesses in planning impede the effective elimination of hazards posed to workers and members of the public.

2. Summary of Vulnerability.

Weaknesses in planning are evident in the site maintenance program, facility andor process construction and design, management of chemicals, and packaging of waste materials. Maintenance programs are not effective in preventing facility deterioration to minimize the loss of chemicals from facility systems.

Relatively new system designs have not incorporated engineered controls (redundant safety systems design) to prevent chemical exposures. Because of lack of overall site planning, older facilities are being used to store hazardous materials, despite the lack of minimal safety systems that are common to general industry. Site chemical inventories are incomplete and do not provide the detail needed to plan appropriately for procurement, use, storage, and disposal of hazardous chemicals.

3. Basis.

a. Requirements:

- The Occupational Safety and Health Act (OSHA) requires evaluation and communication of chemical hazards to employees (29 CFR 1910.1200 and 29 CFR 1910.1450). Provisions for chemical inventories are also included in these regulations.

- Emergency management requirements for notification and communication of chemical hazards are contained in community right-to-know regulations (40 CFR 355 and 40 CFR 370).

- Requirements for evaluation and control of hazardous chemical processes and operations at DOE contractor-operated facilities are given in DOE 5483.1A and DOE 5480.10; maintenance management requirements for DOE facilities are found in DOE $4330.4 \mathrm{~A}$

b. Chemicals Involved: All potentially hazardous chemicals. Brookhaven National Laboratory (BNL) has large quantities of compressed gases and laboratory chemicals in containers of less than 1 pint or quantities of less than 1 pound. Materials are tracked for Emergency Planning Community Right-toKnow Act (EPCRA) at the 1-gallon/5-pound level. Specific chemicals observed that contribute to vulnerabilities are chlorine and ethyl ether.

c. Relevant Self-Evaluation Data: Lack of fire detection and suppression systems was noted in the BNL self-evaluation. The new Hazardous Waste Management Facility (HWMF), scheduled to open in calendar year 1996 or later, should reduce the potential for chemical safety vulnerabilities.

d. Contributing Causes:

- Restrictive waste acceptance criteria and changing regulations (e.g., Resource Conservation and Recovery Act [RCRA]) often require resampling and/or repackaging of materials by a facility (e.g., HWMF) that is not equipped to perform this function. 
Site/Facility: Brookhaven National Laboratory

Vulnerability Number: CSVR-BNL-000-01

Functional Area(s): Identification of Chemical Holdings, Facility Physical Condition, Operational Control and Management Systems

3. Basis, (Continued)

- Lack of definition of radioactive release or content criteria for activated scrap metal has resulted in material being cut up for disposal as hazardous, contaminated waste instead of being recycled. This situation further reduces available financial and human resources dedicated to chemical management and potentially exposes employee to added chemical hazards.

- Chemical inventories in BNL facilities are incomplete. Chemical tracking practices vary widely, depending on the rigor applied by each facility in formulating inventories.

- Increases in maintenance funding have not been sufficient to address the deterioration of aging facilities at BNL.

e. Potential Consequences:

- Resampling and/or repackaging of waste in facilities that do not have adequate engineering controls can result in increased exposure of workers to chemical hazards.

- Additional processing of materials as waste, instead of pursuing a recycling program, can increase worker exposure to chemical hazards.

- Decreased maintenance can lead to an unacceptable facility condition, which will increase the likelihood of release of chemicals to the environment and result in employee exposures to chemicals, fire, or explosions.

- A potential exists for explosions or fires in site facilities if unstable materials are not controlled.

- These conditions and circumstances represent a medium- to high-priority vulnerability with a potential for short-term consequences.

4. Supporting Observations.

- DOE 5480.10 requires that chemical hazards in the workplace be identified and evaluated and that control measures be implemented to prevent or mitigate exposures.

- Neither an annual site maintenance plan nor a maintenance implementation plan has been prepared as defined in DOE $4330.4 \mathrm{~A}$.

- An annual maintenance plan (i.e., an outline document requested by the Chicago Operations Office) govems the preventive and corrective maintenance budget for fiscal year (FY) 92 through FY 98 . No annual update to this document has been requested or furnished since FY 92. 


\section{Site/Facility: Brookhaven National Laboratory \\ Vulnerability Number: CSVR-BNL-000-01 \\ Functional Area(s): Identification of Chemical Holdings, Facility Physical Condition, Operational Control and Management Systems}

4. Supporting Observations. (Continued)

- Little predictive maintenance is being conducted at BNL. Thermography is used intermittently to locate hot spots on the high-voltage electric power system, and some transformer oil analysis is done. Vibration analysis is conducted at the Central Steam Plant and at the Central Chilled Water Plant, neither of which were visited at part of this review. However, no formal ultrasonic or radiographic surveys are undertaken to monitor thickness or vessel integrity of corrosion-or erosion-susceptible pipes for systems that could pose chemical hazards.

- Personnel and budgets for preventive and corrective maintenance have been kept constant for the past 4 years. The addition of new tasks means that more activities are required under a fixed maintenance budget. The current preventive maintenance staff consists of 140 personnel; 20 are supervisors, and 120 are maintenance craft personnel.

- The manner in which the preventive maintenance budget is used at a given facility is based on the discretion of the facility manager (programmatic maintenance) and the manager of plant engineering (facility maintenance).

- Safety showers were inoperable (repaired the week of 5-9-94) at HWMF (this issue was identified in the self-evaluation). Portable showers were used in the building as an interim measure. An emergency shower in Building 444 had no record of maintenance functional testing since 1991.

- Brass fittings on the chlorine gas manifold at Building 624 were corroded, and an indication of a chlorine leak was observed immediately downstream of the pressure regulator on the six-bottle manifold.

- Materials tracked for EPCRA reporting are included in the sitewide inventory for the Tandem Van de Graaff Accelerator. Several elements and compounds used for source and target preparation were not included in the sitewide inventory because they were below the 5-pound/1-gallon reporting requirement, but they were included in a building-specific/cabinet-specific inventory.

- Materials were found in laboratories that were not on the EPCRA inventory or building inventory. Containers of ethyl ether were found in two fume hoods that were not included in the last building-specific/laboratory-specific inventory. One container of ether was found with an expiration date of May 1994, which violates decomposition or instability guidance given in BNL-ES\&H Standard 2.1.1, "Chemical Hygiene Plan," Section IX. The proposed implementation of the Pacific Northwest Laboratory chemical tracking system will minimize future vulnerabilities of this type. 


\section{Site/Facility: Brookhaven National Laboratory}

Vulnerability Number: CSVR-BNL-000-01

Functional Area(s): Identification of Chemical Holdings, Facility Physical Condition, Operational Control and Management Systems

4. Supporting Observations. (Continued)

- Lack of planning in facility design and construction was indicated at the chlorine (gas) system used at the Central Water Treatment Plant (Building 624). An audible alarm was installed at the chlorinator to warn operators of leaking gas. In the event of a chlorine cylinder or piping failure, personnel would be required to wear self-contained breathing apparatus to control the leak. Neither the manifold nor the individual pigtails were equipped with emergency shutdown devices to limit chlorine flow in the event of a manifold or pigtail failure.

- Because of lack of clear policy and integrated waste management requirements (a DOE-wide issue), the limited resources available to manage chemical hazards at the site are often spent staging and dispositioning waste. For example, magnet segments of copper or steel exhibiting neither measurable direct nor smearable contamination are scheduled to be cut up and packaged as waste and subsequently transported to Hanford. Based on the apparent lack of radiological hazard associated with this sort of material, the undefined, added risks to operators and the environment make the need for this unclear.

- Because of lack of clear policy and integrated waste management requirements (a DOE-wide issue), a weakness associated with planning was identified at the HWMF. This facility lacks appropriate engineering controls for repackaging of hazardous materials. Repackaging is often performed by operators who must wear personal protective equipment because of the lack of engineering controls. The need for multiple repackaging has occurred to meet waste acceptance criteria. Resampling of moratorium-generated wastes that were previously lab-packed and ready for shipment was conducted at HWMF. Because of funding constraints, materials packed in the late 1980 s were not shipped. When funds became available, shipment, resampling, and repackaging were required. Concrete vaults packed for shipment in the mid-1980s must be opened with a jackhammer, emptied, characterized, and repacked.

- A group of about 15 subcontractor personnel attended the New Employee Safety Orientation Course before onsite asbestos abatement activities began. Only one member of the group spoke English; he translated the course into the native language of the group. No measures such as written or verbal tests were used to validate comprehension.

- Specifications for the subcontract under which the asbestos abatement project was conducted contained a clause stating: "Workers shall be able to comprehend work and safety instructions in English or a supervisor who can translate shall be provided and be present at all times." When enforced, this clause when enforced provides some measure of assurance that non-English speakers will be aware of safety requirements and potential hazards in the workplace. An individual safety engineer requires that this clause be incorporated in all contracts that he supervises: it is not an institutional requirement. Therefore, the requirement would not necessarily be included in the specifications of all contracts having similar circumstances. 
Site/Facility: Brookhaven National Laboratory

Vulnerability Number: CSVR-BNL-000-02

Functional Area(s): Human Resource Programs, Operational Control and Management Systems, and Emergency Management Program

1. Brief Description of Vulnerability.

Protracted implementation of core safety programs increases the potential for chemical safety vulnerabilities.

2. Summary of Vulnerability.

Protracted implementation of core safety program elements could lead to chemical safety vulnerabilities in several areas, including (1) hazards assessment to support emergency management; (2) implementation of environment, safety, and health (ES\&H) training; and (3) guidance concerning chemical inventory in ES\&H Standards for Hazard Communication and the Laboratory Chemical Hygiene Plan.

3. Basis.

a. Requirements:

- The Occupational Safety and Health Act requires evaluation and communication of chemical hazards to employees (29 CFR 1910.1200 and 29 CFR 1910.1450).

- Requirements for evaluation and control of hazardous chemical processes and operations at DOE contractor-operated facilities are provided in DOE 5483.1A and DOE 5480.10.

- Requirements for training of hazardous waste operations and emergency preparedness personnel are provided in 29 CFR 1910.120. Additional training and qualification requirements for nonreactor nuclear facilities personnel are provided in DOE 5480.20 .

- The framework for a program to ensure personnel receive adequate information regarding hazards associated with chemicals in the workplace is provided in Brookhaven National Laboratory (BNL) ES\&H Standard 2.1.1, "Chemical Hygiene Plan."

b. Chemicals Involved: All potentially hazardous chemicals at BNL.

c. Relevant Self-Evaluation Data: The site self-evaluation did not identify this issue as a potential vuinerability.

d. Contributing Causes: Perceived sense of low risks, low allocation of resources to core safety programs, and reluctance to increase spending on overhead projects.

e. Potential Consequences: Potential consequences include personnel injury or death and property damage. These conditions and circumstances represent a medium-priority vulnerability with a potential for short-term consequences. 
Site/Facility: Brookhaven National Laboratory

Vulnerability Number: CSVR-BNL-000-02

Functional Area(s): Human Resource Programs, Operational Control and Management Systems, and Emergency Management Program

4. Supporting Observations.

- An ES\&H appraisal conducted by Chicago Operations Office during January 18-28, 1994, stated that "the Hazards Assessment, which determines the extent and scope of emergency planning and preparedness activities, has not been completed." This weakness has been identified to BNL on numerous occasions, even by the Brookhaven Area Office. The problem still exists as of the date of the field verification visit. DOE 5480.10 requires, in part, that chemical hazards in the workplace be identified and evaluated and that control measures be implemented to prevent or mitigate exposures.

- BNL has started gathering the information (e.g., chemical inventory, building layouts, weather records) necessary to perform the hazards assessment and has requested funding. The current funding for this effort is $\$ 10,000$, with an additional $\$ 90,000$ or more needed. BNL has requested funding to perform hazards assessments in previous budgets, but the priority assigned to the task, based on risk, has fallen below the funding cutoff.

- The schedule for implementation of the ES\&H training programs is protracted. The level of effort currently directed to training course development will yield courses that satisfactorily address the mandated safety training in about 2 years.

- The BNL Training Policy has been approved; however, program implementation is incomplete and lacks the rigor associated with a formal training program. Job-specific training developed by the operating facilities is not required to undergo a systematic review by the professional staff training office to ensure (1) consistent content and (2) application of accepted training standards and BNL. safety requirements. A BNL training manual is in the early stages of development.

- A formalized, performance-based, position-specific training program has not been developed for the members of the emergency response organization other than the BNL fire/rescue department. Instead, as their means of training, BNL replied on individual employees to read the emergency response procedures for which they are responsible, to attend a procedure briefing when new procedures are issued, and to participate in drills and exercises as their means of training. This has been identified as a weakness on a number of occasions. 
Site/Facility: Brookhaven National Laboratory

Vulnerability Number: CSVR-BNL-000-02

Functional Area(s): Human Resource Programs, Operational Control and Management Systems, and Emergency Management Program

4. Supporting Observations. (Continued)

- Some personnel providing performance evaluations of on-the-job training (OJT) have not been certified as OJT instructors.

- Visitors may gain unescorted access to some facilities prior to completing the required safety training.

- Materials tracked for Environmental Protection and Community Right-to-Know Act (EPCRA) reporting are included in the sitewide inventory for the Tandem Van de Graaff Accelerator. Because several elements and compounds used for target preparation were below the reporting threshold, they were not included in the sitewide inventory but were included in a building-specific/laboratory-specific inventory.

- Materials were found in laboratories that were not on the EPCRA inventory or building inventory. Containers of ethyl ether that were not contained in the last building-specific/laboratory-specific inventory were found in two laboratory hoods. One container of ether was found that had an expiration date of May 1994. Storage of out-of-date materials that pose a hazard due to decomposition or instability is contrary to guidance given in BNL-ES\&H Standard 2.1.1 "Chemical Hygiene Plan," Section IX. The proposed implementation of the Pacific Northwest Laboratory chemical tracking system will minimize future vulnerabilities of this type.

- Implementation of the self-assessment program is incomplete.

- The BNL Environment, Safety and Health Self-Assessment Program is in draft form.

- The 1992/1993 Annual Self-Assessment has not been published.

- Feedback is not always provided to the senior managers and staff affected by self-assessments.

- Personnel have not been trained to perform self-assessments. 
Site/Facility: Brookhaven National Laboratory

Vulnerability Number: CSVR-BNL-000-03

Functional Area(s): Operational Control and Management Systems

1. Brief Description of Vulnerability.

Shortfalls in resources could lead to new chemical safety vulnerabilities and could impede the ability to resolve identified issues in a timely manner.

2. Summary of Vulnerability.

The BNL Safety and Environmental Protection (S\&EP) Division provides technical expertise to line programs and supports independent reviews of self-assessments by various operating organizations. A declining Laboratory budget, combined with a fairly rigid control over general and administrative expenses (which is where most costs for the S\&EP organization are funded), means that Brookhaven National Laboratory $(B N L)$ is entering a period in which there could be real decreases in resources applied to environment, safety, and health (ES\&H). Budget constraints will create pressures to limit or delay efforts to carry out mandated ES\&H programs. The relatively small number of personnel at BNL who are well qualified to recognize and provide solutions to chemical safety vulnerabilities can be expected to decrease with time, unless special efforts are made to recruit and train personnel.

3. Basis.

a. Requirements: Section 161 of the Atomic Energy Act requires DOE to ensure that management and operations contractors "protect health and minimize danger to life or property." DOE implements this requirement through the nuclear safety clause in contracts and through the issuance of DOE 5483.1A, "Occupational Safety and Health Program for DOE Contractor Employees at Government-Owned Contractor-Operated Facilities," which mandates application of standards comparable to those promulgated by the Occupational Safety and Health Administration (OSHA). Good practices would be those identified for OSHA's Voluntary Protection Program (VPP) and contained in 29 CFR 1910.119, "Process Safety Management," even where chemical quantities are below the requirements level.

b. Chemicals Involved: Water Treatment Facility: chlorine gas. Tandem Van de Graaff Accelerator: small quantities of various types of flammable material used and stored in a cabinet; a variety of chemicals in small quantities; tens of thousands of pounds of sulfur hexafluoride, plus other asphyxiants. Hazardous Waste Management Facility: up to drum quantities of acids, caustics, and organics are stored or repackaged and held for shipment from the site (capacity of up to 104 drums per area). Many other areas on the site also contain hazardous chemicals (liquids, solids, and compressed or liquefied gases).

c. Relevant Self-Evaluation Data: BNL self-evaluation indicated that controls were adequate to prevent worker exposure. It also states that the "long-range objectives for the Laboratory in these areas are to ensure that those organizations which need formal Conduct of Operations and Maintenance Management programs, implement them along with a continuous improvement program to achieve excellence in operations and maintenance." [page 15] 
Site/Facility: Brookhaven National Laboratory

Vulnerability Number: CSVR-BNL-000-03

Functional Area(s): Operational Control and Management Systems

3. Basis. (Continued)

d. Contributing Causes: A ceiling imposed on general and administration expenses limits ability to recruit new staff, and limitations in overall funding for BNL in fiscal year (FY) 95 will reduce the base for resolving identified shortfalls in ES\&H performance. Strong emphasis on applying resources to perceived risks creates strong dependency on correctly gauging the relative risks of various site activities. Aging physical infrastructure increases reliance on administrative controls to prevent or mitigate incidents; any deterioration in plant will complicate efforts to eliminate or reduce chemical safety concerns.

e. Potential Consequences: The number of incidents and noncompliances will increase with time, as will the potential for events leading to releases of hazardous chemicals. These conditions and circumstances represent a medium-to high-priority vulnerability with a potential for short-term consequences.

4. Supporting Observations.

- In letters of August 21, 1987; July 30, 1990; and February 21, 1992, the Laboratory Director raised overhead rates from 44.5 percent to 49.5 percent. These rates would have been 55.5 percent or more if requests had been approved. (The cited letters note that increases would have been 11 percent instead of 6 percent but for special efforts made by BNL, including staff reductions in the G\&A pool.) In the past, staff reductions occurred in non-ES\&H areas.

- Staff levels for S\&EP have gone from 110 to 190 since 1988. Staff levels for industrial hygienerelated functions are low relative to overall site staff (e.g., nine full-time equivalents for industrial hygiene for a site staff of roughly 3,000 , versus 40 industrial hygienists at a site where the staff is about 8,000 ). Even though these two figures are not exactly comparable, they may be indicative of the impact of budget constraints.

- "Environmental Safety and Health Management Plan, Fiscal Years 1994-2000," dated April 13, 1994, identifies a number of strategic plans, but many are unfunded or occur some years from now. Interviews suggest that requests for funds are substantially in excess of funds provided; the ability to find creative solutions to problems depends on a highly motivated and supportive ES\&H staff. 
Site/Facility: Brookhaven National Laboratory

Vulnerability Number: CSVR-BNL-000-03

Functional Area(s): Operational Control and Management Systems

4. Supporting Observations. (Continued)

- Recent reviews in crucial areas reveal substantial shortfalls in performance, below requirements (see "Operations Assessment, Hazardous Waste Management Facility," [by EM-25], October 4-8, 1993, and the "Environmental Protection Program Appraisal Report," Chicago Operations Office, January 18-27, 1994). Although not all concerns may be due to resource constraints, efforts to eliminate concerns identified by such reviews will require additional resources.

- The site uses a graded approach to apply resources to areas of perceived higher risk. The BNL Operations and Maintenance Manual contains several standards or guidance documents that describe or require the graded approach (see the manuals BNL-O\&M-I-01 and BNL-O\&M-IV-01, which reference and invoke other BNL standards - e.g., BNL ES\&H Standard 1.3.3; the Safety and Environmental Division Standard SEAPPM 1.3.0, Attachment 4; the Quality Assurance standard, BNL-QAG-301; and the BNL Internal Notice 94-01 on Startup and Restart of Nuclear Facilities). However, as noted in those various documents, the actual decision on how to proceed is left to individual line managers, who may have no special expertise in identifying or characterizing chemical safety vulnerabilities and who may have a limited cadre of S\&EP staff because of constrained resources.

- The chlorine delivery system at the Central Water Treatment Plant was found to be visibly corroded, with an evident smell of chlorine on entry. The detector for chlorine appeared to be inappropriately located (the flow of leaking chlorine would be away from the detector). The impression was that the decision to upgrade the existing chlorine system instead of replacing the system was due in some measure to resource constraints.

- The new Hazardous Waste Management Facility will be completed no sooner than 1996 . The need for a replacement facility was evident years ago; but resource constraints and reassignments of responsibility within DOE Headquarters appeared to have caused this project to be delayed. This project is now tied to a cleanup requirement under a Federal Facilities Compliance Agreement.

- The budget for maintenance and ES\&H staff was said to have peaked in 1994, with staff reductions to occur in 1995 and beyond, unrelated to need.

- Staff levels for training are low for a site having staff of about 3,000 (about 30 FTEs for training, versus a staff of 3,000 ). Staff levels for training at several other DOE facilities are on the order of 120 FTEs for a staff of 7,000. A direct correlation is not valid, but the magnitude of the variation may be indicative of the budget constraints. 
Site/Facility: Brookhaven National Laboratory

Vulnerability Number: CSVR-BNL-000-04

Functional Area(s): Human Resource Programs

1. Brief Description of Vulnerability.

Formal control measures have not been implemented to ensure that personnel who do not read or speak English understand the safety requirements and potential hazards associated with work in hazardous environments.

2. Summary of Vulnerability.

Subcontractor personnel who do not read or speak English are performing environmental activities, including asbestos abatement, without Brookhaven National Laboratory (BNL) having positive assurance that workplace safety requirements and hazards are understood.

3. Basis.

a. Requirements: The Occupational Safety and Health Act requires evaluation and communication of chemical hazards to employees (29 CFR 1910.1200 and 29 CFR 1910.1450).

b. Chemicals Involved: Hazardous chemicals primarily associated with environmental remediation at BNL. facilities.

c. Relevant Self-Evaluation Data: BNL did not identify this issue as a potential chemical safety vulnerability.

d. Contributing Causes:

- BNL has not defined requirements and procedures to address the ramifications of a non-Englishspeaking work force.

- Lack of a positive measure of safety requirements knowledge (such as testing) during subcontractor training.

e. Potential Consequences: The consequences include personnel injury or death and property damage. These conditions and circumstances represent a high-priority vulnerability with a potential for shortterm consequences. 


\section{Site/Facility: $\quad$ Brookhaven National Laboratory.}

Vulnerability Number: CSVR-BNL-000-04

Functional Area(s): Human Resource Programs

4. Supporting Observations.

- A group of about 15 subcontractor personnel attended the New Employee Safety Orientation Course prior to starting asbestos abatement activities on site. Only one member of the group spoke English; he translated the course into the native language of the group. No measures, such as written or verbal tests, were used to validate comprehension of safety requirements and potential hazards by non-English speakers.

- The specifications for the subcontract under which the asbestos abatement project was conducted contained a clause stating: "Workers shall be able to comprehend work and safety instructions in English or a supervisor who can translate shall be provided and be present at all times." This clause when enforced provides some measure of assurance that non-English speakers will be aware of the safety requirements and hazards in the workplace. A safety engineer requires that this clause be incorporated in all contracts he supervises; it is not an institutional requirement. The requirement, therefore, would not necessarily be included in the specifications of all contracts having similar circumstances.

- A safety engineer has, on several occasions, suspended work on a job site by invoking the contract clause that requires a bilingual person to be present on the work site at all times. 
ATTACHMENT 3

\section{SELECTED ACRONYMS}

DOE

BNL

FY

HWMF

ES\&H
U.S. Department of Energy

Brookhaven National Laboratory

Fiscal Year

Hazardous Waste Management Facility

Environment, Safety, and Health 


\title{
APPENDIX K
}

\author{
FIELD VERIFICATION REPORT \\ LOS ALAMOS NATIONAL LABORATORY \\ MAY 16 - 25, 1994
}

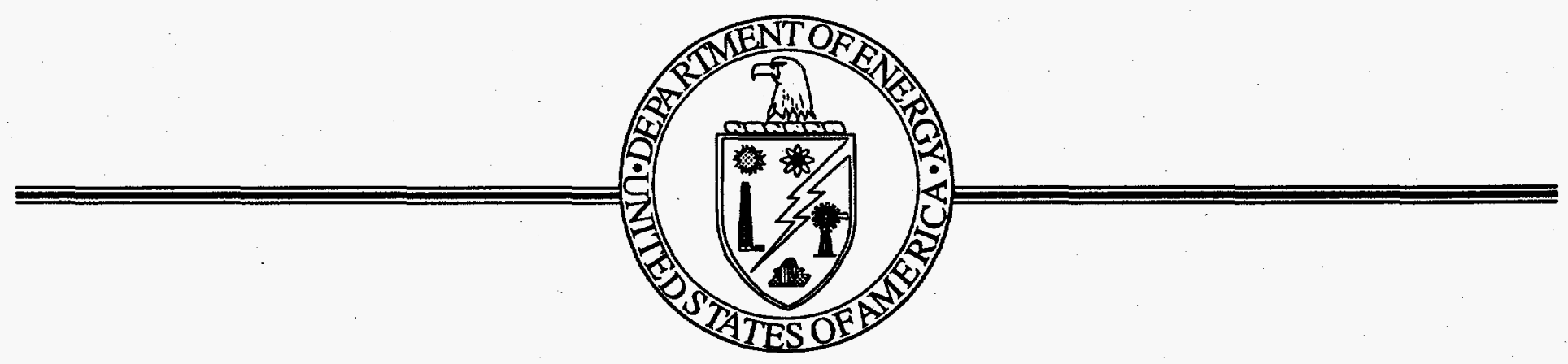





\section{CONTENTS}

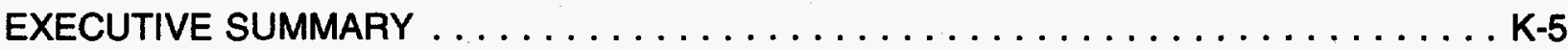

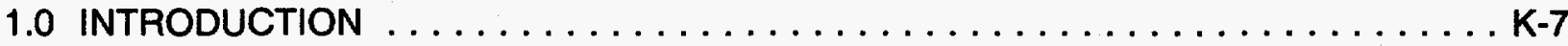

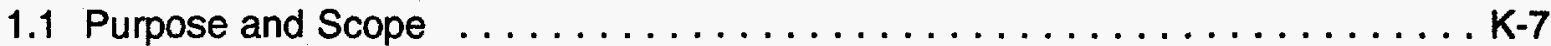

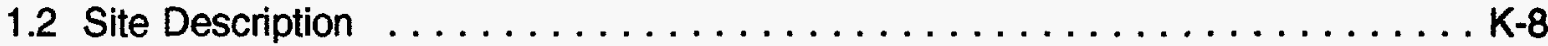

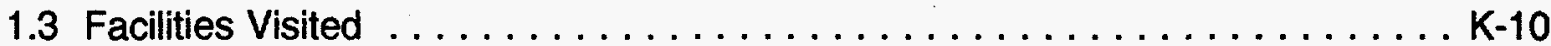

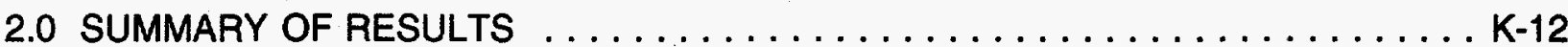

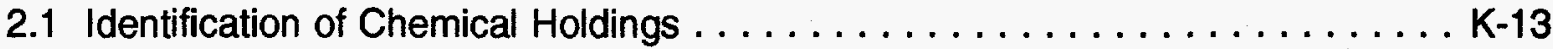

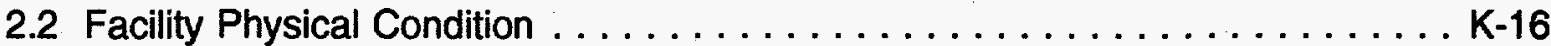

2.3 Operational Control and Management Systems $\ldots \ldots \ldots \ldots \ldots \ldots \ldots \ldots$ K-18

2.4 Human Resource Programs $\ldots \ldots \ldots \ldots \ldots \ldots \ldots \ldots \ldots \ldots \ldots \ldots$. . . . . . . . . . . . . . . . .

2.5 Emergency Management Program . . . . . . . . . . . . .

3.0 CATEGORIZATION AND PRIORITIZATION OF VULNERABILITIES $\ldots \ldots \ldots \ldots$ K-25

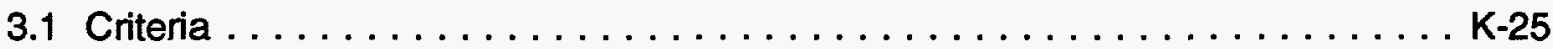

3.2 Chemical Safety Vulnerabilities at the Los Alamos
National Laboratory $\ldots \ldots \ldots \ldots \ldots \ldots \ldots \ldots \ldots \ldots \ldots \ldots \ldots \ldots \ldots \ldots$

ATTACHMENTS

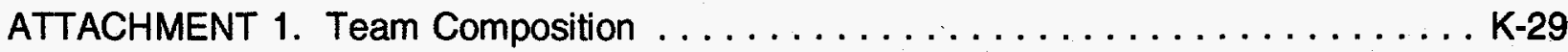

ATTACHMENT 2. Vulnerability Forms $\ldots \ldots \ldots \ldots \ldots \ldots \ldots \ldots \ldots \ldots \ldots \ldots \ldots \ldots \ldots \ldots$

ATTACHMENT 3. Selected Acronyms $\ldots \ldots \ldots \ldots \ldots \ldots \ldots \ldots \ldots \ldots \ldots \ldots \ldots \ldots \ldots$ 



\section{EXECUTIVE SUMMARY}

This report presents the results of a review of chemical safety vulnerabilities associated with facilities owned or operated by the Department of Energy (DOE) at Los Alamos National Laboratory (LANL). The field verification review took place on May 16-25, 1994, and was part of the Chemical Safety Vulnerability Review being conducted by the Office of Environment, Safety and Health at the direction of the Secretary of Energy. The purpose of the review is to identify and characterize conditions or circumstances involving potentially hazardous chemicals at DOE sites and facilities. Specifically, the review is designed to identify, characterize, and prioritize chemical safety vulnerabilities associated with conditions or circumstances that might result in (1) fires or explosions from uncontrolled chemical reactions, (2) exposure of workers or the public to chemicals, or (3) releases of chemicals to the environment.

Activities involving the use of hazardous chemicals at LANL include research and development laboratory processes; production-related processes and operations; cleanup of facilities being shut down; laboratory processes; long-term, large-scale storage; and the treatment and disposal of hazardous wastes. The lines of inquiry developed for the Chemical Safety Vulnerability Review were used as a guide for field verification activities at LANL. All facilities included in the LANL self-evaluations were reviewed, and additional facilities were reviewed when further information was needed.

The LANL field verification was conducted with a view toward identifying possible DOE-wide chemical safety vulnerabilities. Three chemical safety vulnerabilities were identified at LANL, none of which represents a potential consequence of high severity in the near term:

- Significant accumulations of hazardous chemicals and wastes are being stored for prolonged periods, some under unsatisfactory conditions;

- The lack of funding could affect the safe cleanup or transition of aging and/or inactive facilities; and

- The absence of a consistent approach to chemical safety at LANL can result in unanticipated chemical risks.

These vulnerabilities, along with those identified at other DOE sites, will be evaluated to identify DOE-wide generic vulnerabilities. Information from the Office of Environmental Management's Surplus Facilities Inventory Assessment and the extended review of potential organic-nitrate vulnerabilities (similar to those at Tomsk-7) will also be considered. The results of these activities will be reviewed for additional insights into potential chemical safety vulnerabilities confronting the Department.

The field verification team also identified the following commendable practices pertaining to chemical safety at LANL:

- The use of an innovative labeling system that incorporates DOE, Clean Air Act, Department of Transportation, Environmental Protection Agency, LANL, Resource 
Conservation and Recovery Act, and American National Standards Institute labeling requirements into a single label;

- The development and use of the new Hazardous Materials Training Facility for training and conducting practical hands-on, hazardous-materials drills for both onsite and offsite emergency response organizations; and

- The modification of Meteorological Information and Dose Assessment System software, which calculates and displays dispersion data for hazardous materials plumes, to incorporate site-specific meteorological factors.

Based on this review in general and these practices in particular, the field verification team concludes that LANL personnel have a strong commitment to chemical safety. Although a consistent overall approach for implementing a sound chernical safety program is lacking, many of the essential elements of such a program are in place and improvements are planned. 


\subsection{INTRODUCTION}

\subsection{Purpose and Scope}

Based on direction from the Secretary of Energy, the Assistant Secretary for Environment, Safety and Health established the Chemical Safety Vulnerability Working Group to review and identify chemical safety vulnerabilities at facilities operated by the Department of Energy (DOE). The information obtained from the review will provide the Working Group with valuable input for identifying generic chemical safety vulnerabilities that confront the DOE complex. Prioritizing the generic chemical safety vulnerabilities that are identified will establish the proper basis for departmental focus on programs, funding, and policy decisions related to chemical safety. The Secretary directed the Office of Environment, Safety and Health (EH) to lead this review, with full participation from DOE line organizations having operational responsibilities.

The Chemical Safety Vulnerability Review was designed and undertaken to identify and characterize adverse conditions and circumstances involving potentially hazardous chemicals at facilities owned or operated by the Department. Specifically, the review is intended to identify, characterize, and prioritize chemical safety vulnerabilities associated with conditions or circumstances that might result in (1) fires or explosions from uncontrolled chemical reactions, (2) exposure of workers or the public to hazardous chemicals, or (3) release of hazardous chemicals to the environment. Using input provided by line organizations with operational responsibilities, the Working Group developed the "Project Plan for the Chemical Safety Vulnerability Review," dated March 14, 1994, to guide the review.

The field self-evaluation phase of the review used a standardized question set developed and distributed by the Working Group to collect data related to chemical safety from 84 facilities located at 29 sites. Based on analysis of self-evaluation data, nine large sites, including Los Alamos National Laboratory (LANL), and four small sites were selected to participate in the field verification phase of the review. The field verification process was designed to use independent teams of technical professionals with experience in a variety of technical disciplines to confirm the accuracy and completeness of the data compiled during the field self-evaluation phase of the review. This report documents activities related to the field verification phase of the Chemical Safety Vulnerability Review.

The field verification team visiting LANL examined a broad range of facilities (based on facility type and operational status), with special attention given to those facilities being transitioned to, awaiting, or undergoing decontamination and decommissioning (D\&D). Different types of chemical- and waste-handling facilities were examined to permit identification of vulnerabilities arising from hazardous chemicals and wastes at the site. (See Section 1.3 for a listing of the key facilities visited.)

The field verification team, under the direction of a DOE team leader, was composed of DOE and contractor personnel with technical expertise in various aspects of chemical safety, including management and operations, training, chemical process safety, industrial hygiene, maintenance, environmental protection, and emergency management. The team included one working group member and two site liaisons. A team composition list is provided in Attachment 1 of this appendix. 
The team began its review by visiting each of the facilities selected for self-evaluation. Team members met with management or technical representatives from each of the facilities reviewed. Individual and small group meetings were also held, and team members conducted walkthroughs, document reviews and personnel interviews to gather information related to potential chemical safety vulnerabilities at LANL. The team leader met periodically with management personnel to discuss the team's activities and issues that may have surfaced during the previous day. Before the field verification team left LANL, management from local DOE and contractor organizations conducted a factual accuracy review of the draft report. An outbriefing was conducted on Wednesday, May 25, 1994, and a draft copy of this report was left with DOE and contractor management.

\subsection{Site Description}

Located in north-central New Mexico, the Los Alamos National Laboratory comprises about 43 square miles of DOE-owned land in Los Alamos, Sandoval, and Santa Fe Counties. LANL is about 90 miles driving distance north of Albuquerque and 35 miles driving distance northwest of Santa Fe. The site and the adjacent communities of Los Alamos and White Rock are situated on the Pajarito Plateau, a volcanic shelf on the eastern slope of the Jemez Mountains, at an elevation of about 7,000 feet. LANL currently comprises about 50 designated technical areas (TAS) that reflect a variety of functions, including building sites, experimental areas, waste disposal locations, roads, and rights-of-way for utilities. (See Figure 1.)

Most LANL installations are situated on mesa tops, although a few important facilities are located in canyons. Historically, the isolation of the region and its low population density have contributed to public safety and the security of LANL's facilities, although public access is permitted to certain parts of the site. In general, LANL is surrounded by undeveloped land, with large tracts to the north, west, and south belonging to the Santa Fe National Forest, the Bureau of Land Management, Bandelier National Monument, the General Services Administration, and Los Alamos County. The San Ildefonso Indian Reservation borders the site to the east.

The LANL site includes facilities constructed during World War II as well as recently built modern structures. LANL's original mission was to design, develop, and test new defense and security technologies. Today, however, LANL's activities focus on the development of innovative technologies involving energy, nuclear safeguards, biomedical science, environmental protection and cleanup, computational science, materials science, and other types of basic scientific research and development.

The organization of work at Los Alamos provides a number of mechanisms through which information about chemical safety practices and requirements can be communicated. The two groups with principal responsibility in this area are the University. of California, which is the management and operating contractor for LANL, and Johnson Controls World Services, Inc. $(\mathrm{JCl})$, which is the main support services contractor. $\mathrm{JCl}$ operations include 


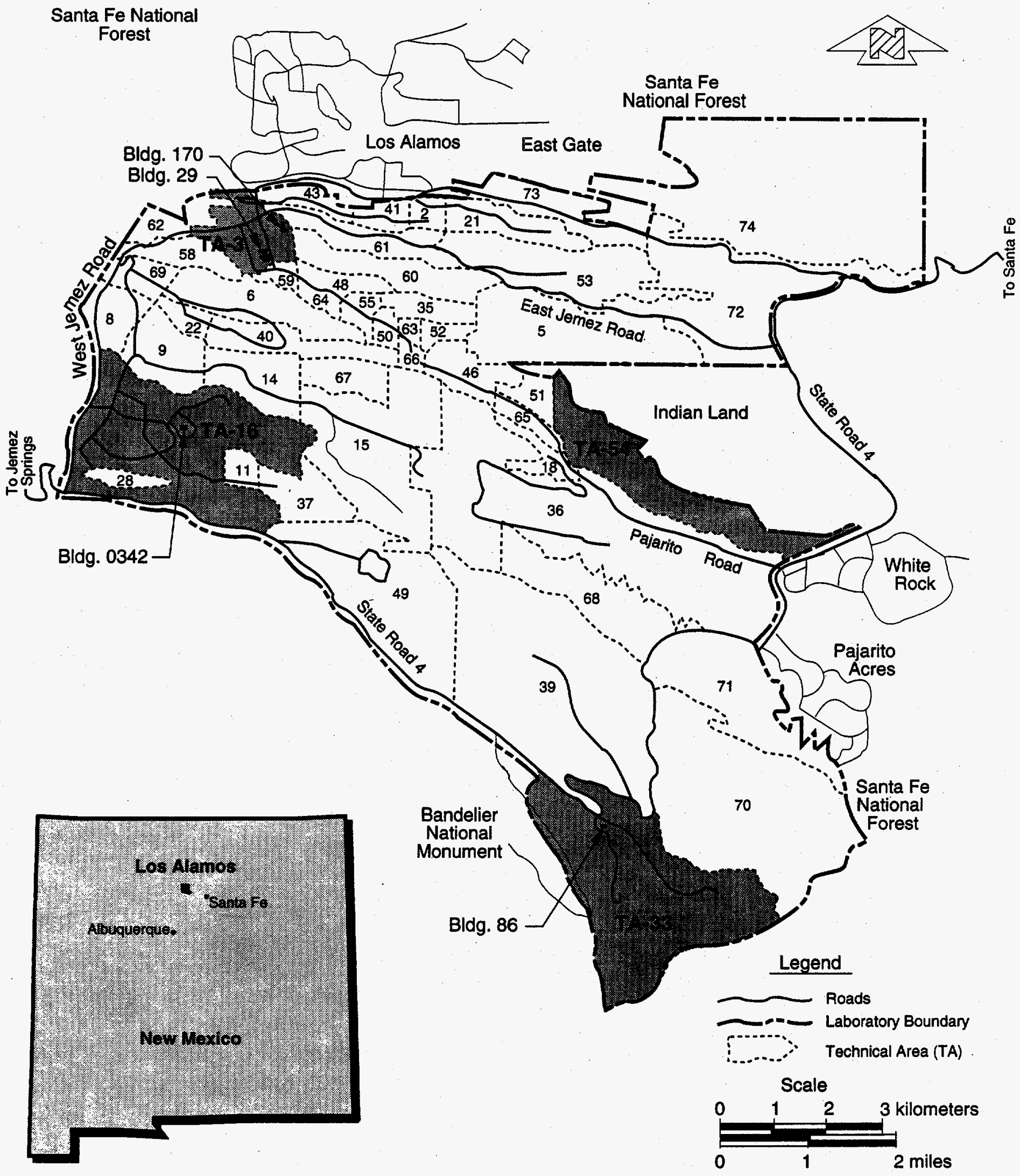

Figure 1. Los Alamos National Laboratory Site 
the water treatment systems, which use large quantities of chlorine. Smaller organizations, such as VWR Scientific, Inc., which supplies chemicals to site facilities, and the LANL Fire Department also provide crucial services that can affect chemical safety.

\subsection{Facilities Visited}

Table 1 identifies key facilities visited by members of the field verification team at the Los Alamos National Laboratory and includes information related to the physical condition and mission of each facility. In addition, the field verification team observed activities at the Laboratory's primary dedicated Emergency Operations Center (EOC), the dedicated altemate EOC, and the Hazardous Materials Training Facility.

Table 1. Key LANL Facilities Visited

\begin{tabular}{|c|c|c|}
\hline FACILITY & MISSION & DESCRIPTION \\
\hline $\begin{array}{l}\text { Chemistry and } \\
\text { Metallurgy Research } \\
\text { Facility } \\
(\text { TA-3, Bldg. 29)* }\end{array}$ & $\begin{array}{l}\text { Nonreactor nuclear laboratory } \\
\text { facility }\end{array}$ & $\begin{array}{l}\text { Constructed in } 1952 \text {, this } 550,000 \text {-square-foot building is classified } \\
\text { as a nonreactor nuclear laboratory facility. The building includes } \\
\text { seven three-story laboratory wings and an administrative wing. } \\
\text { Most laboratories are located on the second level and are used for } \\
\text { analytical chemistry, materials research, and processing science. } \\
\text { Chemicals, hazardous wastes, and mixed wastes are located in } \\
\text { designated storage areas in each wing. }\end{array}$ \\
\hline $\begin{array}{l}\text { General Warehouse } \\
\text { Building } \\
\text { (TA-3, Bldg. SM-30) }\end{array}$ & $\begin{array}{l}\text { Materials receiving, storage, } \\
\text { distribution, and shipping }\end{array}$ & $\begin{array}{l}\text { This } 60,000 \text {-square foot warehouse, office, and technical support } \\
\text { building is constructed of poured concrete. It is divided by a } \\
\text { permanent firewall running north and south through the building. It } \\
\text { contains a high-bay roof supported by concrete pillars. Building } \\
\text { operations include the receipt of chemical radioisotopes in small } \\
\text { quantities. }\end{array}$ \\
\hline $\begin{array}{l}\text { Chemical Warehouse } \\
\text { Building } \\
\text { (TA-3, Bldg. SM-31) }\end{array}$ & $\begin{array}{l}\text { Receipt, storage, and } \\
\text { distribution of hazardous } \\
\text { chemicals }\end{array}$ & $\begin{array}{l}\text { This } 30,000 \text {-square-foot warehouse and office building is } \\
\text { constructed of poured concrete. It is divided by a permanent } \\
\text { firewall running north and south. It contains a high-bay roof } \\
\text { supported by concrete pillars with loading docks on the north, } \\
\text { east, and west sides of the building. Hazardous chemicals in the } \\
\text { building are managed by VWR Scientific, Inc., and the LANL } \\
\text { Business Operations Division (BUS) receives, stores, and issues } \\
\text { fumiture, metal drums, and anticontamination clothing. }\end{array}$ \\
\hline $\begin{array}{l}\text { Compressed and } \\
\text { Liquified Gas Facility } \\
\text { (TA-3, Bldg. 170)* }\end{array}$ & $\begin{array}{l}\text { Warehousing and distribution } \\
\text { services for numerous inert, } \\
\text { flammable, toxic, and } \\
\text { oxidizing gases and for bulk } \\
\text { storage of gas products }\end{array}$ & $\begin{array}{l}\text { This facility includes several structures. The main building, } \\
\text { SM-170, is an } 8,900 \text {-square-foot structure used to store inert gas } \\
\text { products. SM-1650 (constructed in 1988) is a metal storage } \\
\text { building for flammable gas cylinders. SM-476 is an all-metal } \\
\text { prefabricated storage building for toxic gas cylinders. SM- } 1942 \text { is } \\
\text { an all-metal transport container used for general storage. Tube } \\
\text { trailers associated with the facility are used for bulk storage, hold } \\
\text { an average of } 59,000 \text { cubic feet of product, and are transported to } \\
\text { users across the LANL site. }\end{array}$ \\
\hline
\end{tabular}


Table 1. Key LANL Facilities Visited (Continued)

\begin{tabular}{|c|c|c|}
\hline FACILITY & MISSION & DESCRIPTION \\
\hline $\begin{array}{l}\text { Explosives } \\
\text { Development } \\
\text { Processing Facility } \\
\text { (TA-16, Bldg. 340) }\end{array}$ & $\begin{array}{l}\text { High-explosive processing, } \\
\text { raw material and hazardous } \\
\text { waste storage }\end{array}$ & $\begin{array}{l}\text { This } 25,000 \text {-square-foot facility has nine operating bays and is } \\
\text { used for the formulation of high explosives. No raw material is } \\
\text { stored in the facility. Each operating bay contains a satellite } \\
\text { waste storage area, and Room } 114 \text { contains a } 90 \text {-day storage } \\
\text { area. }\end{array}$ \\
\hline $\begin{array}{l}\text { High Pressure } \\
\text { Tritium Laboratory } \\
\text { (TA-33, Bldg. 86)* }\end{array}$ & $\begin{array}{l}\text { Nonreactor nuclear laboratory } \\
\text { facility }\end{array}$ & $\begin{array}{l}\text { This facility consists of a one-story, steel-reinforced concrete } \\
\text { building with dimensions of about } 36 \times 16 \times 6 \text { meters. A small } \\
\text { penthouse on the main roof at the north of the building shelters } \\
\text { the ventilation and exhaust system for the process room. The air } \\
\text { in the process room is exhausted through a } 23-\text { meter stack at the } \\
\text { north end of the building. Before it was shut down, the facility was } \\
\text { used for experimental activities involving gaseous tritium and other } \\
\text { hydrogen lsotopes. }\end{array}$ \\
\hline $\begin{array}{l}\text { Wastewater } \\
\text { Treatment Facilities } \\
\text { (TA-46) }\end{array}$ & $\begin{array}{l}\text { Treatment of sanitary } \\
\text { wastewater from LANL } \\
\text { facilities }\end{array}$ & $\begin{array}{l}\text { This plant consists of several structures located on about } 10 \\
\text { acres. It began operation in } 1992 \text {. The plant includes a } 2,640- \\
\text { square-foot building that houses offices, control room, laboratory, } \\
\text { and maintenance shop. Wastewater is treated using an extended } \\
\text { aeration, nitrification-denitrification process. Plant components } \\
\text { include equalization basins, aeration basins, clarifiers, chlorination } \\
\text { facilities, sludge-drying beds, and treated effluent-retum system. } \\
\text { The chlorine supply building contains four } 1 \text {-ton chlorine cylinders } \\
\text { under a protective shed. }\end{array}$ \\
\hline $\begin{array}{l}\text { Waste Storage } \\
\text { Facilities (TA-54)" }\end{array}$ & Waste storage and treatment & $\begin{array}{l}\text { These facilities occupy } 2.58 \text { acres on Mesita del Buey, a finger } \\
\text { mesa that is bounded by Canada del Buey Canyon on the north } \\
\text { and by Pajarito Canyon on the south. The complex lies on about } \\
700 \text { feet of Bandalier Tuff at an } 6,400-6,700 \text {-foot elevation. Solid } \\
\text { mixed wastes are managed at Area G, and chemical and mixed } \\
\text { wastes are managed at Area L. }\end{array}$ \\
\hline $\begin{array}{l}\text { Well-Water } \\
\text { Chlorination Station, } \\
\text { Pajarito Booster } \\
\text { No. 2, } \\
\text { (TA-54, Bldg. 1008) }\end{array}$ & Chlorination of well water & $\begin{array}{l}\text { This } 180 \text {-square-foot concrete-block building houses a chlorination } \\
\text { station for several wells. The building typically contains two } 150 \text { - } \\
\text { pound chlorine cylinders on line and five in storage. }\end{array}$ \\
\hline
\end{tabular}

Facilities marked with an asterisk (") were included in the field self-evaluation process. 


\subsection{SUMMARY OF RESULTS}

The field verification process was designed to use independent teams of safety professionals to verify the accuracy and completeness of data provided to the Chemical Safety Vulnerability Working Group by LANL facilities selected to participate in the field self-evaluation process. The verification process offers an opportunity to scrutinize site-specific chemical safety vulnerabilities and to make informed judgments about the possible relevance of these conditions to determinations of generic chemical safety vulnerabilities.

During the onsite portion of the review, team members visited facilities selected for selfevaluation and conducted interviews with site personnel to verify reported observations and to look for other conditions or circumstances that might result in chemical safety vulnerabilities. Water treatment facilities using chlorine that were not included in the original self-evaluation were also reviewed. Team members who visited these facilities coordinated with their site counterparts to arrange for the appropriate walkthroughs or interviews.

To support effective team management and to expedite the identification of vulnerabilities across a wide range of technical disciplines associated with chemical safety, the field verification review was organized to include five functional areas:

- Identification of chemical holdings, including the properties of chemicals located at the facility, the characterization of those chemicals, and an analysis of the inventory.

- Facility physical condition, including engineered barriers, maintenance conditions, chemical systems, safety systems, storage, monitoring systems, and hazards identification.

- Operational control and management systems, including organizational structure; requirements identification; hazard analysis; procedural adherence; maintenance control; engineering and design reviews; configuration control; safe shutdown plans; and site programs for quality assurance, chemical safety, inventory control, access control, disposal, transportation and packaging, and corrective actions.

- Human resource programs, including technical competence, staffing, training and qualifications, employee involvement, employee concerns, personnel performance requirements, and visitor and subcontractor access control.

- Emergency management program, including the emergency response plan, in-plant consequences, environmental issues, coordination with the community, and community right-to-know issues.

These functional areas were evaluated based on lines of inquiry provided in Attachment 1 of the "Field Verification Guide for the Chemical Safety Vulnerability Review," dated April 8, 1994. A summary of results for each of the functional areas is provided below. Completed chemical safety vulnerability forms resulting from the field verification activities at LANL are provided in Attachment 2 of this appendix. 


\subsection{Identification of Chemical Holdings}

Verification activities associated with the chemical holdings functional area included a review of chemical, hazardous, and mixed waste inventories and an evaluation of storage practices, chemical processes, and associated physical and administrative controls for facilities identified in the LANL chemical vulnerability self-evaluation. The review focused on those activities having a potential for presenting a significant risk to personnel, facilities, the public, or the environment. Chemicals and wastes observed at LANL included laboratory chemicals, acids, caustics, compressed gases, and radioactive and mixed wastes. Particular emphasis was placed on evaluating controls for highly toxic materials (including carcinogens) and acute toxins (including phosgene and arsine).

Chemical inventories at LANL are managed by the Automated Chemical Inventory System (ACIS), which was developed to upgrade chemical management capabilities at the Laboratory. ACIS is being actively used in LANL facilities for a number of purposes, including screening for chemicals that exceed threshold quantities established by the Occupational Safety and Health Administration (OSHA) and the Environmental Protection Agency (EPA) and to satisfy the reporting requirements of Title III of the Superfund Amendments and Reauthorization Act (SARA) for State, local, and Laboratory emergency planning organizations. LANL requires annual updates to the ACIS inventory, but the Materials Research and Processing Science Group (MST-5) at the Chemistry and Metallurgy Research Facility (CMR) (TA-3, BIdg. 29), on its own initiative, is using ACIS as a tool to control chemical inventory. The chemical safety coordinator for this group regularly updates ACIS whenever information related to changes in chemical inventory is provided.

Some features of ACIS are not currently being used (e.g., providing chemical inventory information on a near real-time basis and monitoring shelf life of chemicals). These features have not been implemented because of lack of resources within the Industrial Hygiene and Safety Group (ESH-5) and because the system has not been fully accepted by some Laboratory organizations. Weaknesses in ACIS as it is currently implemented were also observed. For example, the system does not require an industrial hygiene review of chemical purchases, LANL buyers do not always specify appropriate locations for delivery of purchased chemicals to facilitate bar-coding and entry into ACIS, and chemicals are not tracked to their ultimate waste form. In addition, chemical storeroom inventories managed by VWR Scientific, Inc., are not entered into ACIS until they are withdrawn from stores by a LANL requisitioner. Thus, ACIS does not accurately reflect the Laboratory's total chemical inventory at any given time.

Chemical and waste storage at LANL is performed in accordance with permits, requirements, and agreements between LANL, the State of New Mexico, and EPA. Generally, strict adherence to these requirements is observed and wastes are properly characterized, labeled, segregated, and supervised. Flammable chemicals at LANL are properly segregated and stored in accordance with the provisions of applicable administrative requirements (ARs). Storage of chemicals in laboratories is controlled by the LANL Chemical Hygiene Plan, which has been effective in controlling chemical storage of laboratory chemicals. However, storage criteria regarding other chemical-related issues (e.g.; incompatibilities, secondary containment, flammable vapor monitoring, or the concurrent storage of chemicals with radioactive or fissile materials) either do not exist or are unclear. 
Several hundred gallons of acids and caustics were observed in a small storage area in the CMR with several drums containing radioactive and fissile materials. Secondary containment was not in place to prevent the commingling of incompatible chemicals or damage to radioactive and fissile materials drums in the event of an unplanned chemical release. If an unplanned chemical release should occur, potential consequences include personnel exposures, violent chemical reactions, fire, radioactive materials releases, unnecessary hazardous or mixed waste generation, or exposure to the public or the environment. (See Vulnerability CSVR-LANL-OMS-03.)

Documented hazards analyses were available for all facilities reviewed in the self-evaluation, as well as for the Wastewater Treatment Facilities (TA-46). Draft safety analysis reports (SARs) were prepared for the High Pressure Tritium Laboratory (HPTL) (TA-33, Bldg. 86), the Explosives Development Processing Facility (TA-16, Bldg. 340), and CMR. A safety assessment was prepared for the Compressed and Liquified Gas Facility (TA-3, BIdg. 170), and preliminary hazards analyses (PHAs) were prepared for the Waste Storage Facilities (TA-54) and the Wastewater Treatment Facilities. The analyses varied in the extent to which chemical hazards were analyzed. The draft SAR for the CMR building includes a comprehensive analysis of chemical risks; in contrast, the draft SAR for the HPTL primarily considers radiological risks.

Because of a recent chlorine accident at the Idaho National Engineering Laboratory the field verification team was asked to expand the scope of its review to include operations at LANL facilities in which chlorine was used or stored. The main users of chlorine at LANL are the Wastewater Treatment Facilities and eight well-water chlorination stations located across the Laboratory. The wastewater plant is the only LANL facility of any type that routinely exceeds OSHA threshold quantities for hazardous chemicals cited in 29 CFR 1910.119 or 40 CFR 68. The wastewater plant uses 1-ton cylinders of chlorine and normally has an inventory of 8,000 pounds of chlorine, whereas the well-water stations use smaller 150-pound cylinders. The Pajarito Booster No. 2 well-water station normally has an inventory of 1,050 pounds of chlorine, and the Compressed and Liquified Gas Facility has an inventory of 1,200 pounds. Other facilities at LANL use smaller amounts of chlorine in lecture-bottle containers.

The chlorination systems examined by the verification team were modern and well maintained. Designs used for chlorine feed and cylinder storage and procedures for chlorine alarm response, chlorine station entry, and cylinder changeout were found to be satisfactory and minimized hazards arising from potential chlorine leaks. However, the Wastewater Treatment Facilities are not equipped with a direction indicator (e.g., windsock) to ensure that personnel are able to evacuate the site upwind of a potential airborne release. A single crew of trained operators changes out all chlorine cylinders on the site. Changeout procedures require that an operator entering the chlorine room carry a full-face respirator equipped with a chlorine cartridge. A standby operator with a self-contained breathing apparatus (SCBA) must be present. At LANL, operators carry the respirators but do not wear them routinely. A chlorine monitor is installed in each chlorination facility.

A release from the wastewater plant could affect occupants of nearby buildings or the public. About 600 people are housed in LANL buildings located within 1 kilometer of the Wastewater Treatment Facilities. Although there were no indicators that the risk of chlorine release at LANL is higher than that for well-designed and well-maintained municipal facilities, use of 
alternatives to gaseous chlorination (e.g., sodium hypochlorite solution or ultraviolet treatment) would decrease risks. A process safety management program has been prepared and is currently being implemented at the Wastewater Treatment Facilities.

Liquid and solid wastes at LANL are characterized at the point of generation through process knowledge and/or sampling and analysis before disposition. At the waste management facility in TA-54, 1 percent of all incoming waste containers are sampled as a quality assurance measure. An innovative labeling system used at LANL incorporates DOE, Clean Air Act (CAA), Department of Transportation, EPA, LANL, Resource Conservation and Recovery Act (RCRA), and American National Standards Institute labeling requirements into a single label that is more efficient and reduces opportunities for error.

Solid mixed waste is managed at TA-54, Area G, in an enclosed structure. Chemical and liquid mixed wastes are managed at TA-54, Area $L$, where a waste pit, 3 surface impoundments, and 34 shafts were originally located. Area $L$ has since been capped and paved. The area is controlled physically and administratively and will eventually be remediated under the Hazardous and Solid Waste Amendments to RCRA. Active storage units for mixed waste have been located on the open paved area where they are exposed to the elements. Two thousand drums of mixed and nonregulated radioactive waste are being stored at this location. Construction of a storage building is expected to begin in June 1994. About 500 cylinders of waste flammable and toxic gases are stored in Area L. By the end of 1994, all but about 100 cylinders will have been transferred to offsite treatment facilities. The ultimate disposal plan for the solid mixed waste, liquid mixed waste, and waste compressed gas cylinders is being developed under the Federal Facility Compliance Agreement. The facility is being operated in accordance with its RCRA permit. (See Vulnerability CSVR-LANL-CH-01.)

At CMR, the team noted delays in the disposition of hazardous wastes from a satellite accumulation area where waste is being held from a laboratory that has been abandoned for more than 2 years. These delays were attributed to a lack of sufficient sampling and analytical support.

The LANL Environment, Safety and Health (ESH) Division is responsible for administering the Spill Prevention Control and Countermeasure Plan, which provides for spill prevention, secondary containment, quick spill response, and cleanup of oils and chemicals. Defined engineering and administrative controls reduce risk to workers and the public. Records indicate that few chemical spills are reported at LANL and that most of these can be traced to container handling and equipment leaks.

The Water Quality and Hydrology Section of the Environmental Protection Group (ESH-8) has responsibility for the identification and characterization of hazardous constituents in wastewater discharges. All outfalls have been identified and characterized. Sixty-two outfalls are in the process of being permitted in accordance with EPA National Pollutant Discharge Elimination System requirements. Engineering and administrative controls are in place to prevent unplanned releases of regulated materials into the environment.

The Air Quality and Meteorology Section of the Environmental Protection Group (ESH-8) is responsible for quantifying nonradioactive air emissions at LANL. Air emissions sources have 
been divided into three categories: (1) power plants, (2) potable and wastewater treatment facilities, and (3) remaining laboratory facilities. Emissions from the power plant and water treatment facilities are based on measurements and process knowledge. Other facility emissions are generally quantified using the assumption that the quantity of chemicals purchased is the quantity released. LANL's approach is conservative and meets the requirements of the CAA and the State of New Mexico operating permit program.

Verification activities related to the identification of chemical holdings indicated that chemicals and wastes at LANL are being managed responsibly and appropriately. The two vulnerabilities related to this functional area emphasize the need for continued efforts in addressing chemical safety issues at LANL. (See Vulnerabilities CSVR-LANL-CH-01 and CSVR-LANL-OMS-03.)

\subsection{Facility Physical Condition}

Verification activities associated with the facility physical condition functional area included review of general maintenance conditions at all facilities selected to participate in the field selfevaluation. The review focused on conduct of maintenance activities, maintenance program controls, work controls, and structural and mechanical integrity for various systems and structures (e.g., heating, ventilation, and air conditioning).

Facility physical conditions observed by the field verification team varied among the facilities visited. For example, the Compressed and Liquified Gas Facility (TA-3, Bldg. 170) was in excellent condition, but portions of the Explosives Development Processing Facility (TA-16, Bldg. 340) were in fair to poor condition. Maintenance activities are generally accomplished in a safe manner. When appropriate safety measures are included, work control documents are generally adequate to control maintenance activities. Improvements in this aspect of work control are needed.

The Chemistry and Metallurgy Research Laboratory (TA-3, Bldg. 29) is currently in a transition phase. Equipment in many laboratories has been removed, and plans are in place to convert the facility to other missions. Several modifications are now under way, including the replacement of electrical system switchgear. To refurbish or upgrade the facility in a manner that meets current standards requires replacement or repair of old or obsolete equipment (e.g., exhaust fans and filter equipment). This situation represents a chemical safety challenge because much of the equipment may be contaminated with residual hazardous and/or radioactive material. Characterization of these systems and equipment to determine the extent of this contamination is not yet complete. However, a conceptual design review has been undertaken to address these issues.

Maintenance at the Explosives Development Processing Facility needs more attention. The LANL self-evaluation noted instances of residual explosive material in this facility. At the time of this review, general system and facility conditions were only fair to poor; specifically, the roof showed evidence of cracks and leaks, pressure and temperature instrumentation for process systems was not well maintained, and deactivated equipment had not been removed from individual explosive process bays. Process equipment in the facility is in acceptable condition, but some has not been operated for several years. These problems can be traced to lack of program funding for maintenance activities and lack of workload for the facility. 
Surveys of user groups have been conducted to determine what equipment should receive continued maintenance and what should be put into standby, thereby facilitating more efficient use of limited resources. To complicate this situation, plans are under way to use two of the facility's nine bays for work activities being transferred from another DOE facility. However, the funding to implement upgrades needed to support this change in workload has not yet been approved by DOE.

Conditions at the High Pressure Tritium Laboratory (HPTL) (TA-33, Bldg. 86) have improved consistently since 1992, although problems still exist. For example, work areas were cleaned up and contaminated items were removed to approved waste storage areas. Attempts have been made to process and remove accountable tritium via installed systems, but the poor reliability of the process equipment limited the success of this effort. Accountable amounts of tritium remain in process systems. Accessible portions of the facility are generally in good condition, and maintenance is conducted in a manner ensuring that most of the facility (e.g., heating and ventilation systems) will continue to function properly. The tritium process systems could not easily be maintained because of high levels of contamination and the age of the equipment. Funding for maintenance and operations activities and for characterization and removal of residuals in fiscal year (FY) 95 has not yet been identified. The only potential source of funding appears to be reprogrammed Laboratory funds provided by the Headquarters Office of Defense Programs. (See Vulnerability CSVR-LANL-OMS-02 for a discussion of how lack of funding for aging facilities has contributed to a potential chemical safety vulnerability.)

The Waste Storage Facilities at TA-54 and the Compressed and Liquified Gas Facility were observed to be in very good physical condition. Maintenance activities at the gas plant are especially effective, and the facility is maintained in a manner that would minimize problems involving chemical safety. A recently completed modification of the lightning arrestor system was noted as a positive maintenance upgrade that improved the safety of flammable gas storage areas. The waste storage area at TA-54 does not represent a significant maintenance problem. Because the facility's inventory of operating equipment is small, maintenance requirements are few.

Corrective and preventive maintenance conducted at LANL are primarily accomplished by the support contractor (i.e., JCl) or by dedicated technicians at individual facilities. Safety and health and maintenance engineering personnel interact successfully with the maintenance work force. Work control documentation requires input from the Environment, Safety and Health (ESH) Division staff before most work activities begin. The only exception to this involves equipment related to specific programs-for example, the Explosives Development Processing Facility, where onsite specialists accomplish the required safety reviews. JCl has only a limited safety and health staff, which must interact with laboratory personnel for ensuring safe work practices. The ESH Division has implemented other controls to ensure that proper safety measures are incorporated into work activities. For major tasks, an environment, safety, and health (ES\&H) questionnaire is provided to the initiating group to identify appropriate information and/or concerns related to the proposed work activities. When used, information from the questionnaire is translated into safety requirements in subsequent work process documents. Enhancements in the use of this questionnaire are being planned. 
Maintenance activities at LANL are generally conducted in a manner that reduces the potential for chemical hazards; however, the age of some facilities and the lack of sufficient funding for maintenance activities could contribute to chemical safety vulnerabilities in the future. (See Vulnerability CSVR-LANL-FM-02.)

\subsection{Operational Control and Management Systems}

Verification activities for the operational control and management systems functional area at LANL followed the lines of inquiry established by the Chemical Safety Vulnerability Working Group. Each of the self-evaluation reports compiled by LANL referenced management programs, procedures, and/or reports that were used to conduct preliminary interviews and to establish areas of emphasis related to the transition and cleanup of aging facilities containing chemical residues.

A recent Laboratory-wide reorganization has resulted in broader spans of control and has eliminated a layer of management. At the same time, a Laboratory Leadership Council has been formed, consisting of the Laboratory Director and Deputy Director, Division Directors, Program Directors, Office Directors, and the Laboratory Counsel. These changes are intended to force decision making down through the organization and to promote horizontal integration of the various divisions, offices, and program directorates. In addition, a facility manager concept is being implemented to promote line management ownership of ES\&H matters and to provide for the overall management and operation of major Laboratory facilities or groups of facilities. These changes have created a measure of uncertainty about ES\&H roles and responsibilities throughout the Laboratory, but they have not compromised chemical safety at LANL.

Chemical safety at LANL is implemented through multiple programs. No Laboratory-wide policy for chemical safety exists; however, various administrative requirements (ARs) are in place to implement programs that support chemical safety. No single document describes an overall chemical safety program or how various programmatic elements are integrated. In addition, the implementation of programs supporting chemical safety has been fragmented. The verification team concluded that LANL has many of the essential elements in place for a good chemical safety program, but a consistent overall approach for implementing such a program is lacking. (See Vulnerability CSVR-LANL-OMS-03.)

Information on hazards is effectively communicated to employees. Health hazard information is available and accessible to Laboratory employees through the use of material safety data sheets (MSDSs) and through contact with representatives from the Industrial Hygiene organization. Implementation of requirements for the application of labels and hazard warnings to chemical and waste containers and process lines has been one of LANL's successes-chemicals and waste materials have been effectively labeled.

The effectiveness of procedures and administrative controls varies greatly within the Laboratory. At some facilities (e.g., Explosives Development Processing Facility; TA-16, Bldg. 340), formal procedures govern operations and personnel adhere strictly to these requirements. In laboratory areas (e.g., the Chemistry and Metallurgy Research Facility, or CMR; TA-3, Bldg. 29), procedures and controls are often viewed as guidelines. Employees, scientists, and supervisors occasionally make individual judgments about how Laboratory 
policies and guidelines should be applied. Adherence to policies, procedures, and controls is not uniform across the Laboratory, and prescriptive sitewide guidance related to this issue does not exist.

Although ARs specify storage criteria for wastes, flammable liquids, and laboratory-scale chemicals, LANL has not established criteria addressing chemical incompatibilities, flammable vapor monitoring, or the concurrent storage of chemicals with radioactive or fissile materials. At present, chemical storage criteria are established informally on the basis of discussions between facility and ES\&H personnel.

Medical surveillance programs, including those for asbestos, beryllium, lead, carcinogens, highly toxic chemicals, and hazardous wastes, have been established to manage health risks for LANL employees. Workplace monitoring is performed to support these functions, and minimal monitoring is conducted to address personnel exposures for personnel not enrolled in designated medical surveillance programs. For example, baseline monitoring has not been performed for personnel working in the Explosives Development Processing Facility because these workers are not considered to be "high risk." Although hazard inventories exist for some waste and chemical process facilities, LANL has not implemented a sitewide hazards inventory program. The Industrial Hygiene and Safety Group (ESH-5) has requested Laboratory funding for a health hazards assessment program that would identify chemical, physical, and biological hazards in the workplace and that would result in a risk-based approach for mitigating those hazards. The funding request for this program has been submitted twice over the past 2 years but has not been approved.

LANL provides safety equipment and necessary personal protective equipment for employees performing work with chemicals and wastes. However, some emergency eyewash units have not been selected or installed appropriately. Drench hoses are often installed where eyewashes are necessary; nonpotable water may be used instead of potable water; and eyewash and shower stations may not be readily accessible. Inappropriate or inaccessible emergency wash stations could contribute to personal injury in the event of an accident involving hazardous chemicals or wastes.

An ES\&H questionnaire (described in AR 1-10, "Environment, Safety, and Health Questionnaire," dated August 30,1991 ) is used to review proposed research projects, process changes, and facility modifications. As a result of this process, chemical, carcinogenic, and biological hazards are identified and mitigating actions are developed. Although this system provides a framework for identifying hazards, it has not been implemented consistently or in a timely manner.

The lessons-learned program at LANL is managed by the Appraisal and Performance Analysis Group (AA-1) of the Audits and Assessments Office. The current program has been in existence since early 1992. This group publishes information bulletins, good work practice bulletins, lessons-learned newsletters, and lessons-learned caution bulletins. This information is distributed to LANL managers (group leaders and above) and to other interested parties. In addition, facility managers and trainers collect lessons-learned information from a variety of other sources (e.g., the operating experience weekly summary originating within the Occurrence Investigation Group, ESH-7). At the facilities visited during this review, however, interviews indicated that lessons learned do not always reach facility managers, trainers, or 
workers. For example, when asked about a recent chlorine uptake incident at the Idaho National Engineering Laboratory, no one knew about the accident. In fact, the facility manager of the Compressed and Liquified Gas Facility (TA-3, Bldg. 170) indicated that he learned about the incident during the inbriefing for this review. The LANL lessons-learned program is expected to benefit from recommendations of the newly established DOE Lessons Learned Working Group, which includes representation by AA-1.

A new configuration management system is currently being implemented at CMR.

Authorization basis documents will serve as the baseline for change control. As part of that plan, the facility manager at CMR is attempting to document process histories and to update building configuration drawings wherever possible. At present, changes to chemical processes and related equipment are reviewed only insofar as they affect the baseline authorization basis documents. However, any new activities involving Category I chemicals are reviewed by ESH-5.

Although a formal configuration management plan does not exist at the Explosives Development Processing Facility, changes to chemical processes and equipment are carefully controlled through the use of special work permits (SWPS) and high-explosive documents (HEDs). Both SWPs, used for temporary or experimental changes, and HEDs, used for major changes to chemical processes and systems, require a minimum of two levels of line management approval, as well as review and approval by the Environment, Safety and Health Division.

Loss of corporate knowledge related to process and facility history at both the CMR and the High Pressure Tritium Laboratory (HPTL) (TA-33, Bldg. 86) is an issue impeding the progress of cleanup activities. For example, wastes have been stored in Wing 4 of the CMR for 2 years. The contents of these containers must be analyzed because the generator of these wastes is no longer at LANL. Similarly, knowledge about processes and building systems at HPTL resides essentially with one person who is currently a Laboratory Associate. HPTL management expressed concern that this individual may not be available for the protracted timeframe required for the characterization and removal of tritium and other chemical residues.

Based on interviews conducted at the Waste Storage Facilities (TA-54, Area L) and the Compressed and Liquified Gas Facility and on a spot check of training records, the verification team concluded that drivers transporting hazardous materials meet all established requirements and that their certifications are current.

Overall, LANL has many of the essential elements in place for a good chemical safety program. However, program effectiveness has been hampered by lack of a consistent approach to program implementation.

\subsection{Human Resource Programs}

Verification activities associated with the human resource programs functional area at LANL focused on technical competence, staffing, training and qualifications, employee involvement, employee concerns, personnel performance requirements, and visitor and subcontractor access control. During the course of these activities, no chemical safety vulnerabilities related to human resource programs were identified. 
At the facilities visited, the field verification team concluded that employees are competent to perform their duties and are dedicated, conscientious about safety, and strongly motivated to excel. Further, employees exhibited a high level of knowledge specific to facility mission, priorities, procedures, operations, and job safety. In most cases, personnel assigned to specific programs and projects have several years of relevant experience.

In general, staffing levels at the reviewed facilities are adequate to ensure that work involving chemical hazards is accomplished safely and within the bounds of established procedural constraints. Routine operations requiring use of the "buddy system" (e.g., entry into toxic gas storage areas or placing chlorine cylinders in or out of service) are adequately staffed. In the event that sufficient qualified personnel are not available to perform a given task, the work is placed on hold. None of the facilities visited require employees to work exorbitant amounts of overtime. In fact, overtime rates overall are very low.

Where appropriate, supervisors and employees cooperate to develop individual training plans for each worker and to identify the types of training required to perform specific tasks for which the employee will be responsible. The ES\&H Course Catalog contains descriptions of the courses offered by the LANL ES\&H Training Group, as well as job-specific training matrices and hazard-specific training guidelines. Included in the catalog are course descriptions and recommended audiences for topics such as asbestos awareness, beryllium health hazards, cryogen safety, hydrogen gas safety, and pressure safety. Not every chemical in use at the reviewed facilities is specifically addressed in the catalog, but training coordinators and operations managers who use the catalog find it beneficial for designing individual training plans. Unfortunately, not all training coordinators know that the catalog is available. Those who learned about its existence during this review requested a copy for future use.

At each facility visited, it was clear that management actively solicits employee involvement to identify and correct workplace hazards, including chemical hazards. When new tasks or projects are undertaken at a facility, workers and management work together to identify potential hazards. This type of cooperation is evident during the planning stage, during equipment installation and checkout (if applicable), during the writing and reviewing of test and operating procedures, and during the actual testing and operation stage of each new task or project.

At LANL, the Whistleblower Policy Office and the Employee Customer Concerns Office (ECCO) receive employee concerns via several means, including the Whistleblower Hotline, the ES\&H Hotline, and the ES\&H Deficiency Ticket System. Employees can use these mechanisms to report unsafe conditions or practices associated with hazardous chemicals or any other concern. Personnel at ECCO and the Whistleblower Policy Office have developed effective means for dealing with issues brought to their attention, including maintaining confidentiality, channeling concerns to the right managers for resolution, providing feedback to initiators, and, when appropriate, providing input to the LANL lessons-learned program. To the extent possible, employee concerns raised anonymously are processed in the same manner as those for which names are included. The ECCO and the Whistleblower Policy Office are currently active in processing employee concerns. A search of the ECCO data base (which includes the ES\&H Hotline, ES\&H Deficiency Tickets, the Laboratory Suggestion Program, and the Customer Concerns Program) indicated that in 1992 and 1993 about 
13 percent of the issues reported dealt with chemical safety, about 85 percent of which have been tracked to closure. However, not all employees understand that these programs are active and may be used to raise concerns. The reason for this can be traced to the recent LANL reorganization, which shifted many responsibilities and programs from one organization to another. Workers seem to be aware of the programs' existence before the reorganization, but some are uncertain about the current program status. Confusion should diminish as the reorganization matures.

All workers interviewed demonstrated a solid understanding of their "stop work" authority, as promulgated by LANL ES\&H training and reinforced by management policies and direction. Workers indicated that they would be comfortable in exercising this authority, as demonstrated by two instances described to the team in which that authority was actually invoked.

At the time of this review, LANL was in the process of testing the recently implemented "360 Degree" employee appraisal system in two of its divisions, including the Dynamic Experimentation Division. This system provides for the traditional review of employee performance, including safety performance, by management. In addition, this system provides a mechanism for workers to participate in the evaluation of management's performance. This approach for appraising employee performance has the potential to increase employee and management accountability for safety at all personnel levels.

At each of the facilities visited during this review, access control was excellent, with particular emphasis placed on controlling access by visitors, subcontractors, and others not normally assigned to the facility. Unauthorized access to potential chemical hazards is effectively prevented either by using locked gates or by posting guards. Where locked gates are used, facility-specific indoctrination training, including chemical safety, must be satisfactorily completed before escorted access is allowed. At the two facilities with posted guards, an access list is checked by a guard before casual visitors and their escorts are allowed to proceed past the guard post. Facility managers at these locations have implemented control measures that require a visitor to complete the required access training before his or her name is added to the access list.

Although some weaknesses exist, the verification team concluded that human resource programs at LANL have the necessary elements in place to ensure the safety of workers and visitors at facilities in which chemical hazards exist. Areas for improvement appeared to be recognized by those who were interviewed, and appropriate steps are being taken to effect the desired improvement.

\subsection{Emergency Management Program}

Verification activities for the review of the emergency management program functional area included evaluation of the effectiveness of emergency management activities, plans, and program elements as they relate to chemical safety at selected LANL facilities. All facilities examined by the LANL self-evaluation were reviewed, and the scope of the review was expanded in some emergency management areas to include sitewide emergency operations at LANL. 
The LANL Emergency Management System comprises several comprehensive emergency management program elements, including emergency plans and emergency plan implementing procedures (EPIPS), coordination between LANL and the community, emergency response training, drills and exercises, emergency supplies and equipment, and emergency support facilities.

The top-level document establishing and describing LANL's overall emergency management program is the Los Alamos National Laboratory Emergency Management Plan 1993 (LANL EMP) and its associated EPIPs. These documents specifically address emergency response to hazardous chemical accidents. Subordinate to the LANL EMP are specific Building Emergency Plans (BEPs) for facilities in each technical area, relevant standard operating procedures, and pre-fire plans. The Laboratory and Los Alamos County have established an Emergency Management Steering Committee (which includes representatives from offsite agencies) to meet for the purpose of reviewing, analyzing, and discussing emergency planning, preparedness, and response issues. An external Local Emergency Planning Committee (LEPC) is currently being designed and will include a representative from LANL. The LANL Emergency Management System is already well integrated, but the formation of the LEPC will help improve integration and coordination with offsite agencies.

In the event of a hazardous chemical emergency, occupants of the affected facility would evacuate to a predesignated staging area. A sitewide " 911 " telephone line and several radio channels are available to report occurrences promptly. A "911" call or a radio transmission reporting an incident would go to LANL's Central Alarm Station, where a 24-hour-a-day dispatcher would initiate onsite and offsite emergency response notifications. Several automatic alarms can also generate a chemical emergency response through the Central Alarm Station.

LANL has effectively implemented the use of the Incident Command System in response to all emergencies. The Incident Command System is based on the on-scene management structure protocols of the Federal Emergency Management Agency's National Interagency Incident Management System. The LANL Incident Control Group is part of the LANL Emergency Response Organization. This Incident Control Group is composed of an emergency manager, who assumes the role of the Incident Commander from the initial incident commander at the scene; emergency response personnel with command functions; and specialized teams, as required (e.g., the Laboratory's Hazardous Material [HAZMAT] Response Team, the Crisis Negotiation Team, or the Hazardous Device Team). Local police support, traffic control, and fire and medical response are provided by agreements with Los Alamos County. These personnel respond and function under protocols associated with the Incident Command System. The State of New Mexico and various local communities provide additional support through agreements or memorandums of understanding (MOUs). Federal support is provided through agreements and by request. LANL has 21 such agreements or MOUs in place.

The frequency of formal drills and exercises that include full-scale offsite agency participation and that emphasize hazardous chemical accident scenarios has doubled since 1992. On January 13,1994, LANL's annual exercise scenario focused on an accident involving a stakebed trailer truck carrying three 1-ton chlorine cylinders. Based on the increased complexity of the scenarios and the incorporation of multiagency participation, the quality of 
these drills is good and is improving. A relatively new Hazardous Materials Training Facility in TA-49 is being used to train and conduct practical hands-on HAZMAT drills for both onsite and offsite emergency response organizations (including State organizations). The facility is being supplied with a variety of props for hazardous materials drills, including a wrecked vehicle, leaking process system pipes, ruptured tanks; leaking drums, leaking gas cylinders, mannequins, and a small building used as a drill site. Additional enhancements are planned, including preestablished training areas containing specific types of permanent training props, thereby reducing the staging time for drills. A routine training drill observed at the facility during this review indicated that cooperation, trust, and cross-training between the various specialized teams are facilitated by these activities. The field verification team considers the development and use of this facility to be a commendable practice.

Some facilities reviewed at LANL contain significant quantities of hazardous chemicals. Sufficient types and quantities of HAZMAT response equipment and spill materials are available to mitigate incidental, nonthreatening, easily containable spills. The responses required for a larger spill include evacuating the facility and making appropriate notifications. The HAZMAT Response Team is responsible for containing and/or mitigating HAZMAT situations. The HAZMAT Response Team is part of the Hazardous Materials and Response Group (ESH-10) and, based on its composition, is unique within the DOE complex. The team consists of dedicated, full-time personnel who are trained to the HAZMAT "specialist" level, most of whom have received several hundred hours of HAZMAT training. Professional personnel have either industrial hygiene or health physics backgrounds. The team has been equipped with a state-of-the-art HAZMAT vehicle, plus other vehicles and trailers containing personnel protective equipment, supplies, and the tools needed to mitigate HAZMAT situations. On request, the team provides HAZMAT response to LANL, surrounding communities, and the State of New Mexico. In addition, ESH-10 coordinates safety and health support for the offsite deployment of the Accident Response Group, the Nuclear Emergency Search Team, and the Radiological Assistance Plan.

LANL maintains an Emergency Operations Center (EOC) in TA-59 and an alternate EOC in TA-49 to support the Laboratory's emergency response efforts. After touring these facilities, the field verification team concluded that the LANL EOC is in excellent condition and contains mostly state-of-the-art equipment. A computer software model, Meteorological information and Dose Assessment System (MIDAS), was recently installed to calculate and display hazardous material plume dispersions. As part of the Laboratory's search for better modeling accuracy, and at significant cost and effort, MIDAS has been extensively modified to incorporate site-specific meteorological factors to account for the effects of the complicated local terrain on dispersion calculations performed at the LANL site. The field verification team considers these modifications to be a commendable practice. The Laboratory has the capability to perform hazardous chemical plume dispersion calculations by various approved computer models both in the EOC and in the field.

LANL has developed, maintains, and continues to improve its Emergency Management System. The system is fully capable of responding to and mitigating the consequences resulting from chemical emergencies. No explicit chemical vulnerability issues related to the LANL Emergency Management System were identified. 


\subsection{CATEGORIZATION AND PRIORITIZATION OF VULNERABILITIES}

\subsection{Criteria}

A vulnerability is defined as a weakness or potential weakness involving hazardous chemicals that could result in a threat to the environment, the public, or worker health and safety. Vulnerabilities can be characterized by physical or programmatic conditions associated with uncertainties, acknowledged deficiencies, and/or unacknowledged deficiencies in the area of chemical safety. Conditions required to create the vulnerability should either currently exist or be reasonably expected to exist in the future based on degradation of systems and chemicals or through expected actions (e.g., D\&D of facility).

A vulnerability will be determined to exist if current or expected future conditions or weaknesses could result in either of the following:

- The death of or serious physical harm ${ }^{1}$ to a worker or a member of the public or continuous exposure of a worker or member of the public to levels of hazardous chemicals above hazardous limits; or

- Environmental impacts resulting from the release of hazardous chemicals above established limits.

The prioritization of chemical safety vulnerabilities is based on professional judgment of team members concerning the immediacy of the potential consequences posed by each vulnerability and on the potential severity of those consequences. The first step in the prioritization process was to group vulnerabilities according to the timeframe in which they are expected to produce consequences. The following categories are defined for the timeframe within which the consequences are expected to occur:

- Immediate - Any chemical safety vulnerability that could result in immediate consequences.

- $\quad$ Short-Term - Any chemical safety vulnerability at a facility in which there is a significant chance of a consequence occurring within a 3-year timeframe as a result of chemical degradation, change in mission for the facility, degradation of the containment systems, change in personnel at the facility, or other factors affecting the facility.

- Medium-Term - Any chemical safety vulnerability at a facility in which there is a significant chance of a consequence occurring within a 3-10-year timeframe as a result of chemical degradation, change in mission for the facility, degradation of the containment systems, change in personnel at the facility, or other factors affecting the facility.

1 Serious physical harm is defined as impairment of the body, leaving part of the body functionally useless or substantially reducing efficiency on or off the job. 
- Long-Term - Any chemical safety vulnerability at a facility in which there is a significant chance of a consequence occurring within a timeframe of more than 10 years as a result of chemical degradation, change in mission for the facility, degradation of the containment systems, change in personnel at the facility, or other factors affecting the facility.

Vulnerabilities within each category should be further prioritized to specify "high," "medium," or "low" priority. Consequences of high priority would cause death or irreversible injury to workers or the public, or would cause environmental damage that would be irreversible or very costly to remediate. Low-priority consequences would consist of reversible injuries, illnesses, or environmental damage.

\subsection{Chemical Safety Vulnerabilities at Los Alamos National Laboratory}

The chemical safety vulnerabilities summarized in this section were derived from observations made during the field verification process. Three vulnerabilities were identified at Los Alamos. These vulnerabilities have been prioritized in accordance with guidance provided in Section 3.1, which was derived from Attachment 7 of the "Project Plan for the Chemical Safety Vulnerability Review," dated March 14, 1994. (Completed vulnerability forms are provided in Attachment 2 of this appendix.)

CSVR-LANL-CH-01: Significant accumulations of hazardous chemicals and wastes are being stored for prolonged periods, some under unsatisfactory conditions.

A legacy of hazardous chemicals and wastes, resulting from decades of operations, exists at LANL. Many of these materials are being collected, characterized, stored, and prepared for disposal. Some materials are stored temporarily under less-than-satisfactory conditions that could lead to personnel hazards or environmental releases caused by leakage from corroded tanks, drums, or gas cylinders. For example, the deterioration of drums and cylinders exposed to the elements could result in the release of hazardous chemicals and radioactivity. These conditions and circumstances represent a medium-priority vulnerability with a potential for short-term consequences.

CSVR-LANL-FM-02: The lack of funding could affect the safe cleanup or transition of aging and/or inactive facilities.

Many aging and/or inactive facilities at LANL are candidates for transition (e.g., to D\&D). Funding for these facilities is uncertain or not available, and workload changes are contemplated. These circumstances result in an unacceptable level of maintenance and surveillance at facilities in which residual hazardous chemicals may pose a threat to workers, the public, or the environment. These conditions and circumstances represent a mediumpriority vulnerability with a potential for short-term consequences.

CSVR-LANL-OMS-03: The absence of a consistent approach to chemical safety at Los Alamos National Laboratory can result in unanticipated chemical risks.

The absence of a consistent and integrated approach to chemical safety at LANL has resulted in improper chemical safety practices. A Laboratory-wide chemical safety policy does not exist, and supporting programs have not been developed in a timely manner. The absence of 
a consistent and integrated chemical safety program could result in a variety of undesirable consequences: chemical inventories may be inaccurate; waste in facilities and process equipment may not be properly characterized; unwanted chemical reactions, including explosions, could occur; workers, the public, and the environment could be exposed to hazardous substances; fires could be started; and unnecessary hazardous or mixed waste could be generated. These conditions and circumstances represent a medium-priority vulnerability with a potential for short-term consequences. 
K-28 


\section{ATTACHMENT 1}

TEAM COMPOSITION

\section{Area of Responsibility}

Team Leader

Management/Operations

Management/Training

Chemical Process Safety

Industrial Hygiene

Environmental Protection

Maintenance

Emergency Management

Site Liaisons

Senior Coordinator

Coordinators-In-Training

Technical Editor

\section{Name/Organization}

Leonard M. Lojek

Office of Safety and Quality Assurance

U.S. Department of Energy

Bernard R. Kokenge

BRK Associates, Inc.

Nels C. Jensen

EG\&G Idaho, Inc.

Harold J. Groh

HJG, Inc.

Ronald E. Alexander

Environmental Management Associates

Julie M. Magness

EG\&G Mound Applied Technologies

David M. Johnson

Program Management, Inc.

Robert D. Mogle

Battelle, Pacific Northwest Laboratory

John T. Ryan

Los Alamos Area Office

U.S. Department of Energy

Jeffrey E. Schinkel

Los Alamos National Laboratory

Stephanie G. West

Fernald Environmental Management Company of Ohio

Lisa L. Alexander

Program Management, Inc.

Florence G. Parkhill

Program Management, Inc.

Darla Treat Courtney

Environmental Management Associates 
$K-30$ 


\section{ATTACHMENT 2}

CHEMICAL SAFETY VULNERABILITY REVIEW

VULNERABILITY FORM

DATE: May 25, 1994

Site/Facility: $\quad$ Los Alamos National Laboratory

Vulnerability Number: CSVR-LANL-CH-01

Functional Area(s): Identification of Chemical Holdings

1. Brief Description of Vulnerability.

Significant accumulations of hazardous chemicals and wastes are being stored for prolonged periods, some under unsatisfactory conditions.

2. Summary of Vulnerability.

A legacy of hazardous chemicals and wastes, resulting from decades of operations, exists at Los Alamos National Laboratory (LANL). Many of these materials are being collected, characterized, stored, and prepared for disposal. Some materials are stored temporarily under less-than-satisfactory conditions that could lead to personnel hazards or environmental releases caused by leakage from corroded tanks, drums, or gas cylinders.

3. Basis.

a. Requirements:

- 29 CFR 1910.119, "Process Safety Management of Highly Hazardous Chemicals," describes process safety management programs for preventing or minimizing the consequences of releases of toxic, reactive, flammable, or explosive chemicals.

- 40 CFR 68, "Risk Management Programs for Chemical Accidental Release Prevention," requires hazards assessments and risk management plans for accidental chemical release prevention.

- DOE 5480.10, "Contractor Industrial Hygiene Program," requires contractors to identify and evaluate chemical hazards in the workplace and to implement control measures to prevent or minimize exposure to these hazards.

- 40 CFR 260 through 40 CFR 270, "Federal Hazardous Waste Management Regulations," describe generation, treatment, storage, and disposal of hazardous wastes.

- Federal Facility Compliance Agreement (FFCA), dated June 1993, outlines schedules for characterization, treatment, and disposal of mixed wastes at LANL.

b. Chemicals Involved:

- Flammable and toxic gases

- Mixed hazardous waste

- Radioactive liquid wastes

c. Relevant Self-Evaluation Data: The self-evaluation lists drums of mixed wastes and gas cylinder wastes, recognizes the potential for deterioration and leakage, and describes a plan to erect a shelter over the mixed-waste drums. 
Site/Facility: Los Alamos National Laboratory

Vulnerability Number: CSVR-LANL-CH-01

Functional Area(s): Identification of Chemical Holdings

3. Basis. (Continued)

d. Contributing Causes:

- Aging drums and cylinders are susceptible to leakage.

- The decision-making process for negotiating and implementing disposal options is protracted.

- Technologie's to treat and dispose of wastes are limited.

e. Potential Consequences: The deterioration of drums and cylinders exposed to the elements could result in the release of hazardous chemicals and radioactivity, causing worker exposures and releases to the environment. These conditions and circumstances represent a medium-priority vulnerability with a potential for short-term consequences.

4. Supporting Observations.

The verification team did not conduct a comprehensive review of legacy wastes at LANL. The following examples were observed at the facilities included in the self-evaluation report.

- Several thousand gas cylinders containing a wide variety of flammable and toxic gases were collected from LANL facilities during 1990-91 and stored as waste at the Waste Storage Facilities (TA-54, Area $L$ ). About 500 cylinders remain at the site, about 30 of which are uncharacterized. The remaining uncharacterized cylinders will be sampled and analyzed by an onsite contractor by June 1994 . The cylinders are stored in metal racks in Area $L$ under a structure consisting of an aluminum frame and laminated polyester fabric; the structure is equipped with lightning protection. The uncharacterized cylinders are stored separately from those that have been characterized. Many cylinders are old and corroded. Gases contained in the waste cylinders include flammables (e.g., propylene, isobutane, hydrogen, and methane), corrosive gases (e.g., hydrogen fluoride, hydrogen chloride, nitric oxide, and sulfur dioxide), and toxic gases (e.g., arsine, phosgene, cyanogen, and phosphine). By the end of 1994, all but about 100 cylinders will have been transferred to offsite treatment facilities. The remaining cylinders are radiologically contaminated, are not in Department of Transportation-approved containers, or cannot be processed in offsite treatment facilities. Disposition plans for the remaining cylinders are being developed under the FFCA between the Los Alamos Area Office and Environmental Protection Agency (EPA), Region 6. Disposal will probably require new treatment units at LANL and may take several years to complete. 
Site/Facility: $\quad$ Los Alamos National Laboratory

Vulnerability Number: CSVR-LANL-CH-01

Functional Area(s): Identification of Chemical Holdings

4. Supporting Observations. (Continued)

- About 4,000 drums of waste have been accumulated in above-ground storage facilities at TA-54.

- At Area $L$, about 1,000 drums of mixed waste and 1,000 drums of nonregulated, radioactive wastes are stored on wooden pallets, unprotected from the weather and stacked two or three drums high. Thirty of the 2,000 drums remain uncharacterized, but these will be sampled and analyzed as part of a continuing program. The drums in Area $L$ contain liquids and labpack wastes in a variety of hazard classes, including acids, oxidizers, flammables, and caustics. The metal drums provide secondary containment (overpacks). Corrosion of the drums could cause leaks. The storage area is inspected daily. Construction of a containment structure is scheduled to begin in June 1994, and the drums will be transferred to secondary containment pallets. Requirements for the containment structure and the pallets were negotiated in the FFCA, and the Resource Conservation and Recovery Act Part B permit has been modified to allow construction of the storage facility. The ultimate disposal plan for these wastes is being developed under the FFCA.

- At Area G, about 2,000 drums of solid mixed waste are stored in an enclosed structure for protection from the weather. These drums contain a variety of hazardous materials, including uranium, mercury, cadmium, and barium-contaminated waste. About 1,000 of the drums contain de-watered sludge from the radioactive liquid waste treatment plant. The ultimate disposal plan for these wastes is being developed under the FFCA.

- Four tanks in TA-3, Bldg. 154, contain about 3,100 gallons of radioactive waste from the hot cells in Wing 9 of the Chemistry and Metallurgy Research Facility (CMR) (TA-3, Bldg. 29). Building personnel indicated that this waste has been in Building 154 about $1 \frac{1}{2}$ years without full characterization.

- An abandoned laboratory in the CMR facility contains hazardous waste in several drums that have been in storage in a satellite accumulation area for about 2 years without being completely characterized. Because the waste originated in a controlled radiation area, it should be regarded as suspect mixed waste. Some sampling and analysis have been peiformed, but to be official, the results must be analyzed by a laboratory approved by the EPA. The laboratory operated by Chemical Science and Technology Division, Environmental Chemistry Group (CST-9), is the approved laboratory on site, but backlogs for samples are as long as 6 months. 
K-34 
Site/Facility: $\quad$ Los Alamos National Laboratory

Vulnerability Number: CSVR-LANL-FM-02

Functional Area(s): Facility Physical Condition

1. Brief Description of Vulnerability.

The lack of funding could affect the safe cleanup or transition of aging and/or inactive facilities.

2. Summany of Vulnerability.

Many aging and/or inactive facilities at Los Alamos National Laboratory (LANL) are candidates for transition (e.g., to decontamination and decommissioning, or D\&D). Funding for these facilities is uncertain or not available, and workload changes are contemplated. These circumstances result in an unacceptable level of maintenance and surveillance at facilities in which residual hazardous chemicals may pose a threat to workers, the public, or the environment.

3. Basis.

a. Requirements:

- DOE 4330.4B, "Maintenance Management Program," requires that maintenance activities be implemented to ensure safe working conditions.

- "DOE Office of Environmental Management (EM-40) D\&D Guidance Document" provides D\&D process guidance.

b. Chemicals Involved:

- Hazardous wastes

- Residual explosive materials

- Flammable solvents

- Radioactive waste

c. Relevant Self-Evaluation Data: The self-evaluation for the High Pressure Tritium Laboratory (HPTL) (TA-33, Bldg. 86) recognized that a complete knowledge of the facility's chemical hazards is lacking and that residual explosives materials are potentially located in some systems at the Explosives Development Processing Facility (TA-16, Bldg. 340).

d. Contributing Causes:

- Lack of funding for maintenance and surveillance activities at inactive facilities in transition (e.g., HPTL).

- Lack of funding for maintenance activities and uncertainty about future funding for the Explosives Development Processing Facility.

- Increased workload without committed funding for the Explosives Development Processing Facility.

- Poor condition of some process support system equipment at the Explosives Development Processing Facility.

- Aging of such facilities as HPTL and the Explosives Development Processing Facility.

e. Potential Consequences: Residual hazardous substances at LANL could pose a threat to workers, the public, or the environment in facilities that are either inactive or are not well maintained. These conditions and circumstances represent a medium-priority vulnerability with a potential for short-term consequences. 
Site/Facility: $\quad$ Los Alamos National Laboratory

Vulnerability Number: CSVR-LANL-FM-02

Functional Area(s): Facility Physical Condition

4. Supporting Observations.

- The Explosives Development Processing Facility is an aging facility in need of increased maintenance attention. The general condition of the facility and support systems range from fair to poor. The roof is cracked and shows evidence of leaks, and process instrumentation lacks effective maintenance. Further deterioration of this equipment is expected because the need for this equipment has not been projected. Facility management indicated that there has been a significant reduction in programmatic operations and maintenance funds over the past 4 years, declining from about $\$ 2$ million in fiscal year (FY) 90 to only $\$ 350,000$ this year.

- DOE plans to transfer its explosive powder operations from another DOE site to the Explosives Development Processing Facility. To accomplish this added workload, the Dynamic Experimentation Division (DX-16) has requested funding to upgrade equipment and to address many of the problems cited above. However, DOE has not yet committed funds to support this request.

- Tritium samples, molecular sieves, and tritiated water are currently being removed from HPTL using existing reprogrammed Laboratory funds provided by the Office of Defense Programs (DP). The removal of most of these accountable tritium materials is scheduled to be completed by the end of FY 94 . However, the remaining tritium residuals and other chemical residues will not be removed as part of this effort.

- Currently, there are no committed funds for FY 95 to complete the characterization of HPTL and to remove residuals. The only potential source of funding appears to be existing DP Laboratory funds, which have not yet been identified. Without sufficient funds to prepare this aging facility for a safe surveillance and maintenance condition, hazards resulting from residuals will continue to pose a threat to workers and the environment.

- LANL has identified about 100 facilities on its "Environmental Flestoration and Waste Management Facility Inventory and Assessment Database." Of these, about 60 facilities are classified as surplus and are radiologically and/or chemically contaminated. Although a preliminary characterization of most of these 60 facilities is now under way and should be completed by the end of FY 94, there is no commitment by either DP or the Office of Environmental Management to fund the cleanup and deactivation of these facilities. The purpose of the deactivation process is to prepare these facilities for a safe surveillance and maintenance condition while they await ultimate D\&D.

- The Explosives Development Processing Facility and the HPTL, in addition to similar facilities at other DOE sites, are in deteriorating condition, indicating that the Department has not effectively addressed the issue of the overall life cycle of its facilities. Having completed their missions, such facilities are not adequately funded for deactivation and a safe surveillance and maintenance condition while awaiting D\&D. 


\section{Site/Facility: Los Alamos National Laboratory}

Vulnerability Number: CSVR-LANL-OMS-03

Functional Area(s): Operational Control and Management Systems

1. Brief Description of Vulnerability.

The absence of a consistent approach to chemical safety at Los Alamos National Laboratory can result in unanticipated chemical risks.

2. Summary of Vulnerability.

The absence of a consistent and integrated approach to chemical safety at Los Alamos National Laboratory (LANL) has resulted in improper chemical safety practices. A Laboratory-wide chemical safety policy does not exist, and supporting programs have not been developed in a timely manner.

3. Basis.

a. Requirements:

- 29 CFR 1910.119, "Process Safety Management of Highly Hazardous Chemicals," describes requirements for chemical processes.

- DOE 5480.10, "Contractor Industrial Hygiene Program," requires routine chemical monitoring and a health hazards inventory.

- The National Fire Protection Association 40 series of standards describes requirements for storage of flammables.

b. Chemicals Involved:

- Acids

- Caustics

- Oxidizers

- Reducing agents

- Organics

- Radioactive materials

- Fissile materials

- Petroleum products

c. Relevant Self-Evaluation Data: Chemical inventories exist for most LANL facilities.

d. Contributing Causes:

- Inappropriate management priorities

- Insufficient resources

- Inadequate guidance on chemical safety practices

- Lack of comprehensive chemical hazards analyses

- Ineffective communications among Laboratory divisions and groups 
Site/Facility: $\quad$ Los Alamos National Laboratory

Vulnerability Number: CSVR-LANL-OMS-03

Functional Area(s): Operational Control and Management Systems

e. Potential Consequences: The absence of a consistent and integrated chemical safety program could result in a variety of undesirable consequences: chemical inventories may be inaccurate; waste in facilities and process equipment may not be properly characterized; unwanted chemical reactions, including explosions, could occur; workers, the public, and the environment could be exposed to hazardous substances; fires could be started; and unnecessary hazardous or mixed waste could be generated. These conditions and circumstances represent a medium-priority vulnerability with a potential for short-term consequences.

4. Supporting Observations.

- Several hundred gallons of acids and caustics are stored alongside drums containing radioactive and fissile materials in a small storage area in the Chemistry and Metallurgy Research Facility (CMR)(TA-3, Bldg. 29). Secondary containment has not been provided to prevent the commingling of incompatible chemicals or damage to radioactive and fissile materials drums in the event of an unplanned chemical release. If a chemical release should occur, unplanned chemical reactions, explosions, exposure to the public or the environment, or personnel exposures to toxic materials could result.

- Although administrative requirements (ARs) include storage requirements for wastes, flammable liquids, and laboratory-scale chemicals, LANL has not established criteria addressing concerns such as chemical incompatibilities, flammable-vapor monitoring, or the concurrent storage of chemicals with radioactive or fissile materials. Storage criteria for other chemicals are not well defined or understood.

- LANL management has not addressed chemical safety-related issues in a timely manner, and various aspects of a comprehensive chemical safety program do not exist. For example, Occupational Safety and Health Administration (OSHA) regulations required LANL to begin implementing a laboratory safety program in January 1990, but LANL did not have a chemical hygiene plan until June 1993. LANL has not prepared a lead management program in response to 29 CFR 1926.62. In addition, LANL has not prepared a formal underground storage tank program or a chemical process safety management plan.

- A questionnaire (described in AR 1-10, "Environment Safety, and Health Questionnaire") intended for use in review of proposed research projects, process changes, and facility modifications has not been used consistently and is sometimes not completed in a timely manner. 
Site/Facility: $\quad$ Los Alamos National Laboratory

Vulnerability Number: CSVR-LANL-OMS-03

Functional Area(s): Operational Control and Management Systems

4. Supporting Observations. (Continued)

- LANL allows individual organizations a wide latitude in the implementation of Laboratory policies and standards. Some personnel see LANL policies and standards as requirements, whereas others regard them as guidance only. For example, one scientist (who was aware of a LANL requirement to the contrary) justified storing laboratory quantities of acids and caustics in the same location because the chemicals were dilute.

- Some chemical emergency eyewash stations and drench hoses use nonpotable water that may contain chemical and bacteriological contaminants. In the event of a chemical accident, use of this water could contribute to eye injury or damage.

- Health hazard assessments have not been performed for many LANL facilities in which chemical uses and processes are located. Funding is not currently approved to perform a comprehensive health hazards assessment.

- Chemical waste in tanks at TA-3, Bldg. 154, has not been fully characterized. Facility personnel indicated this waste has been in the tanks for about $1 \frac{1}{2}$ years. The waste, which originated in the hotcell wing of the CMR, is radioactive. 
$K-40$ 


\section{ATTACHMENT 3}

\section{SELECTED ACRONYMS}

CFR Code of Federal Regulations

D\&D Decontamination and Decommissioning

DOE U.S. Department of Energy

EH DOE Office of Environment, Safety and Health

EPA U.S. Environmental Protection Agency

ES\&H Environment, Safety, and Health

FY

Fiscal Year

$\mathrm{JCl}$

Johnson Controls World Services, Inc.

LANL Los Alamos National Laboratory

OSHA Occupational Safety and Health Administration

RCRA Resource Conservation and Recovery Act

SARA Superfund Amendments and Reauthorization Act

TA Technical Area 


\section{APPENDIX L}

FIELD VERIFICATION REPORT

SANDIA NATIONAL LABORATORIES, NEW MEXICO

MAY $16-25,1994$

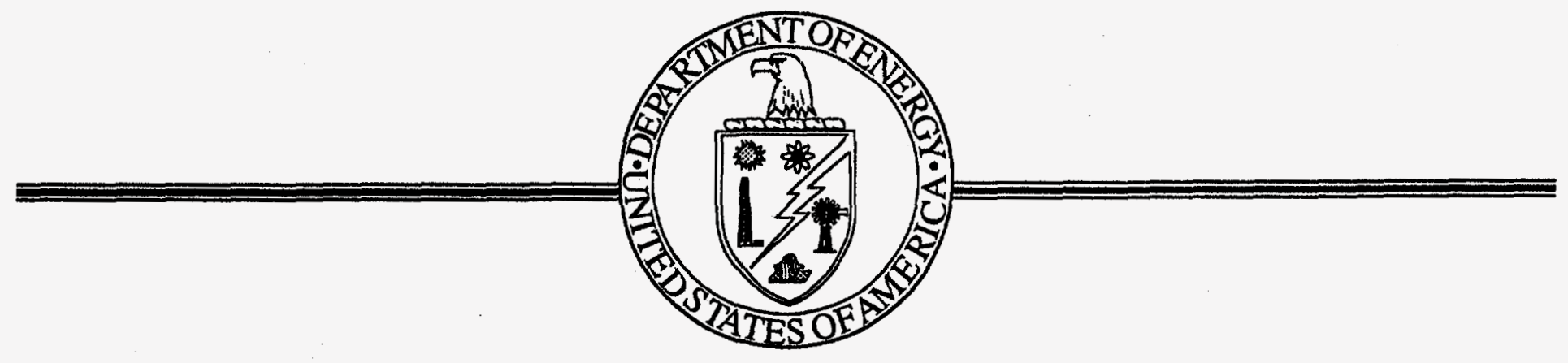




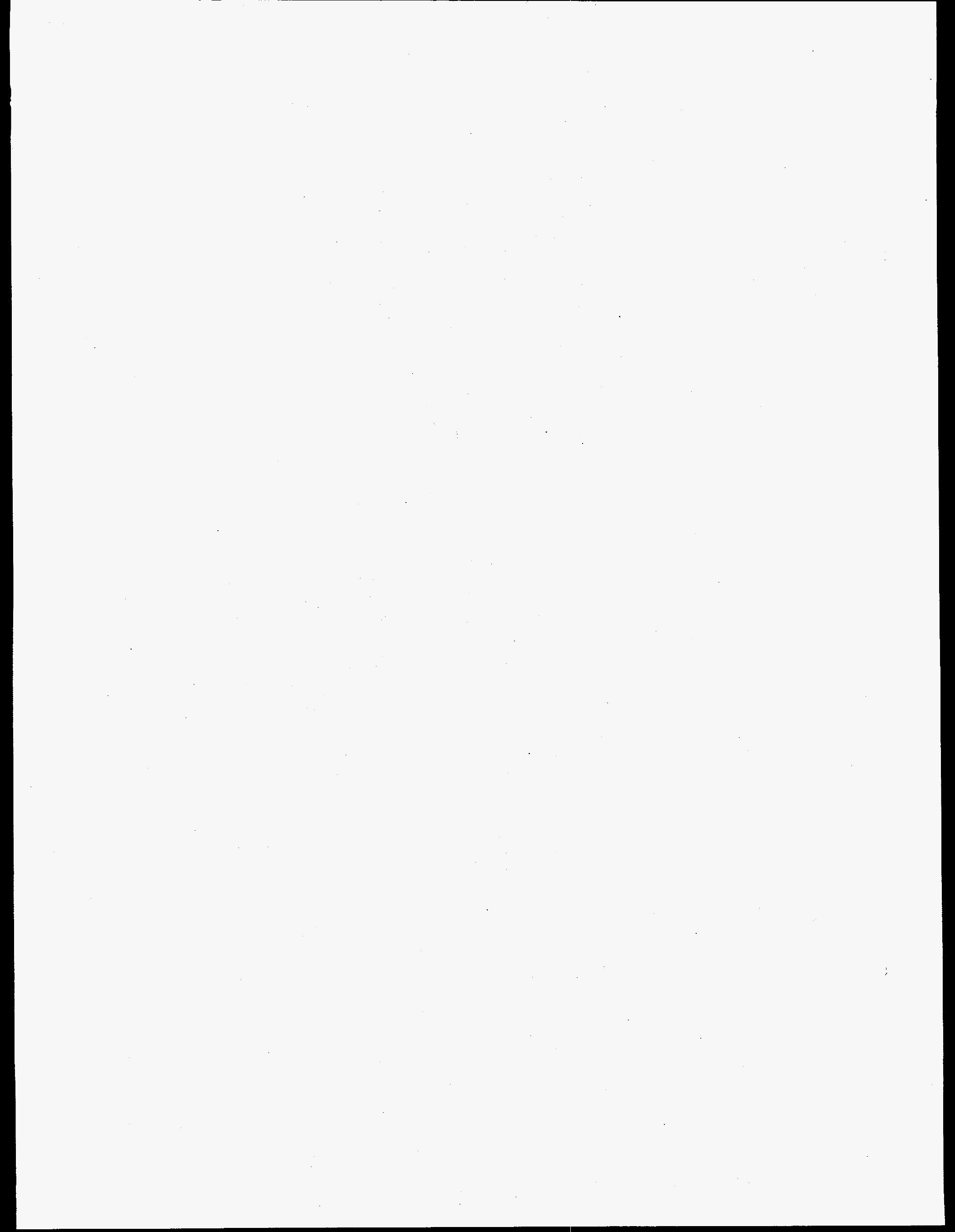




\section{CONTENTS}

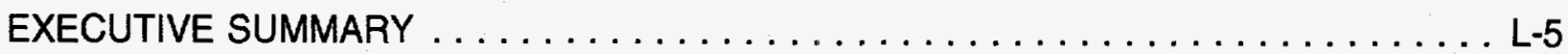

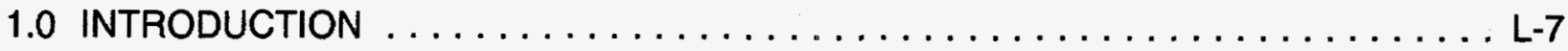

1.1 Purpose and Scope $\ldots \ldots \ldots \ldots \ldots \ldots \ldots \ldots \ldots \ldots \ldots \ldots \ldots \ldots \ldots$

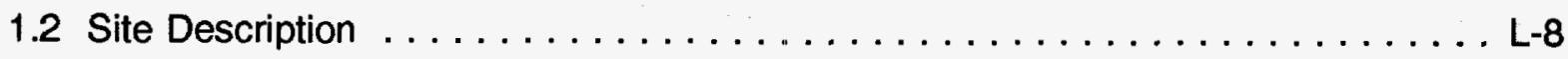

1.3 Facilities Visited $\ldots \ldots \ldots \ldots \ldots \ldots \ldots \ldots \ldots \ldots \ldots \ldots \ldots \ldots \ldots$. . . . . . . . . . . . . .

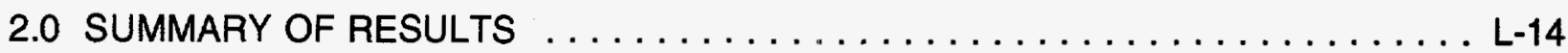

2.1 Identification of Chemical Holdings $\ldots \ldots \ldots \ldots \ldots \ldots \ldots \ldots \ldots \ldots$ L-15

2.2 Facility Physical Condition $\ldots \ldots \ldots \ldots \ldots \ldots \ldots \ldots \ldots \ldots \ldots \ldots \ldots \ldots \ldots \ldots$

2.3 Operational Control and Management Systems $\ldots \ldots \ldots \ldots \ldots \ldots \ldots$ L-20

2.4 Human Resource Programs $\ldots \ldots \ldots \ldots \ldots \ldots \ldots \ldots \ldots \ldots \ldots \ldots \ldots \ldots$

2.5 Emergency Management Program $\ldots \ldots \ldots \ldots \ldots \ldots \ldots \ldots \ldots \ldots$ L-25

3.0 CATEGORIZATION AND PRIORITIZATION OF VULNERABILITIES $\ldots \ldots \ldots \ldots$ L-27

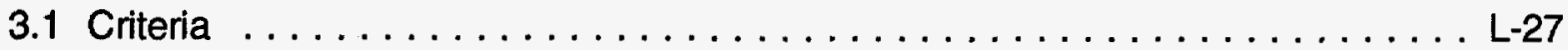

3.2 Chemical Safety Vulnerabilities at the Sandia National Laboratories, New Mexico.

\section{ATTACHMENTS}

ATTACHMENT 1. Team Composition $\ldots \ldots \ldots \ldots \ldots \ldots \ldots \ldots \ldots \ldots \ldots \ldots \ldots \ldots \ldots \ldots \ldots$

ATTACHMENT 2. Vulnerability Forms $\ldots \ldots \ldots \ldots \ldots \ldots \ldots \ldots \ldots \ldots \ldots \ldots \ldots \ldots$

ATTACHMENT 3. Selected Acronyms $\ldots \ldots \ldots \ldots \ldots \ldots \ldots \ldots \ldots \ldots \ldots \ldots \ldots \ldots$ 


$$
\text { L-4 }
$$




\section{EXECUTIVE SUMMARY}

This report presents the results of the field verification visit at the Sandia National Laboratories, New Mexico (SNL/NM) from May 16 to May 25, 1994. This effort is part of the Chemical Safety Vulnerability Review initiated by the Secretary of Energy to assess chemical safety vulnerabilities that exist at facilities owned or operated by the Department of Energy (DOE). The overall purpose of the review is to identify and characterize weaknesses or conditions involving hazardous chemicals representing vulnerabilities at DOE facilities: Specifically, the Chemical Safety Vulnerability Review is designed to identify, characterize, and prioritize facility-specific, site-specific, and DOE-wide generic chemical safety vulnerabilities that might result in (1) fires or explosions from uncontrolled chemical reactions, (2) exposure of workers or the public to chemicals, or (3) releases of chemicals to the environment.

A field verification team reviewed self-evaluation data on chemical safety vulnerabilities facing SNL/NM to gain insight into unique and generic problems that exist at DOE facilities. Ongoing activities at SNL/NM include the varied use, handling, transportation, retention, and disposal of hazardous chemicals primarily related to research and development and manufacturing activities. During the field verification review, the team concentrated its efforts on reviewing the five facilities involved in the self-evaluation effort. In addition, the field verification team also visited eight other facilities to gain a broader perspective on chemical safety programs at SNL/NM.

The field verification team noted that SNL/NM has made significant improvements in the area of chemical safety since the Tiger Team Assessment in 1991. Several programs were singled out as representing commendable practices. Other areas of excellence were also noted. Although SNL/NM management systems are maturing, there are concerns that the programs are ineffective in identifying, analyzing, and mitigating all chemical hazards because an integrated approach among different organizations is lacking. Significant weaknesses were identified in some areas associated with hazards analysis; maintenance and design engineering processes; sector-level emergency preparedness; and Environment, Safety, and Health Coordinator effectiveness that indicate a lack of overall integration. In addition, it was noted that the lack of a responsible individual who is cognizant of and has controls over all facility operations and maintenance activities in multiuser facilities was leading to significant problems associated with integrated work control and configuration management.

Commendable practices identified related to chemical safety at SNL/NM include the following:

- A "just-in-time" procurement system for commonly used chemicals,

- The Facilities Space Management Program,

- Deactivation documentation for the Light Initiated High Explosive Facility,

- The prejob planning process for the Facilities Operations and Maintenance Center, 
- The use of Management Assurance Notebooks, and

- DOE Kirtland Area Office coordination and cooperation with the New Mexico Environmental Department in regulatory oversight.

The three vulnerabilities identified as a result of the SNL/NM field verification review follow, none of which represents a condition or circumstance with the potential for severe near-term consequences:

- Inadequate integrated work control of maintenance and construction activities in multiuser facilities represents a medium-priority vulnerability with a potential for short-term consequences.

- Weaknesses in, and lack of integration among, SNL/NM programs for identifying, characterizing, and mitigating chemical hazards represent a medium-priority vulnerability with a potential for short- to long-term consequences.

- Inadequate configuration management in aging laboratory facilities represents a mediumpriority vulnerability with a potential for short-term consequences.

The vulnerabilities identified at SNL/NM, along with those identified at other DOE sites during the field verification phase of the Chemical Safety Vulnerability Review, will be evaluated to determine DOE-wide generic vulnerabilities. Facility-specific and site-specific vulnerabilities are made available to the sites for use in developing management response plans, which in turn will provide input to the DOE-wide management response plan. 


\subsection{INTRODUCTION}

\subsection{Purpose and Scope}

Based on direction from the Secretary of Energy, the Assistant Secretary for Environment, Safety and Health established the Chemical Safety Vulnerability Working Group to review and identify chemical safety vulnerabilities within the Department of Energy (DOE). The Office of Environment, Safety and Health was designated to lead the review, with full participation from DOE line organizations having operational responsibilities. The information obtained from the review will provide the Working Group with valuable for determining generic chemical safety vulnerabilities that face the DOE complex. Identifying and prioritizing generic chemical safety vulnerabilities will enhance the Department's focus on programs, funding, and policy decisions related to chemical safety.

The Chemical Safety Vulnerability Review was designed and undertaken to identify and characterize adverse conditions and circumstances involving potentially hazardous chemicals at facilities owned or operated by the Department. Specifically, the review was designed to identify, characterize, and prioritize chemical safety vulnerabilities associated with conditions or circumstances that might result in (1) fires or explosions from uncontrolled chemical reactions, (2) exposure of workers or the public to hazardous chemicals, or (3) release of hazardous chemicals to the environment. A project plan ${ }^{1}$ was developed, using input from line organizations with operational responsibilities, to guide the review.

This report documents activities related to the field verification visit at Sandia National Laboratories, New Mexico (SNL/NM) from May 16 to May 25, 1994. The field verification process was designed to use independent teams of technical professionals with experience in a variety of environment, safety, and health (ES\&H) disciplines to verify the accuracy and completeness of the data compiled during the field self-evaluation phase of the review. The field self-evaluation phase of the review used a standardized question set developed and distributed by the Working Group to collect data related to chemical safety from 84 facilities located at 29 sites. Based on review of this input, nine sites, including SNL/NM, were chosen to participate in the field verification phase.

The review considered a broad range of facilities at SNL/NM (based on facility type and operational status), with special attention given to those facilities being transferred to, awaiting, or undergoing decontamination and decommissioning. Different types of chemicaland waste-handling facilities (i.e., laboratories, process facilities, and waste treatment and storage facilities) were visited during the review to permit identification of vulnerabilities arising from hazardous chemicals and wastes at SNLINM. The team spent most of the time verifying data at the five facilities that were involved in the self-assessment phase of the Chemical Safety Vulnerability Review. To provide the team with a broader perspective on chemical safety vulnerabilities at SNL/NM, eight additional facilities were visited.

The SNL/NM field verification team, under the direction of a DOE team leader, was composed of DOE staff and contractor personnel with technical expertise in various aspects of chemical

1 "Project Plan for the Chemical Safety Vulnerability Review," dated March 14, 1994. 
safety, including management, operations, training, chemical process safety, industrial hygiene, maintenance, environmental protection, and emergency management. A team composition list is provided in Attachment 1 of this appendix.

The team met with management or technical representatives from each of the facilities reviewed. Individual and small group meetings were also held, and team members conducted facility walkthroughs, document reviews, and personnel interviews to gather information related to potential chemical safety vulnerabilities at SNL/NM. The team leader met regularly with DOE and contractor management personnel to discuss the team's activities and any issues that may have surfaced. Before the field verification team left the SNL/NM site, management from the local DOE and contractor organizations conducted a factual accuracy review of the draft document. An outbriefing was conducted for DOE and contractor management on Wednesday, May 25, 1994. A draft copy of this report was provided to DOE and contractor management.

\subsection{Site Description}

SNL/NM is located at the foot of the Manzano Mountains adjacent to the city of Albuquerque, New Mexico. The SNL/NM facilities are about 3 miles south of Interstate 40, and about 7 miles east of downtown Albuquerque (see Figure 1). SNL/NM is operated for DOE by the Sandia Corporation, a subsidiary of Martin Marietta Corporation. Oversight of SNL/NM is provided by the DOE Albuquerque Operations Office $(A L)$ through the Kirtland Area Office (KAO). The SNL/NM site is essentially surrounded by Kirtland Air Force Base (KAFB), and DOE has 1- to 5-year land-use permits for some Air Force property. An area of the Manzano Mountains east of KAFB has been withdrawn from the Forest Service for the exclusive use of the Air Force and DOE.

SNL/NM is a multiprogram laboratory, organized into three areas of support: (1) defense programs, (2) energy and environment, and (3) work for other Federal agencies. Specific research applications in which SNL/NM is involved include (1) advanced manufacturing technologies, (2) technical contributions to the space program, (3) information systems, (4) transportation systems, and (5) health care. There are about 10,000 DOE, operating contractor, and subcontractor personnel at the site.

SNL/NM has 546 major buildings, totaling 4.6 million gross square feet. Operations are conducted in six locations, called Technical Areas I, II, III, IV, and V, and the Coyote Test Field. Technical Area I is for administration, site support, technical support, component development, research, energy programs, microelectronics, defense programs, and exploratory systems. Technical Area II was established for the casting and assembly of chemical, high-explosive main charges for nuclear weapons, and is now used for testing explosive components. Technical Area III is devoted to testing and simulating a variety of natural and induced environments; it includes two rocket-sled tracks, two centrifuges, and a radiant-heat facility. Technical Area IV is a remote research location for pulsed power sources such as x-ray, gamma-ray, particle-beam fusion, and accelerators, all of which are used to simulate nuclear weapon effects and to conduct research on inertial-confinement fusion and 


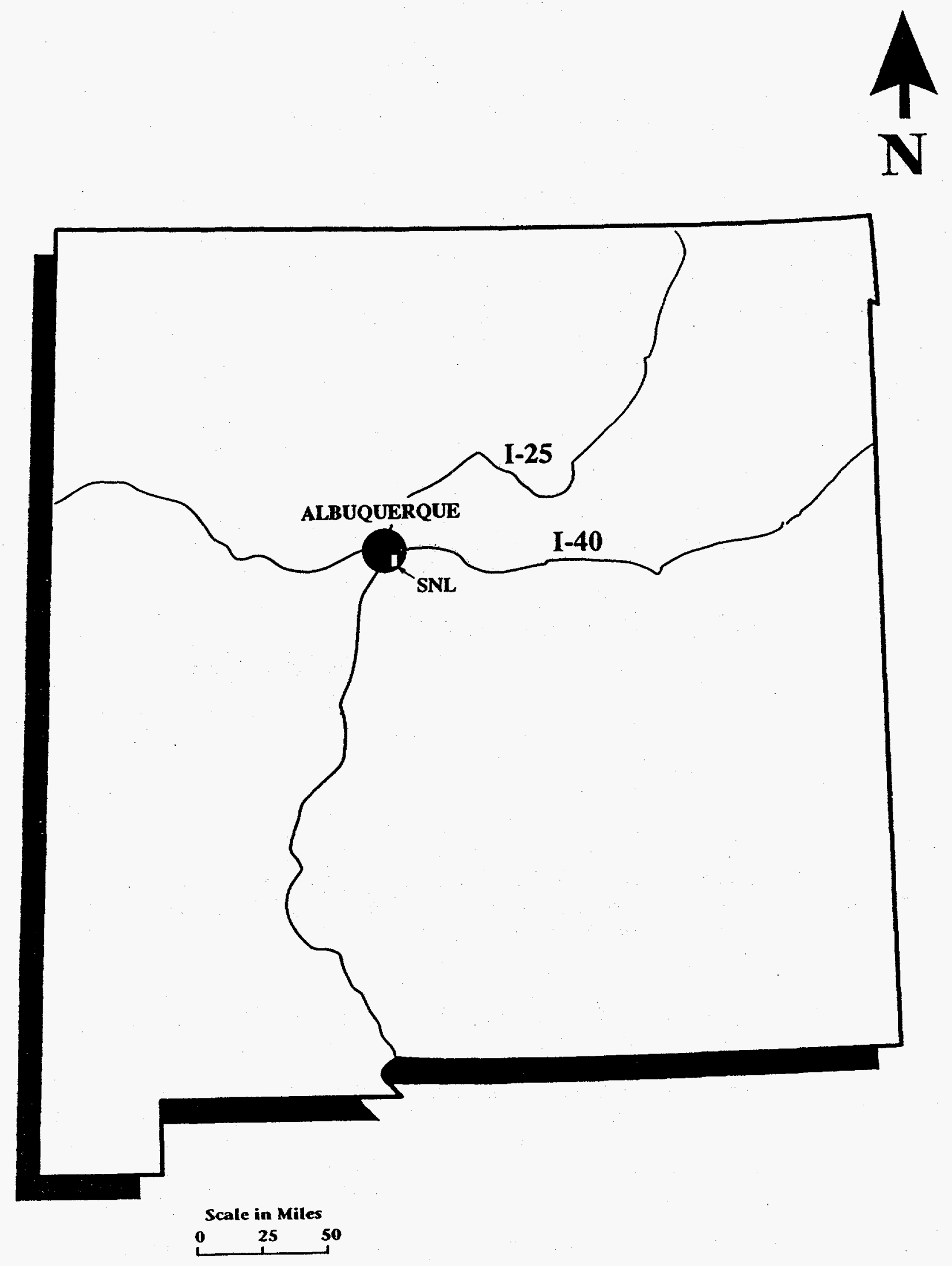

Figure. 1. SNL/NM Location 
particle-beam weapons. Technical Area $V$ is the remote research area where experimental and engineering nuclear reactors and some particle accelerators are located. The Coyote Test Field contains testing operations requiring large land areas and unusual terrain, with facilities separated by large buffer zones. Facilities include explosively driven shock tubes, aerial cable sites for high-speed impact tests to a ground target, a test site where large amounts of cased conventional explosives can be detonated, numerous small explosive sites, igloos for the storage of explosives, and a laser strain seismometer.

\subsection{Facilities Visited}

Visiting every DOE facility at SNL/NM was not possible under the time constraints of this review. As a result, the field verification team focused its efforts to achieve the maximum results possible in the time available. Operations selected for field review focused on facilities involved in the SNL/NM self-evaluation. These included the Microprocessor Development Laboratory (MDL), Building 858; Laboratory Facilities in Buildings 805, 806, and 807; the Advanced Manufacturing Process Laboratory (AMPL), Building 878; the Hazardous Waste Management Facility (HWMF), Building 958; and the Light Initiated High Explosive Facility, Building 6715 (see Figure 2). All buildings are in Technical Area I, except for the Light Initiated High Explosive Facility, which is in Technical Area III. In addition, eight other facilities were visited by the field verification team, including the Centrifuge Facility, Building 6526; the Facilities Operations and Maintenance, Building 6587; the Lurance Canyon Burn Site; the Thunder Range Explosive Facility; the Chemical Waste Landfill; the KAFB Fire Department; the Compound Semiconductor Research Laboratory, Building 893; and the Particle Beam Fusion Accelerator II, Building 983.

The MDL, Building $\mathbf{8 5 8}$, is a microelectronics research, development, and fabrication facility. The MDL has a gross area of 243,100 square feet, a net area of 72,200 square feet, and was first occupied in 1988. The facility contains the 12,500-square-foot Class I Heavy Laboratory, 10,200 square feet of chase and service aisles, a 12,300-square-foot basement, 34,300 square feet of interstitial area, a 4,000-square-foot water plant, and 12,000 square feet of support areas. The MDL is operated by the Microelectronics and Photonics Core Competency Center.

Buildings $\mathbf{8 0 5}, \mathbf{8 0 6}$, and $\mathbf{8 0 7}$ are multipurpose laboratories providing bench-scale research and development activities. Building 805 has a gross area of 75,000 square feet, a net area of 48,500 square feet, and was first occupied in 1959. Building 806 has a gross area of 61,000 square feet, a net area of 38,700 square feet, and was first occupied in 1961 . Building 807 has a gross area of 104,400 square feet, a net area of 48,700 square feet, and was first occupied in 1966 . These buildings are used by a variety of organizations including the Research and Exploratory Technology Division, the Physical and Chemical Sciences Center, the Microelectronics and Photonics Core Competency Center, the Computational/Computer Sciences and Math Center, the Materials and Process Sciences Center, the Intelligent Systems and Robotics Center, the Energy Components and Technologies Center, the Surety Components and Instrumentation Center, the Exploratory Systems Development Center, and the Aerospace Systems Development Center.

The AMPL, Building 878, contains multiple processes, including printed-circuit fabrication, hybrid microcircuit fabrication, electronic fabrication, plastics and ceramics development, 


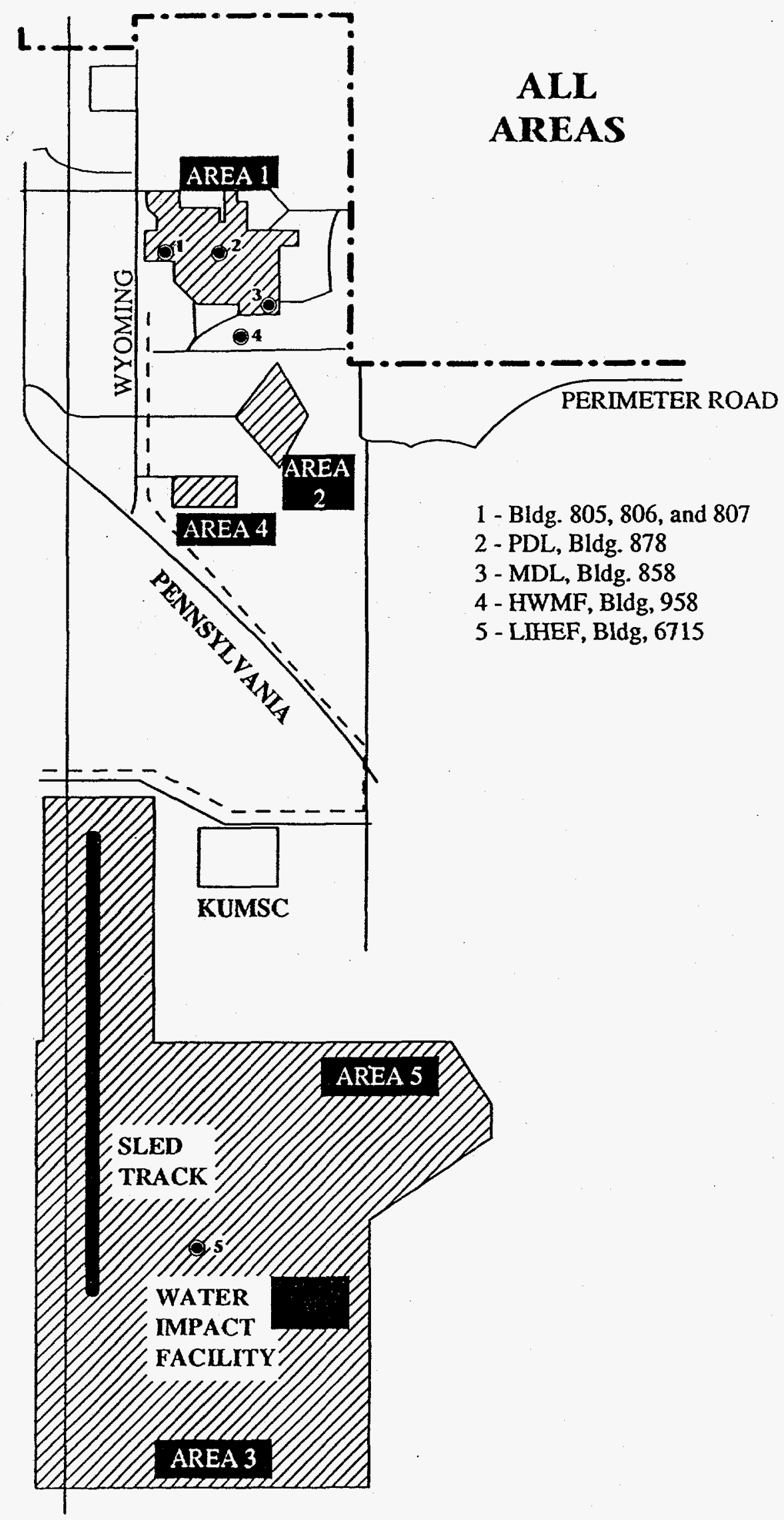

Figure 2. SNL/NM Site 
machining operations, and additional support capabilities. The facility has a gross area of 137,800 square feet, a net area of 76,300 square feet, and was first occupied in 1989 . The facility is occupied by the Manufacturing Technology Center, the Advanced Manufacturing Technology Center, and the Computational/Computer Sciences and Math Center.

The HWMF is the central collection point for all chemical waste generated at Sandia. Wastes are segregated into compatible Department of Transportation (DOT) hazard classes and packaged into DOT-approved containers for shipment to permitted treatment, storage, and disposal facilities. The facility has a process capacity of 750,000 kilograms per year, a gross area of 3,700 square feet, a net area of 3,500 square feet, and was first occupied in 1988 . This facility is managed by the Waste Operations Department, and Rinchem, Inc., provides the packaging and shipment functions.

The Light Initiated High Explosive Facility was previously used to stimulate and study the effects of Exoatmospheric Nuclear Bursts upon nuclear weapons. The facility is currently in "inactive-partial shutdown" with an option for restart. The building has a gross area of 3,400 square feet, a net area of 2,600 square feet, and was first occupied in 1962 . The facility was used by the Administrative Practices Department, the Mechanical and Climate Test Department, and the Environmental Test Department.

The Large Centrifuge Facility, Building 6526, is used to conduct acceleration tests on large and hazardous items in support of the SNL/NM broad mission of research and development. The 29-foot-radius indoor centrifuge has a 1.6 million $\mathrm{g}-\mathrm{lb}$ dynamic capacity (largest of any machine in the United States). It has the capability to accelerate 16,000 pounds to $100 \mathrm{~g}$, or lighter loads to nearly $300 \mathrm{~g}$. A modified electrodynamic shaker mounted on the 29-foot indoor centrifuge arm permits combined vibration and acceleration testing. Items weighing up to 50 pounds can be vibrated while undergoing $50 \mathrm{~g}$ of acceleration.

Facilities Operations and Maintenance, Building 6587, is used by SNL/NM organization 7818, Remote Areas Maintenance, to provide electrical, mechanical, and structural support to customers in Technical Area III, Technical Area V, the Coyote Test Field, Manzano, and the Solar Power Tower. Building 6587, located in Technical Area III, has a designated $20 \times 20$-foot room used mainly for storage of flammable liquids, which include paint, electrical contact cleaner, and drywall cement.

The Lurance Canyon Burn Site, which has fire-testing capabilities, is used to simulate the effects of transportation and handling accidents for nuclear safety studies and for evaluating hazardous-materials shipping containers. The Burn Site conducts open-pool fire tests. Windshielded fire-test capabilities exist in the Smoke Emissions Reduction Facility, which is a $10 \times 10$-foot pool and $20 \times 20$-foot test chamber.

The Thunder Range Explosive Facility is a collection of several explosive firing sites. In addition to range access control and explosive storage and assembly facilities, six explosively powered shock tubes are available-varying from 2 feet to 19 feet in diameter. The largest firing site can safely accommodate fragmentation at ranges up to 3,500 feet.

The Chemical Waste Landfill, an active Resource Conservation and Recovery Act (RCRA) site opened in 1962, has received a variety of chemical wastes including mineral acids, 
oxidizing agents, reducing agents, organic compounds, reactive chemicals, metals (reportedly including some radioactively contaminated beryllium), inorganic salts, and chromic acid. Six unlined pits are located in the southern portion of the Chemical Waste Landfill area. IT Corporation identified these RCRA-regulated landfill pits in their Solid Waste Management Unit report. The pits were constructed by excavating into the natural soil to a depth of about 9-10 feet. Pit 2 is divided into two separate areas for the disposal of oxidizers and reducers. Many of the wastes dumped into the old pits and trenches contained liquids. SNL/NM is currently planning to close the Chemical Waste Landfill by capping the trenches and shipping the waste containers off site for disposal.

The KAFB Fire Department provides SNL/NM with primary emergency response functions for fire, hazardous-materials events, and medical emergencies. KAFB Fire Department resources include five fire stations, 24-hour dispatch and firefighter personnel, and appropriate vehicles and equipment.

The Compound Semiconductor Research Laboratory, Building 893, performs compound semiconductor device research, including sample/device fabrication as well as Molecular Beam Epitaxy and Molecular Organic Chemical Vapor Deposition growth activities and ion implantation. The facility consists of a clean room (East and West Annexes), a light laboratory, Deionization Water Equipment Annexes, Clean Room Parts and Chemical Storage Annex, House System Equipment Annexes, a Gas Cabinet Room, a Boiler Room Annex, an Acid Exhaust Scrubber Room, and Equipment Cargo Container No. 5.

The Particle Beam Fusion Accelerator II, Building 983, is a research facility providing experimental data for use in development of fusion technology. This facility is the first superpower accelerator specifically designed for light ion fusion experiments. Operating on the principle of pulsed power, the Particle Beam Fusion Accelerator II stores electrical energy over a period of minutes, then releases it in a concentrated burst. Thirty-six identical accelerator modules converge to produce a single, extremely short, powerful pulse of energy that can be focused on a single target. 


\subsection{SUMMARY OF RESULTS}

The field verification process was designed to verify the accuracy and completeness of the data provided to the Chemical Safety Vulnerability Working Group by the SNL/NM facilities selected to participate in the field self-evaluation process. The verification process offered an opportunity to examine any facility-specific chemical safety vulnerabilities and to make informed judgments about the seriousness of these conditions.

The goal of the field verification visit was to develop a prioritized list of facility-specific chemical safety vulnerabilities at the SNL/NM. Before arriving on site, team members reviewed the self-evaluation data and other documents to develop a list of observations related to potential vulnerabilities for their functional areas. During the onsite portion of the review, team members visited facilities selected for self-evaluation to verify reported observations and to look for other conditions or circumstances that might result in chemical safety vulnerabilities. Eight facilities that were not included in the original self-evaluation were also visited to provide the team with a broader perspective on chemical safety vulnerabilities at SNL/NM.

To facilitate effective team management and to expedite the identification of vulnerabilities across a wide range of disciplines associated with chemical safety, the field verification review was organized to include five functional areas:

- Identification of chemical holdings, including the properties of chemicals located at the facility, the characterization of those chemicals, and an analysis of the inventory.

- Facility physical condition, including engineered barriers, maintenance conditions, chemical systems, safety systems, storage, monitoring systems, and hazards identification.

- Operational control and management systems, including organizational structure; requirements identification; hazard analysis; procedural adherence; maintenance control; engineering and design reviews; configuration control; safe shutdown plans; and site programs for quality assurance, chemical safety, inventory control, access control, disposal, transportation and packaging, and corrective actions.

- Human resources programs, including technical competence, staffing, training and qualifications, employee involvement, employee concerns, personnel performance requirements, and visitor and subcontractor control.

- Emergency management program, including the emergency response plan, inplant consequences, environmental issues, coordination with the community, and community right-to-know issues.

These functional areas were evaluated on the basis of lines of inquiry provided in Attachment 1 of the "Field Verification Guide for the Chemical Safety Vulnerability Review," dated April 8, 1994. Verification of the self-evaluation data was accomplished by walkthrough of facilities, conduct of interviews with management and technical personnel, 
examination of facility and site documentation, and review of incident reports and other documents.

Three vulnerabilities were identified as a result of the SNL/NM field verification:

(1) inadequate integrated work control of maintenance and construction activities in multiuser facilities; (2) weaknesses in, and lack of integration among, SNL/NM programs for identifying, characterizing, and mitigating chemical hazards; and (3) inadequate configuration management in aging laboratory facilities.

Commendable practices identified related to chemical safety at the SNL/NM include (1) a "just-in-time" procurement system for commonly used chemicals, (2) the Facilities Space Management Program, (3) the Light Initiated High Explosive Facility deactivation documentation, (4) the Facilities Operations and Maintenance Center's prejob planning process, (5) the use of Management Assurance Notebooks, and (6) KAO coordination and cooperation with the New Mexico Environmental Department in regulatory oversight.

Overall, it was the field verification team's opinion that the SNL/NM self-evaluation document provided a fair and thorough representation of conditions at the five facilities involved in the effort. Several minor inconsistencies in the self-evaluation were resolved between the field verification team members and SNL/NM personnel. With help from AL, KAO, and SNL/NM personnel, the field verification team was able to provide additional insight on chemical safety vulnerabilities at SNLNM. The following sections summarize the field verification team's understanding of chemical safety programs at SNL/NM. Chemical safety vulnerabilities are specified where applicable.

\subsection{Identification of Chemical Holdings}

Field verification of the chemical holdings functional area determined that many hazardous materials are used and stored in the SNL/NM facilities that were reviewed, with the greatest variety being in the research laboratories (Buildings 805,806 , and 807 ) and the largest quantities being in the MDL and AMPL (Buildings 858 and 878). Materials involved range from common acids, bases, oxidants, solvents, and maintenance products (e.g., oils, greases, paints, adhesives) to specialty organics, explosives, and toxic/pyrophoric gases. The MDL uses moderate quantities of hazardous gases (i.e., hydrogen, chlorine, phosphine, arsine, diborane, silane, boron trichloride, tungsten hexafluoride). The AMPL uses large quantities of hydrogen gas from a bulk-storage trailer. This review determined that hazardous materials are being stored and handled safely and in accord with SNLNM corporate procedures and applicable standards; however, different levels of performance are apparent in different facilities.

Comprehensive inventory lists of chemicals are maintained, usually on a room-by-room basis, for each of the facilities reviewed. The ChemMaster data base is currently the official inventory system for SNL/NM. The inventory is based on an original physical inventory of all chemicals in the facilities and is updated annually. The major uses of this data base are for environmental reporting required by Title III of the Superfund Amendments and Reauthorization Act (SARA) and for identifying locations requiring special industrial hygiene emphasis to protect workers or to aid emergency response personnel. However, ChemMaster has major deficiencies: (1) it does not actually track hazardous materials, rather it indicates 
the maximum quantities that may be in inventory; and (2) the master data base is updated only once a year. ChemMaster neither fully meets all SARA Title III reporting needs, nor can it meet all emergency response needs. A new system, the Chemical Information System (CIS), is being implemented to replace ChemMaster. The CIS, already in use at another SNL site, can track individual containers of chemicals from receipt to disposal, using a bar-code system. Most chemicals currently procured are being entered into the CIS and are being tracked. For CIS to be fully operational, a physical inventory of all onsite chemicals must be conducted, the containers bar-coded, and the chernicals entered into the system. SNL/NM personnel estimate that this activity will be completed in about 2 years, if adequate funding is received. Until the CIS is fully operational, the above-named facilities are maintaining current inventory data bases to meet their individual safety, quality, and reporting requirements. Several SNL/NM facilities have elected to provide more current information to the emergency response organization, even though this is not required by emergency preparedness procedures.

SNL/NM procedures require that all chemicals and hazardous materials be reviewed by industrial hygiene personnel before initial procurement, as described below in Section 2.3. A "just-in-time" procurement system for commonly used chemicals encourages minimization of chemical storage and decreases the likelihood of materials becoming outdated. The system also enables the site to avoid or minimize the need for central receiving, warehousing, and transporting of hazardous materials. This procurement system is judged to be a commendable practice. A materials exchange program provides a mechanism by which unopened excess chemicals can be made available to other users. The quantity of hazardous materials stored in SNL/NM facilities is reported to have decreased in recent years and is being controlled largely by management initiatives.

Each SNL/NM worker is trained in the use of hazardous materials and is informed of hazards in his or her workplace; material safety data sheets (MSDSs) are available in "Right-to-Know Centers" in the workplace. With few exceptions, hazardous materials are appropriately labeled, facilities in which these materials are used or stored are posted as required, and chemicals are stored according to procedures that specify segregation by hazard categories.

There is no program for systematically surveying all structures, components, and systems for the presence of chemical residuals at SNL/NM. Thus, there is no comprehensive inventory of chemical residues, and it is possible that unknown hazardous residues may exist in locations such as pipes, process equipment, ventilation ducts, or building structures. To address this situation, SNL/NM uses the Building Modification Hazard Assessment (BMHA) program to identify and characterize chemical hazards in facilities and to ensure protection of maintenance and construction workers and building occupants during modification activities. The program currently involves only those workspaces that are scheduled for modification. Workspaces are evaluated from records, by inspection, by radiation survey, occasionally by interviews with current and former employees, and sometirnes by sampling. Not only are requirements for current work documented, but a comprehensive report (Industrial Hygiene Investigation Report) is prepared and entered into a data base for future reference. SNL/NM does not have a program to gather data systematically from long-service employees on possible chemical and radiological contamination at older facilities that are not undergoing modifications or ownership changes. It is noted that DOE guidance in this area is lacking. 
The Facilities Space Management Program requires that SNL/NM facilities, when no longer needed for an existing activity, be evaluated for hazards and remediated if necessary before being transferred to other users. There is an incentive for users to clean and relinquish unneeded facilities because users are charged a space fee if they continue occupancy. The purposes of this program are to minimize the potential for exposure of workers to preexisting hazards when they move into an area, to expedite remediation of contaminated areas, and to track the presence of chemical and radiological residues. The program is considered a commendable practice. The Light Initiated High Explosive Facility, Building 6715, was evaluated and determined to need remediation before reassignment. Process equipment was removed, and the structure was extensively cleaned to remove explosive residues. These activities were thoroughly documented in written reports and video recordings that will provide information to future users regarding facility safety and condition. The thoroughness of documentation in this instance is commendable.

SNL/NM has a strong and compliant hazardous waste management program. The Laboratory is a "large-quantity generator" of hazardous waste, as defined by RCRA, and operates a permitted storage unit on site to facilitate proper waste management. Formal procedures are implemented through ES\&H standards to manage the diverse wastes from the multifaceted research and development programs. Generator knowledge is the primary means for waste identification, with sampling and analysis performed as necessary. Qualified personnel review planned generation of wastes for control, minimization, and compliance with applicable laws, rules, and regulations that govern the generation, handling, storage, and final disposition of wastes. Internal audits are conducted throughout the waste-handling process, and external audits are conducted at the facilities accepting the hazardous waste. In addition, SNL/NM is addressing nearly 200 known or potential release sites in accordance with RCRA Corrective Action requirements. Procedures are in place to control activities that might unearth additional waste sites and to protect workers engaged in such activities.

SNL/NM has implemented effective programs to control emissions to air and water. Data on air emissions are updated annually. The Laboratory is initiating a more comprehensive survey of air emission points and is estimating the emission potential of each source. This is being done to comply with 1995 requirements of Title V of the Clean Air Act Amendments and the administering agency, the Albuquerque-Bernalillo County Air Quality Control Board. SNLNMM has conducted similar surveys to characterize onsite process and sanitary water wastes. Applicable wastewater permits have been obtained from the city of Albuquerque, and sampling is conducted as required. In addition, industrial areas that may affect stormwater discharges have been characterized, and a permit application has been submitted to the Environmental Protection Agency. A recently updated Spill Prevention Control and Countermeasures Plan is being implemented through formal ES\&H procedures.

\subsection{Facility Physical Condition}

Generally, it was determined that the physical condition of facilities visited at SNL/NM was good. As identified in the SNL/NM self-evaluation, there are concerns with essential support equipment in aging laboratory buildings (i.e., Building 805, 806, and 807). Engineering and maintenance are performed in a professional manner using standards that encompass DOE Orders and appropriate national consensus standards. The facility maintenance and design-engineering processes, however, do not ensure a level of safety review, approval, and 
testing that is commensurate with the consequences of failure or the chemical safety risk involved. SNL/NM has many service organizations that function independently and were found to have their own effective approach to work control. There is, however, no responsible individual who is cognizant of and has control over all facility operations and maintenance activities in multiuser facilities; this degrades chemical safety because of an absence of configuration control and work not being controlled in a fully integrated manner.

The design of facilities, systems, and equipment is controlled by SNL/NM engineering standards. These standards encompass all requirements of DOE Orders and the appropriate national consensus documents. Engineering design is performed in a professional manner and is, for the most part, consistent with the best standards of commercial industry. For chemical systems, the standards are based on chemical type (i.e., species and concentration) and service (e.g., state, temperature, pressure) and contain criteria for workmanship, qualification, and initial testing. Yet, SNL/NM engineering procedures fail to consider the specific consequences of (1) system or equipment failure; (2) risk to the public; (3) risk to workers; (4) safety significance (e.g., essential or vital systems); (5) proximity to other essential systems or heavily staffed areas; (6) impact of failure on programs; (7) levels of rigor in analyses; and (8) levels of review, verification, and approval, including those requirements for prestartup safety evaluation. Typically, these additional requirements and considerations are applied in a multilevel quality assurance program, using a "graded approach," as referenced in the DOE Orders. (See Vulnerability CSVR-SNL/NM-MO-02 in Section 3.2 and in Attachment 2 of this appendix.)

In spite of rapidly changing customer requirements and numerous modifications to its processes, SNL/NM has been relatively successful in maintaining as-built documentation for newer facilities. All new work being performed at SNL/NM is documented as individual maintenance tasks, and projects are systematically completed and closed. In the older facilities reviewed, however, there was an obvious lack of up-to-date, as-built drawings and equipment files. In an aging laboratory complex (i.e., Buildings 805,806 , and 807 ), some utility and ventilation systems were observed to be operating at, or slightly beyond, maximum design capacities and were reported to be experiencing higher than normal breakdown incidence rates. The self-evaluation prepared by this laboratory complex indicated that suspect indoor air quality continues to be an issue.

The equipment problems described, and the reported air quality issue in Buildings 805,806 , and 807 , are the result of an inadequate configuration management program for essential building systems during numerous facility modifications. The tendency continues for these laboratory buildings to make many small-scale modification projects without adequate configuration control. These modification projects seldom carry sufficient funding to evaluate the impacts of the proposed changes on the entire utility system(s) of the laboratories involved. Individually, the impacts of a single project may be of minor significance; however, over the years, the cumulative effects has proven to be significant. The result is excessive fresh air makeup and exhaust flows and constant problems in maintaining proper air balance and aifflow direction in these facilities. (See Vulnerability CSVR-SNL/NM-FM-03 in Section 3.2 and in Attachment 2 of this appendix). The problem in Buildings 805, 806, and 807 is exacerbated by the many independent tenant organizations attempting to exert control over portions of these buildings without the presence of a single responsible individual who is cognizant of and controls all facility operation and maintenance activities. To relieve these 
problems, SNL/NM is planning gradually to relocate part of its ongoing hazardous chemical research to other facilities in less densely populated areas of the site, thereby reducing the ventilation and cooling requirements for this complex.

Maintenance at SNL/NM is performed by many organizations, which function independently. Facilities Operations and Maintenance operates and maintains central and building utilities, including heating, ventilating, and air conditioning; electrical power; steam; and domestic water and sewer systems. A Facilities Express organization performs quick repairs and modifications, such as minor office rearrangements and lighting installations. Operating technicians service their own process and process-support equipment. Offsite vendors provide and maintain some systems such as compressed gas, water treatment, and ultra highpurity water deionizers within SNL/NM facilities. Other organizations not associated with facilities maintenance, but with active service assignments within SNL/NM facilities, were also identified.

SNL/NM maintenance organizations appear to have adequate internal engineering support and integrate engineered requirements into their maintenance programs and work packages. All SNL/NM maintenance workers interviewed by the field verification team commented on their absolute dependence on industrial hygiene personnel to detect the presence of hazardous chemicals and to advise them of the requirements for personal protection before they breach ventilation systems and process drains.

Individually, each of the maintenance organizations was found to have its own approach to the safe control of work, including performing prejob safety evaluations, training and qualification, lockout/tagout, and use of personal protective equipment (PPE). Moreover, each approach appeared to be effective. While SNL/NM procedures specifically assign ownership of each square foot of building space to an organization, there is no responsible individual who is cognizant of and has control over all facility operations and maintenance activities in multiuser facilities. In a complex facility, several maintenance organizations may "own" and maintain equipment, and many have unrestricted access to the space. These separate maintenance organizations are required sometimes to perform independent work simultaneously. Chemical hazards are not always considered when establishing ownership boundaries. This may result in a situation where personnel are not cognizant of the chemical hazards associated with the activities and operations of other organizations. (See Vulnerability CSVR-SNLNMM-FM-03 in Section 3.2 and in Attachment 2 of this appendix.) Because facility research and development processes are complex, little detailed knowledge of the associated hazards is shared among the maintenance organizations.

The Facilities Operations and Maintenance Center's work control process for facilities maintenance is conducted under the direction of planners. Before releasing the work package, the planner first reviews the data from the work requester, then reviews such data with the appropriate facility organization to verify correctness, and finally performs a field walkdown of the work area to identify potential job hazards. Often, the planner is accompanied by the maintenance supervisor who will ultimately be responsible for performing the work. This program was judged to be a commendable practice.

SNL/NM has attempted to implement a centralized preventive maintenance program; however, the current process requires that a maintenance planner purposely query the preventive 
maintenance data base to obtain specific facility listings of due or past-due tasks. Because this system is cumbersome and often provides incomplete listings, individual facility maintenance mechanics have resorted to developing and maintaining their own preventive maintenance records. No preventive maintenance task is reported to be delinquent, and there is no evidence that equipment is failing prematurely because of inadequate preventive maintenance attention. SNL/NM will soon implement a new, computerized, equipment-based work control system that will link specific systems to safety and health requirements and that will record historical equipment data and track preventive maintenance activities. SNL/NM is also considering the use of predictive maintenance techniques, such as vibration analysis, thermography, and used lube oil analysis, to warn of pending equipment failure.

In addition to reducing process chemical inventories, SNL/NM has effectively minimized inventories of maintenance solvents and has replaced many hazardous solvents with nonhazardous substitutes where possible. Maintenance workers have received appropriate training in the control and use of hazardous chemicals, including the use and care of PPE. Painters, who continue to use some hazardous solvents in their work, are given additional training. MSDSs are available near chemical storage areas.

The physical condition of the facilities and waste sites was found to be as reported in the site self-evaluations. Aside from the noted problems with aging laboratory support equipment, all chemical piping, valves, essential instruments, tankage, pressure vessels, and primary and secondary chemical containers were found to be appropriately labeled and in good mechanical condition. Likewise, secondary containments, including berms, dikes, and engineered containments, were found to be adequate and in good condition, with one exception. An active program for the removal of all single-wall underground fuel tanks at SNL/NM has been ongoing for 2 years. Some have been replaced with double-wall tanks, and only a few of the obsolete design remain. Their removal is planned in the near future.

\subsection{Operational Control and Management Systems}

Field verification of the operational control and management systems functional area determined that SNL/NM management has established systems that currently yield an acceptable degree of chemical safety in Laboratory operations. The industrial hygiene programs have improved dramatically in recent years. However, there are weaknesses in the overall SNL/NM management structure that affect chemical safety; moreover, deficiencies in the current hazards analysis system were judged to be a major supporting component of a chemical safety vulnerability on identifying, analyzing, and mitigating chemical hazards.

SNLNM is organized with a modified matrix management structure that enables close interaction between personnel in different divisions and centers on specifically defined projects. This type of management structure has served the Laboratory well in achieving its research mission objectives. However, in the design, development, and implementation of integrated ES\&H programs, this type of management structure can create situations that lead to potential problems requiring special management attention. An SNL/NM facility is often composed of multiple line organizations, which in turn are supported by other matrix organizational units. Although each square foot of a facility is assigned to an owner, generally there is no responsible individual who is cognizant of and has control over all facility operations and maintenance activities. This structure has created an environment in which 
integrated work control is insufficient to ensure chemical safety. This environment can lead to confusion over responsibilities, and as a result, one group's actions may inadvertently affect another group. (See Vulnerability CSVR-SNL/NM-FM-01 in Section 3.2 and in Attachment 2 of this appendix.) In addition, the lack of a single responsible individual can lead to attempts by independent tenant organizations to exert control over building modifications, which may have ramifications beyond their portion of the facility. (See Vulnerability CSVR-SNL/NM-FM-03 in Section 3.2 and in Attachment 2 of this appendix.)

The SNL/NM organizational structure also complicates uniform implementation of programs that support chemical safety. As a result, programs designed to identify, analyze, and mitigate chemical hazards are not integrated, which causes them to vary greatly in quality and effectiveness. (See Vulnerability CSVR-SNL/NM-MO-01 in Section 3.2 and in Attachment 2 of this appendix.)

Examples of programs and controls necessary to ensure chemical safety that are currently not fully integrated include the following:

- Hazards analysis process,

- Facility maintenance and design engineering processes,

- Emergency preparedness sector planning, and

- ES\&H coordinator effectiveness.

The SNL/NM management system calls for an assessment of the risk category of a proposed new or modified process through the preparation of a safety document determination. This determination is followed (if so indicated) by the preparation of a preliminary hazards assessment (PHA), a safety assessment, or a safety analysis report, depending on the level of the hazard determined. This process is deficient, however, in that the PHAs reviewed were not of adequate quality to ensure a total understanding of the hazards involved. PHAs represent the overwhelming majority of safety documents generated at SNL/NM. Moreover, accident analyses with defined potential consequences were not included in the PHAs that were examined. Discussions with the Risk Management \& NEPA (National Environmental Policy Act) Department management revealed their awareness of the weaknesses in the program. The Risk Management \& NEPA Department has proposed an enhanced and improved hazards analysis program, which will address current deficiencies. The ability to implement the enhanced program depends on the availability of additional resources. These additional resources have been requested for fiscal year (FY) 1995. Under the current situation, standard operating procedures (SOPs) supplement the PHAs in defining hazards associated with existing processes and in imposing meaningful safety-related process operating limits. As such, the SOPs can be used as a resource in upgrading the PHAs in the planned improved risk management program.

Procurement of hazardous materials is controlled by requirements cited in the SNL Environment, Safety, and Health Manual. In accordance with these requirements, requests for procurement of new hazardous chemicals or other hazardous materials, the use of which transcends previous experience, must be reviewed and sanctioned by Laboratory industrial 
hygiene experts before the procurement request can be processed. Responsibility for ensuring that the requester is qualified and equipped to handle the new chemical safely rests with the line manager and the industrial hygiene reviewer. The exact procedure used in the review of such procurement requests varies between SNL/NM divisions and centers; moreover, circumstances are remotely conceivable under which the controls could be circumvented, and a hazardous chemical could be procured without proper verification that the requester is qualified and equipped to handle the chemical. However, the system is under constant scrutiny to eliminate such circumstances, and the likelihood that a chemical safety vulnerability would result from a lapse of adequate controls is very small.

SNL/NM management has implemented a well-structured system for reporting and investigating abnormal events. The requirements of this system are described in the SNL Environment, Safety, and Health Manual. The system, including features for addressing "near misses" and "lessons learned," is practiced uniformly throughout the Laboratory with good results.

$A L$ and KAO maintain effective oversight programs of SNL/NM activities pertaining to chemical safety. Discussions with $\mathrm{AL}$ and $\mathrm{KAO}$ management personnel involved in this oversight function indicated that (1) SNL/NM has recently been appraised by AL and was found to have an industrial hygiene program that is improving but has some continuing deficiencies in hazards analysis and (2) KAO has assigned a full-time employee to monitor and review all SNL/NM safety analysis documentation. This measure is viewed by the Risk Management \& NEPA Department as a positive sign of support of the SNL/NM effort to improve its hazards analysis program.

The SNL/NM industrial hygiene program has qualified industrial hygienists matrixed to each facility and to the facility engineering organization. They were familiar with the people and hazards in their assigned spaces. Despite cutbacks in funding, several initiatives are being pursued, including (1) systematic occupational exposure assessments, (2) IH-Charm (an improved data management program), and (3) the BMHA program, as discussed in Section 2.1 of this appendix.

The occupational exposure assessment program is designed to characterize each workspace annually, using the methodology of the American Industrial Hygiene Association, including the identification of homogeneous exposure groups. However, the level of effort being applied (i.e., one or two industrial hygienists who have responsibility for about 400 additional laboratories) is not sufficient to complete the initial surveys in time for the annual reassessment.

$\mathrm{IH}$-Charm, an improved data management program, is a project to develop an integrated and consolidated industrial hygiene data and records management system. The Industrial Hygiene Department maintains separate data bases of sampling results, ventilation surveys, lasers, confined spaces, investigation reports, and instrumentation calibration. The IH-Charm program will (1) greatly assist in the hazards assessment process, (2) facilitate transfer of employee exposure information to medical personnel, and (3) enable response to requests for data, including those for toxicological data. Although the plan is designed to link existing industrial hygiene data bases, priority is being given to facilitating access to data that are not readily available at the present time. 
Because of the increase emphasis on assessment activities, there have been fewer air samples to quantify chemical exposure in 1992 and 1993 than in recent years. However, the hazards assessment program will ensure that limited sampling resources are applied to areas with the greatest risk. In Building 858 , industrial hygiene sampling is supplemented by a complex toxic and hydrogen gas monitoring system consisting of more than 100 sensors, each monitoring hydrogen or 1 of 12 toxic gases. Building 878 was evaluated extensively by a subcontractor investigating ventilation needs. During the current calendar year, extensive personnel sampling has been done in Buildings 805 and 807 . The sampling results reviewed showed exposure to chemicals to be well below applicable standards. Local exhaust ventilation systems are also evaluated annually, and alarms are being installed on most laboratory hoods to alert the users to low-airflow conditions.

Despite the fact that SNL/NM has an adequate and improving industrial hygiene program, the progress has been limited by the lack of resources. In February 1994, $\$ 500,000$ (about 10 percent) was cut from the FY 94 funding allocated to the Industrial Hygiene Department to provide funds for implementation of the DOE RADCON Manual. These cuts reduced activities designed to improve respiratory protection, to perform systematic occupational exposure assessments, and to support industrial hygiene programs.

\subsection{Human Resources Programs}

Verification activities for the human resources programs functional area at SNL/NM indicated that all program elements were effective and, in some cases, have demonstrated recent improvement. Specifically, the training program was found to have improved since the time of the 1991 Tiger Team Assessment, and staffing levels have increased. Annual appraisals are conducted, which include ES\&H elements, and construction personnel are adequately trained before commencing work on site.

SNL/NM has developed a well-defined training program administered by the ES\&H Training Department of the Human Resources Center. About 95 percent of this training is related to ES\&H aspects. Some courses (e.g., Halogenated Solvents and Laboratory Spill Cleanup) are directly related to chemical safety, whereas the others cover a wide range of topics. The ES\&H Training Manual addresses the procedure for developing a training program. A training catalog lists all courses under the jurisdiction of the ES\&H Training Department. Training programs that are facility-specific are administered by a Training Coordinator for the affected facilities. Training is conducted by lecture, self-study, video presentation, computer-assisted instruction, interactive video, or a combination of these. After course presentation, examinations are administered and graded, and the answers are reviewed with the students. A review of one examination, however, revealed that the correct answers were not being reviewed with the students. In addition, some persons travel off site to receive specialized training. A list of training courses required and attended by each employee is recorded in the TIDBITS computer program. Based on review of a number of personnel training records, the training was found to be current for about 95 percent of the required courses. Some of those not current are for personnel who no longer need to complete the courses (e.g., retired or reassigned persons).

Construction personnel, who typically are transitory, receive a general employee training orientation presentation, similar to that for unescorted visitors, before they are permitted to 
work. For those construction employees who are to work in a location where specific hazards exist, site-specific training is provided by the site training officer. If the construction employee were to leave for work elsewhere and subsequently return, the site-specific training would have to be repeated, because of the possibility that new hazards could have been introduced since the first training session. Records of site-specific training are provided to the construction contractor supervisor, who must ensure that persons who are working at the site are properly trained. In addition, SNL/NM construction engineers and inspectors, as well as the ES\&H Coordinator, conduct spot-checks to ensure that workers are properly trained. Training for personnel performing studies as part of Cooperative Research and Development Agreements (CRADAs) is the same as for construction personnel, if they are to be on site for longer than normal escorted visits. However, site-specific training for CRADA personnel is considered to be current for the same length of time as for full-time employees.

ES\&H Coordinators have been assigned to facilities throughout SNL/NM. AL and KAO have noted that some building and organizational ES\&H Coordinators lack the training, experience, and/or support to perform their duties effectively. (See Vulnerability CSVR-SNL/NM-MO-02 in Section 3.2 and in Attachment 2 of this appendix.) Weaknesses noted during the verification visit that may be attributed to the lack of effectiveness of ES\&H Coordinators include (1) hazards were not fully identified in some PHAs that could have been discovered during review; (2) chemicals were stored at a location more than 100 feet from an eyewash facility, shower, or other source of water; (3) excess flammable chemicals stored in a decontaminated facility and which have no identified use, have been in storage for at least 2 years; and (4) a number of chemical storage areas were found to be without the Sandia Workplace Hazard Awareness signs as required by the SNL Environment, Safety, and Health Manual. A Center ES\&H Coordinator Handbook has been developed to address some of these issues.

Staffing levels were judged to be adequate to ensure that chemical safety training is addressed in the workplace. Vacant positions are filled as soon as qualified persons are available. Some managers indicated that there was a need for additional persons (e.g., the $M D L$ where work for public corporations is expanding and a second shift is to be implemented). Maintenance of a full staff is complicated by the fact that some local manufacturing corporations are expanding their work force and have enticed SNL/NM employees to join them by offering higher salaries and overtime pay.

Contractor personnel are employed to perform many jobs at SNL/NM. These people are treated as part of the organization for whom they perform the work; their training requirements are the same as for full-time employees. Open communications on all work-related matters exist between workers and their management. Personnel are encouraged to exercise their stop-work prerogative if they perceive that their safety may be in jeopardy. Discussions with both workers and managers revealed that there is no hesitancy in communicating with management when a problem is perceived. In the MDL, communication is fostered by the frequency and structure of meetings with all personnel. The first meeting each day is with maintenance personnel who report on equipment status. A second meeting is held with process technicians and machine operators who discuss process equipment status. In addition, a staff meeting is held three times a week. Hazard Communication training, which had been presented by lectures and video tapes, is now presented using a commercially prepared interactive video program. MSDSs are present at or near the work place where chemical hazards exist. 
The performance of all SNL/NM employees is appraised annually, including individual overall ES\&H performance. Awards are made to personnel who have exhibited exemplary performance; this can include recognition for actions taken in the ES\&H area. Chemical safety is addressed as a part of the overall safety umbrella, but is not specifically discussed.

Line management ES\&H performance is aided or facilitated through a program that yields individual and unique Management Assurance Notebooks. This serves as a standard means of organizing and communicating how ES\&H responsibilities are met. The Notebook is the primary repository of information documenting that management and others have fulfilled their ES\&H responsibilities or identifies the location where this information can be found. Each member of management has a slightly different version of the notebook that is tailored to meet the organization's specific needs. As management level increases, the emphasis in the notebook shifts from details to summaries and metrics. The notebook is a living document, which is to be updated at least annually and when major changes occur. This program was judged to be a commendable practice.

\subsection{Emergency Management Program}

Verification activities for the emergency management program functional area indicated that SNL/NM has in place a comprehensive emergency management program. The documentation, resources, organization structure, training and drills, and community interface provide for response to chemical-related emergencies at both the building-specific and SNL/NM-wide levels. Program documentation is appropriate except that the quality and currency of the sector emergency plans, which contain both building-specific planning information and response procedures, do not necessarily correlate with the level of buildingspecific hazards.

The SNL/NM Emergency Plan is the central document that describes the overall emergency management program, and the associated Emergency Plan Implementing Procedures identify the actions necessary to implement the plan. For emergency management purposes, SNL/NM has divided the SNL/NM-controlled areas into numerous "sectors," with each sector composed of one or more buildings. An emergency plan has been developed for each sector to include building-specific planning information (e.g., floor plans, evacuation routes, chemical inventories) and the emergency shutdown procedures for building systems and equipment. Thus, sector plans are used for emergency planning purposes and for emergency actions by both building occupants and emergency responders. There is currently neither consistency of content among the sector plans nor direct correlation between the extent of hazards associated with a building and the content, level of detail, or overall quality of information provided by the respective sector plan. (See Vulnerability CSVR-SNL/NM-MO-02 in Section 3.2 and in Attachment 2 of this appendix.) Additional emergency management documents include responder-specific procedures (e.g., SNL/NM Emergency Response Team procedures and Incident Commander procedures) and varied administrative procedures.

SNL/NM emergency response facilities include a well-equipped central Emergency Operations Center, medical clinic and decontamination facility, and communications command center. Emergency equipment includes a dedicated incident commander vehicle, dedicated hazardous materials response trailer, ambulances, and various types of alarm and communications systems and PPE within individual buildings. In an emergency, a mobile incident command 
post is established near the event scene by the onshift incident commander. Fire response vehicles and equipment, emergency medical vehicles, and a dedicated hazardous materials response vehicle and equipment trailer are maintained by the KAFB Fire Department.

SNL/NM has established an onshift incident commander position, staffed 24 hours per day by experienced persons trained in hazardous materials responise to meet the Occupational Safety and Health Administration (OSHA) requirements of 29 CFR 1910.120. In an emergency, the incident commander is notified by the 24-hour-per-day security dispatcher. On-call responders include the Emergency Operations Center cadre, the ES\&H Emergency Response Team, security officers, the cognizant sector chief, and, during normal working hours, medical clinic staff and ambulance drivers.

During working hours, the sector chief is initially in charge of building-specific response and is supported by assistant sector chiefs and, for higher hazard buildings, by the building emergency response team. Building evacuation is initiated by fire alarm, or toxic gas alarm for higher hazard buildings, and building occupants evacuate to a predesignated assembly point for accountability. Search and rescue teams are used to sweep an evacuated building to ensure complete evacuation, because there is no system for positive accountability of building occupants. Two emergency telephone systems are used for reporting emergency events: (1) "117" is dialed to report a fire and (2) "144" is dialed to report other types of emergencies. SNL/NM is in the process of establishing a standard " 911 " system.

The KAFB Fire Department, in accordance with an interdepartmental agreement between DOE and KAFB, provides SNL/NM with primary emergency response functions for fire, hazardous materials events, and medical emergencies. The Fire Department's primary mission is to provide these functions to KAFB and the adjoining commercial airport. KAFB Fire Department resources include five fire stations, 24-hour dispatch and firefighter staff, and appropriate vehicles and equipment. The Fire Department maintains a copy of the SNL/NM sector emergency preparedness plans and maintains an SINLNM building-specific information data base. Firefighters are trained in hazardous materials response to meet the OSHA requirements of 29 CFR 1910.120 and as emergency medical technicians. The senior fire official at the event scene coordinates with the SNL/NM incident commander to function within a unified incident command structure. For an event involving hazardous materials, the trained SNLNM ES\&H Emergency Response Team works in concert with the KAFB Fire Department.

Additional fire, hazardous materials, and/or emergency medical response resources are available from the City of Albuquerque Fire Department, as provided by a formal agreement. For emergency medical transportation and care, formal agreements are in place with community hospitals and a private ambulance service.

For emergency management purposes, assessment of the specific hazards related to the numerous operations and facilities at SNLNM is evolving. PHAs are currently performed by the line organizations for the operations within their respective spaces (see Section 2.3). An integrated hazards assessment process meeting DOE 5500.3A criteria has been initiated for higher hazard facilities and the resulting documentation, a Hazards Assessment Document, recently has been completed for Building 878 . Hazards Assessment Documents are to provide the technical basis for emergency management. 


\subsection{CATEGORIZATION AND PRIORITIZATION OF VULNERABILITIES}

\subsection{Criteria}

A vulnerability is a weakness or potential weakness involving hazardous chemicals that could result in a threat to the environment, the public, or worker health and safety. Vulnerabilities can be characterized by physical or programmatic conditions associated with uncertainties, acknowledged weaknesses, and/or unacknowledged weaknesses in the area of chemical safety. Conditions required to create the vulnerability should either currently exist or be reasonably expected to exist in the future, based on degradation of systems and chemicals or through expected actions (e.g., decontamination and decommissioning of facility).

A vulnerability will be determined to exist if current or expected future conditions or weaknesses could result in the following:

- The death of or serious physical harm ${ }^{2}$ to a worker or a member of the public or continuous exposure of a worker or member of the public to levels of hazardous chemicals above hazardous limits; or

- Environmental impacts resulting in the release of hazardous chemicals above established limits.

The prioritization of the chemical safety vulnerabilities is based on the professional judgment of team members concerning the immediacy of the potential consequences posed by each vulnerability and on the potential severity of those consequences. The first step in the prioritization process was to group vulnerabilities according to the timeframe in which they are expected to produce consequences. The following categories are defined for the timeframe within which the consequences are expected to occur:

- Immediate-Any chemical safety vulnerability that could result in immediate consequences.

- Short-Term-Any chemical safety vulnerability at a facility in which there is a significant chance of a consequence occurring within a 3-year timeframe as a result of chemical degradation, change in mission for the facility, degradation of the containment systems, change in personnel at the facility, or other factors affecting the facility.

- Medium-Term-Any chemical safety vulnerability at a facility in which there is a significant chance of a consequence occurring within a 3-10-year timeframe as a result of chemical degradation, change in mission for the facility, degradation of the containment systems, change in personnel at the facility, or other factors affecting the facility.

2 Serious physical harm is defined as impairment of the body, leaving part of the body functionally useless or substantially reducing efficiency on or off the job. 
- Long-Term-Any chemical safety vulnerability at a facility in which there is a significant chance of a consequence occurring in the timeframe greater than 10 years as a result of chemical degradation, change in mission for the facility, degradation of the containment systems, change in personnel at the facility, or other factors affecting the facility.

Vulnerabilities within each category are further prioritized, based on the severity of the potential consequences, as "high," "medium," or "low" priority. Consequences of high priority would cause death or irreversible injury or illness to workers or the public or would cause environmental damage that is irreversible or very costly to remediate. Low severity consequences would be reversible injuries, illness, or environmental damage.

\subsection{Chemical Safety Vulnerabilities at the Sandia National Laboratories, New Mexico}

The chemical safety vulnerabilities identified derived from the self-evaluation data and from specific observations made during the field verification process. Three vulnerabilities were identified at SNL/NM as a result of this review.

\section{CSVR-SNL/NM-FM-01: Inadequate integrated work conitrol of maintenance and construction activities in multiuser facilities.}

In multiuser facilities, the presence of several independent process, maintenance, and construction organizations, which function independently, can lead to confusion over responsibilities. One group's actions may inadvertently affect another group. In these multiuser facilities, there is no responsible individual who is cognizant of and has control over all facility modifications and maintenance activities. This results in a lack of integration and work control and does not ensure that chemical-related work procedures are applied uniformly and are well coordinated. Overall, eight service organizations from different research and matrix support groups were identified, each of which may be involved with maintenance functions in a single facility. Although these organizations each have their own effective safety procedures, their approaches to work control vary. There was no clear indication that work is being controlled in a fully integrated manner to ensure chemical safety. As a result, it is possible for maintenance or construction activities in one area of an equipment room to have an adverse effect on activities in another area. This situation may lead to inadvertent exposure of workers to hazardous chemicals or compromise the integrity of safety equipment. These conditions and circumstances represent a medium-priority vulnerability with a potential for short-term consequences.

\section{CSVR-SNL/NM-MO-02: Weaknesses in, and lack of integration among, the SNL/NM programs for identifying, characterizing, and mitigating chemical hazards.}

SNL/NM has not implemented integrated and effective programs for the identification, analysis, and mitigation of chemical hazards. The SNL/NM hazard analysis processes are sometimes inadequate because the level of vigor applied is not appropriate for the level of hazard present. Facility maintenance and design engineering processes do not ensure a level of safety review, approval, and testing commensurate with the consequences of failure or with the risk involved. Plans for the emergency preparedness sector are not always kept current and differ in quality and usefulness in a manner that does not necessarily correlate to the hazards present. It was also noted that the knowledge and effectiveness of building and 
organizational ES\&H coordinators vary greatly throughout SNL/NM. Possible consequences of the conditions cited above may include unrecognized hazards, less than adequate engineering and administrative controls, and a decreased capacity to respond to emergency situations, thereby potentially increasing both the probability and severity of accidents involving chemicals. These conditions and circumstances represent a medium-priority vulnerability with a potential for short- to long-term consequences.

\section{CSVR-SNL/NM-FM-03: Inadequate configuration management in aging laboratory facilities.}

Inadequate configuration management in an aging SNL/NM hazardous-chemical-containing laboratory complex (i.e., Buildings 805,806 , and 807 ) has resulted in the gradual degradation of essential utility and ventilation systems. These systems were reported to be operating at, or slightly beyond, maximum design capacities; experiencing a higher than normal breakdown incidence rate; and providing a contributing cause for indoor air quality issues. The chemical research laboratories undergo many small-scale modification projects that, typically, are not funded for full system engineering evaluations during the design phase. The problem is exacerbated by the many independent tenant organizations attempting to exert control over portions of the building without a responsible individual who is cognizant of and controls all facility operations and maintenance activities. As a result, there is a significant potential for the exposure of laboratory personnel to hazardous chemicals when essential ventilation and other support equipment fails in service. These conditions and circumstances represent a medium-priority vulnerability with a potential for short-term consequences. 


\section{ATTACHMENT 1}

TEAM COMPOSITION

Area of Responsibility

Team Leader

Management/Operations

Human Resource Programs

Chemical Process Safety

Industrial Hygiene

Environmental Protection

Maintenance

Emergency Management

Site Liaisons

Chief Coordinator

Coordinator

Technical Editor

\section{Name/Organization}

Bradley A. Peterson

Office of Performance Assessment

U.S. Department of Energy

Leon $\mathrm{H}$. Meyer

The LHM Corporation

Woodson B. Daspit

WBD Consulting Corporation

John A. Porter

JP Techservices, Inc.

Linda F. Munson

Evergreen Innovations, Inc.

Dale J. Dietzel

Chicago Operations Office

U.S. Department of Energy

John S. Stone

ICF Kaiser Hanford

Thomas A. Kevern

Program Management, Inc.

Michelle D. Chavez

Kirtland Area Office

U.S. Department of Energy

Kim L. Delman

Albuquerque Operations Office

U.S. Department of Energy

Mary E. Meadows

Environmental Management Associates

Norma B. Cameron

Office of Performance Assessment

U.S. Department of Eriergy

Robert F. McCallum

McCallum-Turner, Inc. 


\section{ATTACHMENT 2}

CHEMICAL SAFETY VULNERABILITY REVIEW

VULNERABILITY FORM

DATE: May 25, 1994

Site/Facility:

Sandia National Laboratories, New Mexico

Vulnerability Number: CSVR-SNL/NM-FM-01

Functional Area(s): Facility Physical Condition, Operational Control and Management Systems

1. Brief Description of Vulnerability.

Inadequate integrated work control of maintenance and construction activities in multiuser facilities.

2. Summary of Vulnerability.

In multiuser facilities, the presence of several operations, maintenance, and construction organizations, which function independently, can lead to confusion over responsibilities, and one group's actions may inadvertently affect impact another group. In these multiuser facilities, there is no responsible individual who is cognizant of and has control over all facility operations and maintenance activities. This results in a lack of integration of work control and does not ensure that chemical-related work procedures are applied uniformly and are well coordinated.

3. Basis.

a. Requirements:

- DOE 6430.1A, "General Design Criteria," specifies that facility documentation be updated as modifications are made.

- DOE 5480.19, "Conduct of Operations Requirements for DOE Facilities," Attachment I, Chapter VIII, stipulates that facilities are required to establish administrative control programs to handle configuration changes.

- DOE 5480.10, "Industrial Hygiene," requires that the health of workers be protected.

- DOE 4330.4B, "Maintenance Management Program," stipulates that DOE facilities be maintained such that the health and safety of all workers is ensured at all times.

b. Chemicals Involved: This is a programmatic vulnerability relating to numerous SNL/NM facilities containing hazardous chemicals.

c. Relevant Self-Evaluation Data: The self-evaluation did not identify any issues related to this vulnerability.

d. Contributing Causes:

- Procedures that define worker ownership for every square foot of facility space have been developed and implemented at SNL/NM. However, ownership boundaries are established by type and function of equipment and do not necessarily consider the nature of the chemical hazards present or the locations of hazardous chemical systems. Workers may not be aware of the chemical hazards associated with nearby equipment (including maintenance or modifications being done) if they have not been properly indoctrinated by facility management or if they have not been sufficiently inquisitive to otherwise obtain the information.

- Several service organizations, which function independently, are allowed to work simultaneously in SNL/NM facility equipment spaces that contain hazardous chemical proces'sing equipment and/or significant amounts of hazardous chemicals. In effect, all workers are exposed to the same potential chemical hazards, but all may not be fully aware of these hazards, particularly if they are assigned to perform nonchemical-related activities, as in the case of the utility maintenance crews. 
Site/Facility: $\quad$ Sandia National Laboratories, New Mexico

Vulnerability Number: CSVR-SNL/NM-FM-01

Functional Area(s): Facility Physical Condition, Operational Control and Management Systems

3. Basis. (Continued)

- There is no responsible individual who is cognizant of and has control over all facility operations and maintenance activities. This has the potential to affect chemical safety negatively.

e. Potential Consequences: Because work is not controlled by at single responsible individual, there is a potential that maintenance or construction activities in one area may adversely affect activities in an adjacent area. This may result in inadvertent exposure of personnel to hazardous chemicals or compromise the integrity of safety equipment. Personnel not cognizant of all ongoing chemical processes or work activities being performed by other organizations may be exposed unknowingly to the associated hazards; thus, in the event of a process upset, equipment failure, or inadvertent hazardous chemical release, they may not be properly protected or may be unable to respond properly. These conditions and circumstances represent a medium-priority vulnerability with a potential for short-term consequences.

4. Supporting Observations.

- In the facilities evaluated, several organizations, which function independently, perform operations, maintenance, and construction activities. These organizations are assigned in a matrixed fashion either to use the facility or to service the facility or its equipment. Focusing only on the services sector, the following were found: (1) several groups within the Facilities Operations and Maintenance Center (7800) have assigned individuals to facilities to both operate and maintain the utilities equipment (e.g., electrical distribution, steam, domestic water, and sewer); (2) Center 7800 provides additional mechanics and electricians when repairs are too large or complex for the facility-assigned maintenance crews; (3) Facilities Express (7911) services facilities needing quick repair or modification (e.g., lighting installation, office rearrangement); (4) operating technicians from several user organizations maintain their own process-specific equipment (e.g., air scrubbers, toxic gas supplies, vacuum pumps, exhaust bum boxes); (5) facility users may procure offsite contractor services when needed; (6) when numerous process modifications are required, as in the installation of new tools for microelectronics development, the Manufacturing Facilities Department (7908) may provide an offsite time-and-materials contractor; (7) when facilities or systems require major modification, offsite contractors may become involved through the Program Offices (7903 and 7904); and (8) there are several vendor-owned, vendormaintained systems located within facility equipment spaces that supply compressed gases, water treatment, and highly purified deionized water.

- Each of these service organizations has its own approach to safe work control, including prework safety assessments, training and qualification, lockout/tagout, and use of personal protective equipment. Individually, these work controls appeared to be effective. Further, personnel access to facility equipment spaces was found to be properly controlled such that only those with a need to enter are allowed to do so; however, each of the service organizations listed above could be involved simultaneously in a particular space and, thus, would have access. 
Site/Facility: $\quad$ Sandia National Laboratories, New Mexico

Vulnerability Number: CSVR-SNLNM-FM-01

Functional Area(s): Facility Physical Condition, Operational Control and Management Systems

4. Supporting Observations. (Continued)

- Concern for the safety of workers in hazardous chemical-containing facilities arises because there is no indication that the work is controlled in a fully integrated manner by a single responsible individual who is cognizant of and has control over all facility operations and maintenance activities. It is not apparent that individual work crews are routinely wamed in advance of the planned or ongoing service activities by other crews that may take place in their proximity. Further, they may not be wamed of hazards, including the chemical hazards, that may be encountered as a result of the other crew's activities. In one instance, facility maintenance crews were not fully informed of the chemical hazards associated with an exhaust scrubber located directly adjacent to their ventilating systems. Thus, their only protection in the event of a serious scrubber malfunction would be their individual skills in recognizing hazards and their ability to respond in a conservative manner (in this case, building evacuation). 
Site/Facility: $\quad$ Sandia National Laboratories, New Mexico

Vulnerability Number: CSVR-SNL/NM-MO-02

Functional Area(s): Operational Control and Management Systems, Facility Physical Condition, Emergency Management Program

1. Brief Description of Vulnerability.

Weaknesses in, and lack of integration among, SNL/NM programs for identifying, characterizing, and mitigating chemical hazards.

2. Summary of Vulnerability.

SNL/NM has not implemented integrated and effective programs for the identification, analysis, and mitigation of all chemical hazards. The SNL/NM hazard analysis processes are sometimes inadequate because the level of rigor applied is not appropriate for the level of hazard present. Facility maintenance and design engineering processes do not ensure a level of safety review, approval, and testing commensurate with the consequences of failure or the risk involved. Plans for the emergency preparedness sector vary in quality and usefulness in a manner that does not necessarily correlate to the hazards present. These conditions may result in unrecognized hazards, less than adequate engineering and administrative controls, and a decreased capacity to respond to emergency situations.

3. Basis.

a. Requirements:

- DOE 5480.4, "Environmental Protection, Safety and Health Protection Standards," requires that DOE facilities conform to an established set of standards including the National Electrical Code.

- DOE 5483.1A, "Occupational Safety and Health Program for DOE Contractor Employees at Govemment-Owned Contractor-Operated Facilities," requires heads of Field Organizations to require contractors to furnish contractor employees employment and a place of employment which are as free from occupational safety and health hazards as possible.

- DOE 6430.1A, "Engineering Design," calls for design, verification, and test requirements relating to consequence of failure for engineering and maintenance work.

- DOE 5500.3A, "Planning and Preparedness for Operational Emergencies," requires a hazard assessment to be prepared and used for emergency planning purposes.

- DOE 4330.4B, "Maintenance Management Program," and DOE 5480.19, "Conduct of Operations Requirements for DOE Facilities," require that postmaintenance testing requirements be established and specified on the maintenance work order or accompanying documentation.

- DOE 5481.1B, "Safety Analysis and Review System," establishes the DOE policy to ensure that potential hazards are systematically identified; consequences are analyzed; and reasonable measures are established to eliminate, control, or mitigate the hazards. It also establishes hazard classes. It does not effectively establish requirements for low-hazard facilities.

- SNL/NM Emergency Plan Implementing Procedure No. 560 requires sector plans to be reviewed and updated annually by the cognizant line organization "sector chief."

b. Chemicals Involved: A wide range of hazardous chemicals and chemical wastes are involved with different activities at SNL/NM. 
Site/Facility: $\quad$ Sandia National Laboratories, New Mexico

Vulnerability Number: CSVR-SNL/NM-MO-02

Functional Area(s): Operational Control and Management Systems, Facility Physical Condition, Emergency Management Program

3. Basis. (Continued)

c. Relevant Self-Evaluation Data: The SNL/NM self-evaluation cites identification of hazardous operations through preliminary hazards assessments (PHAs) and, when appropriate, safety assessments and safety analysis reports as a fundamental method for controlling hazardous chemicals at SNLNM. The self-evaluation does not specifically address deficiencies in these systems.

d. Contributing Causes:

- The process used by line management, ES\&H coordinators, and the Risk Management \& NEPA Department for approval and review of PHAs is not effective in identifying deficiencies.

- There are deficiencies in the formal guidance for preparing safety documents.

- There are deficiencies in the qualification and training program for ES\&H coordinators.

- There are deficiencies in the training program for personnel who prepare safety documentation.

- There is a lack of rigor in the conduct of engineering analysis and maintenance of potentially hazardous chemical processing systems.

- There are less than adequate controls covering the content, level of detail, or review process for sector emergency plans.

- The SNLNM organizational structure makes uniform program implementation difficult.

e. Potential Consequences:

- The absence of an adequate hazards analysis program may contribute to the failure to recognize and mitigate hazards. Unrecognized hazards may lead to less-than-adequate engineering and administrative controls, thereby increasing both the probability and consequences of accidents involving chemicals.

- Without current and accurate sector emergency plans, emergency responders may unknowingly subject themselves to hazardous chemical exposures. These conditions and circumstances represent a medium-priority vulnerability with a potential for short- to long-term consequences. 
Site/Facility: $\quad$ Sandia National Laboratories, New Mexico

Vulnerability Number: CSVR-SNL/NM-MO-02

Functional Area(s): Operational Control and Management Systems, Facility Physical Condition, Emergency Management Program

4. Supporting Observations.

- Hazard analysis is sometimes inadequate for the level of hazard present. Chemical hazards in nonnuclear facilities are classified according to the guidance provided by KAO in a January 11, 1994, memorandum to A.O. Bendure. Under this guidance, the majority of chemical processes are classified as nonnuclear low-hazard facilities. Neither risk-based prioritization nor quality assurance levels are assigned for design, construction, or maintenance of facilities, systems, and equipment. Hazard analysis is provided in a PHA prepared by the responsible line organization, approved by line management, and reviewed by organizational ES\&H coordinators and the Risk Management \& NEPA (National Environmental Policy Act) Department. The line organization is responsible for an annual review and update. PHAs may cover a single process, room, or facility; there are about 4,000 PHAs at SNL/NM. Accident analyses with defined potential consequences were not included in the PHAs that were examined. Discussions with management personnel in the Risk Management \& NEPA Department indicated their awareness of deficiencies in the program, which were judged to derive from a lack of clear guidance in the program documents on techniques for preparing PHAs and other safety documentation and inadequate training of the SNL/NM employees assigned the responsibility for preparing the safety analysis documents. The Risk Management \& NEPA Department has proposed an enhanced and improved hazards analysis program, which will address current deficiencies. The ability to implement the enhanced program depends on the availability of additional resources.

- SNL/NM relies heavily on organizational and building ES\&H coordinators to identify hazards and serve as a primary contact with the safety disciplines. AL and KAO have noted that some ES\&H coordinators lack training, experience, and/or support to perform their duties effectively. The knowledge and effectiveness of ES\&H coordinators vary greatly throughout SNLNM, depending on the organizations involved - not necessarily on the chemical or other risks. SNLNM has taken action to increase the effectiveness of the organizational ES\&H Coordinators by furnishing them with the Center ES\&H Coordinators Handbook, which lists sources of requirements and points of contact. Several deficiencies were noted that indicate breakdowns in the effectiveness of ES\&H coordinators.

- For designated low-hazard facilities, facility maintenance and design engineering processes do not ensure a level of safety review, approval, and testing commensurate with the consequence of failure or with the risks involved. The design of facilities, systems, and equipment is controlled by SNL/NM engineering standards that encompass the requirements of DOE Orders and appropriate national consensus standards. The standards include criteria for workmanship and the requirements to be met for qualification and testing. SNL/NM standards do not address design requirements or considerations that relate to (1) specific consequences of failure, (2) risk to the public, (3) risk to personnel, (4) critical or vital safety systems, (5) proximity to critical or vital safety systems, (6) proximity to heavily staffed areas, (7) impact of failure on vital programs, (8) level or rigor in engineering analysis, (9) degree of review, verification, and approval, and (10) requirements for system or equipment prestartup review and approval. Customer-funded modifications may receive, but do not require, input from industrial hygienists and other safety professionals. 
Site/Facility: $\quad$ Sandia National Laboratories, New Mexico

Vulnerability Number: CSVR-SNL/NM-MO-02

Functional Area(s): Operational Control and Management Systems, Facility Physical Condition, Emergency Management Program

4. Supporting Observations. (Continued)

- A project to add a chemical storage room and an acetone distillation apparatus to Building 878 received only limited input from industrial hygiene specialists. The vertilation flow rate was designed to preclude generation of an explosive atmosphere, but there was no documentation that this flow rate was sufficient for the protection of personnel. Although no formal process hazard analysis was performed, the facility was designed in conformance with code requirements with venting panels to relieve pressure from an explosion involving up to 120 gallons of acetone. For this same project, a codes integration specialist determined that the Uniform Building Code required backup power for the ventilation system for the distillation apparatus (based on an interpretation that it was not a closed system). When backup power was found to be unavailable, the facility was designed without it, based on the understanding of a fire protection engineer that it was a closed system. No basis for the second judgment was documented, and no accident analysis covering the loss of power was performed. At the time of the review, the distillation apparatus installation had not been tumed over to the operating group. If a problem is identified, there is no assurance or system to inform the operating group or DOE of the varying judgments concerning the degree of compliance.

- Maintenance standards for repairing and maintaining the facilities, systems, and equipment, including requirements and frequencies for preventive maintenance activities, are based on the specific service without consistent regard for consequence or risk. Further, the requirements for specific postmaintenance testing (e.g., to prove safety and operability before release to the line organization) are not well defined and are not risk based.

- Sector Emergency Plans vary in quality and usefulness in a manner that does not necessarily correlate to the hazards present. The SNL/NM emergency response organization and the Kirtland Air Force Base Fire Department rely on the Sector Emergency Plans for building-specific emergency planning and response information (e.g., building floor plans, location of emergency equipment, presence of hazardous materials). The plans reviewed lacked consistency in format and content and varied in length from about 20 to more than 100 pages. Not all plans had been reviewed or updated annually.

- Prioritization of ventilation projects does not always appear to be based on the risk of chemical exposure. Ventilation deficiencies in Building 878 have required six separate projects to provide recommended airflows for the present facility occupancy. Although five of these, including one to eliminate lunchroom odors in the workplace, have been given funding priority, a $\$ 40,000$ project to reroute the exhaust air from a plastics curing operation (relocating the discharge from directly above a loading dock to a roof stack) was not funded. Although SNLNM has implemented compensatory measures when this ventilation system is in use, the relative priority does not appear to be risk based. 
Site/Facility: $\quad$ Sandia National Laboratories, New Mexico/Laboratory Buildings 805, 806, and 807

Vulnerability Number: CSVR-SNL/NM-FM-03

Functional Area(s): Facility Physical Condition, Operational Control and Management Systems

1. Brief Description of Vulnerability.

Inadequate configuration management in aging laboratory facilities.

2. Summary of Vulnerability.

Inadequate configuration management in an aging SNL/NM hazardous-chemical-containing laboratory complex has resulted in the gradual degradation of essential utility and ventilation systems. These systems were reported to be operating at, or slightly beyond, maximum design capacities, to be experiencing a higher than nomal breakdown incidence rate, and to be a contributing cause of suspect indoor air quality issues. The chemical research laboratories undergo many small-scale modification projects that, typically, do not provide sufficient funding for full system engineering evaluations during the design phase. The problem is exacerbated by the many independent tenant organizations attempting to exert control over portions of these buildings without a responsible individual who is cognizant of and controls all facility operations and maintenance activities.

3. Basis.

a. Requirements:

- DOE 6430.1A, "General Design Criteria," specifies that facility documentation be updated as modifications are made.

- DOE 5480.19, "Conduct of Operations Requirements for DOE Facilities," Attachment I, Chapter VIII, stipulates that facilities are required to establish administrative control programs to handle configuration changes.

- DOE 5480.10, "Contractor Industrial Hygiene Program," requires that the health of workers be protected.

- DOE 4330.4B, "Maintenance Management Program," stipulates that DOE facilities be maintained such that the health and safety of all workers be ensured at all times.

b. Chemicals Involved: Numerous industrial chemicals, toxins, carcinogens, compressed gases, and organics, all in small laboratory quantities; mercury contamination (in laboratory drains); minor depleted uranium contamination; and low levels of other hazardous materials.

c. Relevant Self-Evaluation Data: The self-evaluation performed by the laboratory complex indicated that indoor air quality continues to be an issue. The following concerns related to this subject were identified:

- Fresh-air intakes are at or below grade level and are subject to the capture of vehicle exhaust gases.

- Roof-mounted fume hood exhaust stacks on Building 805 are of insufficient height to ensure that workers are not exposed to hazardous exhaust constituents when performing routine maintenance tasks while on the roof of Building 805.

- There is a potential microbial problem in the ventilation system of one section of these facilities.

- On one occasion, a facility was evacuated because of suspect indoor air quality. 
Site/Facility: $\quad$ Sandia National Laboratories, New Mexico/Laboratory Buildings 805, 806, and 807

Vulnerability Number: CSVR-SNL/NM-FM-03

Functional Area(s): Facility Physical Condition, Operational Control and Management Systems

3. Basis. (Continued)

d. Contributing Causes:

- The facilities have been in use for 30 years, and essential ventilation equipment is nearing the end of its dependable operating life.

- A multitude of small-scale ventilation modifications to support the needs of the laboratory users and their customers have been made over the past several years. These relatively minor modifications have expended available ventilation system excess capacity and have resulted in excessive exhaust flow rates and significant air imbalances in the laboratories.

- Many independent tenant organizations attempt to exert influence over portions of the building without a single responsible individual having overall control.

e. Potential Consequences:

- There is a potential for exposure of laboratory personnel to hazardous chemicals when essential ventilation and other support equipment fails in service.

- Previous exhaust system failures have resulted in pressure reversals, causing not only the loss of chemical vapor control, but also the distribution of the chemical vapors to other parts of the facility.

- These conditions and circumstances represent a medium-priority vulnerability with a potential for shortterm consequences.

4. Supporting Observations.

- In the aging laboratory complex (i.e., Buildings 805,806 , and 807 ), the assigned facility operations and maintenance crew noted that some essential utility and ventilation systems were operating at or slightly beyond maximum design capacities. Systems include (1) makeup air units for Building 805 for both heating and cooling (required to operate at full load because of the large amount of air being exhausted via chemical fume hoods and localized chemical equipment ventilation); (2) water chillers (cooling both the building spaces and an excessive number of computers, laboratory electronics and laboratory processes) for Buildings 805,806 , and 807; (3) chilled-water circulation pumps for Buildings 805,806 , and 807 ; and (4) most fume hood exhaust systems, each of which serves two or more laboratory rooms. Severe operating demands, in combination with almost 30 years of operating service, have significantly reduced the equipment availability (i.e., time available for dependable operation) of these essential systems.

- The self-evaluation report provided by this laboratory complex indicated that suspect indoor air quality was, and continues to be, an issue. In the past, there have been building evacuations due to suspect air quality. This is further illustrated by verbal reports from the assigned maintenance crew: when chemical hood exhaust fans fail (e.g., overload, overheat, failed drive belts), they often coast in reverse rotation. This phenomenon indicates a pressure reversal in the associated fume hoods, allowing potentially hazardous chemicals to escape into laboratory spaces, flowing through hallways to other laboratories with operating exhaust fans. 
Site/Facility: $\quad$ Sandia National Laboratories, New Mexico/Laboratory Buildings 805, 806, and 807

Vulnerability Number: CSVR-SNLNM-FM-03

Functional Area(s): Facility Physical Condition, Operational Control and Management Systems

4. Supporting Observations. (Continued)

- The problems described are symptomatic of inadequate engineering configuration management (i.e., "as-built" documentation) programs and of the tendency for chemical laboratories to require many small-scale modification projects. Such projects usually have insufficient capital resources to allow for performance of formal analyses of entire ventilation systems to determine the effects of the proposed changes on air and heat flows, on static pressures, and on the resulting air balances (direction and velocity of flow that directly affect air quality). The problem illustrated is further compounded in that Buildings 805,806 , and 807 have many independent tenant (customer) research organizations with unrelated budgets and rapidly changing missions in unrelated fields. Further, the three connected facilities received little or no "as-built" attention in their early operating lives; thus, there is an inadequate baseline for engineering analysis.

- Facilities design engineers revealed that, because of multiple organizations controlling different parts of the building, the potential exists for different design groups to be performing concurrently two (or more) modification projects for the same ventilation system without interface or knowledge of the other's work. This situation results from the fact that projects are funded from separate customer organizational research budgets. This situation is particularly critical for modification to aging systems that are operating at or near full capacity.

- A project is ongoing to provide two chilled-water cooling loops for this complex to share space cooling capability among the buildings and to separate building space-cooling flows from laboratory electronics and process cooling flows, but this change will do little to address air quality concerns.

- To relieve this problem, SNL/NM is planning to conduct a gradual relocation of a portion of its ongoing hazardous chemical research work from this laboratory complex to facilities that are sited in less densely populated areas. This move will effectively reduce the ventilation and cooling requirements by decreasing the number of local exhaust systems operating in these buildings. 


\section{L-44}




\section{ATTACHMENT 3}

\section{SELECTED ACRONYMS}

AL DOE Albuquerque Operations Office

AMPL Advanced Manufacturing Process Laboratory

BMHA Building Modification Hazard Assessment

CIS Chemical Information System

CRADA Cooperative Research and Development Agreement

DOE U.S. Department of Energy

DOT U.S. Department of Transportation

ES\&H Environment, Safety, and Health

HWMF Hazardous Waste Management Facility

KAFB Kirtland Air Force Base

KAO DOE Kirtland Area Office

MDL Microelectronics Development Laboratory

MSDS Material Safety Data Sheet

NEPA National Environmental Policy Act

OSHA Occupational Safety and Health Administration/Act

PHA Preliminary Hazard Assessment

PPE Personal Protective Equipment

RCRA Resource Conservation and Recovery Act

SARA Superfund Amendments and Reauthorization Act

SNL/NM Sandia National Laboratories/New Mexico

SOP Standard Operating Procedure 


\title{
APPENDIX M
}

\author{
MINI-VISITS \\ TO SMALL DOE SITES
}

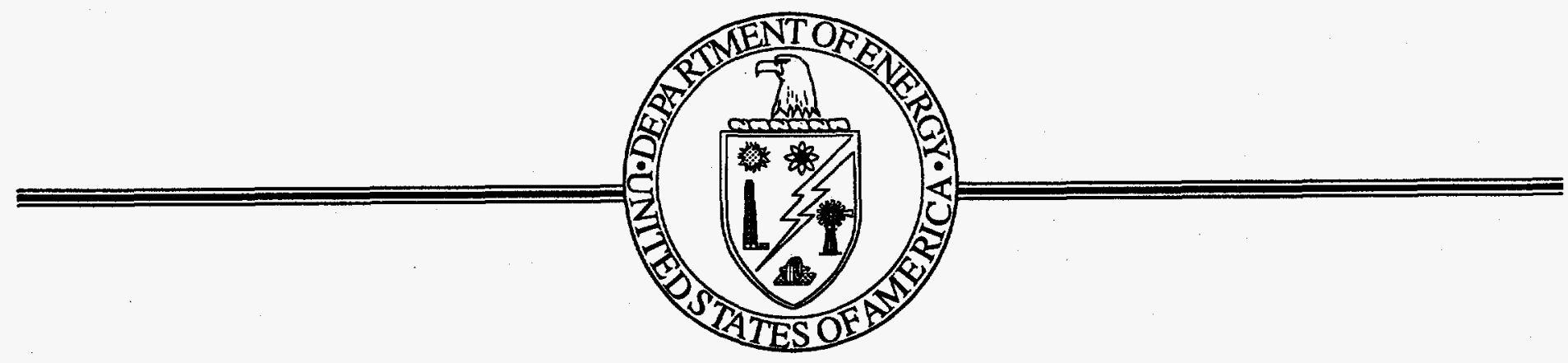





\section{APPENDIX M}

\section{MINI-VISITS TO SMALL DOE SITES}

\section{Introduction}

The Chemical Safety Vulnerability Review was conducted in six phases as described in Appendix B. Nine of the 29 sites involved with the field self-evaluation effort were selected to host field verification visits. These nine sites represented a variety of geographic locations, missions, operating histories, program offices, and management and operating (M\&O) contractors. The nine sites, however, were all considered "large sites." To supplement initial field verification efforts and to ensure that the sites and facilities visited adequately represented the entire Department of Energy (DOE) complex, modified field verification visits (mini-visits) were conducted at four "small sites" (i.e., sites with 1,000 or fewer DOE and contractor employees). Field verification activities to the nine large sites coupled with the mini-visits to four small sites served as a major source of information for determining the generic chemical safety vulnerabilities identified in this report.

\section{Site Selection and Verification Approach}

The four small sites selected-the Energy Technology Engineering Center, Naval Petroleum Reserve in California, Pittsburgh Energy Technology Center, and West Valley Demonstration Project-provide a diverse sample of smaller DOE sites. Field verification teams consisting of a DOE team leader, an industrial hygienist, and an environmental expert visited these sites. The duration of the mini-visits ranged from 1 to 2 days, and activities included participation in technical and management discussions, document reviews, and facility tours. Sections III-VI of this appendix summarize the teams' understanding of chemical safety issues for each of the four sites, based on the limited observations permitted in the designated timeframe.

\section{Energy Technology Engineering Center}

Date: May 10, 1994

\section{Site/Project Description:}

Until recently, the primary mission of the Energy Technology Engineering Center (ETEC) was to provide engineering development and testing for components related to liquid metal technology and to conduct applied engineering development of emerging energy technologies. The Office of Nuclear Energy is the responsible program office for ETEC, and the Oakland Operations Office provides local oversight. ETEC's current mission is to continue conducting limited applied engineering research. A number of ETEC facilities associated with sodium research are in the process of being transferred to the Office of Facility Transition (EM-60). Rocketdyne (a Division of Rockwell International) is the M\&O contractor at ETEC. The site is located in Chatsworth, California, and is part of Rocketdyne's Santa Susana Field Laboratory campus. 
Facilities Visited:

The field verification team visited the following facilities at ETEC: Kalina Demonstration Plant, Sodium Storage Building, Sodium Component Test Installation, Cleaning and Handling Facility, Hazardous Waste Treatment Facility, Chemistry Laboratory, and Sodium Pump Test Facility.

Key Observations:

ETEC shares significant environmental, safety, and health (ES\&H) support with the larger Rocketdyne organization that operates the Santa Susana Field Laboratory. In general, ES\&H support provided by Rocketdyne staff is useful and comprehensive. However, some cases of inadequate storage of incompatible laboratory chemicals and continued storage of excess and aging laboratory chemicals were observed. A review of hazards analyses associated with large storage tanks of ethyl alcohol and ammonia might be useful. ETEC personnel were knowledgeable about wastes and processes, and the training program was good.

\section{Naval Petroleum Reserve in California}

Date: May 11, 1994

Site/Project Description:

The Naval Petroleum Reserves in California (NPRC) is made up of the Naval Petroleum Reserve Number 1 (NPR-1), referred to as the Elk Hills oil field, plus associated facilities and support activities. According to the provisions of a 1944 Unit Plan Contract, NPR-1 is operated as a unitized oil field, with the U.S. Government owning 78 percent of the field and Chevron USA, Inc., owning the rest. Bechtel Petroleum Operations, Inc., is the unit operator for Elk Hills and conducts its work under an M\&O contract with DOE. The mission of NPR-1 is to produce oil and gas under the provisions of the Naval Reserves Production Act of 1976. The Office of Fossil Energy is the responsible program office, and the DOE Naval Petroleum Reserves in California (the DOE site office) provides local oversight.

\section{Facilities Visited:}

The field verification team visited the following facilities at the 35R Complex of NPRC:

Loading Rack, Storage Area, 35R Laboratory, Laboratory Chemical Storage Building, Lean Oil Absorption Plant, Low Temperature Separation Unit No.1, 35R Hazardous Waste Temporary Storage Pad, and 35R Compressed Gas Storage Warehouse.

\section{Key Observations:}

There are inherent risks in the nature of the operations at the NPRC 35R Complex (natural gas processing, fractionation, and reinjection) because of the flammable and explosive nature of the products involved: These risks are well identified, and the physical and management response systems are mature and appropriate. The contractor has a dedicated staff (10 employees) for ES\&H management. Existing programs for environmental protection, compliance, and risk management are generally in place with ongoing development and 
improvement efforts exhibited. Observed shortcomings at NPRC included weaknesses in such areas as disposal of laboratory quantities of hazardous chemicals that were no longer being used and training and oversight of subcontractors assigned to handle compressed gas cylinders. NPRC has made good progress in instituting a conduct of operations program and has improved its training and qualification program.

\section{Pittsburgh Energy Technology Center}

Dates: May 17-18, 1994

Site/Project Description:

The Pittsburgh Energy Technology Center (PETC) is a research and development facility managed by the Office of the Fossil Energy. Research programs at PETC emphasize new technologies that hold promise for increasing the industrial use of clean coal over the long term. In addition to onsite research and development activities, research projects are conducted off site through contractual agreements with industry, research and development organizations, and academia. PETC is also involved in cooperative agreements with industry for developing of demonstration projects.

\section{Facilities Visited:}

The field verification team visited the following facilities at PETC: Buildings 64 (Chemical Handling Facility), 65 (Gas Cylinder Storage), 74 (Wastewater Treatment Facility), 83 (Indirect \& Direct Liquefaction Facility), 84 (Chemical Engineering Laboratory), 92 (Chemical Handling Facility), 93 (Combustion Test Facility), 94 (Analytical Chemistry Laboratory), 99 (Cylinder Gas Distribution System for Buildings 84 and 94), and 141 (Coal Preparation Facility).

\section{Key Observations:}

PETC has prepared and implemented a comprehensive hazard identification program. However, consistent controls to enforce these requirements could not be verified. The team observed inappropriate storage of incompatible materials at the RCRA 90-day accumulation area and at the acid storage area.

\section{West Valley Demonstration Project}

Date: May 25, 1994

Site/Project Description:

The West Valley Demonstration Project is used to process large quantities of radioactive waste. Activities include treating low-level radioactive liquids and vitrifying high-level liquid waste into stainless steel canisters for long-term storage. 
Facilities Visited:

The field verification team visited the following facilities at West Valley: Hazardous Waste Storage Area Locker, Analytical Environmental Laboratory, and Supernate Treatment System.

\section{Key Observations:}

Funding for the ES\&H program (including chemical safety) is provided through the overall line program. The site maintains a very high level of ES\&H awareness. A tour of the hazardous waste storage area indicated that facilities are well maintained and operated (including use of specially designed storage lockers with built-in alarms and fire suppression systems), and a strong management program is in place for the storage and offsite disposal of hazardous waste.

The operating laboratories at the site were well maintained, and management controls have been developed, implemented, and followed. The environmental monitoring laboratory was in the process of being upgraded, and ES\&H requirements have been developed and implemented for laboratory operations. Chemical holdings were kept to a minimum through use of a system that approaches "just-in-time" procurement. At one monitoring laboratory visited, reagents were excessed at the end of their expected shelf life. No large or out-of-date storage of chemicals was found at the site. The main process building was found to be well maintained, and documentation for operating systems was maintained current and incorporated ES\&H requirements.

Overall, the site was observed to have a strong ES\&H program, which in turn was an integral part of the demonstration project. No chemical safety vulnerabilities were identified at the three facilities visited, and based on interviews with key personnel at the site, these three facilities were typical of the high level of ES\&H awareness demonstrated throughout the site.

\section{Conclusions}

Ten observations suggesting chemical safety weaknesses were noted at three of the sites visited. None of the weaknesses identified represents a condition or circumstance with the potential for severe near-term consequences. No chemical safety weaknesses were noted for the West Valley Demonstration Project. Each observation was reviewed to determine whether it supported a vulnerability identified at another site or whether it provided the basis for a new generic vulnerability. The observations generated during the mini-visits were also examined collectively to determine whether some vulnerabilities might be unique to smaller sites.

All individual observations generated during the mini-visits appeared to support some element (e.g., supporting observations, contributing cause, potential consequence) of vulnerabilities at one or more of the "large sites." At ETEC, for example, an observation related to lack of knowledge and understanding of health and safety requirements supports vulnerabilities identified at the larger sites (e.g., Vulnerabilities CSVR-SRS-0000-03 and -04, CSVR-OR-ORR-04, CSVR-RFP-000-01 and -02, CSVR-LANL-OMS-03, and CSVR-SNL/NM-MO-02). 
None of the observations generated during the mini-visits could be combined to support identification of a new generic vulnerability. Examined collectively as a subset of existing generic vulnerabilities, these observations did not require that a new generic vulnerability be established or that existing vulnerabilities be recast for adequate consideration under the management response plan. The chemical safety vulnerabilities established from observations at large DOE sites appear to be generic to both large and small DOE sites. 
APPENDIX N

\section{WORKING GROUP MEETING \\ JUNE 7 - 8, 1994}

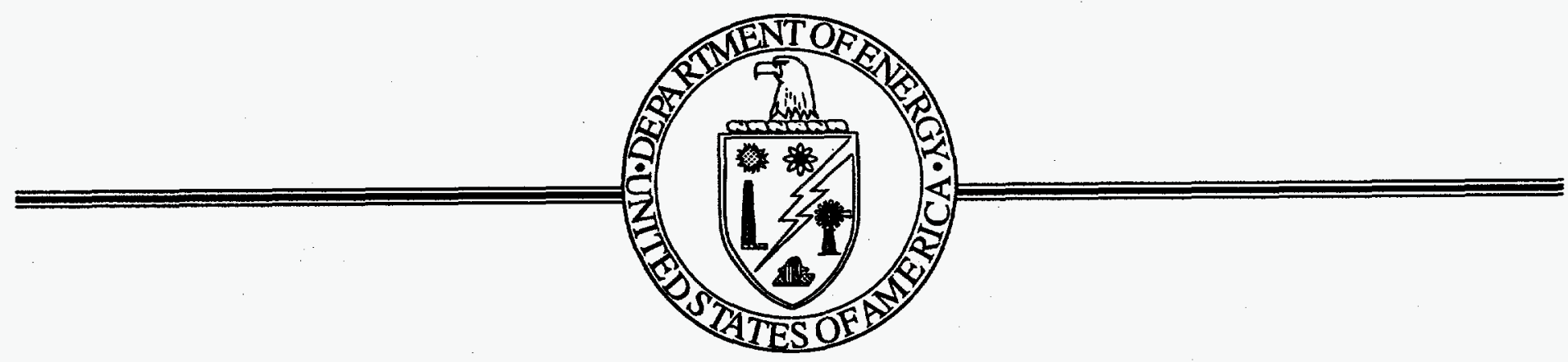





\section{ATTENDANCE LIST \\ CHEMICAL VULNERABILITY WORKING GROUP MEETING \\ JUNE 7-8, 1994}

Department of Energy

Don Boyce, NV

Laura Cindel, RFO

Victor Crawford, EH-24

Kim Delman, AL

Nancy Demond, BPA

Dale Dietzel, $\mathrm{CH}$

John Dowicki, NE-44

Dave Evans, RL

Albert Evans, ER-13

Jerry Granzen, BAO

Harvey Grasso, OAK

Rebecca Hansen, EH-321

Don Harvey, DP-31

Jim Hawkins, LM

Donna Jackson, SR

Vishwa Kapila, EH-33

Michael Kilpatrick, EH-24

Max Klaussen, FM

Jay Larson, ER-8

Leonard M. Lojek, EH-321

Oliver D.T. Lynch, Jr., EH-32

Don Michaelson, ID

Ken Murphy, EH-331

Bradley Peterson, EH-321

Brian Raleaugh, ER-8

Mark Robinson, OR

David Rohrer, EH-411

John Sourbeer, PETC

Ted Teresinski, ER-2

Ted Tomsck, ER-13

Robert Vrooman, DP-62

Patricia Worthington, EH-12

DOE Contractors and Subcontractors

Lisa Alexander, PMI

Rex Beach, LLNL

Michael Brooks, EG\&G RF

Del Bunch, MSI 
DOE Contractors and Subcontractors (Continued)

Bill Griffing, NREL

Doan Hansen, BNL

H. Mac Hayes, PPPL

Glenn Hoenes, Battelle PNL

Jim Jackson, LLNL

John Janous, INTECH

Dave Johnson, PMI

Ed Kahal, WSRC

Tom Kevern, PMI

John Kovach, EG\&G METC

Todd Lewis, B\&W Idaho

Julie Magness, EG\&G Mound

Mary Meadows, EMA

Bruce Miller, EG\&G Idaho

Steve Parker, SNL

Gerry Paulson, WINCO

Carmen Romano, EG\&G METC

Tom Rudolph, WHC

Saleem Salaymeh, WSRC

Jack Salazar, LBL

Steve Saunders, SAIC

Jeffrey Schinkel, LANL

John Schmerber, MK-Ferguson

Ann Schubert, WVNS

David Sheffey, MMES

Dusty Simonson, Weston

Bob Skier, REECo

John S. Stone, KEH

Donna Thompson, PMI

John Usher, BNL

Carol Vega, MSE

James L. Woodring, ANL

Danny Yee, LLNL

Bill Zwick, LANL 


\section{CHEMICAL SAFETY VULNERABILITY WORKING GROUP SECOND MEETING June 7-8, 1994 \\ Gaithersburg Hilton 620 Perry Parkway Gaithersburg, MD 20877 \\ (301) $977-8900$ \\ AGENDA}

June 7,1994

$7: 30-8: 30$

Registration

$8: 30-8: 45$

Opening Remarks/Status

O.D.T. Lynch

$8: 45-9: 30$

Self-Assessment Data/

R. Hansen

Verification Visits

$9: 30-10: 00$

Vulnerabilities!

M. Kilpatrick

Prioritization

$10: 00-10: 15$

Break

$10: 15-12: 00$

Breakout Sessions 1, 2, \& 3 - Prioritization of the Vulnerabilities (DOE Contacts: Vic Crawford, Brad Peterson, Len Lojek)

$12: 00-1: 00$

Lunch

$1: 00-3: 00$

Breakout Sessions (continued)

$3: 00-3: 30$

Presentation of Breakout

Group Leader Group 1

$3: 30-4: 00$

Presentation of Breakout

Group Leader

Group 2

$4: 00-4: 30$

Presentation of Breakout

Group Leader

Group 3

$4: 30-5: 30$

Discussion

All 


\section{CHEMICAL SAFETY VULNERABILITY WORKING GROUP SECOND MEETING}

AGENDA

June 8, 1994

\begin{tabular}{|c|c|c|}
\hline $8: 00-8: 30$ & Management Response Plan & R. Barber \\
\hline $8: 30-12: 00$ & \multicolumn{2}{|c|}{$\begin{array}{l}\text { Breakout Sessions 1, 2, \& } 3 \text { - Management Response Plan } \\
\text { (DOE Contacts: Vic Crawford, Brad Peterson, Len Lojek) }\end{array}$} \\
\hline $12: 00-1: 00$ & Lunch & \\
\hline $1: 00-1: 30$ & $\begin{array}{c}\text { Presentation of Breakout } \\
\text { Group } 1\end{array}$ & Group Leader \\
\hline $1: 30-2: 00$ & $\begin{array}{l}\text { Presentation of Breakouk } \\
\text { Group } 2\end{array}$ & Group Leader \\
\hline $2: 00-2: 30$ & $\begin{array}{l}\text { Presentation of Breakout } \\
\text { Group } 3\end{array}$ & Group Leader \\
\hline $2: 30-3: 30$ & Discussion & All \\
\hline $3: 30-4: 00$ & $\begin{array}{l}\text { Schedule for Report and } \\
\text { Management Response Plan } \\
\text { Development }\end{array}$ & O.D.T. Lynch \\
\hline $4: 00-4: 30$ & Wrap-up and Summary & M. Kilpatrick \\
\hline $4: 30$ & Adjourn & \\
\hline
\end{tabular}




\section{APPENDIX $O$}

\section{COMMENDABLE \\ PRACTICES}

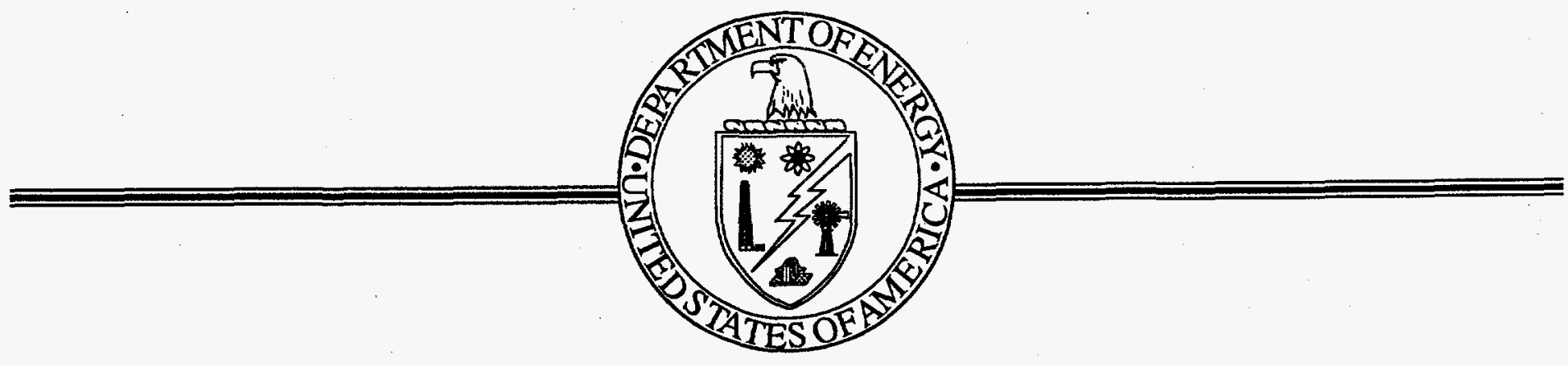





\section{APPENDIX 0}

\section{COMMENDABLE PRACTICES}

This appendix summarizes a number of commendable chemical safety activities and practices observed during the field verification phase of the Chemical Safety Vulnerability Review. These practices provide lessons learned that can be applied elsewhere in the DOE complex. Among the most notable of the practices observed were (1) development and implementation of management systems and other administrative controls or other management systems that have significantly reduced overall hazardous chemical inventories and (2) the maturation of industrial hygiene programs that more effectively address operations and nonroutine work controls involving hazardous chemicals. Other practices noted include efforts to identify and mitigate environmental releases of hazardous chemicals; increased awareness of the need to perform nonnuclear safety analyses; engineered safeguards and controls on chlorine and other toxic gas systems; substitution of less hazardous chemicals for more hazardous chemicals; and development of space management programs to address problems associated with hazardous chemical residuals in facilities.

For the purpose of this appendix, the list of commendable practices described below begins with those that are programmatic in nature and ends with those that meet more specific needs. In each case, a point of contact is designated to provide additional information.

Evaluating and Reducing Hazards During Life Cycle of Operations: Martin Marietta Energy Systems, Inc. (MMES), uses both corporate-wide and site-specific procedures to ensure that all stages of the life cycle of an operation are treated with an appropriate degree of rigor, while simultaneously providing flexibility for dealing with individual needs. This approach depends on the actual requirements imposed by corporate-wide procedures and on the care exercised in assessing vulnerabilities associated with specific activities. There are substantial differences in the actual implementation of systems and procedures important to chemical safety that can be traced to fundamental differences between the guidance provided by the sponsoring program offices at DOE Headquarters. Nonetheless, it should be noted that MMES has adopted good practices by specifically requiring that "efforts to ensure the safety of ... operations shall be applied in all stages of the life cycle of these operations" (Y70-811, "Safety of Operations," dated March 1, 1993). In recent years, a substantial effort has been made to apply this philosophy to processes used for evaluating and reducing hazards.

(Contact: Paul Stumb; Organization: MMES)

Facilities Space Management Program: When facilities at Sandia National Laboratories, New Mexico (SNL/NM), are no longer needed for an existing program, user organizations have a strong financial incentive (i.e., space charges) to make these facilities available to other organizations. To effect a transfer, thereby avoiding space charges, the user must work through the Facilities Center to have the facility evaluated for residual hazards. If hazards are present, the user must take remedial actions before the Facilities Center will accept the facility. By performing such evaluations before space ownership is transferred, SNL/NM seeks to avoid the potential exposure of employees who are moving to new work areas, to decrease physical hazards in workplaces, to expedite the remediation of contaminated areas, and to track the presence of chemical and radiological residues. At SNLINM, environmental, safety, and health $(E S \& H)$ space evaluations are performed by the Industrial Hygiene/Toxicology, 
Safety Engineering, and Radiation Protection organizations before transfer of ownership is approved. The space transfer process is part of the Facilities Space Management Program. When a request for transfer of ownership is received by the Facilities organization, the request is routed through an ES\&H space transfer coordinator in the Industrial Hygiene Department. The coordinator provides copies of the request to the Industrial Hygiene/Toxicology, Radiation Protection, and Safety Engineering organizations. Subsequently, each organization inspects the space for potential hazards. If problems are detected, the space owner is responsible for correcting them before transfer of ownership is approved. Information gathered on past and current processes and chemical use can support initial efforts to compile data on potential chemical residues for those areas that undergo ES\&H evaluation. (Contact: Kirk Hodge; Organization: SNL/NM)

Chemical Management System: The most notable improvements to chemical safety observed during the field verification visits were those related to the overall reduction of hazardous chemical inventories. All sites visited had expended significant effort to identify their excess hazardous chemicals and to reuse, dispose of, or sell these materials. Some sites have adopted "just-in-time" procurement practices to maintain inventories of hazardous chemicals at minimum levels. This approach has reduced the need for large inventories. Sites have chosen to substitute nonhazardous chemicals in processes previously requiring hazardous chemicals, thereby minimizing the risks associated with hazardous chemicals. These efforts to identify and reduce inventories and to maintain minimum quantities of hazardous chemicals have led to the adoption of "near-real-time" inventory controls at some sites. Although there was little evidence across the DOE complex that these revised chemical inventory data are being used as the basis for emergency management implementation planning, those sites already implementing proactive inventory controls recognize the importance of taking this next step.

A model chemical inventory control program was identified at Pacific Northwest Laboratory (PNL) at the Hanford Site. The Chemical Management System (CMS) is a computer-based chemical inventory system developed at PNL to inventory chemicals, provide hazard information about chemicals, and minimize chemical waste. CMS has been in use since November 1991. The system was designated as an outstanding model by the Office of Safety and Quality Assurance's worker protection pilot initiative. PNL is actively working with Brookhaven National Laboratory (BNL) to establish a comparable system; the National Renewable Energy Laboratory, Lawrence Berkeley Laboratory, and others have requested PNL's assistance in developing similar programs; and Argonne National Laboratory-West (ANL-W) has adapted basic concepts from CMS to improve its use of material safety data sheets. (Contact: Glenn R. Hoenes; Organization: PNL)

ANL-W has an exemplary chemical hygiene program that meets and exceeds the requirements of the Occupational Safety and Health Administration's (OSHA) Laboratory Standard (29 CFR 1910.1450), the OSHA Hazard Communication (HAZCOM) Standard (29 CFR 1910.1200), and DOE 5480.10, "Contractor Industrial Hygiene Program." Chemical hygiene personnel have taken a proactive approach to the implementation of this program. The storage, labeling, and administrative controls for chemicals are excellent. In particular, the methodology for chemical segregation of normal laboratory chemicals, carcinogens, organics, and other materials is commendable. Using this approach, chemical hygiene personnel at ANL-W have reduced the inventory of high-risk chemicals such as ethers, 
benzene, and other organics. The performance-based training program provided to Analytical Laboratory personnel is current and complete. (Contact: Mary Adamic; Organization: ANL-W)

Building 559 at RFP has an exemplary chemical management system that uses a facility-specific, accurate, real-time data base coupled with a facility-designated chemical control officer to provide complete inventory information on all hazardous chemical wastes. The system includes computerized tracking of chemicals (via unique bar-codes) from prepurchase approval through storage, use, and final disposition. (Contact: William A. Adams, Organization: EG\&G Rocky Flats, Inc.)

A comprehensive, online, computerized, Laboratory-wide chemical tracking system (Chem Track) and material safety data sheet system is in the initial stages of implementation at LLNL. Bar-coded labeling will facilitate the tracking of current chemical purchases and existing individual chemical containers throughout the Laboratory. ChemTrack will also facilitate compliance with regulatory requirements. A new system, the Facility Management Information System (FAMIS), is being developed, which will allow a graphic display of every laboratory and facility within the Chemistry and Materials Science Directorate (with the potential for extending this capability sitewide). Linking FAMIS with ChemTrack would enable an almost instant display of ChemTrack inventory data at any selected geographical location at LLNL and would, thus, provide valuable safety-related information to anyone coping with an emergency situation at that location. (Contact: Rex Beach, Organization: LLNL)

Hazardous Waste Labeling System: TA-54 at the Los Alamos National Laboratory (LANL) developed a hazardous waste labeling system that uses one label to meet all Resource Conservation and Recovery Act, American National Standards Institute, U.S. Department of Transportation, and Clean Air Act requirements. The label is also bar-coded for hazardous waste inventory and chemical tracking purposes. The one-label system ensures that all pertinent information is placed on containers and facilitates segregation of hazardous waste materials. (Contact: Jeffery E. Schinkel; Organization: LANL)

Emergency Response Nomograph For Toxic Chemical Spills: A new nomograph to determine evacuation distance requirements for toxic chemical spills is being developed at Westinghouse Idaho Nuclear Company (WINCO) for the Idaho Chemical Processing Plant (ICPP). This nomograph will provide for a rapid determination of distance affected by a chemical spill and is expected to improve emergency response to chemical incidents by personnel on the backshifts without relying on sophisticated computer models. (Contact: Gerald Gibeault; Organization: WINCO)

ES\&H Management Assurance Notebooks: Each manager at SNL/NM prepares a Management Assurance Notebook (MAN) to serve as a standard means for organizing and communicating ways to meet ES\&H responsibilities. The notebook is the manager's primary repository of ES\&H information. The notebook has value during internal and external audits, reviews and assessments, and when transferring management responsibilities by clearly defining ES\&H responsibilities within the organization. Each level of management has a slightly different version of the MAN, tailored to meet specific responsibilities and needs. As management level increases, the focus of the MAN shifts from details to summaries and 
metrics. Each notebook is a "living document" and is updated annually or when major personnel changes occur. (Contact: Ralph Bonner; Organization: SNL/NM)

Contract Initiative to Ensure Adequate Hazard Communications: At BNL, a construction safety engineer (on his own initiative) incorporated the following clause in all contracts for which he has responsibility: "Workers shall be able to comprehend work and safety instructions in English or a supervisor who can translate shall be provided and be present at all times." When enforced, this clause provides some measure of assurance that non-English-speaking personnel will be aware of safety requirements and workplace hazards. On several occasions, this construction safety engineer has suspended work by invoking the contract clause that requires a bilingual person to be on the work site at all times. In another instance, a group of about 15 subcontractor personnel attended the New Employee Safety Orientation Course before starting asbestos abatement activities on site. Only one member of the group spoke English, and that person translated the course into the native language of the group. (Contact: Mary White; Organization: BNL)

Applying Graded Approach to Hazards Analysis: BNL uses a graded approach, based on the level of hazard, to review facilities and operations. Although minor, low-hazard operations may be reviewed by individual departments, those BNL operations with increasing hazard levels receive correspondingly more rigorous safety and health review and independent laboratory process review. ES\&H standards and other key BNL site documents state that most safety-related work at BNL is organized according to a graded approach. Numerous documents require that the level of quality, formality, safety analysis, and equipment requirements be determined through an analysis of the risks posed by the prospective operations. The standards and manuals go further and provide helpful details on how to implement a graded approach. BNL-O\&M-I-010, Operations and Maintenance Manual, delegates responsibility for establishing the BNL Conduct of Operations and Maintenance Management programs and for the administration of these programs to the Associate Director for Management and Physical Plant. (Contact: John DiNicola; Organization: BNL)

Chemical Salvage Program: Westinghouse Savannah River Company (WSRC) initiated a chemical salvage program to dispose of or find uses for chemicals that are no longer in use at the Savannah River Site (SRS). Similar programs can be found elsewhere on site. WSRC is proactively combining all such activities and extending them to the entire site through a recently established Chemical Commodities Group. The Chemical Commodities Group will be used to address issues associated with procurement, storage, reuse, and disposal of chemicals. (Contact: Vic Reynolds; Organization: WSRC)

The Chemical Exchange Warehouse (CHEW) at LLNL is currently being implemented to enhance use and control of chemicals and reduce quantities of hazardous wastes. The CHEW allows for the reapplication of excess chemicals in lieu of classification as hazardous wastes. (Contact: Rex Beach, Organization: LLNL)

Sharing Chemical Safety Program Information: To reduce cost and use the insights acquired from other successful programs, WSRC shares information with the Westinghouse Hanford Company (WHC) in many program areas related to chemical safety. For example, WHC sends operators to WSRC for hands-on training on similar wastewater treatment systems. (Contact: Saleem Salaymeh; Organization: WSRC) 
Sitewide Wastewater Discharge Minimization Program: The Hanford Tri-Party Agreement (TPA) signed in 1987 identified 33 discharge "streams" to be controlled. A plan based on a two-phased approach was subsequently developed to minimize and treat these "streams" and to achieve stringent reductions in flow and contaminant concentrations. Over the past 4 years, WHC, PNL, and their subcontractors have cooperated to produce significant reductions in flow and pollutant concentrations. WHC and PNL have cooperated to reduce wastewater production in the 300 Area through a hierarchial approach of source reduction, segregation, recycling, and treatment and discharge. This program has reduced wastewater in the 300 Area from 1,500 gallons per minute in 1988-89 to a current level of about 125 gallons per minute. The program received a Federal Facilities Energy (Conservation) Efficiency award in 1993. (Contact: Doug Shoop; Organization: WHC)

Participation, Coordination, and Cooperation With Regulatory Agencies: DOE is sponsoring a regulatory oversight program in 14 states across the country, including New Mexico. States receive grants to provide direct oversight of environmental activities. The program is known as the "Agreement in Principle" and is fully implemented at SNL/NM via the Kirtland Area Office (KAO). The New Mexico Environmental Department has five individuals located at SNL/NM to provide DOE with direct independent oversight and monitoring of environmental activities. KAO reports that this program has helped to build additional credibility for the Department with regulatory agencies and the local community. DOE Headquarters judges the New Mexico oversight program, and in particular the program at SNL/NM, as the most effective program of its type in the DOE complex and attributes its success to the high level of coordination and communication between DOE, the State, and SNLNM. (Contact: John Olav Johnson; Organization: KAO)

Chlorine and Toxic Gas Control Programs: Because of a near-miss chlorine release recently experienced at Idaho National Engineering Laboratory, field verification teams for the Chemical Safety Vulnerability Review were directed to focus particular attention on potential vulnerabilities associated with chlorine and other compressed gases. Some sites that previously used large amounts of chlorine in their water-treatment processes had either substituted less hazardous chemicals for chlorine (e.g., sodium hypochlorite) or had significantly reduced the use of chlorine and instituted more stringent administrative controls over its use. The most significant reduction of chlorine-related risk was noted at SRS, where sodium hypochlorite has replaced chlorine in the primary domestic water treatment process. The safe use of chlorine was also noted at LANL, K-25 Site, Rocky Flats Plant, and SNL/NM. The use of toxic gases in DOE processes and laboratories was also evaluated. Although such gases continue to be used in research and microelectronics production processes, all installations observed also used enclosed toxic gas cabinets, gas monitors, and alarms to safeguard workers. (Contact: Jeffery E. Schinkel; Organization: LANL)

Elimination of Chlorine Gas in Water Treatment Operations: WSRC has substituted sodium hypochlorite for chlorine gas in the treatment of water at the SRS. All chlorine gas cylinders have been removed from the Water Chlorination Facility, which has a capacity to store about 70 1-ton cylinders. All chlorine cylinders containing gas were returned to the supplier in June 1993. Empty 1-ton cylinders were cut up for scrap. Liquid sodium hypochlorite is received in 15-gallon carboys and is added to the raw water stream by a small electrically driven chemical pump. (Contact: Don Harrison; Organization: WSRC) 
Work Control Program For Engineering And Maintenance: WINCO has implemented a highly effective work control program for engineering and maintenance work related to the ICPP. Specific programmatic elements pertinent to the Chemical Safety Vulnerability Review include the following:

- Providing general and facility-specific training to maintenance workers in chemical safety, based on the requirements of 29 CFR 1910.120, "Hazardous Waste Operations and Emergency Response";

- Defining quality assurance levels and associated safety classifications for all plant systems;

- Applying and verifying the application of the requirements mandated by quality level and safety classification of systems to system-related engineering and maintenance activities;

- Implementing a formal configuration management program, including "as-building" all critical and safety systems, piping and instrumentation diagrams, control diagrams, and power distribution drawings;

- Continuing to reduce the "as-built" drawing backlog by 50 percent every 2 years;

- Proceduralizing and tracking specific preventive and predictive maintenance, which has eliminated the backlog of electrical preventive maintenance and produced a preventive maintenance backlog for mechanical equipment of less than 0.5 percent;

- Establishing and tracking maintenance performance indicators, including backlog hours, skin contaminations and first-aid reportables, instrument calibrations, and calibration error occurrences;

- Holding both employees and managers fully accountable for safety performance;

- Minimizing and controlling inventories of hazardous chemicals used in maintenance (primarily solvents) and providing safety information to all maintenance workers; and

- Empowering employees at all levels for the entire work control process, including worker safety.

WINCO maintenance and engineering programs embody the best practices of industry and are based on modern, innovative management methodologies. (Contact: Larry Chingbrow; Organization: WINCO)

Computer-Based Maintenance Control Reporting System: The Maintenance Control Reporting System (MCRS) is used to develop comprehensive work packages for a wide range of corrective and preventive maintenance at BNL. MCRS provides computer-generated information related to specific work orders, including (1) work procedures, (2) maintenance work orders, (3) replacement part serial numbers, (4) warehouse inventory for over 10,000 consumable replacement parts, and (5) cost-accounting information. MCRS was developed "in house" using a computer system consultant and off-the-shelf computer software. 
MCRS is configured to provide contract maintenance services, maintain records, and issue billings for programmatic and scientific maintenance activities. (Contact: John DiNicola; Organization: $\mathrm{BNL}$ )

Removing Residual Chemicals From Unused Chemical Process Equipment: Planning, execution, and documentation for flushing chemical storage and processing systems at WINCO's Fluorinel Dissolution Process and Fuel Facility and the Fuel Processing Facility in Idaho exemplified proper removal of residual chemicals from processing equipment. Fluorinel fuel dissolving equipment was cleaned of process residues and flushed before being placed in standby status. Similar procedures were developed for the cleanout of solvent extraction and denitration equipment. (Contact: Thomas R. Bymes; Organization: WINCO)

At ANL-W, two unused, obsolete Analytical Laboratory chemical systems (a low-level waste evaporator and a spent-acid collection system) have been flushed of all residual chemicals. These efforts were accomplished safely in accordance with specifically developed procedures for sampling residuals, characterizing samples, and flushing and rinsing equipment. The procedures conservatively addressed safety and health considerations associated with the work preformed. (Contact: Mary Adamic; Organization: ANL-W)

Documentation Of Facility Dismantling: The Light Initiated High Explosive Facility at SNL/NM was shut down about 2 years ago. After removal of the process equipment, both the equipment and the facility were thoroughly cleaned to remove all traces of explosives. The manner in which the facility was dismantled and cleaned was documented in reports and videos that demonstrate "before" and "after" conditions and show the techniques used for cleaning. The facility is now in a safe standby mode, awaiting a mission. The extensive documentation of the condition of this facility will provide valuable information to future users of the facility. (Contact: Floyd Mathews; Organization: SNL/NM)

Hazardous Material (Hazmat) Response Team Preparedness For Chemical Spills: Some facilities reviewed at LANL contain significant quantities of hazardous chemicals. Sufficient types and quantities of hazardous materials (HAZMAT) response equipment and spill materials are available to mitigate incidental, nonthreatening, easily containable spills. The responses required for a larger spill include evacuating the facility and making appropriate notifications. The HAZMAT Response Team is responsible for containing or mitigating HAZMAT situations. The HAZMAT Response Team is part of the Hazardous Materials and Response Group (ESH-10) and, based on its composition, is unique within the DOE complex. The team consists of dedicated, full-time personnel who are trained to the HAZMAT "specialist" level, most of whom have received several hundred hours of HAZMAT training. Professional personnel have either industrial hygiene or health physics backgrounds. The team has been equipped with a state-of-the-art HAZMAT vehicle, plus other vehicles and trailers containing personnel protective equipment, supplies, and the tools needed to mitigate HAZMAT situations. On request, the team provides HAZMAT response to LANL, surrounding communities, and the State of New Mexico. (Contact: Jeffery E. Schinkel; Organization: LANL)

Dispersion Model To Calculate and Display Plume Dispersions: Meteorological Information and Dose Assessment System (MIDAS), a computer software model, was recently installed at LANL to calculate and display plume dispersions for hazardous materials. As part 
of the Laboratory's search for better modeling accuracy, MIDAS has been extensively modified to incorporate site-specific meteorological factors to account for the effects of the complicated local terrain on dispersion calculations performed for the LANL site. The Laboratory has the capability to perform hazardous chemical plume dispersion calculations by using a variety of approved computer models both in the Emergency Operations Center and in the field. (Contact: Jeffery E. Schinkel; Organization: LANL) 


\section{APPENDIX P}

\section{RELATED CHEMICAL SAFETY INITIATIVES AT DOE}

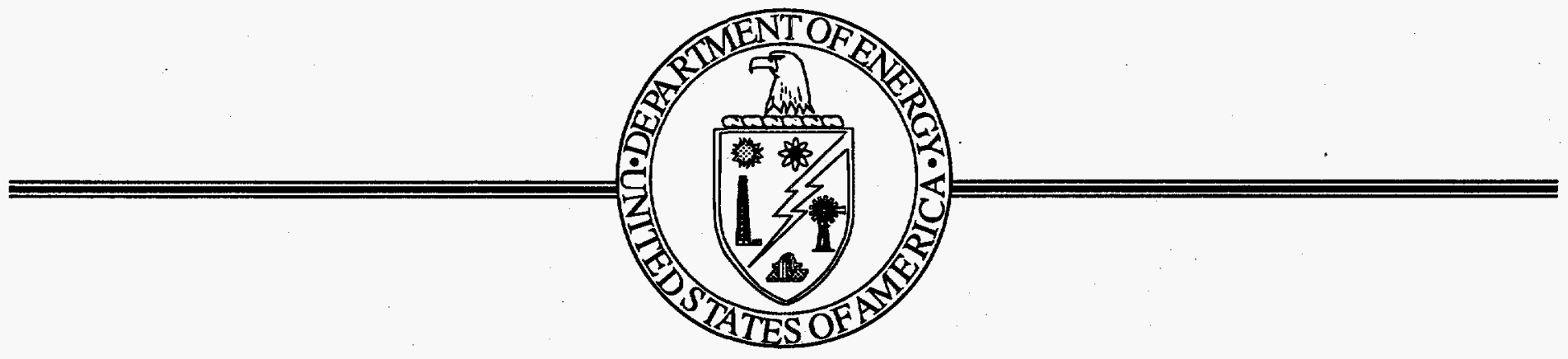





\section{APPENDIX P}

\section{RELATED CHEMICAL SAFETY INITIATIVES AT DOE}

\section{The Surplus Facility Inventory and Assessment Project}

The Department of Energy's (DOE) change in mission, aging infrastructure, and declining program budgets have resulted in a dramatic increase in the number of surplus facilities (i.e., facilities no longer needed to support operational, programmatic, or departmental missions). The Department responded to this dynamic growth in the inventory of surplus contaminated facilities in 1992 by establishing the Office of Facility Transition and Management (EM-60) within the Office of Environmental Management (EM) and by tasking the new office to manage the acceptance and deactivation of surplus facilities. A number of major facilities were subsequently designated as surplus and transferred to EM-60. These included most facilities at the Rocky Flats Plant, the Plutonium and Uranium Extraction Facility and the Fast Flux Test Facility at the Hanford Site, and the Idaho Chemical Processing Plant at the Idaho National Engineering Laboratory. Currently, two entire sites (the Mound and Pinellas Plants) and a number of select facilities at other sites (Savannah River reactors and Oak Ridge National Laboratory isotope facilities) are being prepared for transfer to EM-60 under memorandums of agreement (MOAs). Although these MOAs provide a vehicle to transfer assets from other program offices to EM, they serve only as "stop-gap" measures until a formal and comprehensive transfer policy and acceptance process are developed.

Paralleling these events was the appointment of a new Secretary of Energy and Assistant Secretary for Environmental Management. Driven by recognition of an aging complex, growing frustrations with cleanup efforts, and an increasing inability to respond to questions from the Office of Management and Budget and the General Accounting Office about the legacy of surplus facilities, Secretary Hazel O'Leary and Assistant Secretary Thomas Grumbly requested an accurate accounting of the number of surplus facilities within the DOE complex. Unfortunately, such an accounting could not be provided. Several factors precluded obtaining a timely and accurate determination of these assets. These factors ranged from the recurring Cold War mentality of placing an asset in "standby" for quick restart to the inability of departmental data systems to provide information needed for planning, budgeting, and managing contaminated surplus assets. A further examination of this growing problem revealed (1) that the determination of what to declare as surplus generally coincides with the DOE budget cycle, creating a situation in which neither the "donor" program nor the "receiving" program has the opportunity to plan and budget adequately for the facility, and (2) that the determination of what to declare as surplus is a dynamic process subject to many internal and external factors, some of which (e.g., Congressional budgets) are not within the program's control. Thus, the ability to provide long-range forecasts of facility surpluses is, at best, limited. The need to address these issues directly, coupled with the inability to respond fully to outside questions, provided the impetus for an initiative aimed at identifying the number of surplus facilities and defining the resources needed to manage them. In response to these needs, the Surplus Facility Inventory and Assessment (SFIA) Project was developed in June 1993. 


\section{Overview}

The Secretary of Energy formally initiated the SFIA on October 4, 1993, and tasked EM with responsibility for managing the project. (EM-60 was assigned the day-to-day management of the project.) The purpose of the ongoing SFIA effort is to determine the following:

(1) The number of contaminated facilities that are, or will be, designated as surplus before fiscal year (FY) 99;

(2) The condition of surplus facilities (e.g., physical structure and level of chemical and radiological combination) and the associated risks, liabilities, and costs required for adequate surveillance, maintenance, and characterization; and

(3) The priority for transferring these facilities to EM for deactivation, decommissioning, and final disposition.

The SFIA project consists of three phases, each with stated goals that provide the foundation for the next phase. This three-phased approach reflects the input received from the field during the development of the project.

Phase 1, which was completed in January 1994, involved the development of an accurate inventory of all DOE facilities, with special emphasis on process-contaminated facilities and their associated ancillary units. With the exception of the Power Marketing Administrations, Naval Reactors, and selected structures considered to have a low probability of being contaminated, all DOE facilities were included in Phase 1 of the effort.

Phase 2, which was completed in April 1994, involved identified surplus assets and included determining and assessing the condition of physical structures and systems contamination (radiological and chemical) status; waste and chemical inventory; the chemical and radiological contents of storage tanks; safeguards and security requirements; immediate and serious problems or conditions with respect to workers, the public, the environment, and the structure itself; the order and priority for transfer based on a threat-based ranking system; and first-order cost estimates for managing high-ranking facilities designed for transfer to EM in FY 96.

Phase 3, which is scheduled for completion by December 1994, involves developing cost estimates to support owner program and/or landlord budgets, including costs for managing, maintaining, and characterizing surplus contaminated facilities that will not be transferred to EM during FY 96.

\section{The U.S. Department of Energy Lessons Learned Program for Preventing Accidents Similar to the Tomsk-7 April 6, 1993, Incident}

\section{Background}

On April 6, 1993, a sequence of events occurred at the Tomsk-7 nuclear fuel reprocessing plant in Siberia, Russia, that caused substantial physical damage to the facility. A runaway 
exothermic chemical reaction occurred in a large process vessel containing a concentrated solution of uranyl nitrate, nitric acid, plutonium nitrate, residual fission products (totaling about 560 curies), and amounts of organic constituents derived from the solvent extraction process. The reaction produced large amounts of flammable organic and inorganic gases and steam, which pressurized and breached the vessel and dislodged the concrete cell cover. Based on the available evidence, ignition then occurred in the area immediately above the cell. The resulting explosion caused substantial damage to the crane bay area, nonreinforced masonry wall, and the roof and its intemal components. The accident contaminated an area of about 123 square kilometers with about 40 curies of radioactive material, including 30 grams of plutonium.

This accident has been attributed to a chemical reaction between degraded organic material and concentrated nitric acid, which had been added to adjust the $\mathrm{pH}$ of the solution for subsequent purification by solvent extraction. The degraded organic material was the result of an accumulation of process residual chemicals that had been allowed to age over a period of at least 6 months. The accident was attributed to several operator errors, the most serious of which was the failure to operate the mixing (gas-sparging) system as required by procedure.

Exothermic tri-n-butyl phosphate (TBP)-nitrate reactions are frequently referred to as "red oil" reactions. Red oil generally refers to a mixture that is reddish or orange in color and contains TBP, its complexes with uranyl nitrate and nitric acid, and its degradation products (e.g., dibutyl phosphate and various nitrated cyclic hydrocarbons). Red oil can be formed as a result of the prolonged contact at elevated temperatures of uranyl nitrate and nitric acid with a solution of TBP in an organic hydrocarbon diluent, such as that used in solvent extraction operations. It should be noted that the presence of the colored compound is not necessary for exothermic reactions to occur in TBP-nitrate mixtures.

Three events similar to the incident at Tomsk-7 had previously occurred at DOE facilities (i.e., at Savannah River Site on January 12, 1953; Hanford Site in July 1953; and Savannah River Site on February 12,1975). However, all three DOE facility events occurred when a heavy metal nitrate solution containing, or in contact with, TBP was heated in excess of $130^{\circ} \mathrm{C}$. The event at Tomsk-7 differed from the U.S. events in that no external heat was added to the Tomsk-7 tank. The primary control present to prevent red oil reactions in DOE facilities has been to limit the temperature of the solution to less than $130^{\circ} \mathrm{C}$. There were no external heat sources at Tomsk-7, but there were multiple sources of "self-heating." The hazards associated with mixing organic compounds and oxidizing agents has been an issue in processing nuclear fuels. The Tomsk-7 accident has emphasized the need to investigate the potential for self-heating in such mixtures and the potential consequences from such reactions. To this end, the Department initiated a proactive effort to ensure that similar conditions do not exist for DOE processing vessels.

\section{Overview}

The DOE Tomsk-7 Lessons Learned Program was initially tasked with accomplishing the following tasks:

(1) Survey and develop an inventory of potentially hazardous tanks and equipment. 
(2) Develop a consensus of understanding concerning the Tomsk-7 incident.

(3) Perform analytical mechanism and modeling studies.

(4) Conduct site-specific reviews and prepare site reports for each of the following:

- Savannah River Site,

- Idaho Chemical Processing Plant,

- Westinghouse Hanford Company,

- Fernald Environmental Management Project, and

- Oak Ridge.

(5) Prepare final summary reports.

Led by the Office of Defense Programs, a core Tomsk-7 team and multidisciplinary sitespecific teams, including technical experts from DOE and contractor organizations, were formed to review DOE sites for hazards associated with organic-oxidizer mixtures. The review was conducted to determine the potential for red oil reactions in DOE operations and to evaluate the controls in place to minimize the chance of potential accidents. The review scope included assessing the adequacy of safety analysis reports (SARs), technical safety requirements, procedures, employee training, process design, safety systems designs, instrumentation, and management systems. When safety deficiencies were noted, the scope of the review was expanded horizontally to include other safety-related concerns.

The initial focus of the Tomsk-7 Lessons Learned Program (referred to as Tomsk I) was on those process areas deemed to exhibit the highest vulnerability for such exothermic chemical reactions. The current understanding of the Tomsk-7 event stresses the probable nitration and energetic decomposition of a substantial quantity of organic liquids, particularly tri-n-butyl phosphate (TBP) and its diluent, through contact with concentrated nitric acid and metal nitrates. This scenario resulted in self-heating, which was exacerbated by the restricted means of heat dissipation due to the lack of mixing with the large amount of liquid in the same vessel. Based on these circumstances, the DOE Lessons Learned Program concentrated on process and interim storage operations involving inventories of organic diluents, TBP, nitric acid, and nitrates with a minimum threshold of 25 liters of material (i.e., those expected for pilot and full-scale operations as opposed to laboratory bench-scale activities). The 25-liter threshold was consistent with the philosophy that the Occupational Safety and Health Administration and Environmental Protection Agency had adopted to designate threshold quantities for toxic and flammable substances.

\section{Conclusions and Followup Activities}

A team of DOE technical experts visited the Tomsk-7 facility for a firsthand review of postaccident conditions. This information was documented and has been used to support the DOE Lessons Learned Program. 
Five DOE facilities were visited, and all were found to be in a safe condition with no red oil event imminent. However, vulnerabilities were identified that lessen the apparent safety margin. Two examples of these generic vulnerabilities are as follows:

(1) Self-heating reactions (as occurred at Tomsk) of nitrate-organic mixtures are not recognized in SARs, operator training, or emergency procedures. As a result, operating procedures generally are not based on such reactions.

(2) The significance of TBP degradation during long-term storage has not been taken into account during safety evaluations.

The results of these site-specific reviews have been completed and documented and should be referenced for more specific information.

Senator John Glenn (D-Ohio), Chairman of the Governmental Affairs Committee, followed the DOE's Tomsk-7 review process closely. Senator Glenn commended the Department for its review effort but recommended that the scope of the review be extended to include waste storage tanks and their associated vapor spaces. Consequently, the scope of the DOE Lessons Learned Program was expanded to include (but was not limited to) other processes and operations having the potential for combustion, self-heating, and/or other exothermic reactions due to nitrate-organic mixtures.

Based on lessons learned from the Tomsk I review of DOE facilities, a self-assessment questionnaire was transmitted through the operations offices to the sites for contractor response. This questionnaire forms the basis of the Tomsk II review. Because of the number of facilities involved (33 DOE facilities and more than 300 different reporting locations), followup visits were scheduled only when responses to the questionnaire indicated a need for more indepth information. Evaluation of these responses and preparation of the report are being performed concurrenty with the Chemical Safety Vulnerability Review, and conclusions of the Tomsk II review are not yet available. Preliminary data suggest the following conclusions:

(1) No significant generic vulnerabilities for nitrate-organic chemical reactions have been identified.

(2) No systematic design defects or significant processing equipment deficiencies were noted.

(3) Well-characterized plans are in place to monitor or remediate the flammability and other reaction hazards for waste storage tanks.

(4) Ion-exchange resins exposed to nitrate media are being handled properly and, where possible, are being removed from nonoperating process systems and scheduled for disposal.

(5) Stored materials are segregated according to chemical compatibility and are separated with physical barriers. 
The Tomsk II report is expected to include chemical holdings tabulated by facility for organics and nitrates. Additional information will be provided on how these chemicals are segregated and on the potential for adverse reactions. 


\section{APPENDIX Q}

\section{REGULATORY FRAMEWORK AND INDUSTRY INITIATIVES RELATED TO CHEMICAL SAFETY}

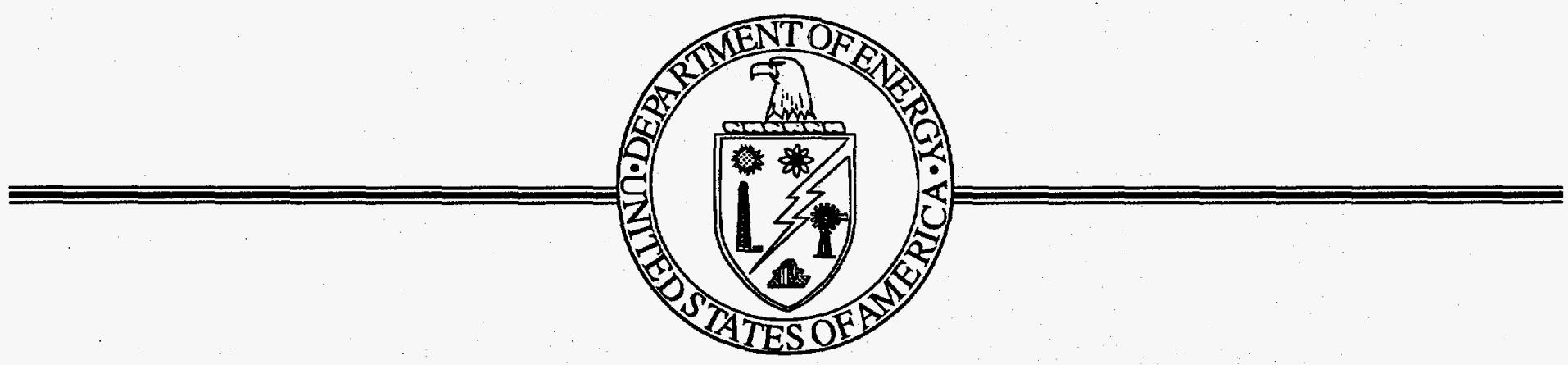





\section{APPENDIX Q \\ REGULATORY FRAMEWORK AND INDUSTRY INITIATIVES \\ RELATED TO CHEMICAL SAFETY}

\section{Environmental Regulations}

Resource Conservation and Recovery Act of 1976 (RCRA) and the Hazardous and Solid Waste Amendments of 1984 (HSWA). RCRA and HSWA and their implementing regulations (40 CFR 260 through 40 CFR 280) establish requirements for managing hazardous wastes. Hazardous wastes are defined to include any discarded materials, including chemicals, that are either listed in 40 CFR 261 or exhibit a specific "characteristic," including corrosivity, reactivity, ignitability, or toxicity. Most hazardous chemicals that are either spent or discarded are classified as hazardous wastes. It is the responsibility of the waste generator to determine whether the waste is hazardous, either by applying "process knowledge" or through chemical analysis.

The regulations also require that hazardous materials be managed to minimize their potential for adversely affecting workers, the public, or the environment. 40 CFR 262 through 40 CFR 265 contain a variety of rules designed to ensure that wastes being stored, treated, or disposed of are managed properly. Specific requirements have been developed for a variety of waste categories (e.g., incompatible chemicals, ignitable waste, and "acutely hazardous waste"). Some operating requirements are based on worker safety standards, whereas others focus on emergency planning (contingency plans and emergency preparedness). The regulations also impose rigorous administrative requirements, including reporting waste generations, recording inspections of safety and emergency equipment, and tracking shipping papers (manifests).

40 CFR 280 contains specific regulations for storing chemicals and petroleum products in underground storage tanks (USTs), except where hazardous wastes are involved. These regulations require upgrades for older USTs to prevent and detect leaks and to limit the effects of overfilling. General administrative requirements are also provided.

Comprehensive Environmental Response, Compensation, and Liability Act (CERCLA) and the Superfund Amendments and Reauthorization Act (SARA). CERCLA and SARA are primarily concerned with cleanup of hazardous materials that have been improperly disposed or spilled. Title III of SARA, known as the Emergency Planning and Community Right-To-Know Act (EPCRA), establishes requirements for chemical reporting and emergency planning. 40 CFR 300 through 40 CFR 372 contain regulations promulgated to implement CERCLA, SARA, and EPCRA.

CERCLA and SARA focus primarily on the identification and cleanup of areas where hazardous materials were improperly disposed. Although these laws and their implementing regulations (40 CFR 300 through 40 CFR 355 ) are not specific to chemical management, they do establish rigorous notification and cleanup standards for contaminated areas. Reporting requirements relate to actual releases (e.g., spills) of hazardous substances and to identification of facilities where hazardous wastes have been disposed of or where such 
release might potentially occur. 10 CFR 302 and 10 CFR 355 identify and provide standards for reporting specific release quantities of hazardous and extremely hazardous substances, respectively.

EPCRA established three major requirements related to (1) emergency planning notification, (2) emergency release notification, and (3) community right-to-know information on chemicals and releases. Many EPCRA requirements for emergency planning and notification were integrated with the CERCLA and SARA regulations (10 CFR 300 through 10 CFR 355). 40 CFR 370 requires submission of material safety data sheets and reports on hazardous chemical inventories (above certain quantities) to the Local Emergency Planning Committee (LEPC). In addition, EPCRA requires that toxic chemical releases be reported, including emissions (i.e., wastes) to the air, water, and land.

The Clean Air Act. The Clean Air Act (CAA) was amended in 1990 to incorporate a number of additional requirements pertaining to the safe management and control of toxic air pollutants. Section 112 of the CAA, the National Emission Standards for Hazardous Air Pollutants (NESHAPS), contains specific criteria for managing chemicals that pose a significant hazard to the community. The CAA requires that the Environmental Protection Agency develop regulations for prevention of and response to accidental or catastrophic releases of hazardous substances. Regulations proposed by EPA on October 20, 1993, should be finalized in 1995 . The proposed regulations would require regulated entities to take steps to prevent and mitigate accidental releases.

Title III of the CAA, Hazardous Air Pollutants, identifies and regulates substances that present a threat to human health or the environment. EPA has established emission standards for over 180 toxic chemicals and is specifying maximum achievable control technology (MACT) standards.

Toxic Substances Control Act. Although the Toxic Substances Control Act (TSCA) focuses primarily on the manufacture and processing of toxic chemical substances, it also provides extensive requirements for managing polychlorinated biphenyls (PCBs). 40 CFR 761 imposes requirements for labeling, storage and disposal, spill cleanup, and recordkeeping for equipment and substances containing PCBs.

Federal Water Pollution Control Act (Clean Water Act). The Clean Water Act (CWA) established a number of programs designed to limit discharges of hazardous substances to bodies of water throughout the United States. Hazardous substances are designated in 40 CFR 116. The National Pollutant Discharge Elimination System (NPDES), which derives its authority from the CWA, establishes discharge limits to and from publicly owned treatment works and U.S. waters. Permits issued under the NPDES normally contain effluent limits for hazardous substances, and industrial wastewater discharges to Publically Owned Treatment Works are typically required to comply with limits on discharges of hazardous substances.

Occupational Safety and Health Regulations. Federal standards governing the health and safety of workers are promulgated under the authority of the Occupational Safety and Health Act (OSHA) of 1970, as amended. These standards cover a broad range of activities. OSHA regulations specific to chemical safety are summarized below. 
- Compressed Gases. Regulations covering compressed gases (29 CFR 1910.101-105 and $110)$ address the safe storage, handling, use, and labeling of compressed gases.

- Flammable and Combustible Liquids. Regulations related to flammable and combustible liquids regulations (29 CFR 1910.106) apply to bulk and portable container storage within a facility and its ancillary storage areas. These regulations include (1) design requirements for tanks, storage rooms and buildings, and storage cabinets and (2) information regarding the safe use and handling of these materials, as well as limitations for storage in terms of quantity and location.

- Process Safety Management. The process safety management standard (29 CFR 1910.119) includes requirements for preventing or minimizing the consequences of catastrophic releases of toxic, reactive, flammable, or explosive chemicals. This regulation applies to chemical processes involving the use of chemicals above established threshold quantities. The standard addresses employee participation, process safety information, hazard analysis, operating procedures, prestartup safety review, mechanical integrity, management of change, training, contractors, emergency planning and response, hot-work permits, incident investigation, compliance audits, and trade secrets. (See Figure Q-1.)

- Hazardous Waste Operations and Emergency Response (HAZWOPER). The HAZWOPER standard (29 CFR 1910.120) covers cleanup operations required by a govemmental body, corrective actions involving sites covered by RCRA, voluntary cleanup operations, and operations involving hazardous wastes that are conducted at hazardous waste treatment, storage, and disposal facilities (TSDs). In addition, paragraph (q) of the standard addresses emergency response operations for release of hazardous substances without regard to the location of the hazard. The regulation requires the development of an emergency response plan, training, and medical surveillance for response personnel. The emergency response plan must address evacuation routes and procedures, pre-emergency planning, site security, decontamination, emergency medical treatment, emergency alerting and response procedures, and procedures for critiquing and followup of response efforts.

- Air Contaminants. The air contaminants regulation (29 CFR 1910.1000) identifies permissible exposure limits for a select group of chemicals. Limits are provicied in terms of an 8-hour time-weighted average that cannot be exceeded during an 8-hour shift. In addition, some chemicals have short-term exposure and ceiling limits. Where exceedances are noted, the regulation stipulated that employers must attempt engineered and administrative controls before requiring the use of personal protective equipment.

- Chemical Specific Standards. Chemical-specific standards are established for 27 materials, including lead, benzene, and formaldehyde (29 CFR 1910.1001-1050). In addition to identifying permissible exposure limits and action limits, these standards address program requirements, exposure monitoring, medical surveillance, training, labeling, and the safe handling and use of each specific material.

- Asbestos. The asbestos regulation (29 CFR 1926.58) addresses engineered and administrative controls to be followed during construction, repair, alteration, maintenance, removal, or renovation activities involving asbestos-containing materials. In addition, the 
standard includes requirements for training, medical survelllance, exposure monitoring, and labeling.

- Hazard Communication. The hazard communication regulation (29 CFR 1910.1200) requires that employees receive information about the hazardous chemicals in their workplace by means of a hazard communication program, chemical labeling, material safety data sheets, and training. In addition, chemical manufacturers and importers are required to assess the hazards of the chemicals they produce.

- Occupational Exposure to Hazardous Chemicals in Laboratories. OSHA's laboratory health and safety regulation (29 CFR 1910.1450) applies to the use of chemicals on a "laboratory scale," rather than chemicals used as part of a production process. The regulation requires that a chemical hygiene plan be established to address standard operating procedures for safety and health, exposure monitoring, engineered controls, personal protective equipment, medical evaluation, and additional protective measures for work with particularly hazardous substances. Laboratory employees must receive training and information on the hazards associated with chemicals used and stored in the laboratory and on the contents of the chemical hygiene plan. 


\section{Process Safety Information}

Process Hazard Analysis

Pre-Startup Safety Review

Mechanical Integrity

Trade Secrets

Employee Participation

Subtier Contractor Safety

Training

Management of Change

Operating Procedures

\author{
Nonroutine Work \\ Authorizations \\ Compliance Audits \\ Emergency Planning
Response
}

Incident Investigation
Maintain complete and accurate on the process technology, process equipment, and hazardous characteristics and physical properties of all chemicals and intermediates for all covered processes.

Perform Process Hazardous Analyses to identify and assess process hazards for each covered process.

Establish a procedure and perform pre-start safety reviews for new facilities and for modified facilities when the modification is significant enough to require a change in the process safety information.

Ensure the integrity and safe operation of process equipment through inspection, testing, preventative maintenance, and quality assurance.

Ensure all information is available to support the PSM Rule. When necessary, confidentiality or nondisclosure agreements may be used.

Ensure that workers are consulted and have access to information regarding all elements of the PSM program.

Ensure that the level of safety is not comprised by subtier contractor operations on or in the vicinity of a process using highly hazardous chemicals.

Establish and implement a training program for all employees involved in operating a covered process. The program must include both initial and refresher training and provide a means of determining successful completion.

Establish and implement written procedures to manage changes (except for "replacements in kind") to process chemicals, technology, equipment, and procedures; and to manage changes to facilities that affect a covered process.

Develop and implement written operating procedures that provide clear instructions for safety conducting activities involved in each covered process. Procedures should address operating limits, safety and health considerations, safety systems, and their functions.

Ensure that appropriate measures are taken any time nonroutine opdrations are performed on or near covered process areas that might or promote a release.

Ensure that the PSM program is operating in an integrated and effective manner in compliance with PSM requirements.

Establish and implement an emergency action plan for the entire plant that is in compliance with 29 CFR 1910.38(a) and that also addresses small releases.

Establish a written incident investigation procedure that requires a team investigation of any incident which results in, or could reasonably result in, a catastrophic release of highly hazardous chemical. The procedures must require a written report and establish a system to promptly address and resolve any report findings and recommendations. 


\section{Chemical Manufacturers Association - Responsible Care Program}

In addition to Federal requirements governing the safe handling of chemicals and their byproducts and wastes, the Chemical Manufacturers Association, a national trade group representing the major chemical producers, has promulgated a set of voluntary standards governing the handling of chemicals and efforts to protect public health and safety, as well as the environment. The Guiding Principles of Responsible Care are as follows:

- Recognizing and responding to community concerns regarding chemicals and company operations;

- Developing and producing of chemicals that can be manufactured, transported, used, and disposed of safely;

- Making health, safety, and environmental considerations a priority in planning for all existing and new products and processes;

- Reporting promptly to officials, employees, customers, and the public information on chemical-related health or environmental hazards and recommending protective measures;

- Counseling customers on the safe use, transportation, and disposal of chemical products;

- Operating plants and facilities in a manner that protects the environment and the health and safety of employees and the public;

- Extending knowledge by conducting or supporting research on the health, safety, and environmental effects of products, processes, and waste materials;

- Working with others to resolve problems created by past handling and disposal of hazardous substances;

- Participating with Government and others in creating responsible laws, regulations, and standards to safeguard the community, workplace, and the environment; and

- Promoting the principles and practices of Responsible Care by sharing experiences and offering assistance to others who produce, handle, use, transport, or dispose of chemicals.

\section{Center for Chemical Process Safety (CCPS) of the American Institute for Chemical Engineers (AIChE)}

In 1985, AIChE established CCPS with an overall goal of contributing to the prevention of catastrophic accidents from the manufacture and handling of hazardous chemicals. In accomplishing this goal, CCPS has identified four objectives:

- Establish and publish the latest scientific and engineering practices for prevention and mitigation of incidents involving toxic and/or reactive materials; 
- Encourage the use of such information by dissemination through publications, seminars, symposia, and continuing education programs for engineers;

- Advance the state-of-the-art in engineering practices through research in prevention and mitigation of catastrophic events; and

- Develop and encourage the use of undergraduate education curricula which will improve the safety knowledge and consciousness of engineers.

In 1988, CCPS published Chemical Process Safety Management: A Challenge to Commitment. This document described a comprehensive model for sound process safety management; the model is comprised of 12 distinct, but interrelated, elements. These elements are as follows: (1) accountability objectives and goals; (2) process knowledge and documentation; (3) capital project review and design procedures; (4) process risk management; (5) management of change; (6) process and equipment integrity; (7) human factors; (8) training and performance; (9) incident investigation; (10) company standards, codes, and regulations; (11) audits and corrective actions; and (12) enhancements to process safety knowledge.

To enhance further understanding and acceptance of these process management safety principles, CCPS conducts a variety of activities and programs, including the following:

- Development of technical guidelines for various aspects of process safety management;

- Sponsorship of national and international conferences and symposia on emerging developments in process safety management;

- Distribution of a directory of chemical process safety services listing organizations offering consulting, emergency, and testing services and training courses; and

- Development of process safety management training course for manufacturing, engineering, and research and development managers. 


\section{APPENDIX R}

CHEMICAL INVENTORY DATA

FROM FIELD SELF-EVALUATION REPORTS

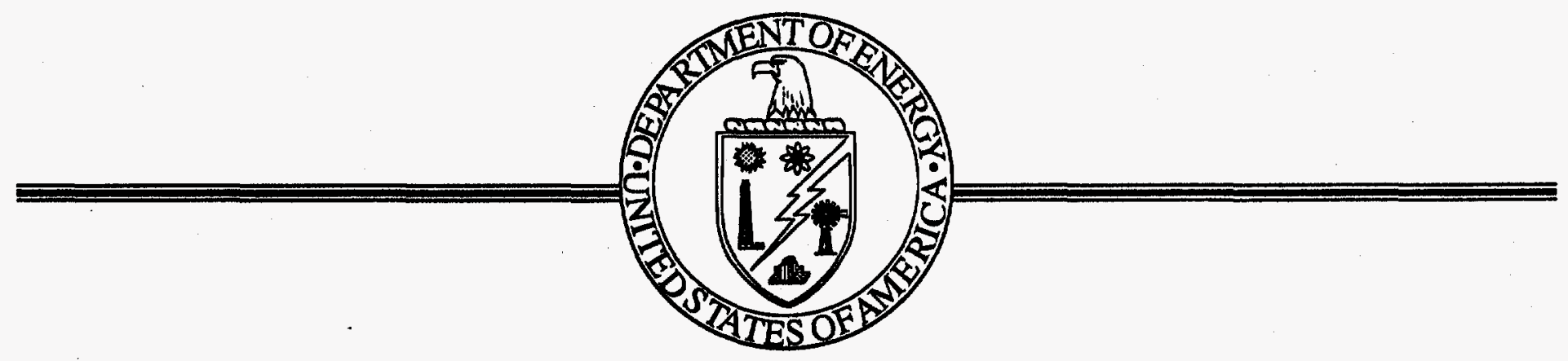




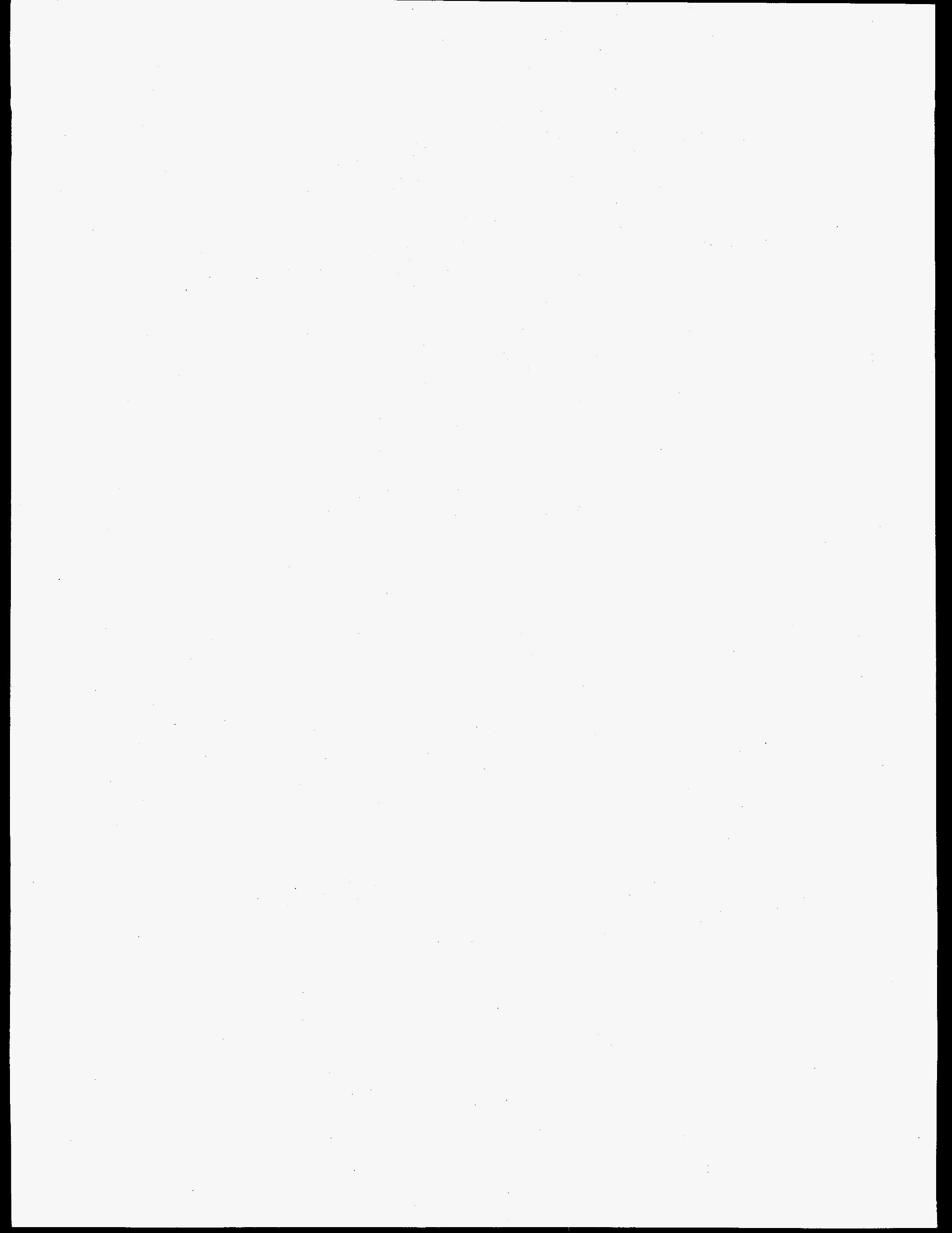




\section{CHEMICAL INVENTORY DATA FROM FIELD SELF-EVALUATION REPORTS}

Carrying out the various missions of the Department of Energy (DOE) complex has required the use of numerous chemicals, ranging from common acids, bases, oxidants, solvents, heavy metals, and maintenance products (e.g., oils, greases, paints, adhesives) to specialty organics, explosives, hydrocarbon fuels, and toxic or pyrophoric gases. The quantities used have also varied widely (including large numbers of small laboratory quantities and large amounts of hazardous chemicals needed for manufacturing or large-scale processing operations), sometimes exceeding the threshold quantities established under the Occupational Safety and Health Administration's chemical process safety management regulations. In addition, DOE facilities treat, store, and dispose of a variety of hazardous wastes (which are regulated under the Resource Conservation and Recovery Act) and polychlorinated biphenyls (which are regulated under the Toxic Substances Control Act). To complicate matters, some of these chemical wastes are contaminated with radionuclides. The Chemical Safety Vulnerability Working Group requested that the 29 sites involved in the self-evaluation phase of the Chemical Safety Vulnerability Review provide estimates of hazardous chemicals, hazardous wastes, and chemical residuals present in the 84 facilities evaluated.

The inventory data in the table that follows were derived from the information furnished by these sites. The inventory data reported are not intended to represent a complete list of chemicals in use at DOE facilities but included examples of the types and amounts of chemicals that may exist in DOE facilities. The criteria used by the sites for reporting inventory data were as follows:

- Hazardous chemicals in quantities that meet or exceed 25 percent of the amounts listed in either 29 CFR 1910.119 or 40 CFR 68,

- Hazardous chemicals below the threshold quantities listed in 29 CFR 1910.119 or 40 CFR 68 that do not have adequate controls to prevent worker exposure,

- Residual hazardous chemicals present in nonoperating facilities, and

- Any other hazardous chemicals which are of concern to the sites.

The nomenclature used in the table is as follows:

$\mathrm{HC}$ denotes hazardous chemical;

HW denotes hazardous waste;

RS denotes residual hazardous material; MW denotes mixed waste;

$B$ denotes bulk material;

$M$ denotes many small quantities; and

UNK denotes quantities of materials that were qualitative, unknown, or unreported in the self-evaluation.

The range, nature, and quantities of hazardous chemicals, wastes and residues at the facilities that provided inventory data in their self-evaluations are represented in Table Q-1. 
TABLE Q-1. CHEMICAL INVENTORY DATA

CHEMICAL NAME

Argonne National Laboratory - East

Chemistry Division, Building 200 (M-Wing Hot Cells)

Lead Bricks

HW/B

4,430

Chemistry Technology, Building 205 (IFR Pyroprocessing)

Cadmium Residues

$\mathrm{RS} / \mathrm{B}$

UNK

Waste lon Exchange Facility, Building 579

Radioactive Resin

RS/B

UNK

Argonne National Laboratory - West

Analytical Laboratory, Building 752

Lead Gloves

Heavy Metal Solutions

Diesel/Toluene

Mixed Wastes

Perchloric Acid
HW/M

HW/M

HW/B

HW/M

RS/B

55
UNK

UNK

UNK

UNK

Bonneville Power Administration

Ross Maintenance Facility

Miscellaneous

$\mathrm{HC} / \mathrm{M}$

1,000

RCRA Wastes

HW/M

95,000

HW/M

870

TSCA Wastes without PCB

HW/M

3,172

Brookhaven National Laboratory

Hazardous Waste Storage Facility

Chromium Waste

HW/B

15,000

HW/M

900

HW/B

3,800

Elemental Lead

HW/B

114,351

Ignitable Liquid

HW/B

4,400

HW/B

1,200

Mercury Waste

Oils

HW/B

32,245

Spent Solvents

HW/M 
Brookhaven National Laboratory (Continued)

Wastewater Treatment Facility, Building 575, Tank 490-07/Operating

Domestic Sewage Sludge

HW/B

UNK

Sodium Hypochlorite

HM/B

UNK

\section{Energy Technology Englneering Center}

Kalina Facility

Ammonia Hydroxide

$\mathrm{HC} / \mathrm{B}$

$\mathrm{HC} / \mathrm{B}$

UNK

Anhydrous Ammonia

$\mathrm{HC} / \mathrm{B}$

Lubricating Oils

HW/B

UNK

UNK

Used Lubricating Oils

UNK

Sodium Storage

Lithium

$\mathrm{HC} / \mathrm{B}$

UNK

NaK (sodium-potassium)

$\mathrm{HC} / \mathrm{B}$

UNK

Sodium

$\mathrm{HC} / \mathrm{B}$

UNK

Fernald Environmental Restoration Management Corp.

Biodenitrification Facility

Sulfuric Acid

$H C / B$

UNK

Methanol

$\mathrm{HC} / \mathrm{B}$

UNK

\section{Bulk Chemical Storage (HF Tank Car)}

Hydrofluoric Acid

HW/B

4,400

Silo 3

Characterized Waste

HW/B

932,000

Water Treatment Plant, Building 20A

Chlorine Gas

$\mathrm{HC} / \mathrm{B}$

900

Sulfuric Acid

HW/B

UNK

\section{Hanford Site}

Chemical Engineering Laboratory, Building $2703 \mathrm{E}$

Miscellaneous Chemicals

$\mathrm{HC} / \mathrm{M}$

UNK

Miscellaneous Chemical Wastes

HW/M

UNK

High Bay Engineering Laboratory, Building 324

Nitrous Oxides

$H W / M$

UNK 
Hanford Site (Continued)

Life Sciences Laboratory, Building 331

Formaldehyde waste

Liquid Chromatography Cocktail Waste

Hazardous Wastes

Inorganic/organic Acids

Organic Solvents

Inorganic Acid Residuals

PUREX Plant, 202A Building

Cadmium Nitrate (drums)

Nitric Acid

Nitric Acid

Nitric Acid/Metal

Paraffin/Tributyl Phosphate

Sodium Hydroxide

Sodium Nitrate

Sodium Nitrate (100 bags)
MW/M

MW/M

HW/B

$\mathrm{HC} / \mathrm{M}$

$\mathrm{HC} / \mathrm{M}$

RS/M

$\mathrm{HC} / \mathrm{B}$

$\mathrm{HC} / \mathrm{B}$

$\mathrm{HC} / \mathrm{B}$

$M W / B$

HW/B

$\mathrm{HC} / \mathrm{B}$

$\mathrm{HC} / \mathrm{B}$

$H C / B$

$\mathrm{HC} / \mathrm{B}$

$\mathrm{HC} / \mathrm{B}$

HW/M

HW/M

$\mathrm{HC} / \mathrm{B}$

$\mathrm{HC} / \mathrm{M}$

RS/M
15

15

150

120

120

1,200

UNK

UNK

UNK

Chemical Waste

Mixed Waste

Nitric Acid

Nitric Acid

Nitric Acid

Idaho National Engineering Laboratory

Army Reentry Vehicle Facility Site (ARVFS)

NaK Eutectic

MW/B

1,285

ICPP Fuel Processing Facility, Buildings 601-602-621

Chromic Acid (in tanks)

RS/M

RS/M

Hydrofluoric Acid

RS/M

Mercuric Nitrate

$\mathrm{HC} / \mathrm{B}$

Nitric Acid

$H C / B$

39,355

33,665

UNK

UNK

38,977

200

UNK
UNK

UNK

UNK

10,700

203,000 
Idaho National Engineering Laboratory (Continued) ICPP Tank Farm

Aluminum Bearing Waste

MW/B

MW/B

3,000

Dilute Waste Solution

MW/B

274,000

Fluoride Bearing Acidic

$\mathrm{HC} / \mathrm{B}$

Dichromate Solution with/Chro

$M W / B$

Sodium Bearing Acidic

MW/B

Zirconium Bearing Waste

Power Burst Facility, Corrosive Waste Disposal Evaporation Pond

Aqueous Solution with Cesium 137 and Chrome III

MW/B $700,000(\max )$

\section{RWMC (Waste Storage Pad A, Waste Disposal Pit 9)}

Beryllium

Carbon Tetrachloride

Lead

Mercury

Nickel Carbonyl

Potassium Nitrate

Sodium Nitrate

Sodium Nitrate

Trichloroethane

Trichloroethylene
MW/B

$M W / B$

$M W / B$

MW/B

MW/M

MW/B

$M W / B$

MW/B

MW/B

MW/B
47,750

114,000

6,600

220,000

UNK

126,000

595,000

270,000

32,000

41,000

Kansas City Plant

Chemical Storage Building

Flammables

HCM

$\mathrm{HC} / \mathrm{M}$

20,000

Formaldehyde

$\mathrm{HC} / \mathrm{B}$

320

160

Industrial Waste Water Pretreatment Plant

Waste Sludge

HW/B

$90,000 / y r$

Storage Facilities (Acid pad, L-Lot, and Red-X Lot)

Corrosive Wastes

HW/B

HW/B

UNK

Toxic Metal Wastes

HW/B

UNK

Flammable/Combustible Wastes

UNK

Tank Farm

Flammables

HW/B

73,500 
Lawrence Berkeley Laboratory

Microelectronic Research Systems Laboratory, Building 70-A

Dichlorosilane

Hexamenthyldisilazane

Phosphine in Nitrogen

Phosphine in Silane/Ammonia

Photoresist \& Resins

Silane

Vacuum Pump Oil
$\mathrm{HC} / \mathrm{M}$

HW/M

$\mathrm{HC} M$

$\mathrm{HC} / \mathrm{M}$

$H W / M$

HCM

HW/M
UNK

UNK

UNK

UNK

UNK

UNK

UNK

Lawrence Livermore National Laboratory

Chemical and Materials Sciences Facility, Building 235

Aqueous with $\mathrm{HNO}_{3} / \mathrm{U}_{238}$

MW/M

12

HEPA filter with $\mathrm{Cr}, \mathrm{Be}, \& \mathrm{U}_{238}$

MW/B

The B-222-229 Complex (8 buildings)

Lab Wastes, Acidic

Lab Wastes, Heavy Metals

Lab Wastes, Unclassified

Lab Wastes, Oils/Solvents

Chem Waste with Silver Contam

Acetone and $U_{238}$

Solvents, Oils/Metal

Metals and Tritium Contam

Listed Solvent/Oils

Miscellaneous Actinide Wastes

Organic Lab Waste

Solvent Lab Waste with Oil

Scintilation Cocktail with Organics

Aqueous Solv with $\mathrm{HNO}_{3}$ and $\mathrm{U}_{238}$

Organic Solv with Acetone and $\mathrm{U}_{238}$

Waste Oil

Waste Oil with Trace Metals

Waste Scintilation Cocktail with Organics
MW/M

MW/M

MW/M

MW/M

MW/M

MW/M

MW/M

MW/M

MW/M

MW/M

MW/M

MW/M

MW/M

MW/M

MW/M

$M W / M$

MW/M

$M W / M$
275

610

430

400

3

40

55

10

20

3

8

1

5

40

40

1

0.5

6

The B-825-827 Complex (7 Buildings)

HEPA Filters with $\mathrm{Cr}, \mathrm{Be}, \mathrm{U}_{238}$

MW/B 20

MW/B 
Los Alamos National Laboratory

Chemical and Metallurgy Research Facility, Building TA-3-29

Miscellaneous Mixed Wastes

Miscellaneous Hazardous Chemicals

Chemical Residues

Waste Oils
MW/M

$\mathrm{HC} / \mathrm{M}$

RS/M

MW/M
UNK

UNK

UNK

UNK

Gas Cylinder Distribution Plant, Building TA-3-170
$\mathrm{HC/B}$

$\mathrm{HC} / \mathrm{B}$

$\mathrm{HC} / \mathrm{B}$

$\mathrm{HC} / \mathrm{B}$

$\mathrm{HC} / \mathrm{B}$

$\mathrm{HC} / \mathrm{B}$

$\mathrm{HC} / \mathrm{B}$

HC/B

$\mathrm{HC} / \mathrm{B}$

non- $\mathrm{HC} / \mathrm{B}$

$\mathrm{HC} / \mathrm{B}$

$\mathrm{HC/B}$

$\mathrm{HC/B}$

$\mathrm{HC} / \mathrm{B}$

$\mathrm{HC} / \mathrm{B}$

$\mathrm{HC} / \mathrm{B}$

non-HC/B

$\mathrm{HC} / \mathrm{B}$

$\mathrm{HC} / \mathrm{B}$

$\mathrm{HC} / \mathrm{B}$

$\mathrm{HC} / \mathrm{B}$

$\mathrm{HC} / \mathrm{B}$

$\mathrm{HC} / \mathrm{B}$

$\mathrm{HC} / \mathrm{B}$

RS/M

Explosives

Tritium High Pressure Lab, Building TA-33-86
708

19,363

26,223

46,531

600

4,000

1,500

1,500

625

1,190

3,232

638

910

300

1,190

455

18,373

67,449

14,000

11,229

2,442

4,800

UNK

UNK 
Los Alamos National Laboratory (Continued)

Waste Storage Facilities, Technical Area 54, Area L \& G

Barium-Contaminated

HW/B

590

Cadmium-Contaminated

HW/B

770

Chem-Strip

Lead

HW/B

1,290

Lithium Hydride

$H W / B$

41,230

HW/B

1,930

MW1-Flammables

MW/B

13,275

MW2-Oxidizers

MW/B

430

MW3-Acids

MW/B

2,550

MW4-Reactives

MW/B

785

MW5-Caustics

$M W / B$

5,255

MW6-Poisons

MW/B

1,300

Mercury-Contaminated

$M W / B$

670

Sludges, Dewatered

MW/B

69,525

Uranium Chips/Tumings

HW/B

6,435

Morgantown Energy Technology Center

Chemical and Gas Storage B-16

Carbonyl Sulfide
Hydrogen
Hydrogen Sulfide
Methane
Nitrous Oxide
Propane
Sulfur Dioxide
Miscellaneous Chemical Wastes

$\mathrm{HC} / \mathrm{B}$

UNK

$H C / B$

UNK

$\mathrm{HC} / \mathrm{B}$

UNK

$\mathrm{HC} / \mathrm{B}$

UNK

$\mathrm{HC} / \mathrm{B}$

UNK

$\mathrm{HC} / \mathrm{B}$

UNK

$\mathrm{HC} / \mathrm{B}$

UNK

HC/B

UNK

Wastewater Treatment Facility

Miscellaneous Chemicals

Miscellaneous Chemical Wastes

$\mathrm{HC} / \mathrm{M}$

UNK

HW/M

UNK

\section{Mound Plant}

Explosives Formulation Facility, Building 1

Explosives

HC/M

UNK

Miscellaneous Chemical Residues

RS/M

UNK

Hazardous Waste Storage, Building 72

Miscellaneous Chemicals

$\mathrm{HC} / \mathrm{M}$

UNK

Miscellaneous Chemical Wastes

HW/M

UNK 
Mound Plant (Continued)

PETN Recrystalization Facility, Building 27

Miscellaneous Chemicals

HC/M

UNK

Miscellaneous Chemical Wastes

HW/M

UNK

Process/Laboratory Facility, WD Building, WDA Building

Rad Waste (liquid)

MW/M

UNK

National Renewable Energy Laboratory

Field Test Laboratory Building, South Table Mountain Site

Alcohol

Laboratory Chemicals

R\&D Laboratory, Denver West Office Park, Building 16

Lab Chemicals

Miscellaneous Chemical Wastes

\section{Naval Petroleum Reserve In California}

35R Complex

Butane

$\mathrm{HC} / \mathrm{B}$

$H C / B$

$\mathrm{HC} / \mathrm{B}$

$\mathrm{HC} / \mathrm{B}$

$\mathrm{HC} / \mathrm{B}$

$H C / B$
$\mathrm{HC} / \mathrm{M}$

HWM
100

UNK

UNK 880

Nevada Test Site

Area 23, REECo Facility, Analytical Laboratory

Numerous Lab Reagents

Aqueous Solution Methylene Chloride

Aqueous Solution of Leached Metals

Halogenated Solvents

Scintilation Cocktails
440,000

1,200

14,800

490,000

250

370,000

Area 25, Acid Storage Tank at Nuclear Engine Test Stand

Residual Caustic Soda

RS/M

UNK

Area 25, Flammable Storage Dock at Building 4320

Yucca Mountain Drilling Samples

HCM

HW/M

HW/M

HW/M

MW/M
UNK

UNK

UNK

UNK

UNK
UNK 
Nevada Test Site (Continued)

North Las Vegas Maintenance Facility, Building 710

Naphtha

Paint Thinner

Solvent Contaminated Rags

Paint Sludge

Oak Ridge K-25 Site

Contaminated Burial Ground

Arsenic Metal and Oxide

HW/M

Beryllium

Depleted Uranium Tumings

Drums, Uncharacterized Scrap Materlals

Lead Nitrate

Waste Filter Cake

Waste Oil

Tellurium

Thorium

Thorium-Beryllium-Uranium Mix

$\mathrm{UO}_{2} \mathrm{~F}_{2}$

Uranium Oxide

Uranium Scrap

Lithium Storage Vaults, Building K-25

Lithium Hydroxide

HC/B

$23,600,000$

Ponds Waste Management Project

Leachable Nickel

MW/B

$2,700,000$

15

10

2,200 drums

1

115

75

140

20

20

113

133

18

HW/M

HW/M

UNK

UNK

HW/M

HW/M

HWIM

HW/M

HW/M

HW/M

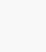

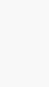

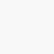


Oak Ridge Y-12 Plant

Hazardous Materials Bulk Storage, 9201-4

Charcoal

$\mathrm{HC} / \mathrm{B}$

450

Ferric Sulfate

$\mathrm{HC} / \mathrm{B}$

Ferrous Sulfate

$H C / B$

180

Glues and Adhesives

$\mathrm{HC} / \mathrm{M}$

Hydraulic Fluid

$\mathrm{HC} / \mathrm{B}$

300

$\mathrm{KCl}$ and $\mathrm{LiCl}$ Electrolyte

$\mathrm{HC} / \mathrm{B}$

60,000

Metallic Mercury

$\mathrm{HC} / \mathrm{B}$

35,000

Oils and Lubricants

$H C / M$

20

Residuals

RS/B

Sodium Hydroxide with Mercury

$\mathrm{HC} / \mathrm{B}$

Sodium Sulfate

$\mathrm{HC} / \mathrm{B}$

41,580

1,600

Compressed Gas Bulk Storage Warehouse, 9720-5

Miscellaneous Chemicals

HW/M

UNK

HW/R

UNK

Pantex Plant

Explosives Machining Facilities, Building 11-50

Explosive Parts (C1-A)

Explosive Scrap (C1-A)

$\mathrm{HC} / \mathrm{M}$

2,000

$\mathrm{HC} / \mathrm{M}$

200

Explosives Machining Facilities, Building 12-24N

Class A Explosive Parts

Explosive Scrap Class A

$\mathrm{HC} / \mathrm{M}$

2,000

$\mathrm{HC} / \mathrm{M}$

200

High Explosives Synthesis Facility, Building 11-36

Class-A Explosives

HC/M

10/mo

Miscellaneous Chemical Wastes

HW/M

$300 / \mathrm{mo}$

Sewage Treatment Facility, Building 13-47

Chlorine (gas)

$\mathrm{HC} / \mathrm{B}$

1,150

Sulfuric Acid (gas)

$\mathrm{HC} / \mathrm{B}$

4,800

Pinellas

Industrial Wastewater Neutralization, Building 550

EPA Hazardous Waste (F006)

HW/B

Sulfuric Acid

$\mathrm{HC} / \mathrm{B}$

500

7,600 
Pinellas (Continued)

Tank Farm at the Liquid Waste Storage Area near Building 1040

Flammables (various)

Toxics (various)

Pittsburgh Energy Technology Center

Wastewater Treatment Facility

Caustic Soda Tank

Diesel Fuel for Emergency Generator

Ferric Chloride

Waste Oil

\section{Rocky Flats Plant}

Analytical Laboratory, Building 559

$$
\begin{aligned}
& \text { Mixed Residuals } \\
& \text { Mixed Waste } \\
& \text { Moratorium Waste }
\end{aligned}
$$

Analytical Laboratory, Building 881

Residual Uranium

Hazard Waste (mixed)

Hazardous Chemicals

Industrial Waste Storage Tank, Building 207

Low-Level Radwaste

Warehouse and Machine Shop, Building 551

Chlorine (gaseous)

Flammable Solvents, Paints, and Aerosol Cans

Waste Storage and Analytical Laboratory, Building 371
RS/M

RS/M
Empty

Empty
$\mathrm{HC} / \mathrm{B}$

$\mathrm{HC} / \mathrm{B}$

$\mathrm{HC} / \mathrm{B}$

$\mathrm{HW} / \mathrm{B}$
UNK

UNK

$250 \mathrm{gal}$

UNK
MW/M

HW/M

HW/M

HW/M

HW/M

HC/M

RS/M

Empty

200 gal

375
UNK

UNK

UNK

UNK

HC/B

$\mathrm{HC} / \mathrm{M}$

$\mathrm{HC} / \mathrm{M}$

$\mathrm{HC} / \mathrm{M}$

$\mathrm{HC} / \mathrm{M}$

MW/M

HC/M
400

UNK

UNK

UNK

UNK

UNK

\section{Sandia National Laboratory}

Hazardous Waste Management Facility, Building 958

Hazardous Wastes

HW/B 200 drums 
Sandia National Laboratory (Continued)

Laboratory Facilities, Building 805, 806, 807 (Tech Area \#l)

Explosives

Mixed Wastes

Light Initiated Explosive Test Facility, Building 6715

Residual Silver in Soil

RS/M

$\mathrm{HC} / \mathrm{M}$

MW/M

$8.5 \mathrm{ft}^{2}$

Microprocessor Development Laboratory, Building 858

Hydrochloric Acid

Sulfuric Acid

Sodium Hydroxide

HF Wastes

Process Development Laboratory, Building 878

Hydrochloric Acid

$\mathrm{HC} / \mathrm{M}$

Savannah River Site

100-P Area, Sodium Hypochlorite Facility, No. 186-001

Residual Paints

RS/M

Sodium Hypochlorite

$\mathrm{HC} / \mathrm{M}$

150

UNK

200-F Area, CTS Pits and Facilities, No. 242-003

Hazardous Waste

Moratorium Waste

Residuals

HW/M

HW/M

RS/M

$\mathrm{HC} / \mathrm{B}$

HCM

HW/M

RSM

RS/M

HC/B

Transite Wall Tile

99-H Area, Maintenance Facility, Building 299

High-level mixed waste

Moratorium waste
HW/B

HW/M
68,350

2,000

6,500

$1,260 / y r$

UNK

Asbestos

$40,000 \mathrm{yd}^{3}$

UNK

UNK

6,000

UNK

UNK

UNK

UNK

412-D Area, Heavy Water Extraction Facility

Low PH Material (oily subs)
RCRA Corrosive 


\section{CHEMICAL NAME}

Savannah River Site (Continued)

H-Area Tank Farm, Waste Reduction Facility

High-Level Waste

Residuals

ITP/ESP, Waste Reduction/Wastewater Facility

Benzene

\section{Strategic Petroleum Reserve}

West Hackberry Facility

$$
\text { Crude Oil }
$$

West Valley Demonstration Project

Analytical Environmental Laboratory

Corrosive Wastes (neutralized)

Chemical Residues

Hazardous Waste Storage Locker

Stored Hazardous Waste

Stored Mixed Wastes

Supermate Treatment System

Sodlum Hydroxide

Western Area Power Administration

Phoenix Maintenance Facility

Miscellaneous Chemical Waste

\section{CHEMTYPE VOL/GAL QUANT/LB}

HW/B $\quad 74,178 \mathrm{~m}^{3}$

RS/M

UNK

$H C / B$

UNK

HC/B $\quad 219,000,000$

barrels

HW/M

RS/M

900/yr

UNK

$\mathrm{HW} / \mathrm{B}$

UNK

MW/B

UNK

$\mathrm{HC} / \mathrm{M}$

UNK

HW/M

13,000 